UNIVERSIDADE DE SÃO PAULO

FFCLRP - DEPARTAMENTO DE FÍSICA

ÉDER JOSÉ GUIDELLI

\title{
Luminescência Opticamente Estimulada em Condições de Ressonância Plasmônica
}


ÉDER JOSÉ GUIDELLI

\section{Luminescência Opticamente Estimulada em Condições de Ressonância Plasmônica}

Tese apresentada à Faculdade de Filosofia, Ciências e Letras de Ribeirão Preto da USP, como parte das exigências para a obtenção do título de Doutor em Ciências.

Área de Concentração:

Física Aplicada à Medicina e Biologia

Orientador:

Oswaldo Baffa Filho

Ribeirão Preto 
Autorizo a reprodução total ou parcial deste documento, por meio convencional ou eletrônico, para fins de estudo e pesquisa, desde que citada a fonte.

\section{FICHA CATALOGRÁFICA}

Guidelli, Éder José

Luminescência Opticamente Estimulada em Condições de

Ressonância Plasmônica / Éder José Guidelli; orientador Oswaldo

Baffa. - Ribeirão Preto, 2015.

127 f. : Il.

Tese (Doutorado) - Universidade de São Paulo, 2015.

1. Luminescência Opticamente Estimulada - 2. Nanopartículas 3. Prata - 4. Ouro -5. Dosimetria - 6. Ressonância Plasmônica. 
Nome: GUIDELLI, Éder José

Título: Luminescência Opticamente Estimulada em Condições de Ressonância Plasmônica

Tese apresentada à Faculdade de Filosofia, Ciências e Letras de Ribeirão Preto da USP, como parte das exigências para a obtenção do título de Doutor em Ciências. Área: Física Aplicada à Medicina e Biologia

Aprovado em:

Banca Examinadora

Prof. Dr. Instituição:

Julgamento: Assinatura:

Prof. Dr. Instituição:

Julgamento: Assinatura:

Prof. Dr. Instituição:

Julgamento: Assinatura:

Prof. Dr. Instituição:

Julgamento: Assinatura:

Prof. Dr. Instituição:

Julgamento: Assinatura: 


\section{Dedico}

À minha namorada Talita, que esteve ao meu lado em todos os momentos, enfrentando os desafios, me confortando com carinho, paz, serenidade e amor.

Aos meus país, Sebastíão e Laura, exemplos de vida, pelo apoio e amor incondicional, a quem certamente dedicarei todas as minhas conquistas. 


\section{Ofereço}

As minhas irmãs, Silvía, Eliana e Ana María, e às suas famílias, pelo apoío, carinho e amizade. Ofereço em especíal à mínha írmã Ana María, por ter me sugerído cursar Física Médica, pelo incentivo para que eu seguisse na pós-graduação, e por todas as nossas grandes "parcerias".

Aos sobrinhos Gu, Lô, Ana Catarina e Augusto, pela alegria que me trazem. 


\section{Agradecimentos}

À Deus, pela onipresença, por sua graça, amor e bondade infinita, que nos ilumina e protege nas caminhadas que trilhamos, proporcionado a sabedoria necessária para a compreensão da ciência e da vida. À Nossa Senhora Aparecida, mãe protetora, que esteve em todos os momentos ao meu lado, intercedendo junto ao Pai.

“... Um pouco de Ciência nos afasta de Deus. Muito, nos aproxima..."

(Louis Pasteur)

Ao Prof. Oswaldo Baffa, grande exemplo e referência, por toda ajuda nas esferas acadêmica e pessoal, pela orientação, pelas oportunidades oferecidas e pelo constante apoio e incentivo.

Às Professoras Ana Paula Ramos e Patrícia Nicolucci, pela colaboração, atenção, disponibilidade e grande ajuda no desenvolvimento desse trabalho.

Ao Prof. David R. Clarke por colaborar com essa tese desde os primeiros meses do doutorado e por me orientar durante o período de estágio no exterior. - I am thankful to Professor David $R$. Clarke, for collaborating since the very beginning of my Ph.D, and for advising me while I've been in United States.

Ao Prof. Eduardo Yukihara, por me receber em seu laboratório, pela atenção dada e pela ajuda nos experimentos e nas discussões.

Ao Prof. Marcelo Mulato por todo apoio desde os tempos de iniciação científica, e que perdurou durante todo o período da pós-graduação.

Ao Prof. Jabá, por renovar e compartilhar o laboratório, pelas conversas e ajudas.

Ao Prof. Amando Suiti Ito e à Dra. Marina Berardi, pela ajuda e disponibilidade na realização dos experimentos de espectroscopia. 
Ao Prof. Serra e ao Dr. Paulo Cesar de Sousa Filho pelo apoio quanto ao uso dos espectrofotômetros de fluorescência e absorção.

Ao Dr. Luiz Carlos de Oliveira, pelas conversas, ajudas e discussões sempre pertinentes.

A todos os funcionários da FFCLRP, em especial à Nilza, Aziane, Lourenço, Rodrigo, Lourivaldo, Ivana e Cláudio, pela dedicação, disponibilidade e pelo trabalho excepcional que desenvolvem.

Aos colegas de laboratório, amigos de graduação e pós-graduação, pela companhia, conversas, almoços, cafés e descontrações.

Aos amigos Ana Paula Rodrigues, Mara Alves de Oliveira e Rafael Pianca Barroso pela amizade e confiança.

Aos meus sogros Netto e Vânia, pelo apoio ao longo de todos esses anos.

À Universidade de São Paulo, à Faculdade de Filosofia, Ciências e Letras de Ribeirão Preto e ao Departamento de Física, pelo espaço físico, funcionários e professores.

Às agências de fomento Capes e CNPq, pelo financiamento da pesquisa.

À Fundação Lemann, pelo apoio financeiro durante o período de estágio no exterior.

À Fundação de Amparo à Pesquisa do Estado de São Paulo (FAPESP - 11/09521-8), pelo apoio financeiro. 
"A ciência nunca resolve um problema sem criar pelo menos outros dez."

George Bernard Shaw 


\section{Resumo}

GUIDELLI, E. J. Luminescência Opticamente Estimulada em Condições de Ressonância Plasmônica. 2015. 127 p. Tese (Doutorado - Programa de Pós-Graduação em Física Aplicada à Medicina e Biologia) - Faculdade de Filosofia, Ciências e Letras de Ribeirão Preto, Universidade de São Paulo, Ribeirão Preto - SP, 2015.

A luminescência opticamente estimulada (OSL) é a luminescência emitida por um material, isolante ou semicondutor, durante exposição à luz e que foi previamente exposto à radiação ionizante. Portanto, depende da quantidade de cargas armadilhadas na estrutura do material, o que por sua vez depende da dose de radiação absorvida pela amostra. Dessa forma, a busca por novos materiais para serem utilizados como detectores de radiação envolve a criação de defeitos que atuem como armadilhas e/ou centros luminescentes. Recentemente, as interações entre os plásmons de nanopartículas metálicas e centros luminescentes têm sido utilizadas para aumentar a intensidade luminescente emitida por diversos materiais. Nesse trabalho, foi investigada a possibilidade de aplicação das propriedades plasmônicas de nanoestruturas de prata e ouro, no aumento da emissão OSL. Para isso, foram testados como dosímetros OSL, compósitos de cloreto de sódio contendo nano e micropartículas de prata; compósitos de óxido de zinco contendo nanopartículas de ouro e prata; e amostras de cloreto de sódio depositado sobre filmes de nanopartículas de prata e ouro. As amostras foram caracterizadas por diversas técnicas como espectroscopia UV-Vis, espalhamento dinâmico de luz, espectroscopia na região do infravermelho, espectroscopia de fotoluminescência, microscopia eletrônica de transmissão, microscopia de força atômica, entre outras. Foi possível verificar que a intensificação dos campos elétricos locais em torno de nanopartículas metálicas em condições de ressonância plasmônica aumenta a taxa de desarmadilhamento de elétrons durante a estimulação OSL. O acoplamento plasmônico causou aumento das taxas de decaimento radiativo e redução das taxas de decaimento não radiativo, produzindo aumento da intensidade OSL. Além disso, as interações entre as armadilhas/centros luminescentes e os plásmons variam de acordo com a distância entre as partes, e a maior intensidade OSL foi obtida para amostras em que houve um espaçamento de aproximadamente $15 \mathrm{~nm}$ entre o $\mathrm{NaCl}$ o filme de nanopartículas de prata. Portanto, é possível utilizar as propriedades plasmônicas de nanoestruturas metálicas para aumentar a intensidade da luminescência opticamente estimulada, dando origem a novos e mais sensíveis detectores e dosímetros das radiações ionizantes.

Palavras-Chave: Luminescência Opticamente Estimulada, Nanopartículas, Prata, Ouro, Dosimetria, Ressonância Plasmônica. 


\begin{abstract}
GUIDELLI, E. J. Optically Stimulated Luminescence Under Plasmon Resonance Conditions. 2015. 127 p. Thesis ( Ph.D. - Graduate Program in Physics Applied to Medicine and Biology) - Faculty of Philosophy, Sciences, and Literature, University of Sao Paulo, Ribeirão Preto - SP, 2015.

Optically stimulated luminescence (OSL) is a well-known light emission process involving light stimulation of an insulator/semi-conductor material previously exposed to ionizing radiation. The intensity of the emitted light is proportional to the ionizing radiation dose previously absorbed by the material. Developing appropriate OSL materials for radiation detection and dosimetry is based on the doping and co-doping of a host material to create defects that can act as traps and/or luminescent centers. In this context, plasmon interaction with luminescent centers from OSL materials could be a new, different, and unexplored method to achieve enhanced OSL intensity and consequently improve their sensitivity as radiation detectors. In this study, we investigated whether it is possible to use the plasmonic properties of noble metal nanoparticles to obtain plasmon-enhanced OSL. To this end, we produced samples of $\mathrm{NaCl}$ containing nano and microparticles; composites of $\mathrm{ZnO}$ containing silver and gold nanoparticles; as well as samples of $\mathrm{NaCl}$ deposited over films of gold and silver nanoparticles. Each sample has been tested as a radiation detector by means of optically stimulated luminescence, in addition to having their materials properties analyzed by UV-Vis absorption spectroscopy, dynamic light scattering, transmission electron microscopy (TEM), atomic force microscopy, and Fourier Transform Infrared spectroscopy (FTIR). We discovered that the electric field intensification around nanoparticles under plasmon resonance conditions enhances the excitation rate of trapped electrons. The plasmon coupling during the emission process increases the radiative and diminishes the non-radiative decay rates, leading to enhanced OSL intensities. Furthermore, the interaction between traps/luminescent centers and plasmons is highly dependent on the distance between them, and the maximum OSL intensity was observed for samples with $15 \mathrm{~nm}$ spacing between the $\mathrm{NaCl}$ and the silver nanoparticle films. Therefore, it is possible to use the plasmon properties of metal nanostructures to increase OSL, giving rise to new and more sensitive ionizing radiation detectors and dosimeters.
\end{abstract}

Keywords: Optically Stimulated Luminescence, Nanoparticles, Silver, Gold, Dosimetry, Plasmon Resonance. 


\section{LISTA DE FIGURAS}

Figura 1.1: Oscilação Plasmônica, induzida pela ação de um campo luminoso, dos elétrons livres na superfície de uma nanopartícula metálica.

Figura 3.1:Espectro UV-Vis das dispersões coloidais com diferentes porcentagens em massa de prata na forma de nanopartículas (a) e micropartículas (b).

Figura 3.2: Espectros de reflectância dos compósitos $\mathrm{NaCl} / \mathrm{Ag}$ na forma de nanopartículas (a) e micropartículas (b).

Figura 3.3: Distribuição de tamanho das nanopartículas de prata obtidas pela técnica de espalhamento dinâmico da luz para as dispersões coloidais relativas aos nano e microcompósitos.

Figura 3.4: Imagens obtidas por microscopia eletrônica de transmissão das nanopartículas de prata recém preparadas (sem $\mathrm{NaCl})(\mathrm{a})$, da amostra $0,05 \% \mathrm{NpAg}$ (b) e (c), e da amostra $0.05 \% \mathrm{MpAg}$ (d). . 34

Figura 3.5: Curva OSL para as amostras $0 \% \mathrm{NpAg}, 0,05 \% \mathrm{NpAg}$ e $0,05 \% \mathrm{MpAg}$ irradiadas com 10 mGy. $\mathrm{O}$ inset mostra a intensidade inicial da curva OSL com maior resolução. 35

Figura 3.6: (a) Intensidade OSL em função da concentração de prata para os nano e microcompósitos. (b) Curva dose-resposta para o $\mathrm{NaCl}$ puro e para a amostra $0,05 \% \mathrm{NpAg}$.

Figura 3.7: Banda de ressonância plasmônica de nanopartículas de prata em solução. As setas indicam os comprimentos de onda onde iniciam as bandas de estimulação OSL com os LEDs azul e verde, bem como a janela de leitura OSL. 38

Figura 3.8: Espectros de radioluminescência para as amostras $0 \% \mathrm{NpAg}, 0,005 \% \mathrm{NpAg}, 0,03 \% \mathrm{NpAg}$ e $0,05 \% \mathrm{NpAg}$.

Figura 3.9: (a) Espectro de luminescência para amostras não irradiadas $(X=350 \mathrm{~nm})$. (b) Intensidade da banda em $425 \mathrm{~nm}$, excitada por comprimentos de onda entre 300-350 nm, e normalizada pela intensidade luminescente da mesma amostra quando excitada em $300 \mathrm{~nm}$.

Figura 3.10: Espectros de luminescência do $\mathrm{NaCl}$ (a) e da amostra 0,05\% $\mathrm{NpAg}$ (b) irradiados com $450 \mathrm{~Gy}$, em 10 medidas consecutivas.

Figura 3.11: Deconvolução da banda de emissão luminescente da amostra $0,05 \% \mathrm{NpAg}$, irradiada com $450 \mathrm{~Gy}$, com excitação em $320 \mathrm{~nm}$.

Figura 3.12: Decaimento da intensidade relativa da área das bandas de emissão luminescente da amostra $0,05 \% \mathrm{NpAg}$, irradiada com $450 \mathrm{~Gy}$ e com excitação em $320 \mathrm{~nm}$, em função do número de medidas.

Figura 4.1: Difratogramas dos nanocompósitos $\mathrm{ZnO} / \mathrm{Ag}$ (a) e $\mathrm{ZnO} / \mathrm{Au}$ (b) 46

Figura 4.2: Reflectância UV-Vis das amostras $\mathrm{ZnO} / \mathrm{Ag}$ (a) e $\mathrm{ZnO} / \mathrm{Au}$ (b).

Figura 4.3: Imagens de microscopia eletrônica de varredura das amostras $\mathrm{ZnO}$ (a), 2mL_NpAg (b), 8mL_NpAg (c), e 8mL_NpAu (d).

Figura 4.4: (a) e (b) Imagens de microscopia eletrônica de varredura, obtidas com e sem (insets) o auxílio de um detector de retroespalhamento de elétrons. (c) Imagem de uma partícula quebrada de $\mathrm{ZnO}$ obtida sem (c) e com o detector de elétrons retroespalhados (d). 50 
Figura 4.5: Ilustração do crescimento do $\mathrm{ZnO}$ na ausência (superior) e na presença (inferior) de nanopartículas metálicas.

Figura 4.6: Espectro de fotoluminescência das amostras $\mathrm{ZnO} / \mathrm{Ag}$ (a) and $\mathrm{ZnO} / \mathrm{Au}$ (b) com excitação em $325 \mathrm{~nm}$. A intensidade da banda UV é proporcional à concentração de nanopartículas (c).

Figura 4.7: (a) Espectros de fotoluminescência para um cristal único de $\mathrm{ZnO}$ para diferentes valores de potência do laser; (b) O mesmo gráfico normalizado pela intensidade em $540 \mathrm{~nm}$ (banda de defeitos).

Figura 4.8:(a) Espectros de fotoluminescência para um cristal único de $\mathrm{ZnO}$ para diferentes valores de potência do laser, normalizados pela intensidade em $540 \mathrm{~nm}$ (banda de defeitos). (b) Espectros de fotoluminescência para os nanocompósitos $\mathrm{ZnO} / \mathrm{Ag}$ com diferentes concentrações de NpAg. É possível verificar que tanto o aumento da potência do laser quanto o aumento da concentração de nanopartículas de prata, causam um deslocamento do espectro para menores comprimentos. 55

Figura 4.9: Decaimento da luminescência no comprimento de onda de $385 \mathrm{~nm}$, das amostras de $\mathrm{ZnO}$,

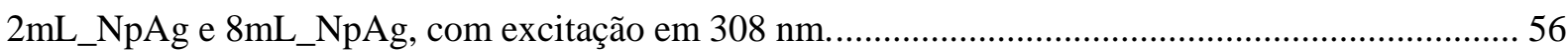

Figura 4.10: Espectro de emissão radioluminescente das amostras de $\mathrm{ZnO}$ e 8mL_NpAg................. 58

Figura 4.11: Curva OSL das amostras de ZnO puro, 2mL_NpAg e 8mL_NpAg irradiadas com $500 \mathrm{~Gy}$. O inset revela o comportamento da intensidade OSL (integral) em função do volume de nanopartículas de prata presente em cada amostra.

Figura 4.12: Sinal OSL das amostras $\mathrm{ZnO}, 2 \mathrm{~mL} \_N p A g$ e $8 \mathrm{~mL} \_N p A g$, irradiados com $500 \mathrm{~Gy}$. O inset mostra a integral da curva OSL em função do volume de nanopartículas de prata.

Figura 4.13: Curvas OSL das amostras de $\mathrm{ZnO}$ puro, $1 \mathrm{~mL} \_\mathrm{NpAg}, 2 \mathrm{~mL} \_\mathrm{NpAg}$ e 8mL_NpAg, irradiadas com $500 \mathrm{~Gy}$ e normalizadas pela intensidade OSL inicial. É possível verificar um decaimento mais rápido da curva OSL à medida que aumenta a concentração de nanopartículas de prata......

Figura 4.14: Curvas OSL das amostras de $\mathrm{ZnO}$ puro e 8mL_NpAg, irradiadas com $1000 \mathrm{~Gy}$, normalizadas pela intensidade OSL inicial. $\mathrm{O}$ decaimento mais rápido para a amostra contendo nanopartículas de prata é ainda mais evidente.

Figura 4.15: Curvas OSL da amostra 8mL_NpAg irradiada com diferentes doses. 64

Figura 4.16: Curvas OSL da amostra 8mL_NpAg, normalizadas pela intensidade inicial, e irradiadas com doses de 100, 500 e 1000 Gy (a). As curvas no item (b) correspondem as mesmas curvas do item (a) porém com a subtração do sinal de fundo

Figura 4.17: Curva dose-resposta para as amostras de $\mathrm{ZnO}$ puro e 8mL_NpAg . 66

Figura 4.18: Curvas OSL para a amostra $8 \mathrm{~mL} \_\mathrm{NpAg}$ e para o substrato de vidro utilizado para depositar as amostras de $\mathrm{ZnO} / \mathrm{Ag}$.

Figura 4.19: Curva dose-resposta para o substrato de vidro. 68

Figura 5.1: (a) Espectro UV-Vis dos filmes de nanopartículas de prata. (b) Espectro de Infravermelho do filme com 10 bicamadas.

Figura 5.2: Imagens de Microscopia de Força Atômica da superfície dos filmes de nanopartículas de prata depositados sobre substratos vítreos. 73 
Figura 5.3: Imagens de Microscopia de Força Atômica da superfície do filme com 3 bicamadas de nanopartículas de prata depositado sobre substrato vítreo.

Figura 5.4: Imagens de microscopia de força atômica dos filmes com 10 bicamadas de nanopartículas de prata depositados sobre substrato de alumínio.

Figura 5.5: Imagem de microscopia de força atômica do filme com 1 bicamada de quitosana/poli(ácido acrílico) depositado sobre substrato de sílica. As imagens laterais correspondem aos perfis referentes aos respectivos traços presentes na imagem de microscopia. A espessura encontrada em cada traço está representada sob o título height presente nas respectivas tabelas.

Figura 5.6: Curvas OSL para o $\mathrm{NaCl}$ depositado sobre o vidro e sobre o filme com 10 bicamadas Qt/NpAg, irradiados com $10 \mathrm{~Gy}$.

Figura 5.7: Ajuste exponencial das curvas de decaimento OSL. 78

Figura 5.8: (a) Intensidade OSL em função do número de bicamadas do filme de nanopartículas de prata. (b) Intensidade OSL em função da absorbância em $470 \mathrm{~nm}$ dos filmes de nanopartículas de prata.

Figura 5.9: (a) Intensidade OSL inicial em função do número de bicamadas do filme de nanopartículas de prata. (b) Intensidade OSL inicial em função da absorbância em $470 \mathrm{~nm}$ dos filmes de nanopartículas de prata. 80

Figura 5.10: Intensidade OSL em função do número de bicamadas dos filmes de nanopartículas de prata depositados sobre substratos de vidro e alumínio.

Figura 5.11: Representação da interação entre uma nanopartícula metálica e uma superfície condutora. (a) $\mathrm{O}$ dipolo paralelo à superfície condutora é cancelado pela imagem induzida. (b) $\mathrm{O}$ dipolo perpendicular à superfície acopla-se com a imagem induzida, causando deslocamento da banda de ressonância plasmônica para maiores comprimentos de onda ${ }^{[104]}$ 83

Figura 5.12: Representação da deposição de bicamadas de Qt/PAA entre o substrato de alumínio e o filme de nanopartículas de prata.

Figura 5.13: Intensidade OSL em função do número de bicamadas de Qt/PAA entre o substrato de alumínio e os filmes de nanopartículas de prata (3_NpAg). 85

Figura 5.14: Representação da deposição de bicamadas de Qt/PAA entre o filme de nanopartículas de prata e o cloreto de sódio. 86

Figura 5.15: Intensidade OSL (integral) em função do número de bicamadas de Qt/PAA (espaçamento) entre o $\mathrm{NaCl}$ e o filme de nanopartículas de prata (3_NpAg). A espessura estimada de cada bicamada de Qt/PAA é de $15 \mathrm{~nm}$.

Figura 5.16: Ilustração das transições eletrônicas e da transferência de energia envolvidas no processo de luminescência opticamente estimulada em condições de ressonância plasmônica. 88

Figura 5.17: Curvas OSL normalizadas pela intensidade inicial, de amostras em pó de cloreto de sódio irradiadas com a mesma dose e obtidas com diferentes potências de estimulação OSL

Figura 5.18: Curvas OSL do $\mathrm{NaCl}$ depositados sobre filmes com 3, 5 e 10 bicamadas de Qt/NpAg, normalizadas pela intensidade inicial das respectivas curvas.

Figura 5.19: Curvas OSL normalizadas para o $\mathrm{NaCl}$ depositado sobre os filmes com 1, 2, 4 e 6 bicamadas de Qt/PAA, sobre filmes com 3 bicamadas de Qt/NpAg. 
Figura 5.20: Ilustração das transições eletrônicas radiativas (OSL) e não radiativas $\left(\mathrm{T}_{\mathrm{nr}}\right)$, envolvidos nos processos de emissão e recuperação do sinal OSL do cloreto de sódio ${ }^{[111]}$.

Figura 5.21: Primeira e segunda leitura do sinal OSL para o $\mathrm{NaCl}$ depositado sobre vidro. A segunda leitura, realizada 10 minutos após a primeira leitura, evidencia a recuperação do sinal OSL.

Figura 5.22: Primeira e segunda leitura do sinal OSL para o $\mathrm{NaCl}$ depositado sobre o filme 10_NpAg/vidro. Não há recuperação do sinal OSL na segunda leitura, evidenciando o total esvaziamento de armadilhas eletrônicas durante a primeira leitura.

Figura 5.23: Ilustração das transições eletrônicas radiativas (OSL), não radiativas $\left(\mathrm{T}_{\mathrm{nr}}\right)$, e do processo de transferência de energia, envolvidos nos processos de emissão do sinal OSL do cloreto de sódio em condições de ressonância plasmônica. 96

Figura 5.24: Curva dose-resposta para o $\mathrm{NaCl}$ depositado sobre o vidro e sobre o filme 3_NpAg...... 97

Figura 6.1: (a) Banda de ressonância plasmônica do filme de ouro com $50 \mathrm{~s}$ de deposição e para os demais tempos de deposição (b). 100

Figura 6.2: Banda de ressonância plasmônica do filme de ouro com $50 \mathrm{~s}$ e $800 \mathrm{~s}$ de deposição. 101

Figura 6.3: Coeficiente de extinção em $470 \mathrm{~nm}$ em função do tempo de deposição dos filmes de ouro.

Figura 6.4: Imagens de Microscopia de Força Atômica dos filmes de ouro com $800 \mathrm{~s}$ de deposição sobre substratos de vidro (a) e alumínio (b). 103

Figura 6.5: Imagens de Microscopia de Força Atômica do filmes de ouro com $800 \mathrm{~s}$ de deposição sobre substratos de vidro, evidenciando os diâmetros das nanopartículas presentes no filme.

Figura 6.6: Imagens de Microscopia de Força Atômica dos filmes de ouro com $800 \mathrm{~s}$ de deposição sobre substratos de alumínio, evidenciando os diâmetros das nanopartículas presentes no filme...... 105

Figura 6.7: Curva OSL para o $\mathrm{NaCl}$ depositado sobre o vidro e sobre o filme de ouro depositado com 800s em substrato vítreo.

Figura 6.8: Intensidade OSL relativa (integral) em função do tempo de deposição (a) e do coeficiente de extinção em $470 \mathrm{~nm}$ (b) dos filmes de ouro. 108

Figura 6.9: Curvas de intensidade OSL relativa e coeficiente de extinção em função do tempo de deposição dos filmes de ouro.

Figura 6.10: Intensidade OSL inicial em função do tempo de deposição (a) e do coeficiente de extinção (b) dos filmes de ouro.

Figura 6.11: Curvas OSL para o $\mathrm{NaCl}$ depositado sobre o vidro e sobre os filmes 800s_Au e 3_NpAg.

Figura 6.12: Curvas OSL normalizadas pela intensidade inicial, para o $\mathrm{NaCl}$ depositado sobre filmes de ouro com diferentes tempos de deposição.

Figura 6.13: Primeira e segunda leitura do sinal OSL para o $\mathrm{NaCl}$ depositado sobre o filme de ouro com 800 s de deposição. Não há recuperação do sinal OSL na segunda leitura, evidenciando o total esvaziamento de armadilhas eletrônicas durante a primeira leitura. 112

Figura 6.14: Curva dose-resposta do $\mathrm{NaCl}$ depositado sobre o filme de ouro (800s), sobre o vidro e sobre o chumbo. 
Figura 6.15: Intensidade OSL em função do tempo de deposição de ouro em substrato de vidro e alumínio.

Figura 6.16: Representação da deposição de bicamadas de Qt/PAA entre o substrato de alumínio e o filme de nanopartículas de ouro.

Figura 6.17: Intensidade OSL normalizada pela intensidade do $\mathrm{NaCl}$ depositado sobre o filme 800s_Au/Alumínio, em função do número de bicamadas Qt/PAA depositado entre o substrato de alumínio e o filme de ouro. A espessura de cada bicamada é de $15 \pm 2 \mathrm{~nm}$.

Figura 6.18: Curva OSL da amostra sobre o filme de ouro depositado diretamente sobre o substrato de alumínio com e sem o filme com 12 bicamadas de Qt/PAA 


\section{LISTA DE TABELAS}

Tabela 2.1: Identificação das amostras para cada variação da porcentagem em massa de prata utilizada.

Tabela 4.1: Tempos de vida obtidos pelo ajuste das curvas de decaimento de luminescência presentes na Figura 4.9. 


\section{LISTA DE SÍMBOLOS E ABREVIATURAS}

OSL Luminescência Opticamente Estimulada

PL Fotoluminescência

RL Radioluminescência

FTIR Espectroscopia na região de Infravermelho por Transformada de Fourier

UV-Vis Região do espectro ultravioleta e visível

DLS Espalhamento Dinâmico da Luz

AFM Microscopia de Força Atômica

TEM Microscopia Eletrônica de Transmissão

SEM Microscopia Eletrônica de Varredura

NpAg Nanopartículas de Prata

NpAu Nanopartículas de Ouro

MpAg Micropartículas de Prata

PVA Álcool Polivinílico

PVP Polivinilpirrolidona

EG Etilenoglicol

ZnO Óxido de zinco

ZnO/Ag Nanocompósito de óxido de zinco e nanopartículas de prata

ZnO/Au Nanocompósito de óxido de zinco e nanopartículas de ouro

Qt Quitosana

PAA Poli(ácido acrílico)

Qt/NpAg Filme fino com uma camada de quitosana e uma de nanopartículas de prata

Qt/PAA Filme fino com uma camada de quitosana e uma de Poli(ácido acrílico) 


\section{Sumário}

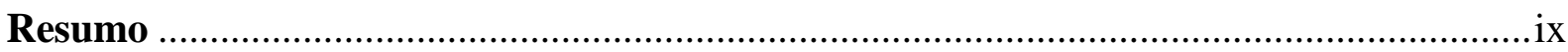

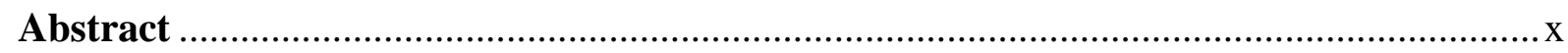

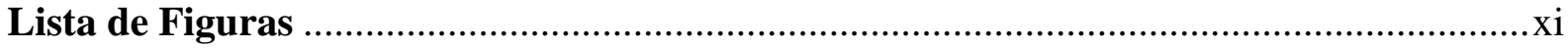

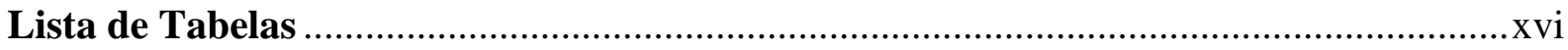

Lista de Símbolos e Abreviaturas....................................................................................

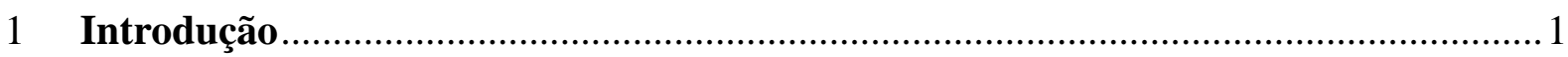

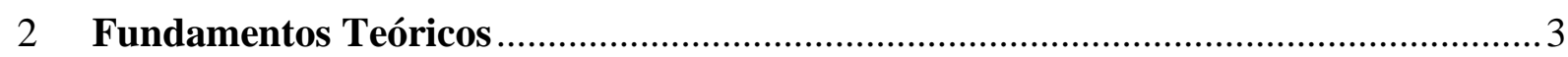

2.1 Luminescência Opticamente Estimulada ........................................................... 3

2.1.1 Armadilhas, Centros de Recombinação e os Processos Luminescentes ..............7

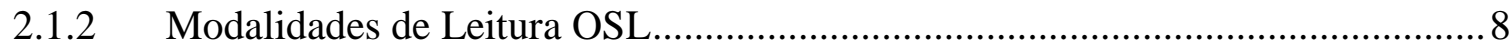

2.1.3 Processos Luminescentes Correlacionados .................................................... 9

2.1.4 Os Métodos Convencionais de Aumento da Luminescência Opticamente

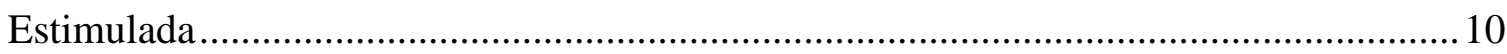

2.2 Ressonância Plasmônica e Luminescência Acoplada aos Plásmons .......................... 11

2.2.1 Ressonância Plasmônica....................................................................................... 11

2.2.2 Luminescência Acoplada aos Plásmons ........................................................ 18

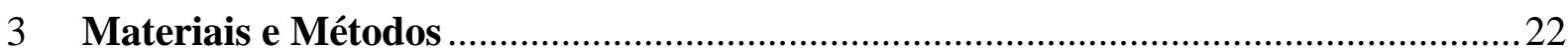

3.1 Preparação das Amostras ................................................................................ 22

3.1.1 Síntese de Nanopartículas de Prata pela redução Química com $\mathrm{NaBH}_{4}$................ 22

3.1.2 Produção dos Nano e Microcompósitos de $\mathrm{NaCl} / \mathrm{Ag}$...........................................22

3.1.3 Síntese das Nanopartículas de Prata e Ouro pelo método do Poliol....................23

3.1.4 Síntese dos compósitos $\mathrm{ZnO} / \mathrm{Ag}$ e $\mathrm{ZnO} / \mathrm{Au}$........................................................2 23

3.1.5 Produção dos filmes de Nanopartículas de Prata............................................... 24 
3.1.6 Produção de filmes com bicamadas de Quitosana/Poli (ácido acrílico)..............25

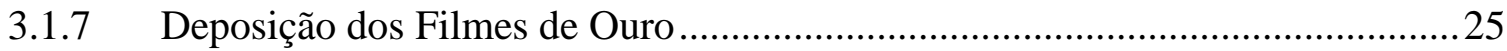

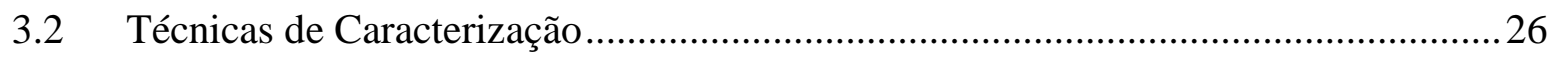

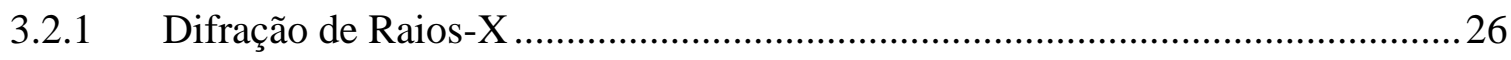

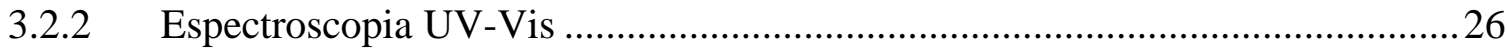

3.2.3 Espalhamento Dinâmico de Luz (DLS).......................................................... 26

3.2.4 Microscopia Eletrônica de Transmissão (TEM), Varredura (SEM) e de Força

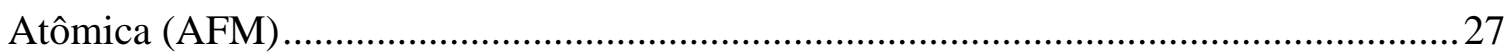

3.2.5 Espectroscopia na Região do Infravermelho por Reflexão Total Atenuada

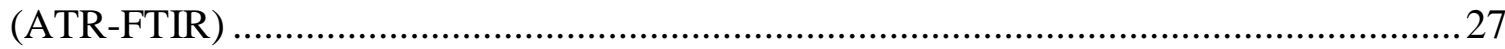

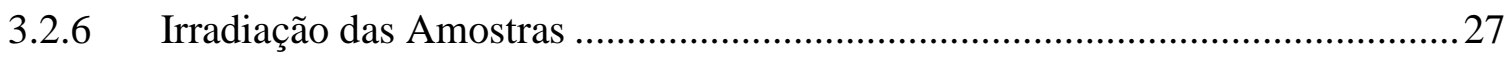

3.2.7 Luminescência Opticamente Estimulada......................................................... 28

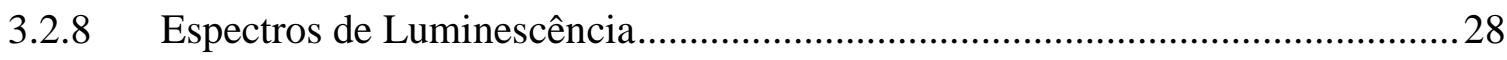

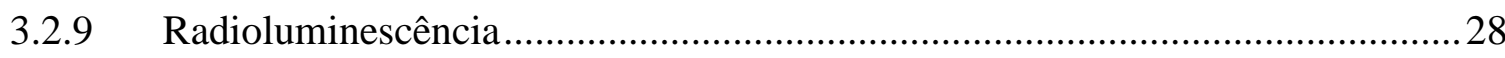

4 Estudo e Caracterização dos Compósitos NaCl/Ag .................................................... 30

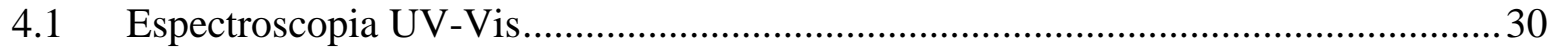

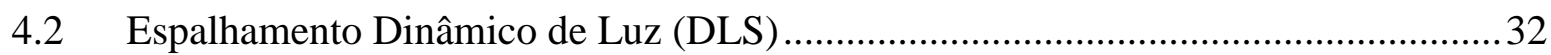

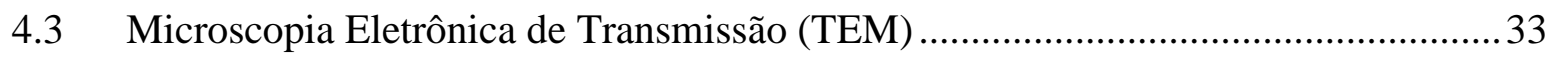

4.4 Luminescência Opticamente Estimulada (OSL) ................................................. 34

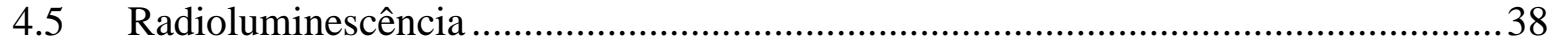

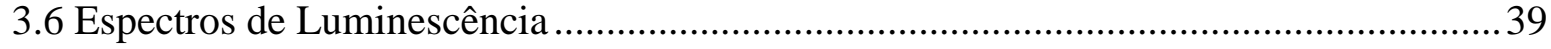

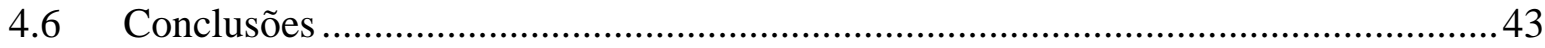

5 Estudo e Caracterização dos Nanocompósitos ZnO/Ag e ZnO/Au ..............................45

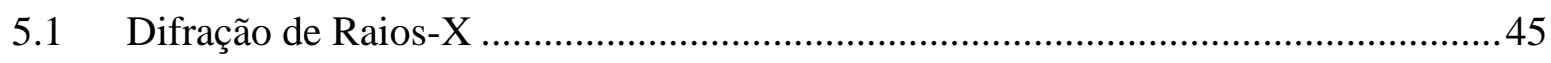

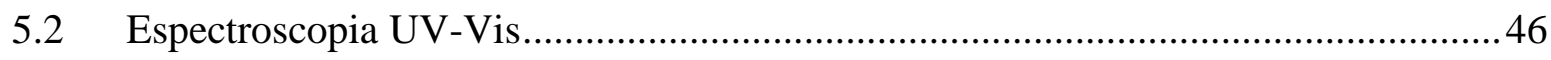

5.3 Microscopia Eletrônica de Varredura .................................................................... 47

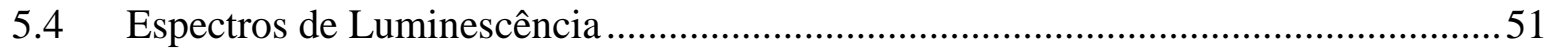

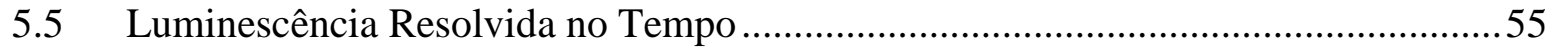

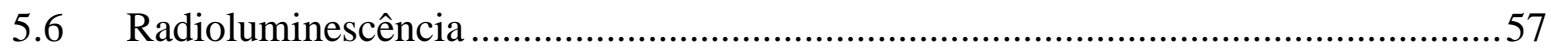

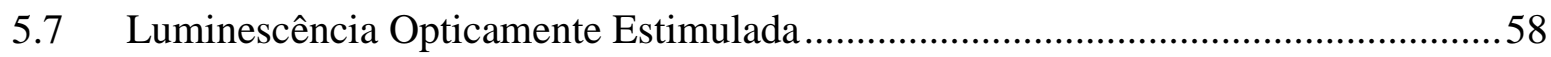

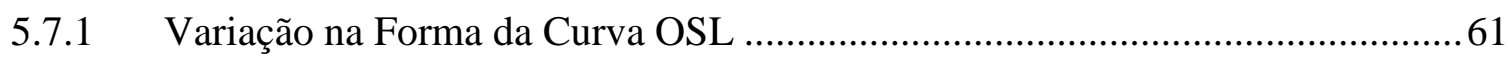


6 Estudo e Caracterização dos Filmes de Nanopartículas de Prata ............................. 70

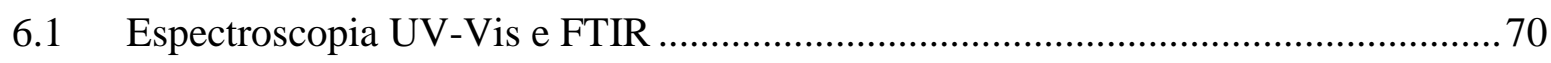

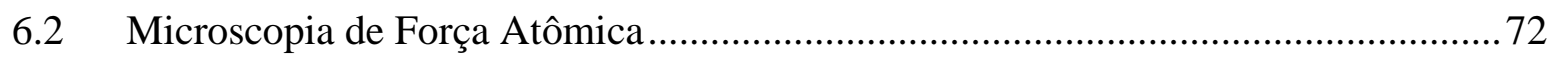

6.2.1 Filmes de Nanopartículas de Prata Depositados em Substratos Vítreos ............ 72

6.2.2 Filmes de Nanopartículas de Prata Depositados em Substratos de Alumínio .... 74

6.2.3 Filmes de Quitosana/Poli(ácido acrílico) ....................................................... 75

6.3 Luminescência Opticamente Estimulada.............................................................. 76

6.3.1 Influência do Número de Bicamadas de Qt/NpAg ......................................... 78

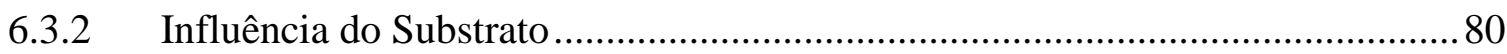

6.3.3 Influência da Distância entre o Substrato Metálico e o Filme de NpAgs ...........84

6.3.4 Influência do Espaçamento entre o Filme de NpAgs e o $\mathrm{NaCl}$........................... 85

6.3.5 Variação na Forma da Curva OSL .................................................................. 88

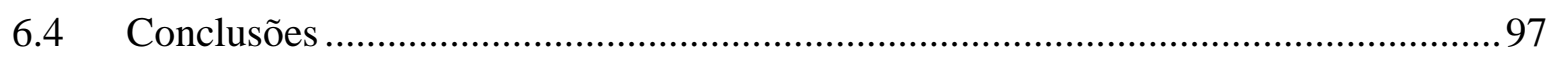

7 Estudo e Caracterização dos Filmes de Nanopartículas de Ouro.............................. 99

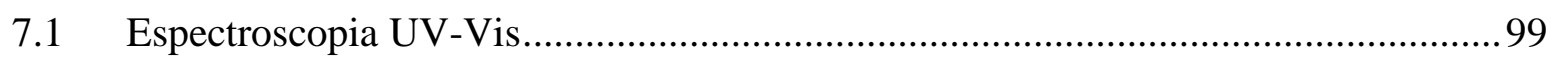

7.1.1 Influência do Tempo de Deposição no Coeficiente de Extinção dos Filmes de Ouro 101

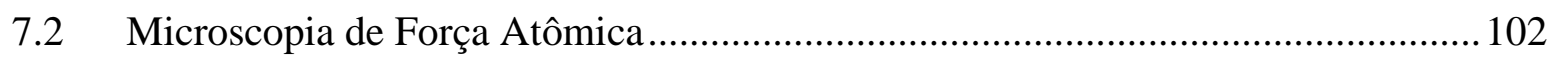

7.3 Luminescência Opticamente Estimulada........................................................... 106

7.3.1 Influência do Tempo de Deposição dos Filmes de Ouro .................................. 107

7.3.2 Variação na Forma da Curva OSL e a Regeneração da Luminescência

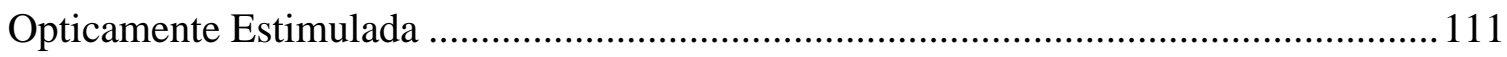

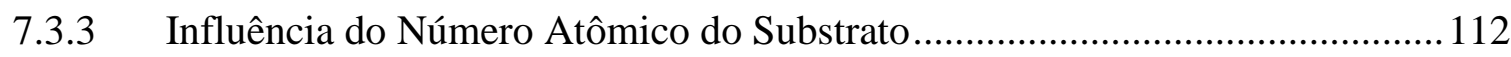

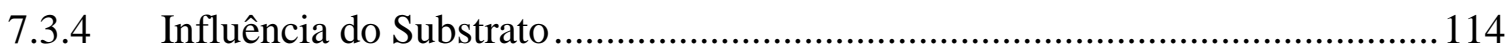

7.3.5 Influência do Espaçamento entre o Substrato e o Filme de Ouro ......................116

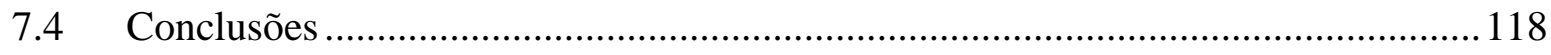

8 Conclusões e Considerações Finais ...................................................................... 120 
9 Referências.

122 


\section{Introdução}

Existem muitos relatos sobre o uso da luminescência opticamente estimulada e da termoluminescência em dosimetria das radiações ionizantes e vamos nos restringir a apenas aqueles que consideramos mais relevantes. Em 1664, Robert Boyle descreveu a emissão luminescente oriunda de um pedaço de diamante natural quando aquecido. Além disso, os primeiros relatos quanto ao uso da luminescência opticamente estimulada são encontrados em trabalhos de Edmond e Henri Becquerel, datados de 1843 e 1883, quando observaram que a fosforescência de sulfatos de zinco e cálcio diminuía quando iluminados com radiação infravermelha. No ano do descobrimento dos raios-X (1895), foi proposta uma teoria de que a separação de cargas elétricas positivas e negativas daria origem a um fenômeno batizado de "thermoluminescenz" [1]. Como essas observações foram feitas antes do desenvolvimento da mecânica quântica, não era possível, na época, a compreensão dos processos de armadilhamento e recombinação de elétrons e buracos. $\mathrm{O}$ uso do termo luminescência opticamente estimulada surgiu anos mais tarde, em 1963, em um trabalho sobre técnicas de dosimetria do estado sólido em medicina [2].

Mas, na verdade, foram os desenvolvimentos realizados nas últimas três décadas que permitiram a expansão da dosimetria OSL em áreas como a dosimetria pessoal, ambiental, espacial, retrospectiva e acidental, além de aplicações em dosimetria médica e datação arqueológica. Foi uma publicação da revista Nature, em 1985, a primeira a propor o uso da técnica OSL para datação e dosimetria ambiental [3], mas foi a introdução do óxido de alumínio dopado com carbono $\left(\mathrm{Al}_{2} \mathrm{O}_{3}: \mathrm{C}\right)$, durante a década de 1990 , que permitiu a difusão da dosimetria OSL. Em 1998 foi introduzido o primeiro sistema comercial de dosimetria OSL [4], mas só em 2014 essa técnica foi aprovada no Brasil pela Comissão Nacional de Energia Nuclear (CNEN). Desde a introdução do óxido de alumínio dopado com carbono, nenhum outro material apresentou propriedades mais adequadas para o emprego da técnica. Por isso, é intensa a busca por novos materiais para utilização em diversas aplicações da dosimetria por luminescência opticamente estimulada.

Ainda mais antigo que os relatos sobre os métodos luminescentes de dosimetria das radiações ionizantes, são os relatos sobre o emprego de nanoestruturas metálicas, que foram utilizadas, por exemplo, para colorir vidros e cerâmicas de obras artísticas durante o Império Romano [5]. No entanto, os primeiros estudos sobre plásmons de superfície são datados do 
início do século $\mathrm{XX}$, baseados em observações de espectros de reflexão de gratículos metálicos [6]. Nessa mesma época, as cores brilhantes de vidros dopados com metais foram descritas usando o modelo de metais de Drude e a teoria de espalhamento Rayleigh por pequenas esferas metálicas [7]. Poucos anos mais tarde, foi então desenvolvida a teoria de Mie sobre o espalhamento da luz por partículas esféricas [8]. Porém, o uso do termo plásmons foi pela primeira vez utilizado cerca de cinquenta anos depois, em um estudo em que as perdas de energia em materiais metálicos foram atribuídas às oscilações coletivas dos elétrons livres no metal. A primeira descrição teórica de plásmons aconteceu em 1957, mas o maior avanço na área ocorreu em 1968, em um trabalho apresentando a metodologia para excitação de plásmons de superfície em filmes metálicos [9]. Desde então, as propriedades plasmônicas de filmes e nanopartículas metálicas têm sido utilizadas para o desenvolvimento de sensores/detectores ópticos, desde sistemas eletrônicos até biomoleculares [10]. Além disso, essas propriedades são também muito utilizadas para aumento do espalhamento Raman e de processos de luminescência como a fluorescência, fosforescência [11], quimiluminescência [12], catodoluminescência [13], entre outros.

Nesse contexto, a tese aqui apresentada tem como objetivo o estudo de duas áreas relativamente antigas da ciência, que são muito exploradas separadamente mas que, pela primeira vez, serão investigadas em conjunto, na busca de novos e mais sensíveis detectores e dosímetros das radiações ionizantes. Portanto, a grande questão levantada desde o início e que guiou o desenvolvimento da presente tese é a seguinte: Podem as propriedades plasmônicas de nanoestruturas metálicas serem utilizadas para aumentar a intensidade da luminescência opticamente estimulada? 


\section{Fundamentos Teóricos}

\subsection{Luminescência Opticamente Estimulada}

A luminescência opticamente estimulada (LOE), ou optically stimulated luminescence (OSL) é produzida por um material, isolante ou semicondutor, durante exposição à luz e que foi previamente irradiado com radiação ionizante. A abreviação OSL é amplamente utilizada em nosso idioma e vamos utilizá-la nesse texto. A intensidade OSL é função da dose de radiação absorvida pela amostra [14-15]. Os elétrons ionizados durante exposição à radiação ficam presos em armadilhas pré-existentes no material. Assim, quando este material irradiado é exposto à luz, os elétrons armadilhados absorvem os fótons, passando para a banda de condução. Em seguida, passam por um processo de desexcitação e retornam para a banda de valência [14-15], o que é acompanhado pela emissão de luz. Dessa forma, a luminescência opticamente estimulada pertence à classe dos fenômenos estimulados, assim como a luminescência termicamente estimulada, que é o fenômeno base da dosimetria termoluminescente (TLD).

Os níveis de energia na estrutura cristalina do dosímetro consistem em bandas de valência e condução, separadas por um gap de energia, conhecido como banda proibida [4]. A radiação ionizante é capaz de ionizar os elétrons da banda de valência para a banda de condução, deixando buracos na camada de valência. Os elétrons na banda de condução e os buracos na camada de valência são livres para moverem-se na rede cristalina até que se recombinem ou sejam capturados por níveis de energia presentes na banda proibida (band gap) $[4,14-15]$. Assim, quanto maior a dose de radiação absorvida pelo material, maior será o número de ionizações e consequentemente, maior será o número de cargas armadilhadas. Em geral, a intensidade OSL é medida em função do tempo. A integral da curva de intensidade luminescente em função do tempo é proporcional à quantidade de cargas armadilhadas, e portanto, é proporcional à dose de radiação absorvida [4].

As cargas armadilhadas podem ser liberadas para a banda de condução por meio de um estímulo óptico e/ou térmico. No caso de estimulação óptica, a probabilidade de uma dada carga escapar é dada pelo produto entre a fluência de fótons $(\varphi)$ de estimulação e a seção de choque de fotoionização $(\sigma)$ do defeito em questão. Após a liberação da carga aprisionada no defeito, a recombinação elétron-buraco pode ocorrer por processo radiativo, dando origem à emissão luminescente, denominada luminescência opticamente estimulada. A intensidade total da luminescência opticamente estimulada é proporcional a concentração total de cargas 
armadilhadas o que, por sua vez, é proporcional à dose de radiação recebida pelo material isolante/semicondutor.

Os defeitos na estrutura de um material podem ser classificados como armadilhas (de elétrons ou buracos) ou centros de recombinação. Esses defeitos podem aprisionar cargas, sendo chamados de armadilhas, ou ainda capturar um buraco da banda de valência e em seguida capturar um elétron da banda de condução, o que o denomina como sendo um centro de recombinação. A diferença entre uma armadilha e um centro de recombinação está na probabilidade que uma carga armadilhada tem de ser estimulada para as bandas de condução/valência, ou de ser capturada por outra carga de sinal oposto no mesmo defeito em que está aprisionada. Se, por exemplo, um elétron armadilhado em um dado defeito tem maior probabilidade de escapar para a banda de condução do que de capturar um buraco e recombinar, então esse defeito é uma armadilha. Na situação oposta, se o elétron tiver maior probabilidade de capturar um buraco do que de ser estimulado para a banda de condução, então o defeito é um centro de recombinação.

Durante a irradiação de um material isolante/semicondutor, pela regra da neutralidade de cargas, o número de elétrons na banda de condução $\left(\mathrm{n}_{\mathrm{c}}\right)$ somado ao número de elétrons presos em armadilhas (n) deve ser igual ao número de buracos na banda de valência $\left(b_{v}\right)$ somado ao número de buracos presos em centros de recombinação (b) [15]:

$$
\boldsymbol{n}_{c}+\mathbf{n}=\mathbf{b}_{\mathbf{v}}+\mathbf{b}
$$

Equação 1

Ao término da irradiação, em condições de equilíbrio térmico, as cargas ionizadas e não aprisionadas se recombinam, de forma que o número de elétrons na banda de condução e o número de buracos na banda de valência é zero $\left(n_{c}=b_{v}=0\right)$. Durante a estimulação óptica de elétrons armadilhados, a neutralidade de cargas estabelece que o número de elétrons presos em armadilhas mais o número de elétrons liberados para a banda de condução deve ser igual ao número de buracos presos nos centros de recombinação [15]:

$$
\boldsymbol{n}_{\boldsymbol{c}}+\boldsymbol{n}=\boldsymbol{b} \quad \text { Equação }
$$

Assim, é possível escrever a taxa de variação de concentração de cargas durante a estimulação óptica do material isolante/semicondutor previamente irradiado como sendo [15]: 


$$
\frac{d n_{c}}{d t}+\frac{d n}{d t}=\frac{d b}{d t}
$$

Considerando a possibilidade de re-armadilhamento de um elétron da banda de condução, a taxa de variação da concentração de elétrons presos em armadilhas pode ser escrita como:

$$
\frac{d n}{d t}=n p-n_{c} A(N-n)
$$

Onde p é a probabilidade do elétron armadilhado escapar; A é a probabilidade de rearmadilhamento de um elétron da banda de condução; e $\mathrm{N}$ é o número total de armadilhas eletrônicas. A probabilidade de escape do elétron armadilhado é dado dada pelo produto entre a fluência de fótons de estimulação $(\varphi)$ e seção de choque de fotoionização $(\sigma)$ do defeito em questão [15]:

$$
p=\varphi \sigma
$$

Equação 5

A taxa de variação de buracos aprisionados pode ser escrita como:

$$
\frac{d b}{d t}=n_{c} A_{m} b
$$

Onde $\mathrm{A}_{\mathrm{m}}$ é a probabilidade de recombinação de um elétron da banda de condução.

Considerando um estado quase estacionário da população de elétrons livres na banda de condução, temos as seguintes aproximações [15]:

$$
\mathbf{n}_{\mathbf{c}} \ll \boldsymbol{n}
$$

Equação 7

$\mathrm{e}$

$$
\mathbf{n}_{\mathbf{c}} \ll \boldsymbol{b}
$$




\section{Portanto:}

$$
\frac{d n_{c}}{d t} \ll \frac{d n}{d t} \text { e } \frac{d n_{c}}{d t} \ll \frac{d b}{d t}
$$

Considerando ainda que a taxa de re-armadilhamento é muito menor que a taxa de liberação de elétrons e buracos temos que [15]:

$$
n_{c} A(N-n) \ll n p
$$

Equação 10

$\mathrm{e}$

$$
A(N-n) \ll n_{c} A_{m} b
$$

Equação 11

Logo:

$$
I_{O S L}=-\frac{d b}{d t}=\frac{d n}{d t}=n p
$$

A solução para essa equação é:

$$
I_{O S L}=n_{0} p e^{(-t p)}
$$

Ou ainda

$$
I_{O S L}=I_{0} e^{\left(-t / \tau_{d}\right)}
$$

Equação 14

Onde $I_{0}$ é a intensidade OSL inicial no tempo $\mathrm{t}=0$ de estimulação e $\tau_{d}$ é a constante de decaimento da curva OSL. Assim, esse modelo de primeira ordem dá origem a um decaimento exponencial para a curva OSL em função do tempo de estimulação OSL. Quando todos os elétrons armadilhados são liberados, a intensidade OSL se torna nula. A área sob a curva OSL pode ser obtida pela integração da equação 14. É fácil perceber que essa integral resulta em $\int I_{O S L} \propto n_{0}$, ou seja, a integral da curva OSL é proporcional ao número de cargas 
armadilhadas, o que por sua vez é proporcional a dose de radiação recebida pelo material, e não depende da potência da fonte estimulação. Já a intensidade OSL inicial é proporcional tanto a número de cargas armadilhadas quanto da potência de estimulação e da seção de choque de fotoionização do defeito $\left(I_{O S L} \propto n_{0} p \propto n_{0} \varphi \sigma\right)$. No entanto, esse modelo simplificado do processo OSL só é valido nas condições de baixa probabilidade de rearmadilhamento de cargas e da existência de um único tipo de armadilha e centro de recombinação. Em materiais reais, esse comportamento monoexponencial pode ser observado muito raramente.

\subsubsection{Armadilhas, Centros de Recombinação e os Processos Luminescentes}

As armadilhas eletrônicas podem ser classificadas em rasas, dosimétricas e profundas, de acordo com o nível de energia que ocupam em relação a banda de condução. As armadilhas rasas são próximas a banda de condução, de forma que elétrons nelas aprisionados são geralmente liberados em temperatura ambiente. As armadilhas dosimétricas, são as armadilhas responsáveis pelos processos OSL e TL, uma vez que estão localizados em níveis de energia que não permitem que os elétrons sejam liberados sem que haja algum estímulo energético externo. Já armadilhas profundas requerem fótons com energia maior que os fótons da luz visível para que haja liberação dos elétrons armadilhados.

Os vários tipos de armadilhas (profundas, dosimétricas e rasas) e centros de recombinação podem alterar tanto a forma como a área da curva OSL, devido ao rearmadilhamento de cargas, à fototransferência de cargas oriundas de armadilhas profundas para armadilhas dosimétricas e/ou rasas, à estimulação térmica de cargas presas em armadilhas rasas, entre outros.

Alguns fatores podem influenciar no processo de armadilhamento de cargas e emissão da luminescência opticamente estimulada e, portanto, é válido estender um pouco a descrição desses processos. O aprisionamento de elétrons por armadilhas rasas geralmente está associado a luminescência que ocorre logo após a irradiação da amostra (fosforescência), produzindo um crescimento inicial na curva OSL e o aparecimento de uma longa cauda no final da mesma. A fosforescência pode ainda ser causada pela liberação de elétrons presos em armadilhas rasas devido a estimulação térmica em temperatura ambiente. Assim, para evitar a influência da fosforescência na curva OSL, é recomendado um intervalo de tempo (característico de cada material) entre a irradiação da amostra e a leitura do dosímetro. Além 
disso, no início da medida OSL ( $\mathrm{t}=0$ ), essas armadilhas rasas estão geralmente vazias e podem então capturar elétrons que foram estimulados de armadilhas dosimétricas para a banda de condução, diminuindo a intensidade OSL inicial. Porém, à medida que as armadilhas rasas vão sendo preenchidas, a captura de cargas por essas armadilhas se torna menos relevante e a intensidade OSL aumenta. Além disso, durante e depois do estímulo óptico, devido as cargas liberadas pelas armadilhas dosimétricas e capturadas pelas armadilhas rasas, a emissão fosforescente pode continuar ocorrendo, produzindo uma longa cauda na curva OSL.

Armadilhas profundas também competem com a emissão OSL durante os processos de irradiação e leitura dos dosímetros. Em geral, a presença de armadilhas profundas acarretam na mudança da sensibilidade do dosímetro em função do histórico de irradiações. Por exemplo, para um dosímetro não irradiado, as armadilhas profundas estão inicialmente vazias, podendo capturar cargas. Assim, a intensidade OSL será reduzida uma vez que a energia dos fótons de estimulação não será suficiente para produzir a liberação desses elétrons. Porém, como essas armadilhas não são esvaziadas durante o estímulo óptico, elas acabam sendo totalmente preenchidas no decorrer das irradiações, aumentando a probabilidade de que um elétron seja capturado por armadilhas dosimétricas. Logo, mais elétrons serão estimulados durante a leitura OSL, produzindo maiores intensidades. Por isso é que alguns materiais podem apresentar aumento da sensibilidade OSL quando expostos à doses mais altas de radiação.

\subsubsection{Modalidades de Leitura OSL}

Existem várias modalidades de leitura OSL. O modo contínuo (CW-OSL) é o mais utilizado e consiste na iluminação contínua simultaneamente com a leitura OSL da amostra [14-15]. O modo OSL pulsado (POSL) consiste em estimular a amostra por um curto pulso de luz e realizar a leitura OSL do dosímetro após o término do pulso [14-15]. Para materiais com centros luminescentes que apresentam longos tempos de vida, a escolha apropriada dos parâmetros de leitura, como tempos de estímulo e de leitura, permitem a detecção da maior parte do sinal OSL, com a vantagem de eliminação do sinal de fundo oriundo da luz de estimulação [14-15]. Isso faz com que uma relação sinal-ruído alta seja obtida, de forma que essa técnica se torna apropriada para dosimetria de baixas doses [14-15].

Além dos modos contínuo e pulsado existe ainda a técnica OSL linearmente modulada (LM-OSL), que consiste de um aumento linear da intensidade da luz de estimulação durante a leitura do dosímetro [14-15]. No entanto, essa técnica não apresenta nenhuma vantagem com 
relação aos modos contínuo e pulsado e, por isso, tem sido pouco utilizada para dosimetria das radiações. A única vantagem da técnica LM-OSL é a distinção das diferentes armadilhas compondo o sinal OSL, desde que possuam seções de choque de fotoionização distintas [15].

\subsubsection{Processos Luminescentes Correlacionados}

A luminescência opticamente estimulada não deve ser confundida com os fenômenos correlatos de fotoluminescência que podem se originar de materiais similares, mas que não dependem da dose de radiação absorvida pelo material [14]. A fotoluminescência é a excitação de um elétron em um defeito cristalino do material através da absorção de luz para um estado excitado dentro do próprio defeito, seguida pela emissão de luz durante o processo de relaxação para o estado fundamental. Assim, não há ionização e aprisionamento do elétron em armadilhas. Como consequência, a energia da luz emitida é menor do que a energia da luz incidente. No caso da luminescência opticamente estimulada, é possível ter a emissão com energia maior (comprimento de onda menor) que a estimulação. Isso porque a energia do fóton emitido depende da transição de um estado excitado para o estado fundamental do centro de recombinação e, portanto, não depende do comprimento de onda de estimulação [15].

A luminescência opticamente estimulada está relacionada também a outros processos de luminescência do material e que são importantes para a melhor compreensão do processo OSL. Dentre eles destacam-se a radioluminescência (RL), a fosforescência e a termoluminescência $[4,15]$. Durante a irradiação, a radioluminescência pode ser detectada devido à recombinação imediata de pares elétron-buraco [4]. Ela é proporcional ao número de recombinações de pares elétron-buraco e pode ser utilizada para determinar a taxa de dose. No entanto, a radioluminescência é influenciada também pelas armadilhas de elétrons no material, uma vez que o processo de armadilhamento é um processo competitivo com o processo de recombinação [15].

Imediatamente após a irradiação, a fosforescência pode ser detectada devido à estimulação térmica de armadilhas rasas, em temperatura ambiente [4, 15]. A fosforescência é um processo que compete com a radioluminescência e prejudica sua eficiência e resolução. Isso porque o armadilhamento de elétrons ou buracos por defeitos da rede impede a recombinação imediata do par elétron-buraco e, como consequência, diminui a emissão RL. A fosforescência também pode ser detectada imediatamente após a estimulação óptica quando 
cargas estimuladas de armadilha dosimétricas são capturadas por armadilhas rasas, resultando em uma longa "cauda" do sinal OSL $[4,15]$.

Dessa forma, as emissões TL, OSL e fosforescente podem competir com a emissão RL uma vez que a três primeiras dependem da quantidade de energia armazenada durante a irradiação, ou seja, depende da quantidade de armadilhas presentes no material. Por outro lado, quanto maior o número de armadilhas, maior o número de elétrons e buracos armadilhados e portanto menor será a recombinação imediata, diminuindo a intensidade RL. Logo, a criação de defeitos em materiais é uma forma muito utilizada para aumentar a emissão luminescente dos processos descritos acima: A criação de centros luminescentes/ recombinação tende a aumentar todos os processos de luminescência (OSL, TL, RL e fosforescência), enquanto que a criação de armadilhas tende a melhorar somente as propriedades de materiais utilizados como dosímetros, os quais dependem do armazenamento de cargas.

\subsubsection{Os Métodos Convencionais de Aumento da Luminescência Opticamente Estimulada}

Em geral, a busca de novos materiais a serem utilizados como detectores de radiação envolvem a criação de defeitos que atuem como armadilhas e/ou centros luminescentes [1621]. O exemplo mais comum é o caso do óxido de alumínio dopado com carbono [14]. Os cristais de $\mathrm{Al}_{2} \mathrm{O}_{3}: \mathrm{C}$ são crescidos geralmente pelos métodos de Czochralski, Verneuil ou Stepanov, em altas temperaturas (em torno de 2300 K) [4] e em atmosfera fortemente redutora na presença de carbono. $\mathrm{O}$ carbono tem papel fundamental na sensibilidade do $\mathrm{Al}_{2} \mathrm{O}_{3}: \mathrm{C}$ ao agir como um catalisador na produção de vacâncias de oxigênio. Essas vacâncias de oxigênio (centros F+ e F-), por sua vez, agem como centros de recombinação aumentando a emissão luminescente do óxido de alumínio.

Outro exemplo seria a utilização de íons de terras-raras como centros luminescentes em materiais utilizados como detectores de radiação. O európio, por exemplo, embora muito utilizado como dopante, não tem seu mecanismo de detecção da radiação completamente elucidado [14]. O primeiro mecanismo foi proposto por Takahashi et al. em 1984 [14]. Nele se propõe que a radiação ioniza os íons $\mathrm{Eu}^{+2}$ convertendo-os em $\mathrm{Eu}^{+3}$. Os elétrons liberados pela ionização são então armadilhados pelos centros F da matriz. Quando exposto à luz, esses 
elétrons são liberados e recombinam-se com os íons $\mathrm{Eu}^{+3}$ que retornam para um estado excitado do $\mathrm{Eu}^{+2}$. No processo de relaxação, o íon excitado $\mathrm{Eu}^{+2}$ emite um fóton.

Assim, os métodos convencionais para aumentar a luminescência de materiais utilizados como detectores de radiação envolvem a criação de defeitos na estrutura cristalina por meio da dopagem com átomos de outros elementos [16-21]. O uso de nanopartículas metálicas poderia ajudar nesse cenário no sentido de que além de poder criar defeitos na estrutura do material elas possuem propriedades ópticas oriundas da nanoescala muito interessantes e que poderiam aumentar a eficiência de emissão luminescente de centros ópticos localizados nas proximidades da nanopartícula, como discutido à seguir.

\subsection{Ressonância Plasmônica e Luminescência Acoplada aos Plásmons}

\subsubsection{Ressonância Plasmônica}

Nanopartículas metálicas, como as de ouro e prata, possuem propriedades distintas do material em "grandes" volumes ou bulk, e que tem sido exploradas em vários campos da ciência como a física, química, biologia e medicina. Por exemplo, nanopartículas metálicas tem sido utilizadas em tratamentos de câncer por meio de radioterapia [22-23], como agentes de contraste em radiografias [24-25], em sistema de entrega de drogas, assim como em sensores e detectores [26]. Além dessas aplicações, nanopartículas de metais nobres ainda são utilizadas devido à possibilidade de ajustar a banda de ressonância plasmônica de acordo com a forma e tamanho dessas partículas. Essa banda de ressonância plasmônica é causada pela oscilação coletiva de elétrons livres na superfície da partícula metálica devido a interação com o campo elétrico da luz [32].

Como o tamanho dessas partículas metálicas é muito menor que o comprimento de onda da luz, à medida que um campo luminoso atravessa uma partícula, os elétrons livres em sua superfície irão sofrer a ação do campo elétrico da onda transiente, de forma a direcionarse em sentido contrário ao do campo elétrico do qual estão submetidas momentaneamente (Figura 2.1). Dessa forma, à medida que a onda se desloca pela partícula, o campo elétrico inverte sua direção alternadamente, causando um movimento oscilatório dos elétrons livres da nanopartícula metálica. Essa oscilação é responsável então por absorver e/ou espalhar a luz 
incidente [33]. Assim, os plásmons de superfície possibilitam a amplificação, concentração e até mesmo a manipulação da luz em dimensões da nanoescala [10].

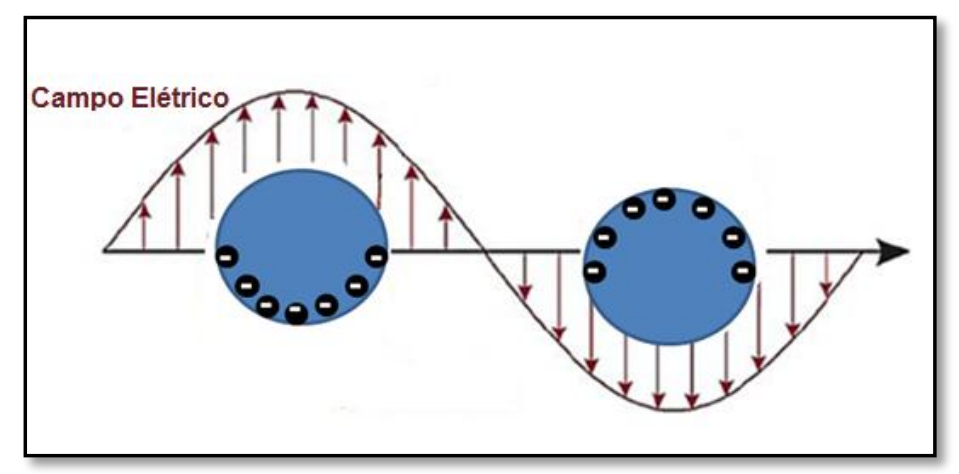

Figura 2.1: Oscilação Plasmônica, induzida pela ação de um campo luminoso, dos elétrons livres na superfície de uma nanopartícula metálica.

Quando uma partícula é exposta a uma onda eletromagnética, os elétrons da partícula oscilam na mesma frequência que a onda incidente. De acordo com a teoria eletromagnética, um elétron oscilante emite radiação eletromagnética com a mesma frequência de sua oscilação. É essa radiação secundária que constitui a luz espalhada. Deve-se ressaltar que a luz espalhada por uma partícula iluminada com luz monocromática tem o mesmo comprimento de onda da luz incidente. As diferentes cores apresentadas por partículas de diferentes tamanhos e composições são produzidas somente quando iluminadas com luz policromática e resulta do fato de que cada tipo de partícula espalha a luz em uma determinada faixa de comprimento de onda. Para luz monocromática, a cor da luz espalhada é a mesma da luz incidente, independentemente do tamanho e da composição da partícula.

As propriedades de espalhamento da luz de uma dada partícula depende da composição, tamanho, forma, homogeneidade e do índice de refração do meio que estão inseridas. É conveniente classificar as partículas entre as que espalham a luz e não absorvem, e aquelas que espalham e absorvem a luz. A absorção da luz é definida como um processo no qual a energia absorvida da luz é convertida em calor. A energia total que é removida do feixe de luz passando por uma suspensão de partículas é igual a soma das energias absorvidas e espalhadas. A combinação desses dois processos é geralmente denominada extinção. Uma partícula se comporta puramente como espalhadora de luz quando a energia incidente não provoca transições eletrônicas nas bandas de absorção do material que compõe a partícula. 
Nesses comprimentos de onda, os elétrons oscilam e espalham, mas não absorvem energia do feixe de luz.

Para uma partícula metálica esférica homogênea de raio $a$ muito menor que o comprimento de onda da luz incidente $(a<<\lambda)$, em um meio é isotrópico e não absorvedor, com constante dielétrica $\varepsilon_{\mathrm{m}}$, pode-se considerar o campo luminoso atravessando a partícula como sendo um campo elétrico estático e uniforme $\mathrm{E}=\mathrm{E}_{0}$. A função dielétrica da partícula é dada em função da frequência da luz incidente $\varepsilon_{\mathrm{p}(\omega)}$, mas será utilizada aqui como um número complexo simples. Assim, o potencial elétrico interno e externo à nanopartícula pode ser escrito como [34]:

$$
\begin{gathered}
\varphi_{\text {int }}=-\frac{3 \varepsilon_{m}}{\varepsilon_{\mathrm{p}}+2 \varepsilon_{m}} E_{0} r \cos \theta \\
\varphi_{\text {ext }}=-E_{0} r \cos \theta+\frac{\varepsilon_{\mathrm{p}}-\varepsilon_{m}}{\varepsilon_{\mathrm{p}}+2 \varepsilon_{m}} E_{0} a^{3} \frac{\cos \theta}{r^{2}}
\end{gathered}
$$

O potencial externo à nanopartícula $\left(\varphi_{\text {ext }}\right)$ descreve a sobreposição do campo elétrico incidente com o campo elétrico de um dipolo localizado no centro da nanopartícula. Assim, o campo externo pode ser reescrito em termos do momento de dipolo p como:

$$
\begin{gathered}
\varphi_{\text {ext }}=-E_{0} r \cos \theta+\frac{\mathrm{p} \cdot \mathrm{r}}{4 \pi \varepsilon_{0} \varepsilon_{m} \mathrm{r}^{3}} \\
p=4 \pi \varepsilon_{0} \varepsilon_{m} \mathrm{a}^{3} \frac{\varepsilon_{\mathrm{p}}-\varepsilon_{m}}{\varepsilon_{\mathrm{p}}+2 \varepsilon_{m}} E_{0}
\end{gathered}
$$

Logo, é possível observar que o campo elétrico aplicado induz um momento de dipolo dentro da nanopartícula metálica esférica com magnitude proporcional ao módulo de $\mathrm{E}_{0}$. O momento de dipolo pode ainda ser escrito em termos da polarizabilidade da nanopartícula metálica como sendo $\mathrm{p}=\varepsilon_{0} \varepsilon_{m} \alpha E_{0}$, sendo a polarizabilidade escrita como:

$$
\alpha=4 \pi \mathrm{a}^{3} \frac{\varepsilon_{\mathrm{p}}-\varepsilon_{m}}{\varepsilon_{\mathrm{p}}+2 \varepsilon_{m}}
$$


Esse é o principal resultado e descreve a polarizabilidade de uma pequena partícula metálica esférica com diâmetro menor que o comprimento de onda da luz. É possível observar que a polarizabilidade apresenta um aumento ressonante na condição em que o módulo do denominador $\left|\varepsilon+2 \varepsilon_{m}\right|$ tende ao valor mínimo. Para o caso de valores em que a componente imaginária da função dielétrica do metal $\operatorname{Im}(\varepsilon)$ seja pequeno (desprezível) ou apresente pequena variação, pode-se escrever a ressonância plasmônica como:

$$
\operatorname{Re}\left[\varepsilon_{\mathrm{p}_{(\omega)}}\right]=-2 \varepsilon_{m}
$$

Essa relação é conhecida como condição de Frohlich. Deve ser ressaltado que a magnitude da polarizabilidade em condições de ressonância é limitada pela redução incompleta do denominador, uma vez que $\operatorname{Im}(\varepsilon) \neq 0$.

A distribuição dos campos elétricos dentro e fora da nanopartícula pode ser obtida pelos potenciais descritos acima:

$$
\begin{gathered}
E_{\text {int }}=\frac{3 \varepsilon_{m}}{\varepsilon_{\mathrm{p}}+2 \varepsilon_{m}} E_{0} \\
E_{\text {ext }}=E_{0}+\frac{3 n(n \cdot p)-p}{4 \pi \varepsilon_{0} \varepsilon_{m} \mathrm{r}^{3}}
\end{gathered}
$$

Como pode ser observado, o aumento ressonante da polarizabilidade causa também um aumento ressonante dos campos elétricos dentro e fora da nanopartícula metálica. É esse aumento de campo elétrico na ressonância plasmônica que origina todas as propriedades plasmônicas utilizadas para aumento de luminescência e do espalhamento Raman, e para aplicações em sensores e dispositivos ópticos.

Até agora, essa descrição foi desenvolvida com base em campos elétricos estáticos, o que não se aplica para casos de campos eletromagnéticos irradiados por pequenas partículas em ressonância plasmônica. Para uma esfera com raio muito menor que o comprimento de onda da luz incidente $(a \ll \lambda)$, a representação como um dipolo ideal é somente válida no regime quase estático, permitindo a variação do campo elétrico, mas desprezando os efeito do retardamento espacial no volume da nanopartícula. Considerando-se uma onda eletromagnética planar, $\mathrm{E}(\mathrm{r}, \mathrm{t})=E_{0} e^{-i \omega t}$, os campos induzem um momento de dipolo oscilante $\mathrm{p}(\mathrm{t})=\varepsilon_{0} \varepsilon_{m} \alpha E_{0} e^{-i \omega t}$, sendo $\alpha$ a polarizabilidade obtida na equação 19. A 
radiação desse dipolo oscilante produz o espalhamento da onda planar pela esfera metálica, podendo ser representada como a radiação emitida por um dipolo.

Do ponto de vista da óptica, é muito importante ressaltar que o aumento ressonante da polarizabilidade causa também o aumento da eficiência de absorção e espalhamento da luz pela nanopartícula. As seções de choque correspondentes ao espalhamento e à absorção podem ser descritas como:

$$
\begin{gathered}
\sigma_{s}=\frac{k^{4}}{6 \pi}|\alpha|^{2}=\frac{8 \pi}{3} k^{4} a^{6}\left|\frac{\epsilon_{p}-\epsilon_{m}}{\epsilon_{p}+2 \varepsilon_{m}}\right|^{2} \\
\sigma_{a b s}=k \operatorname{Im}[\alpha]=4 \pi a^{3} \operatorname{Im}\left(\frac{\epsilon_{p}-\epsilon_{m}}{\epsilon_{p}+2 \varepsilon_{m}}\right)
\end{gathered}
$$

Assim, o coeficiente de extinção é definido como a soma das seções de choque de absorção e espalhamento:

$$
C_{e x t}=\sigma_{a b s}+\sigma_{s}
$$

Para partículas pequenas com $a \ll \lambda$, a eficiência de absorção varia com $a^{3}$ e, portanto, será maior que a seção de choque de espalhamento, que varia com $a^{6}$. Além disso, essas equações evidenciam que, de fato, as seções de choque de absorção e espalhamento aumentam em condições de ressonância plasmônica.

Portanto, a teoria de espalhamento e absorção da luz por uma pequena partícula esférica prediz um aumento ressonante dos campos devido à ressonância da polarizabilidade $\alpha$. Nessas circunstâncias, a partícula age como um dipolo espalhando e absorvendo campos eletromagnéticos ressonantes. Essa descrição teórica é válida estritamente para partículas pequenas e, na prática, a descrição matemática apresentada acima proporciona uma boa aproximação para partículas menores que $100 \mathrm{~nm}$ iluminadas com luz na região UV-visível ou no infravermelho próximo.

Tendo descrito as equações da polarizabilidade de uma esfera metálica na aproximação quase estática, torna-se interessante também analisar alguns aspectos relacionados à posição da largura da banda de ressonância, não previstos por essa teoria. A primeira análise abordará o caso de partículas grandes onde o regime quase estático não 
ocorre, dando origem a efeitos retardados; e a segunda tratará de partículas muito pequenas ( $a$ $<10 \mathrm{~nm}$ ), em que as dimensões da partícula são consideravelmente menores que o caminho livre médio dos elétrons oscilantes.

Para partículas maiores, a polarizabilidade de uma esfera de volume V pode ser escrita como [35]:

$$
\alpha=\frac{1-\left(\frac{1}{10}\right)\left(\varepsilon_{p}+\varepsilon_{m}\right) x^{2}+O\left(x^{4}\right)}{\left(\frac{1}{3}+\frac{\varepsilon_{m}}{\varepsilon_{p}-\varepsilon_{m}}\right)-\frac{1}{30}\left(\varepsilon_{p}+10 \varepsilon_{m}\right) x^{2}-i \frac{4 \pi^{2} \varepsilon_{m}^{3 / 2} V}{3} \lambda_{0}^{3}+O\left(x^{4}\right)} V
$$

Onde $x=\frac{\pi a}{\lambda_{0}}$ é o parâmetro de tamanho, sendo $a$ o diâmetro da esfera e $\lambda_{0} \mathrm{o}$ comprimento de onda no vácuo. Nessa equação, o termo quadrático em $x$ no numerador corresponde aos efeitos de retardamento da onda incidente sobre o volume da esfera, e é responsável por causar um deslocamento da banda de ressonância plasmônica. O termo de terceira ordem é puramente imaginário e representa as perdas radiativas e atenuação da radiação. O termo quadrático ( representado pela letra $O$ por ser muito longo), representa uma correção para o termo de segunda ordem e também causa o deslocamento em energia da ressonância devido ao retardamento do campo de despolarização dentro da nanopartícula. Para metais nobres, o deslocamento da banda plasmônica causado pelos efeitos de retardamento ocorrem em direção a menores energias. Em outras palavras, a posição do pico de ressonância do dipolo desloca-se para maiores comprimentos de onda com o aumento de tamanho da partícula. Esse deslocamento pode ser interpretado como sendo originado pelo maior distanciamento entre as cargas nas interfaces opostas da partícula devido ao seu aumento de tamanho o que, por sua vez, diminui a força restauradora e consequentemente a frequência da ressonância. A inclusão de termos de mais alta ordem na equação 26 origina ressonâncias de mais altas ordens.

Portanto, para o caso de partículas que não obedecem o regime quase estático, a ressonância plasmônica pode ser atenuada por meio de dois processos competitivos: um processo de decaimento radiativo, predominante para partículas maiores; e um processo não radiativo causado pela absorção. O processo não radiativo ocorre devido a formação de pares elétron-buraco por excitações intrabanda na banda de condução ou transições interbandas de orbitais d para orbitais sp da banda de condução para o caso de partículas de metais nobres. Assim, os plásmons podem decair para o estado de energia inicial com um tempo de vida $\tau_{r}$ 
por meio da reemissão de um fóton (transição radiativa); ou então podem sofrem colisões com defeitos de superfície e/ou impurezas, decaindo de forma não radiativa com tempo de vida $\tau_{n r}$. O tempo de relaxação do plásmon $\left(\mathrm{T}_{1}\right)$ pode ser descrito em termos do tempo de decaimento radiativo e não radiativo [34]:

$$
\frac{1}{T_{1}}=\frac{1}{\tau_{r}}+\frac{1}{\tau_{n r}}
$$

No entanto, a atenuação da ressonância plasmônica pode ser descrita em termos do tempo de relaxação $T_{2}$, que inclui também o tempo de defasagem dos plásmons $\left(T_{2}^{*}\right)$, de forma que:

$$
\frac{1}{T_{2}}=\frac{1}{2 T_{1}}+\frac{1}{T_{2}^{*}}
$$

A largura de linha da banda de ressonância plasmônica está relacionada com os processos totais de atenuação da radiação. Assim, o valor de $T_{2}$ pode ser obtido experimentalmente por meio da espectroscopia UV-Vis e da seguinte expressão [34]:

$$
T_{2}=\frac{h}{\pi \Gamma}
$$

Onde h é a constante de Planck e $\Gamma$ é a largura de linha da banda de ressonância plasmônica ( largura à meia altura) em unidade de energia. Experimentos detalhados sobre o decaimento dos plásmons demonstraram que, em geral, o tempo relacionado aos decaimentos radiativos e não radiativos $T_{1}$ é muito menor que o tempo de defasagem $T_{2}^{*}\left(\mathrm{~T}_{1} \ll T_{2}^{*}\right)$ e $\mathrm{T}_{2}=$ $2 \mathrm{~T}_{1}$. Em geral, para nanopartículas de ouro e prata o valor de $\mathrm{T}_{2}$ varia entre 5 e 10 femtosegundos, dependendo do tamanho e do material em torno da nanopartícula.

Cabe ainda ressaltar que as contribuições dos processos radiativos e não radiativos para o tempo de relaxação $T_{1}$ são muito importantes para aplicações onde o aquecimento e/ou o desvanecimento da luminescência de moléculas próximas às nanopartículas devem ser evitados. Nesses casos, o processo radiativo deve ser predominante para produzir menor perda de energia por aquecimento, e aumentar os processos de emissão dos centros luminescentes próximos. 
Para o caso de nanopartículas de prata e ouro com raio menor que $10 \mathrm{~nm}$, um processo adicional de atenuação na interface da nanopartícula com o meio deve também ser considerado. Nesse caso, a taxa de defasagem da oscilação plasmônica é aumentada devido ao espalhamento elástico na superfície da partícula, visto que seu tamanho é consideravelmente menor que o caminho livre médio dos elétrons plasmônicos, que é da ordem de 30 a $50 \mathrm{~nm}$ [34].

Dessa forma, embora o tratamento da interação de pequenas partículas metálicas com uma onda eletromagnética incidente tem sido puramente clássico, para partículas menores que $1 \mathrm{~nm}$, efeitos de confinamento quântico começam a aparecer. A razão pela qual a quantização dos níveis de energia podem ser desprezados para partículas metálicas maiores que $1 \mathrm{~nm}$ é a grande concentração de elétrons na banda de condução dos metais $\left(\mathrm{n}=10^{23} \mathrm{~cm}^{-1}\right.$ ). Nos metais, a banda de condução está preenchida pela metade e a densidade de níveis de energia é tão alta que a distinção desses níveis pode ser observada somente quando a nanopartícula é composta por poucos átomos ( $\mathrm{N}=100$ ). Uma nanopartícula de ouro de $10 \mathrm{~nm}$, por exemplo, tem aproximadamente 30000 átomos e, portanto, efeitos de confinamento quântico são negligenciáveis.

\subsubsection{Luminescência Acoplada aos Plásmons}

As interações entre os elétrons plasmônicos e os centros luminescentes de alguns materiais dão origem à chamada luminescência acoplada aos plásmons [36]. Essas interações têm sido utilizadas para aumentar ou diminuir a intensidade luminescente emitida e também para direcionar a luz emitida por um centro luminescente próximo a um filme metálico nanoestruturado. É difícil prever se uma nanoestrutura metálica acarretará aumento ou diminuição da intensidade luminescente. A física por trás de todo esse processo é complexa e pode ser descrita através da eletrodinâmica clássica, das equações de Maxwell e da teoria de Mie [36]. De acordo com a teoria de Mie, o espectro de extinção de um coloide pode ser devido tanto a absorção quanto ao espalhamento da luz, dependendo do tamanho e forma da partícula [36]. Ainda de acordo com a teoria de Mie, partículas pequenas espalham pouco a luz, de forma que seu espectro de extinção é majoritariamente oriundo da absorção da luz pelas partículas. Já partículas maiores espalham a luz de maneira mais intensa, o que faz com que o espectro de extinção seja predominantemente devido ao espalhamento da luz [36]. 
Assim, segundo essa linha de pensamento, partículas menores promoveriam a redução da intensidade luminescente uma vez que a componente da absorção é maior que o espalhamento. Por outro lado, partículas maiores seriam capazes de promover um aumento da emissão luminosa de um centro luminescente quando próximos, visto que a componente de espalhamento da luz é predominante.

O aumento do rendimento quântico através da emissão acoplada aos plásmons pode ocorrer de duas formas. A primeira considera a forte interação da luz com as nanoestruturas metálicas em condições ressonantes [37-38]. Como dito anteriormente, a ocorrência da condição de ressonância depende, entre outros fatores, do tamanho e forma da partícula, do material que a constitui e do meio em que se encontra. Dessa forma, quando um coloide é iluminado com comprimento de onda ressonante, a partícula metálica pode apresentar uma seção de choque óptica muito maior que sua seção de choque física [37-38]. Assim, quando exposta à luz, as nanopartículas metálicas podem aumentar os campos elétricos locais ao seu redor. Esses campos locais podem então aumentar a excitação de centros luminescentes próximos à superfície metálica, aumentando o rendimento quântico da emissão luminosa [37]. O espectro de emissão do luminóforo não se altera pela presença do metal. Para que esse mecanismo de aumento de luminescência ocorra, é necessário haver sobreposição, total ou parcial, do espectro de excitação do luminóforo com a banda de ressonância plasmônica.

A segunda forma de aumento de luminescência por acoplamento plasmônico está relacionada à indução/criação de plásmons por um luminóforo no estado excitado. Como o tempo de vida das oscilações plasmônicas é muito curto, da ordem de femtosegundos, muitos autores creditam o aumento do rendimento quântico a uma rápida transferência de energia do centro luminescente para os plásmons, que por sua vez irradiam a energia recebida em campo distante [36]. O espectro de emissão é exatamente igual ao espectro característico do luminóforo, a não ser pela redução do tempo de vida, embora essa redução nem sempre possa ser observada. Assim, é difícil distinguir a espécie emissora, se luminóforo e/ou plásmons. Nesse sentido, Lakowicz et.al refere-se a esse sistema acoplado de luminescência como plasmóforo [37]. Para que esse mecanismo de aumento de luminescência ocorra, é necessário que haja sobreposição, total ou parcial, do espectro de emissão do luminóforo com a banda de ressonância plasmônica.

Conceito semelhante e já bem estabelecido é conhecido como transferência de Forster, no qual a transferência de energia de uma molécula "doadora” para uma molécula receptora ocorre com aumento de rendimento quântico desde que a molécula receptora apresente um 
maior rendimento quântico que a doadora. Dessa forma, se a taxa de transferência de energia é alta, a energia é transferida antes mesmo que a molécula doadora decaia de forma não radiativa.

O tempo de vida do luminóforo na ausência de uma nanoestrutura metálica pode ser escrito em função das taxas de decaimento radiativo $\left(k_{r}\right)$ e não radiativo $\left(k_{n r}\right)$ da seguinte maneira [36]:

$$
\tau_{0}=\frac{1}{k_{r}+k_{n r}}
$$

Supondo que a taxa de decaimento radiativo para o luminóforo aumente quando próximo ao metal, a nova taxa de decaimento radiativo será dada por:

$$
\mathbf{k}_{\mathbf{R}}=\mathbf{k}_{\mathbf{r}}+\mathbf{k}_{\mathbf{m}}
$$

Onde $\mathrm{k}_{\mathrm{r}}$ é a taxa de decaimento radiativo do luminóforo e $\mathrm{k}_{\mathrm{m}}$ é a taxa de decaimento radiativo do metal. Assim, o novo tempo de vida do sistema plásmon-luminóforo será:

$$
\tau_{\mathrm{PL}}=\frac{1}{\mathbf{k}_{\mathrm{r}}+\mathbf{k}_{\mathrm{nr}}+\mathbf{k}_{\mathrm{m}}}
$$

O rendimento quântico da emissão luminescente será dado por:

$$
\mathbf{R}=\frac{\mathbf{k}_{\mathrm{r}}+\mathbf{k}_{\mathbf{m}}}{\mathbf{k}_{\mathbf{r}}+\mathbf{k}_{\mathrm{nr}}+\mathbf{k}_{\mathbf{m}}}
$$

Assim, para um luminóforo com baixo rendimento quântico $\left(k_{r} \ll k_{n r}\right)$, o aumento de $k_{m}$ causa redução do tempo de vida e aumento do rendimento quântico da emissão luminescente [39].

A eficiência da transferência de energia para um metal no máximo da emissão do luminóforo também pode ser descrita em função das taxas de decaimento, como à seguir [36]: 


$$
E=\frac{\mathbf{k}_{\mathrm{T}}}{\mathbf{k}_{\mathrm{r}}+\mathbf{k}_{\mathrm{nr}}+\mathbf{k}_{\mathrm{T}}}=\frac{\mathbf{k}_{\mathrm{T}}}{\tau_{0}{ }^{-1}+\mathbf{k}_{\mathrm{T}}}
$$

Onde $\mathrm{k}_{\mathrm{T}}$ é a taxa de transferência de energia dada por:

$$
\mathbf{k}_{\mathrm{T}}=\frac{1}{\tau_{0}}\left(\frac{\mathbf{R}_{0}}{\mathbf{r}}\right)^{\mathbf{n}}
$$

Na equação acima, n é uma constante igual a $4, R_{0}$ é a distância de Forster (distância em que a eficiência de transferência de energia é de 50\%) e r é distância entre o luminóforo e o metal.

Na verdade, o mecanismo pelo qual um luminóforo no estado excitado cria plásmons em nanoestruturas metálicas ainda não está bem estabelecido. $\mathrm{O}$ desvanecimento da luminescência em superfície metálicas foi investigado por vários grupos [36, 40-41], mostrando que o tempo de vida dos luminóforos diminui à medida que se aproximam da superfície até uma distância de aproximadamente $10 \mathrm{~nm}$. Essa redução da intensidade luminescente foi explicada com base no mecanismo de transferência de energia (Forster) do luminóforo para o metal. No entanto, a emissão acoplada aos plásmons ocorre para distâncias maiores que $100 \mathrm{~nm}$, o que é considerado muito distante para a transferência Forster, que ocorre para distâncias entre 2 e 6 nm [42]. Além disso, a redução do tempo de vida não ocorre de forma significativa, como seria esperado para o mecanismo de Forster [36, 43]. Outros trabalhos reportaram a redução do tempo de vida do luminóforo para distâncias de até 100 nm. Esses trabalhos mostram também que há diferenças na interação do luminóforo com um filme metálico fino e espesso. Os resultados sugerem que, nos casos em que há ressonância plasmônica, há um acoplamento entre o centro luminescente e os plásmons, e essa interação pode ocorrer para distâncias de até $400 \mathrm{~nm}$ [36], distância essa muito maior que as distâncias em que o mecanismo de Forster ocorre. 


\section{Materiais e Métodos}

\subsection{Preparação das Amostras}

\subsubsection{Síntese de Nanopartículas de Prata pela redução Química com $\mathrm{NaBH}_{4}$}

As nanopartículas de prata $(\mathrm{NpAg})$ utilizadas foram produzidas por meio da redução de um sal de $\operatorname{Ag}(\mathrm{I})$. Para isso, preparou-se $200 \mathrm{~mL}$ de uma solução aquosa contendo nitrato de prata $\left(\mathrm{AgNO}_{3}\right)$ em concentração $2 \mathrm{mmol} . \mathrm{L}^{-1}$ e álcool polivinílico (PVA) em concentração 1,25 g. $\mathrm{L}^{-1}$. Essa solução foi aquecida até uma temperatura de $60^{\circ} \mathrm{C}$ por 30 minutos sob forte agitação, e então resfriada até a temperatura ambiente. Em seguida, dissolveu-se em água o agente redutor boro hidreto de sódio $\left(\mathrm{NaBH}_{4}\right)$, em uma concentração de 8 mmol.L $\mathrm{L}^{-1}$, totalizando $200 \mathrm{~mL}$ de solução. Adicionou-se então, a solução de $\mathrm{AgNO}_{3}+\mathrm{PVA}$ à solução de $\mathrm{NaBH}_{4}$, mantendo-se o sistema sob forte agitação, em temperatura ambiente, por 30 minutos. A solução final tornou-se amarela, indicando a formação de um sol. A redução da prata ocorre segundo a equação química [44]:

$$
\mathrm{NaBH}_{4}+\mathrm{AgNO}_{3} \rightarrow \mathrm{Ag}^{0}+\mathrm{NaNO}_{3}+\frac{1}{2} \mathrm{~B}_{2} \mathrm{H}_{6}+\frac{1}{2} \mathrm{H}_{2}
$$

A espectroscopia de absorção na região do UV-Visível confirmou a formação de nanopartículas de prata por meio do aparecimento da banda plasmônica. A técnica de espalhamento dinâmico de luz revelou uma distribuição estreita de nanopartículas com tamanho médio em torno de $25 \mathrm{~nm}$.

\subsubsection{Produção dos Nano e Microcompósitos de NaCl/Ag}

Para a produção dos nano e microcompósitos $\mathrm{NaCl} / \mathrm{Ag}$, foi preparada uma solução aquosa de $\mathrm{NaCl}\left(4,3\right.$ mol. $\left.\mathrm{L}^{-1}\right)$. Em seguida, para a produção dos nanocompósitos, foi adicionado $\mathrm{NH}_{4} \mathrm{OH}$ à dispersão coloidal de prata em uma proporção 1:20 em volume, seguida pela adição da solução de $\mathrm{NaCl}$, nas proporções desejadas. Para a produção dos microcompósitos, a solução de $\mathrm{NaCl}$ foi adicionada diretamente à dispersão coloidal e, posteriormente, $\mathrm{NH}_{4} \mathrm{OH}$ foi adicionado apenas para que os micro e nanocompósitos 
apresentassem exatamente a mesma composição. A Tabela 3.1 apresenta a proporção em massa de prata presente nos micro e nanocompósitos, bem como o nome dado a cada amostra.

Tabela 3.1: Identificação das amostras para cada variação da porcentagem em massa de prata utilizada.

\begin{tabular}{ccc}
\hline NaCl (\% Massa) & NpAg (\% Massa) & Nome da Amostra \\
\hline 100,0 & 0,00 & $0 \% \mathrm{NpAg} / \mathrm{NaCl}$ \\
\hline 99,995 & 0,005 & $0,005 \% \mathrm{NpAg} / 0,005 \% \mathrm{MpAg}$ \\
\hline 99,97 & 0,03 & $0,03 \% \mathrm{NpAg} / 0,03 \% \mathrm{MpAg}$ \\
\hline 99,95 & 0,05 & $0,05 \% \mathrm{NpAg} / 0,05 \% \mathrm{MpAg}$ \\
\hline
\end{tabular}

Após a mistura das soluções, o sistema foi caracterizado por diversas técnicas, como será descrito à seguir.

\subsubsection{Síntese das Nanopartículas de Prata e Ouro pelo método do Poliol}

Para a síntese das nanopartículas de prata e ouro pelo método do poliol, $45 \mathrm{mg}$ de nitrato de prata $\left(\mathrm{AgNO}_{3}\right)$ ou $49 \mathrm{mg}$ tetra cloro aurato $\left(\mathrm{HAuCl}_{4}\right)$, e $110 \mathrm{mg}$ de polivinilpirrolidona (PVP) foram dissolvidos em $100 \mathrm{~mL}$ de etilenoglicol (EG). A solução foi aquecida em um forno micro-ondas $(1200 \mathrm{~W})$ por 2 minutos, com agitação a cada $30 \mathrm{~s}$. Após o aquecimento, a mudança de coloração de incolor para amarelo (prata) e vermelho (ouro) indica a formação de uma dispersão coloidal.

\subsubsection{Síntese dos compósitos $\mathrm{ZnO} / \mathrm{Ag}$ e $\mathrm{ZnO} / \mathrm{Au}$}

Para a síntese dos compósitos de óxido de zinco com nanopartículas de prata ( $\mathrm{ZnO} / \mathrm{Ag})$ e dos compósitos de óxido de zinco com nanopartículas de ouro $(\mathrm{ZnO} / \mathrm{Au})$, foram produzidas sementes (seeds) de $\mathrm{ZnO}$ sobre substratos vítreos, por meio de uma solução aquosa $\left(0.01\right.$ mol. $\left.\mathrm{L}^{-1}\right)$ de acetato de zinco dihidratado $\left(\mathrm{Zn}\left(\mathrm{CH}_{3} \mathrm{COO}\right)_{2} \cdot 2 \mathrm{H}_{2} \mathrm{O}\right)$ [45]. Os substratos vítreos foram mergulhados na solução precursora de Zn por 5 minutos, enxaguados com água Milli- $\mathrm{Q}^{\mathrm{TM}}$, e aquecidos a uma temperatura de $500^{\circ} \mathrm{C}$ por 10 minutos. Esse procedimento foi repetido por três vezes.

Em seguida, foi preparada uma solução aquosa de nitrato de zinco hexa-hidratado $\left(\mathrm{Zn}\left(\mathrm{NO}_{3}\right)_{2} \cdot 6 \mathrm{H}_{2} \mathrm{O}\right)$ com concentração $0.5 \mathrm{~mol} . \mathrm{L}^{-1}$, contendo $6 \%$ em volume de hidróxido de 
amônio $\left(\mathrm{NH}_{4} \mathrm{OH}\right)$. Os substratos foram então colocados no fundo de um recipiente vítreo contendo $40 \mathrm{~mL}$ da solução de nitrato de zinco. Posteriormente, 0.1, 0.5, 1, 2, 4, e $8 \mathrm{~mL}$ da dispersão coloidal de prata/ouro foram adicionados em cada recipiente. Os recipientes foram selados e mantidos a uma temperatura de $100^{\circ} \mathrm{C}$ por um período de 12 horas. Amostras controle sem nanopartículas de ouro e prata também foram preparadas.

Após o crescimento dos filmes de $\mathrm{ZnO}$, foi realizado um tratamento térmico a $300^{\circ} \mathrm{C}$ durante duas horas, para eliminação de água residual.

\subsubsection{Produção dos filmes de Nanopartículas de Prata}

Para a preparação dos filmes, as nanopartículas de prata foram produzidas da seguinte maneira: adicionou-se uma solução aquosa de nitrato de prata $(2 \mathrm{mM})$ à uma solução aquosa de boro hidreto de sódio $(8 \mathrm{mM})$, mantendo-se o sistema sob forte agitação por uma hora. A solução final tornou-se amarela, indicando a formação de um sol. A espectroscopia de absorção na região do UV-Visível confirmou a formação de nanopartículas de prata. A técnica de espalhamento dinâmico de luz revelou uma distribuição estreita de nanopartículas com tamanho médio em torno de $25 \mathrm{~nm}$. O potencial zeta das nanopartículas foi de $-36 \pm 2$ $\mathrm{mV}$.

Em seguida, quitosana $(0,1$ wt.\%) foi dissolvida em uma solução aquosa de ácido acético $(\mathrm{pH}=4)$. A solução foi então filtrada utilizando-se uma membrana Millipore ${ }^{\circledR}$, com poros de 0,45 $\mu \mathrm{m}$. Os filmes automontados foram produzidos alternando-se camadas de quitosana (carga positiva) e nanopartículas de prata (carga negativa - potencial zeta) em substratos de vidro e alumínio $(0,5$ x 0,5 cm) pela técnica Layer-by-Layer [46]. Os substratos vítreos foram lavados em solução piranha, enxaguados com água Mili- $\mathrm{Q}^{\mathrm{TM}}$ e acetona antes do início das deposições. Os substratos de alumínio foram lixados com lixas de granulações 1500 e 2000, em movimentos sequenciais que descrevem o número 8, lavados em solução tampão fosfato $(\mathrm{pH} 7,5)$ e enxaguados com água Mili- $\mathrm{Q}^{\mathrm{TM}}$ e acetona. Para a deposição dos filmes, os substratos permaneceram mergulhados por 20 minutos em cada solução, começando pela solução de quitosana. Entre cada camada depositada, foi realizado o enxague dos filmes por meio da imersão dos substratos em água Mili- $\mathrm{Q}^{\mathrm{TM}}$ durante 5 min, seguida pela secagem com nitrogênio gasoso. Foram produzidos filmes com 3, 5 e 10 bicamadas. Para todos os filmes, foi depositada uma camada final de quitosana com intuito de proteger a superfície das NpAgs de processos oxidativos. 
Posteriormente, foram gotejados sobre os filmes $10 \mu \mathrm{L}$ de uma solução 0,02 mol. $\mathrm{L}^{-1}$ $\mathrm{NaCl}$ (20\% água e $80 \%$ acetona v/v) e a secagem foi realizada em temperatura ambiente.

\subsubsection{Produção de filmes com bicamadas de Quitosana/Poli (ácido acrílico)}

Filmes de bicamadas de quitosana (Qt) e poli(ácido acrílico) (PAA), denominados como filmes de Qt/PAA, foram depositados pela técnica layer-by-layer sobre substrato de vidro e alumínio já limpos e secos. Esses filmes foram também depositados sobre os filmes de nanopartículas de prata. Para preparar esses filmes, o poliânion Poli(ácido acrílico) $(0,1 \%$ p/v) foi solubilizado sob agitação magnética em água Milli-Q durante 24 horas. A quitosana (pKa 6,5) foi solubilizada em solução de ácido acético 1,0 \% (v/v) ( $\mathrm{pH} \sim 3,5)$ por 24 horas. Após a solubilização o pH foi ajustado para 4,5 com solução de $\mathrm{NaOH}$. As soluções foram filtradas em membrana de éster de celulose com tamanho de poro igual $0,45 \mu \mathrm{m}$ (Millipore ${ }^{\circledR}$ ) antes do uso. As bicamadas de Qt/PAA foram depositadas, alternando-se poliânion e policátion. Inicialmente, o suporte foi imerso em solução de quitosana por 20 minutos. Então, o suporte foi imerso em água por 5 minutos, com o intuito de remover cadeias do policátion fracamente ligadas e manter a força iônica constante. Após o enxágue o suporte foi seco sob fluxo de nitrogênio gasoso. Na sequência, o suporte foi imerso em solução de Qt e enxaguado com água deionizada e seco $\left(\mathrm{N}_{2}\right.$ gasoso). A repetição dessa sequência permite a obtenção de filmes com qualquer que seja o número de camadas desejadas.

\subsubsection{Deposição dos Filmes de Ouro}

Filmes de ouro foram depositados em substratos de vidro e de alumínio pela técnica de sputtering, em um equipamento BAL-TEC modelo SCD 050 (Fürstentum Liechtestein). A taxa de deposição foi de $0,26 \mathrm{~nm} \cdot \mathrm{s}^{-1}$, e a espessura do filme foi controlada pela variação do tempo de deposição. Durante o processo de recobrimento das amostras, o vácuo na câmara foi mantido em 0,05 mbar.

Posteriormente, foram gotejados sobre os filmes $10 \mu \mathrm{L}$ de uma solução 0,02 mol.L ${ }^{-1}$ $\mathrm{NaCl}$ (20\% água e $80 \%$ acetona v/v) e a secagem foi realizada em temperatura ambiente. 


\subsection{Técnicas de Caracterização}

\subsubsection{Difração de Raios-X}

Medidas de difração de raios-X pelo método do pó foram realizadas em um aparelho Bruker D8-Discover, que utiliza cátodo de cobre e monocromador de germânio para selecionar a região de emissão $\mathrm{K} \alpha_{1}$ do cobre $(1.541 \AA$ A, $40 \mathrm{kV}, 40 \mathrm{~mA})$. Os difratogramas foram obtidos na faixa compreendida entre $30^{\circ} \leq 2 \theta \leq 65^{\circ}$, com incremento de $0.02^{\circ}$. $(\lambda=$ $1,5418 \AA$ ).

\subsubsection{Espectroscopia UV-Vis}

Os espectros na região do ultravioleta-visível foram obtidos utilizando-se um espectrofotômetro Ultrospec 2100 pro (Amersham Pharmacia). Para realização dessas análises, as soluções foram adicionadas em uma cela de quartzo com $1 \mathrm{~cm}$ de caminho óptico. Para as amostras em pó, os espectros UV-Vis foram obtidos por meio de um espectrofotômetro CCD Ocean Optics, modelo USB-2000. Os espectros UV-Vis (transmissão) dos filmes foram obtidos em um espectrofotômetro HP-8453. Os espectros de refletância na região do ultravioleta-visível dos filmes foram obtidos utilizando-se um espectrofotômetro Hitachi U-4001 UV-VIS equipado com uma esfera integradora.

\subsubsection{Espalhamento Dinâmico de Luz (DLS)}

Para medida da distribuição de tamanho de partícula por meio de espalhamento dinâmico de luz (DLS do inglês Dynamic Light Scatterig), foi utilizado um sistema Zeta-Sizer $500 \mathrm{HSa}$ (Malvern Instruments). Os dados foram coletados em um ângulo fixo em $90^{\circ} \mathrm{e}$ comprimento de onda também fixo $(633 \mathrm{~nm} / \mathrm{laser} \mathrm{He}-\mathrm{Ne})$. Para realização dessas análises, as soluções foram adicionadas em uma cela acrílica de $1 \mathrm{~cm}$ de caminho óptico. 


\subsubsection{Microscopia Eletrônica de Transmissão (TEM), Varredura (SEM) e de Força Atômica (AFM)}

A morfologia de algumas amostras foi analisada por um microscópio eletrônico de transmissão (TEM do inglês Trasmission Electron Microscopy) JEOL-JEM-100 CXII. As amostras foram gotejadas em um gratículo de cobre recoberto com um polímero condutor e submetidas a um processo de secagem em temperatura ambiente.

Imagens de microscopia eletrônica de varredura foram obtidas por um microscópio Zeeis - FESEM-Ultra Plus, equipado com um detector de elétrons retro-espalhados (ESB). O microscópio possui um sistema de compensação de cargas, não sendo necessário o recobrimento metálico das amostras.

As imagens de microscopia de força atômica da superfície dos filmes foram obtidas por um equipamento Shimadzu, modelo SPM 9600.

\subsubsection{Espectroscopia na Região do Infravermelho por Reflexão Total Atenuada (ATR- FTIR)}

Para análise dos grupos na superfície do filme foi utilizada a espectroscopia na região do infravermelho por transformada de Fourier com reflexão total atenuada (ATR-FTIR). Os espectros foram coletados em um espectrofotômetro Shimadzu IRPrestige-21 no Laboratório de Bioinorgânica e Terras Raras, do Departamento de Química da FFCLRP, com resolução de $2 \mathrm{~cm}^{-1}$.

\subsubsection{Irradiação das Amostras}

As amostras foram irradiadas no ar com em um tubo de raios-X Magnum, da marca Moxtek, USA, operando com $48 \mathrm{kVp}$ e $0.2 \mathrm{~mA}$ a uma distância de 5 ou $20 \mathrm{~cm}$ da fonte, dependendo da dose necessária. As amostras em pó foram colocadas em cápsulas de dimensões $1 \mathrm{~cm}$ x $0,5 \mathrm{~cm}$. 


\subsubsection{Luminescência Opticamente Estimulada}

As medidas de luminescência opticamente estimulada foram obtidas por um leitor desenvolvido pelo laboratório de Dosimetria e Instrumentação Nuclear da Universidade Federal de Pernambuco. O sistema de excitação é composto por um LED azul com picos de emissão em $470 \mathrm{~nm}$. O sistema de detecção é composto por um tubo fotomultiplicador e um filtro Hoya U340, com transmissão no intervalo de 270 e $370 \mathrm{~nm}$. A leitura foi realizada com o modo OSL contínuo (CW-OSL).

\subsubsection{Espectros de Luminescência}

Os espectros de luminescência foram obtidos por um fluorímetro Spex Triax 550 equipado com uma lâmpada de xenônio e um fosforímetro Fluorog III, no Laboratório de Bioinorgânica e Terras Raras, do Departamento de Química da FFCLRP. Filtros foram utilizados nos feixes de excitação e emissão para melhorar a qualidade do espectro. Espectros de fotoluminescência (PL) foram também obtidos em um espectrômetro LabRAM Aramis (Horiba - Jobin Yvon, Edison, NJ), com excitação laser em $532 \mathrm{~nm}$ e $325 \mathrm{~nm}$, respectivamente, no Clarke Research Group, na Universidade de Harvard.

Medidas do tempo de vida da emissão luminescente foram obtidas por um sistema baseado no método de correlação temporal de fótons únicos do Laboratório de Biofísica do Departamento de Física da FFCLRP. A fonte de excitação utilizada foi um laser pulsado Tsunami 3950 (Spectra Physics) de titânio-safira bombeado por um laser do estado sólido Millenia X (Spectra Physics). A taxa de repetição foi ajustada em $8 \mathrm{MHz}$ por meio de um Pulse Picker 3980 (Spectra Physics). A largura dos pulsos foi de 5 ps. A excitação foi realizada em $308 \mathrm{~nm}$ e a emissão coletada em $385 \mathrm{~nm}$. Os fótons emitidos foram direcionados a um espectrômetro Edinburgh FL900 e detectados por uma fotomultiplicadora Hamamatsu R3809U. As curvas de decaimento foram analisadas por um software fornecido pela Edinburgh Instruments.

\subsubsection{Radioluminescência}


As medidas de radioluminescência foram realizadas no laboratório Dosimetria da Radiações no Departamento de Física da Universidade de Oklahoma - EUA e no Laboratório de Ressonância Magnética do Departamento de Física da FFCLRP, por meio da excitação da amostra com raios-X provenientes de um tubo Magnum Moxtek (modelos TUB00045-1) operando com $40 \mathrm{kVp}$ e corrente de $100 \mu \mathrm{A}$. A luminescência foi coletada por uma lente f/2 de sílica fundida acoplada a uma fibra óptica $(1 \mathrm{~mm}$ de diâmetro e transmissão no intervalo 200 - $1100 \mathrm{~nm}$ ) conectada a um espectrofotômetro CCD (Ocean Optics USB-2000). A taxa de dose estimada na posição das amostras é de aproximadamente $9 \mathrm{~Gy} / \mathrm{min}$. 


\section{Estudo e Caracterização dos Compósitos $\mathrm{NaCl} / \mathrm{Ag}$}

Neste capítulo serão apresentados os primeiros experimentos e resultados na tentativa de responder a questão central dessa tese: É possível utilizar as propriedades plasmônicas de nanopartículas metálicas para aumentar a luminescência opticamente estimulada?

Como ponto de partida, foi decidido pelo uso de nanopartículas de prata porque o máximo de intensidade da estimulação OSL com o LED azul ocorre em $470 \mathrm{~nm}$ e, portanto, se sobrepõe perfeitamente à banda de ressonância plasmônica da prata, aumentando a probabilidade de aumentar os campos elétricos locais em torno das nanopartículas. Uma vez escolhida a nanopartícula, é também crucial a escolha adequada do material luminescente. $\mathrm{O}$ ponto de fusão da prata $\left(967^{\circ}\right)$ limita o uso de óxidos pois estes requerem altas temperaturas para cristalização. Além disso, o ponto de fusão da prata diminui à medida que diminui o tamanho das partículas [47], fazendo o uso de óxidos ainda mais difícil nessa etapa inicial. Dentre os materiais que apresentam luminescência opticamente estimulada, os haletos alcalinos apresentam algumas vantagens: Eles são solúveis, facilitando o crescimento de cristais em torno das nanopartículas em baixa temperaturas. Nesse sentido, a absorção UVVisível dos centros F (envolvidos no processo OSL) do cloreto de sódio [48] é a que melhor se sobrepõe a banda de ressonância plasmônica da prata. Além do mais, várias publicações têm demonstrado o potencial uso do $\mathrm{NaCl}$ para fins dosimétricos [49-50].

Dessa forma, cristais de $\mathrm{NaCl}$ foram crescidos em soluções contendo nanopartículas de prata. Foram também produzidos cristais de $\mathrm{NaCl}$ em soluções contendo micropartículas de prata para verificar se as propriedades luminescentes dependem do tamanho das partículas. Serão discutidas as propriedades de fotoluminescência e luminescência opticamente estimulada, a correlação entre esses dois processos luminescentes, e as diferenças observadas em relação às micro e nanopartículas.

\subsection{Espectroscopia UV-Vis}

Os espectros UV-Vis obtidos para a dispersão coloidal de nanopartículas de prata bem como para as amostras $0,005 \% \mathrm{NpAg}, 0,03 \% \mathrm{NpAg}$ e $0,05 \% \mathrm{NpAg}$ encontram-se na Figura 4.1 (a). Pode-se observar uma banda de absorção com pico em 390 nm, característico de nanopartículas esféricas de prata [51-52]. Esse pico de absorção está relacionado ao 
movimento coletivo dos elétrons de condução na superfície da nanopartícula metálica, i.e, banda de ressonância plasmônica [33].

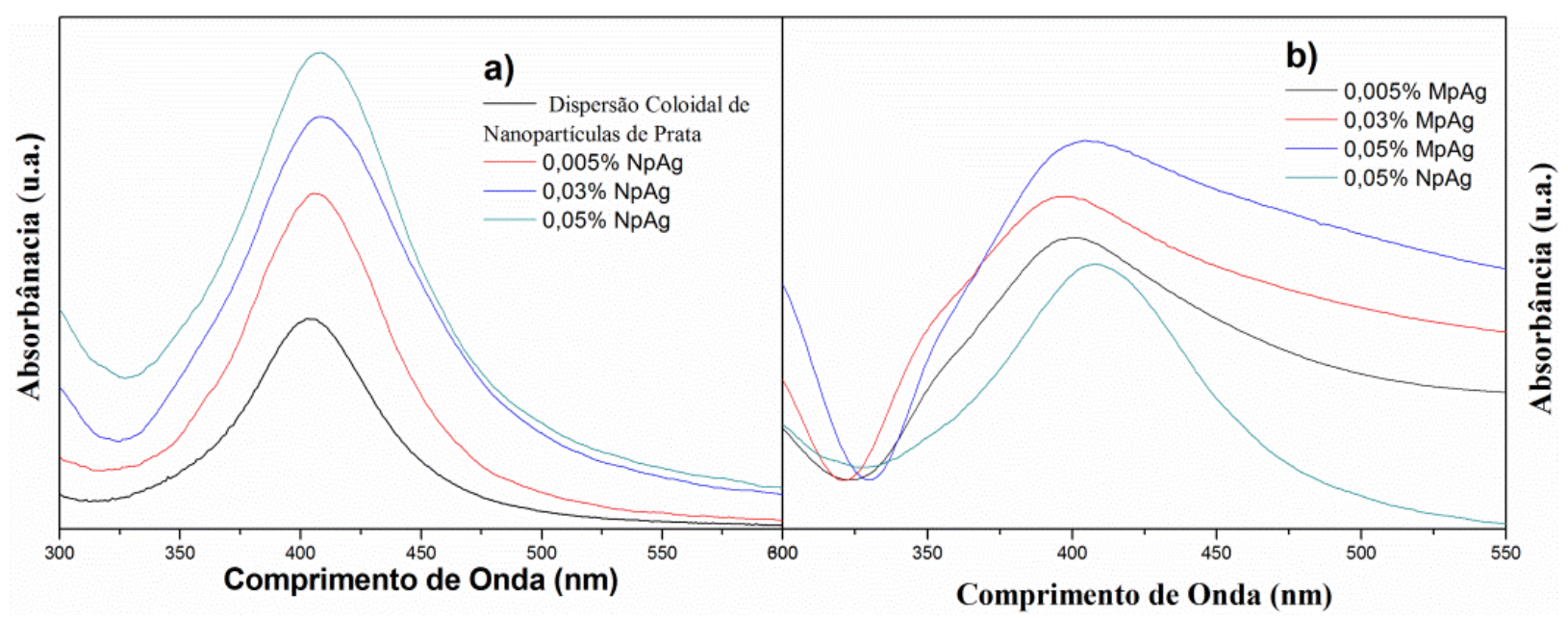

Figura 4.1:Espectro UV-Vis das dispersões coloidais com diferentes porcentagens em massa de prata na forma de nanopartículas (a) e micropartículas (b).

A intensidade do pico de absorção plasmônica é proporcional à concentração de nanopartículas de prata, o comprimento de onda do pico está relacionado com o tamanho das partículas e sua largura a meia altura (FWHM) com a distribuição de tamanho [53]. É notável que os picos plasmônicos mantêm o mesmo padrão para todas as porcentagens em massa de prata em $\mathrm{NaCl}$ para os nanocompósitos, não havendo deslocamentos e aumento da largura à meia altura. Assim, os espectros UV-Vis indicam que as nanopartículas de prata são estáveis e não mudam de forma e/ou tamanho ao interagir com o cloreto de sódio. Já para as soluções relacionadas aos microcompósitos (Figura 4.1(b)), o alargamento da banda de absorção indica crescimento e agregação das nanopartículas metálicas.

Embora os espectros de absorção das amostras líquidas informam a respeito do estado de agregação das nanopartículas, é importante também verificar se essas amostras são estáveis mesmo após o processo de secagem e obtenção dos pós. A Figura 4.2 mostra os espectros de refletância das amostras $\mathrm{NaCl} / \mathrm{Ag}$ em pó, obtidos após a secagem das soluções. Pode-se observar uma banda de absorção em $425 \mathrm{~nm}$ para todas as amostras. Para a amostra 0\%NpAg, essa banda de absorção pode estar associada à absorção devido à presença de defeitos na estrutura cristalina do $\mathrm{NaCl}$, como centros $\mathrm{F}$ ou ainda defeitos originados/ estabilizados por impurezas [48, 54-56]. Para os nanocompósitos (Figura 4.2 (a)) essa banda se intensifica à medida que a concentração de nanopartículas de prata aumenta, devido à absorção plasmônica das nanopartículas de prata. Esse resultado revela que as nanopartículas de prata são estáveis 
mesmo após a secagem das dispersões coloidais. Para os microcompósitos (Figura 4.2 (b)), o alargamento da banda de absorção indica o crescimento e agregação das nanopartículas de prata. Aqui, é válido ressaltar a sobreposição das bandas de absorção plasmônica e absorção dos defeitos do $\mathrm{NaCl}$, condição necessária para que haja aumento de luminescência pelo aumento de campos locais em torno das nanopartículas metálicas.

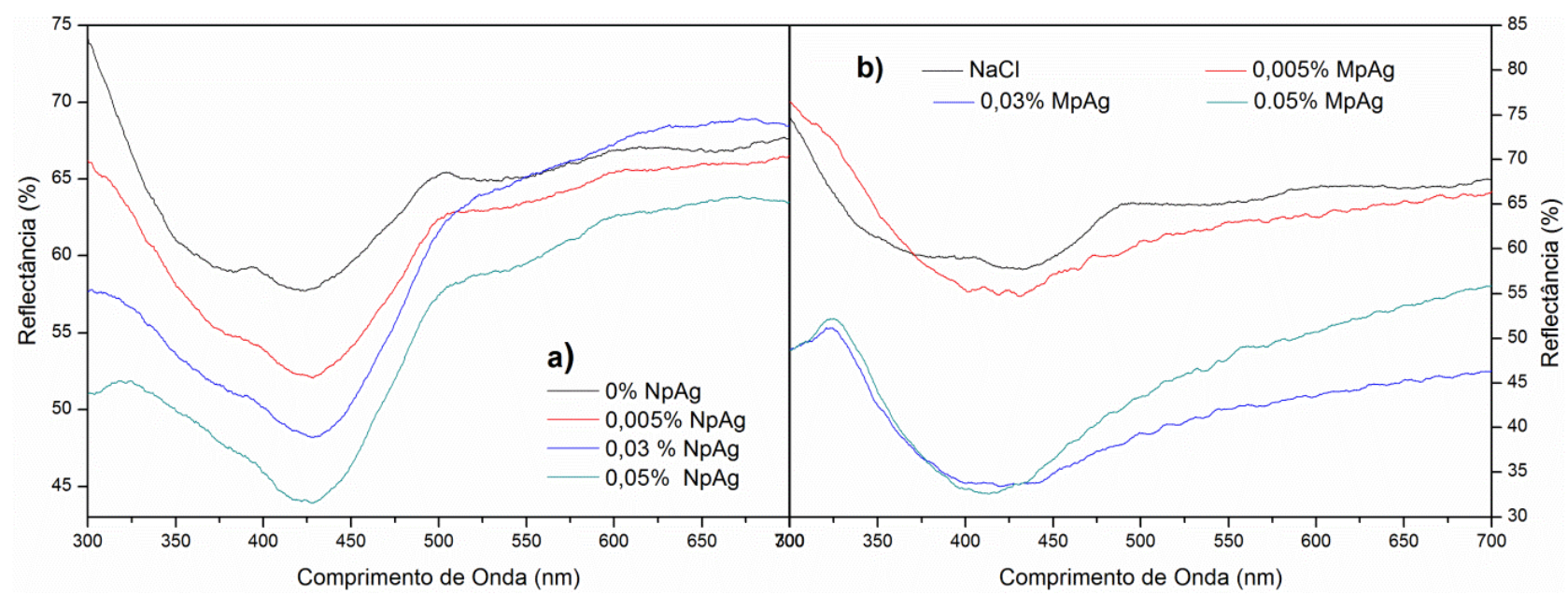

Figura 4.2: Espectros de reflectância dos compósitos $\mathrm{NaCl} / \mathrm{Ag}$ na forma de nanopartículas (a) e micropartículas (b).

\subsection{Espalhamento Dinâmico de Luz (DLS)}

A distribuição de tamanho de partículas obtidas por DLS revelou uma distribuição de partículas com tamanho médio em torno de $25 \mathrm{~nm}$, como mostrado na Figura 4.3 (a). Para as dispersões coloidais relativas aos nanocompósitos, não foi detectada nenhuma alteração relevante na distribuição de tamanho das partículas devido à interação das nanopartículas de prata com o cloreto de sódio, como sugerido pela espectroscopia UV-Vis. Para as dispersões relativas aos microcompósitos, ou seja, dispersões nas quais houve adição do $\mathrm{NaCl}$ antes do $\mathrm{NH}_{4} \mathrm{OH}$, é possível constatar a agregação e crescimento das partículas, que apresentam uma distribuição de tamanho em torno de $300 \mathrm{~nm}$ e outra em torno de $1500 \mathrm{~nm}$. 


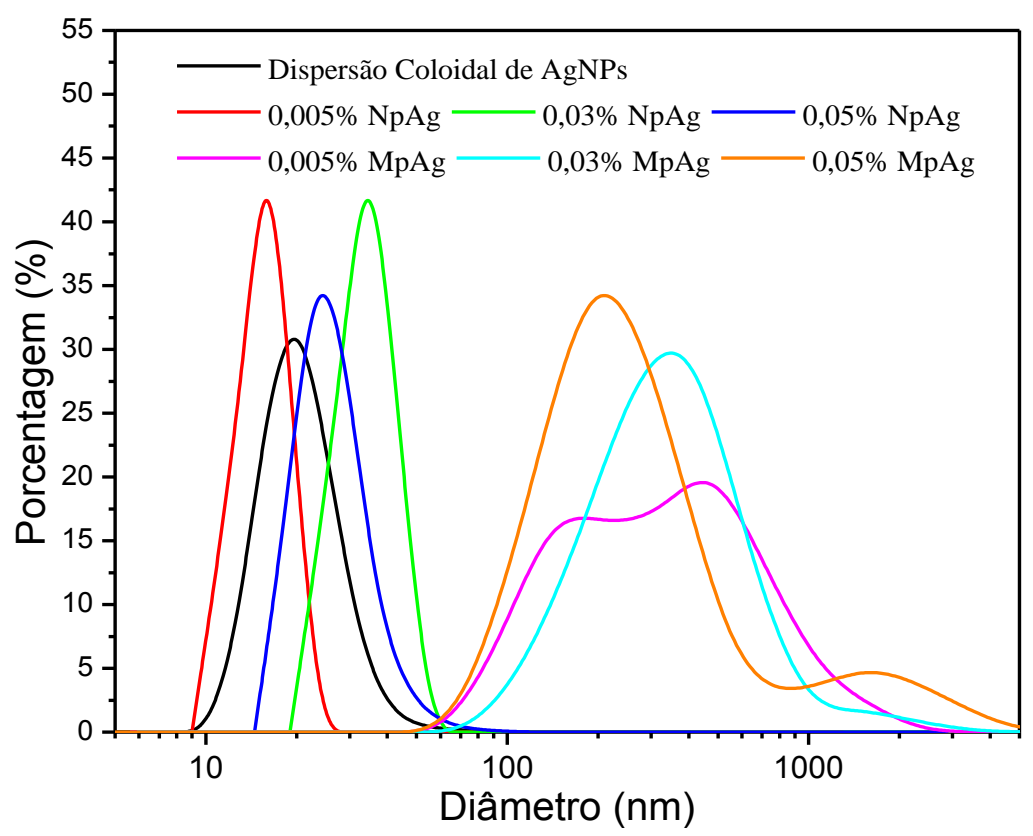

Figura 4.3: Distribuição de tamanho das nanopartículas de prata obtidas pela técnica de espalhamento dinâmico da luz para as dispersões coloidais relativas aos nano e microcompósitos.

\subsection{Microscopia Eletrônica de Transmissão (TEM)}

A Figura 4.4 mostra as imagens obtidas pela técnica de microscopia eletrônica de transmissão das nanopartículas de prata. Uma vez que as técnicas de espectroscopia UV-Vis e DLS apontaram para partículas estáveis em tamanho e forma, independentemente da porcentagem em massa de prata/ $\mathrm{NaCl}$ utilizada, foram obtidas imagens de TEM das nanopartículas de prata recém preparadas, ou seja, antes de adicioná-las a matriz de cloreto de sódio (a), e também da amostra $0,05 \% \mathrm{NpAg}$ (b). A Figura 4.4 (d) mostra a imagem de TEM com magnificação reduzida, de um cristal cúbico de cloreto de sódio. É possível observar a presença das nanopartículas de prata dispersas no cristal. A Figura 4.4 (d) mostra a imagem de TEM para a amostra $0.05 \% \mathrm{MpAg}$, evidenciando que as micropartículas são formadas pela aglomeração e coalescência de nanopartículas de prata. 

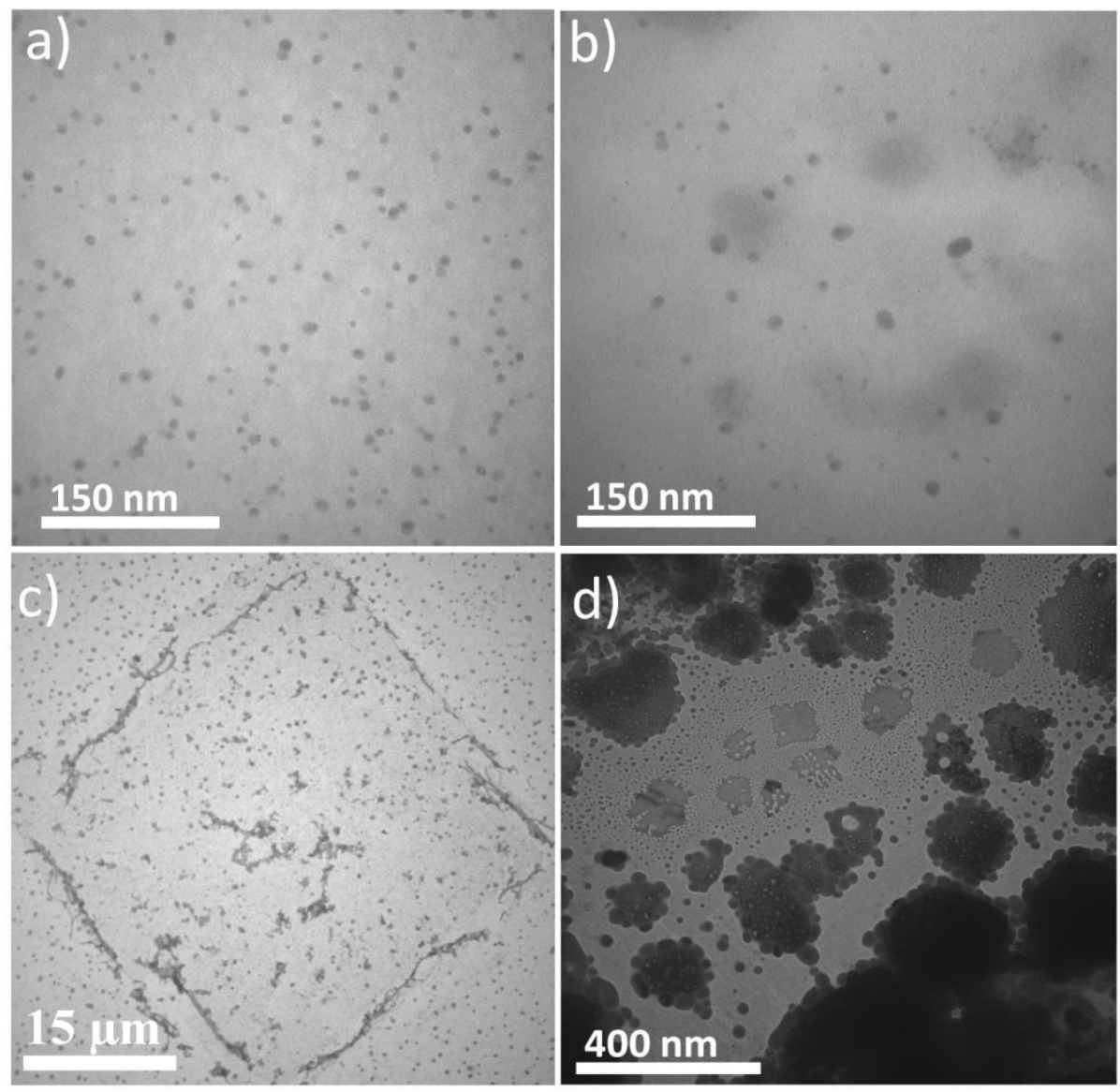

Figura 4.4: Imagens obtidas por microscopia eletrônica de transmissão das nanopartículas de prata recém preparadas (sem $\mathrm{NaCl}$ ) (a), da amostra $0,05 \% \mathrm{NpAg}$ (b) e (c), e da amostra $0.05 \% \mathrm{MpAg}$ (d).

Assim, as três técnicas de caracterizações morfológicas e de tamanho indicam a formação de nanopartículas de prata esféricas e que permanecem estáveis após interagir com o cloreto de sódio, quando adicionado $\mathrm{NH}_{4} \mathrm{OH}$ antes do $\mathrm{NaCl}$. Portanto, o papel do $\mathrm{NH}_{4} \mathrm{OH}$ e o momento de adição durante a preparação dos compósitos determinam a formação de nano ou microcompósitos, como indicado pela espectroscopia UV-Vis e pelo DLS, e confirmado pelas imagens de microscopia eletrônica de transmissão. Ao adicionar o hidróxido de amônio na dispersão coloidal de nanopartículas de prata, antes do $\mathrm{NaCl}$, eleva-se o pH da dispersão, além da possibilidade de formação de complexos dos grupos amina com a prata na superfície das nanopartículas. Logo, o $\mathrm{NH}_{4} \mathrm{OH}$ é responsável por aumentar a estabilidade coloidal e permitir que as partículas fiquem estáveis em tamanho e forma, mesmo após a interação com o $\mathrm{NaCl}$.

\subsection{Luminescência Opticamente Estimulada (OSL)}


Os compósitos de cloreto de sódio contendo diferentes porcentagens em massa de nanopartículas e micropartículas de prata foram aplicados como dosímetros das radiações ionizantes por meio da técnica de luminescência opticamente estimulada. A Figura 3.5 mostra a curva OSL obtida para as amostras de $0 \% \mathrm{NpAg}, 0,05 \% \mathrm{NpAg}$ e $0,05 \% \mathrm{MpAg}$ irradiadas com dose de 10 mGy. É possível verificar um aumento da intensidade OSL para as amostras contendo nanopartículas de prata e a redução da intensidade OSL para as amostras contendo micropartículas de prata.

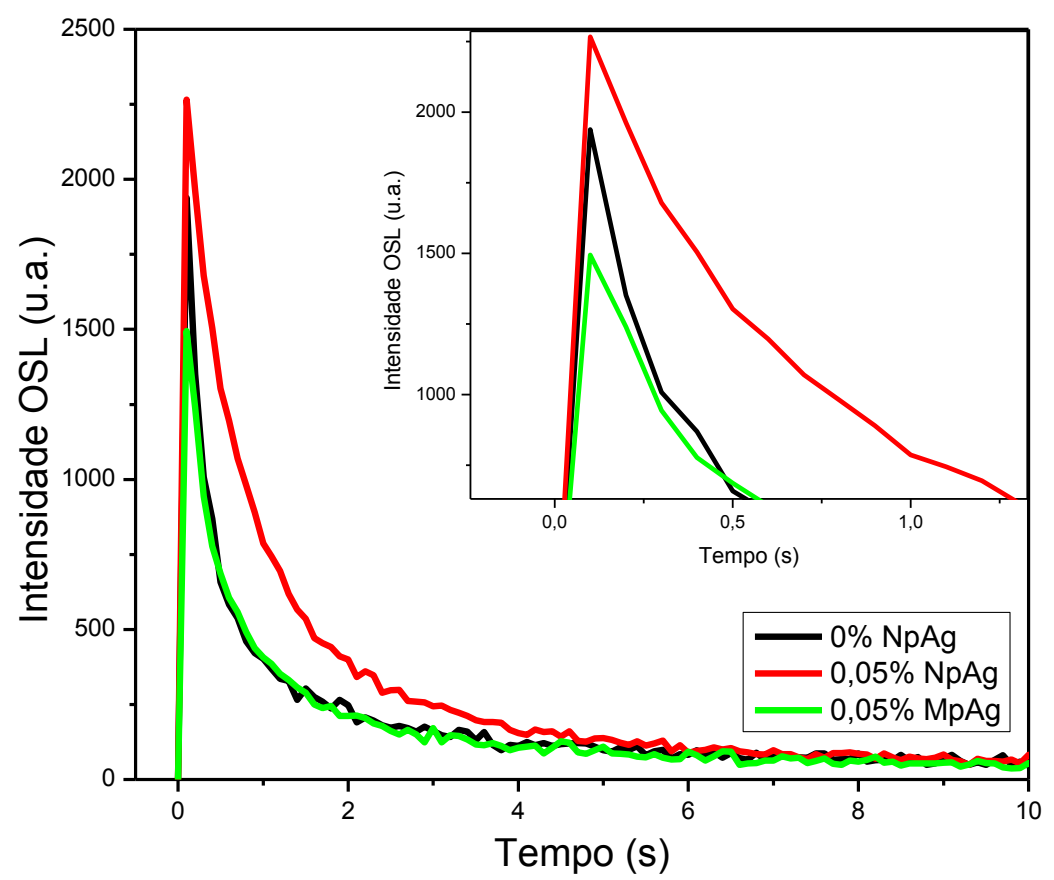

Figura 4.5: Curva OSL para as amostras $0 \% \mathrm{NpAg}, 0,05 \% \mathrm{NpAg}$ e $0,05 \% \mathrm{MpAg}$ irradiadas com 10 mGy. O inset mostra a intensidade inicial da curva OSL com maior resolução.

A Figura 4.5 (a) mostra que a intensidade OSL (área sob a curva OSL) aumenta à medida que a concentração de prata aumenta para os nanocompósitos. No caso dos microcompósitos, para a amostra $0,005 \% \mathrm{MpAg}$ há um aumento da intensidade OSL e, à medida que a concentração de prata aumenta, a intensidade OSL diminui para valores menores do que do $\mathrm{NaCl}$ puro. $\mathrm{O}$ aumento de luminescência para a amostra contendo $0,005 \% \mathrm{MpAg}$ pode estar relacionado ao fato de que o tamanho e o estado de agregação dos microcompósitos está diretamente relacionado à quantidade de partículas de prata inseridas na matriz de $\mathrm{NaCl}$, como evidenciado pelas medidas de DLS. Em outras palavras, quanto maior a porcentagem em massa de prata nos microcompósitos, maior a agregação e crescimento das partículas e consequentemente menor a intensidade OSL. A Figura 4.5 (b) mostra a curva de calibração para o $\mathrm{NaCl}$ puro e para a amostra $0,05 \% \mathrm{NpAg}$. É possível observar que a inserção 
de nanopartículas de prata na matriz de $\mathrm{NaCl}$ não altera a linearidade da curva dose-resposta. Por meio dos coeficientes lineares das duas curvas, o aumento da intensidade OSL encontrado é de aproximadamente 2 vezes.

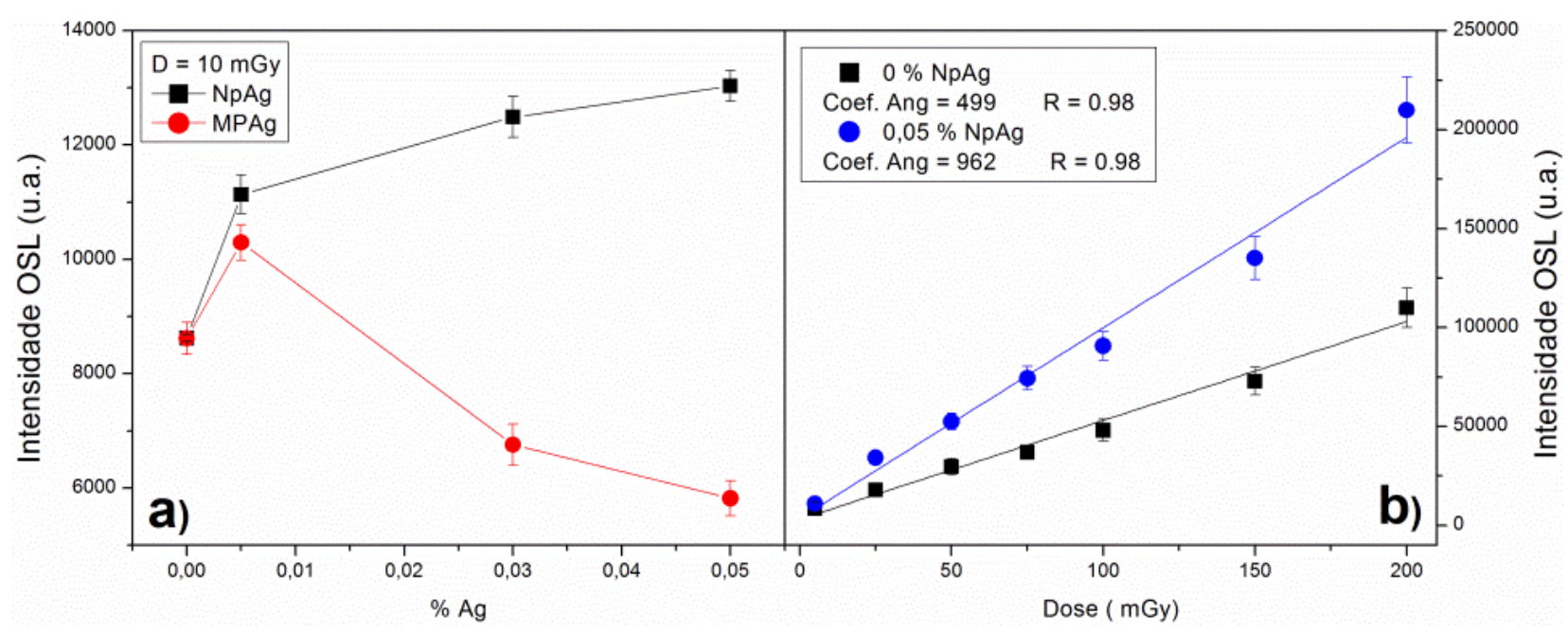

Figura 4.6: (a) Intensidade OSL em função da concentração de prata para os nano e microcompósitos. (b) Curva dose-resposta para o $\mathrm{NaCl}$ puro e para a amostra $0,05 \% \mathrm{NpAg}$.

Sob o ponto de vista de criação de defeitos, o aumento da intensidade OSL pode estar associado à criação armadilhas e/ou centros luminescentes na estrutura cristalina do $\mathrm{NaCl}$ após a recristalização em torno das nanopartículas de prata. Já sob o ponto de vista da nanoplasmônica, nanoestruturas metálicas podem aumentar a intensidade luminescente de luminóforos próximos de duas maneiras: Durante o processo de excitação do centro luminescente e/ou durante o processo de emissão do mesmo. Para haver aumento de luminescência devido ao processo de excitação, em geral, é preciso que o centro luminescente tenha uma banda de excitação que se sobreponha, total ou parcialmente, à banda de oscilação plasmônica da nanopartícula metálica [38,57]. Essa condição é atendida para o caso do cloreto de sódio contendo nanopartículas de prata, visto que a emissão OSL ocorre devido à presença de centros F criados pela radiação ionizante, cuja absorção ocorre em $450 \mathrm{~nm}$ [48]. Em outras palavras, quando uma nanopartícula metálica é iluminada com comprimento de onda ressonante, ela pode apresentar uma seção de choque óptica muito maior que sua seção de choque física [37-38] causando aumento do campo elétrico local em torno da partícula, aumentando a probabilidade de excitação de um centro luminescente próximo. Sua seção de choque óptica pode ser da ordem de $10^{5}$ vezes maior que um fluoróforo comum [38]. Para comprimentos de onda que não obedeçam às condições de ressonância, a seção de choque óptica pode ser igual ou menor que sua seção de choque física [38]. 
Dessa forma, ao incidir um fóton de luz sobre a nanopartícula metálica em um comprimento de onda de ressonância, haverá um aumento do campo elétrico local devido à oscilação dos elétrons plasmônicos. Esse aumento do campo elétrico local aumenta a probabilidade de excitação dos centros luminescentes localizados ao redor da nanoestrutura metálica. Logo, nesse caso, o aumento da luminescência ocorre porque um número maior de centros luminescentes é excitado. No caso da dosimetria OSL com $\mathrm{NaCl}$, um maior número de elétrons seriam desarmadilhados dos centros F.

Aqui cabe um adendo ressaltando que ainda não há consenso a respeito do papel dos centros F na luminescência dos haletos alcalinos. Alguns autores afirmam que os centros $\mathrm{F}$ atuam somente como armadilhas de elétrons, enquanto outros acreditam que eles também possam agir como centros de recombinação [58]. O modelo mais aceito atualmente consiste na recombinação de um centro $\mathrm{F}$ ( elétron preso em uma vacância de $\mathrm{Cl}^{-}$) com um centro $\mathrm{H}$ (pseudomolécula de $\mathrm{Cl}^{-2}$ ), dando origem a emissão luminescente [58-59]. Em amostras dopadas, também pode ocorrer a recombinação de elétrons aprisionados em centros $\mathrm{F}$ com outros centros luminescentes, como $\mathrm{Cu}^{+2} \mathrm{e} \mathrm{Eu}^{+3}$ [60-61].

Havendo sobreposição do espectro de emissão do centro luminescente com o espectro de ressonância plasmônica das nanopartículas metálicas, pode haver transferência de energia do centro luminescente para a nanopartícula metálica [36, 38, 62]. Dessa forma, o centro luminescente no estado excitado pode gerar plásmons na superfície das nanopartículas metálicas. Como o tempo de vida das oscilações plasmônicas é geralmente muito curto (da ordem de fentosegundos)[36], muitos autores creditam o aumento do rendimento quântico de luminescência a uma rápida transferência de energia do centro luminescente para os elétrons plasmônicos, que por sua vez irradiam a energia recebida em campo distante [36, 39].

Por isso, nanopartículas de prata apresentam potencial aplicação em OSL visto que sua banda de ressonância plasmônica coincide tanto com a estimulação (azul e/ou verde), quanto com a emissão $(\lambda<400 \mathrm{~nm}$ ), como mostra a Figura 4.7. Logo, um estímulo OSL ressonante pode causar aumento do campo elétrico local, aumentando a taxa de excitação dos centros F induzidos pela radiação. Esse centro luminescente no estado excitado pode ainda induzir a formação de plásmons na superfície das nanopartículas de prata, uma vez que a emissão OSL coincide com a banda plasmônica da prata. Logo, o aumento da intensidade OSL poderia ocorrer tanto pelo processo de excitação quanto pelo processo de emissão. 


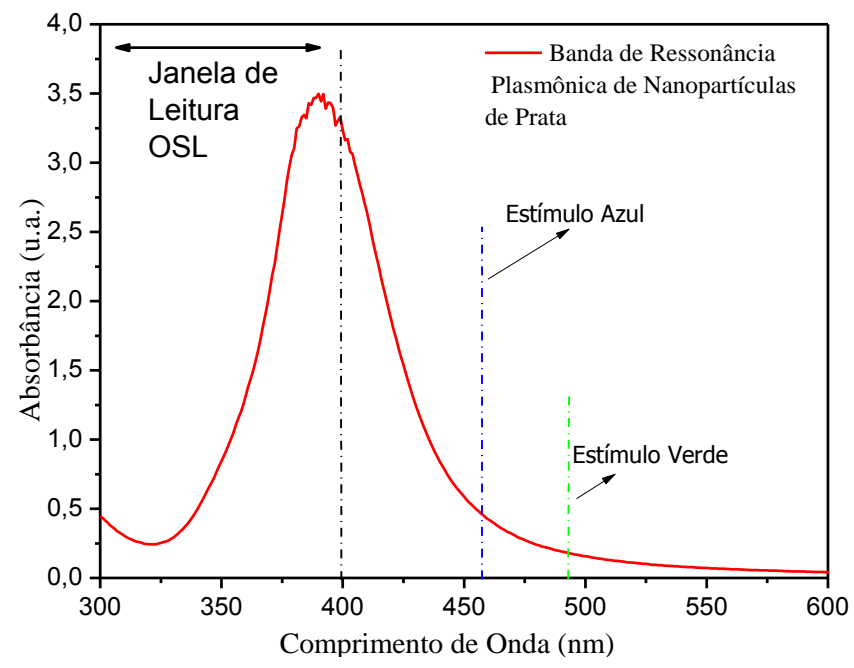

Figura 4.7: Banda de ressonância plasmônica de nanopartículas de prata em solução. As setas indicam os comprimentos de onda onde iniciam as bandas de estimulação OSL com os LEDs azul e verde, bem como a janela de leitura OSL.

\subsection{Radioluminescência}

A intensidade OSL é proporcional tanto ao número de armadilhas existentes/criadas no material quanto ao número de centros luminescentes. Portanto, como discutido anteriormente, o aumento da luminescência OSL pode estar relacionado tanto à criação de mais armadilhas quanto à criação de mais centros luminescentes. Porém, a radioluminescência é originada pelas recombinações elétron-buraco imediatas ocorridas durante a irradiação e, consequentemente, o aprisionamento de elétrons em armadilhas no gap compete com o processo de radioluminescência [4, 15]. Em outras palavras, quanto maior o número armadilhas, menor será a quantidade de recombinação imediata e, consequentemente, menor será a radioluminescência. Dessa forma, a radioluminescência pode dar informação a respeito do tipo de defeito (armadilha ou centro luminescente) criado na estrutura cristalina do cloreto de sódio. Portanto, a redução da radioluminescência da amostra pode indicar um aumento do número de armadilhas enquanto o aumento da radioluminescência pode indicar aumento do número de centros luminescentes.

Por meio da Figura 4.8 é possível observar que a amostra de $\mathrm{NaCl}$ puro tem uma larga banda entre 300 e $600 \mathrm{~nm}$, e está de acordo com os espectros de RL encontrados na literatura [63]. Segundo a literatura, a deconvolução dessa extensa banda revela a presença de três bandas de emissão em torno de 370, 433 e $504 \mathrm{~nm}$ [63]. A banda em $370 \mathrm{~nm}$ está associada a defeitos intrínsecos da estrutura do $\mathrm{NaCl}$ (por exemplo defeitos Schottky e Frenkel). A 
emissão em torno de $430 \mathrm{~nm}$ está relacionada à presença de centros $\mathrm{F}$ e a emissão em $504 \mathrm{~nm}$ é atribuída às vacâncias de $\mathrm{Na}^{+}$na estrutura do $\mathrm{NaCl}$ [63].

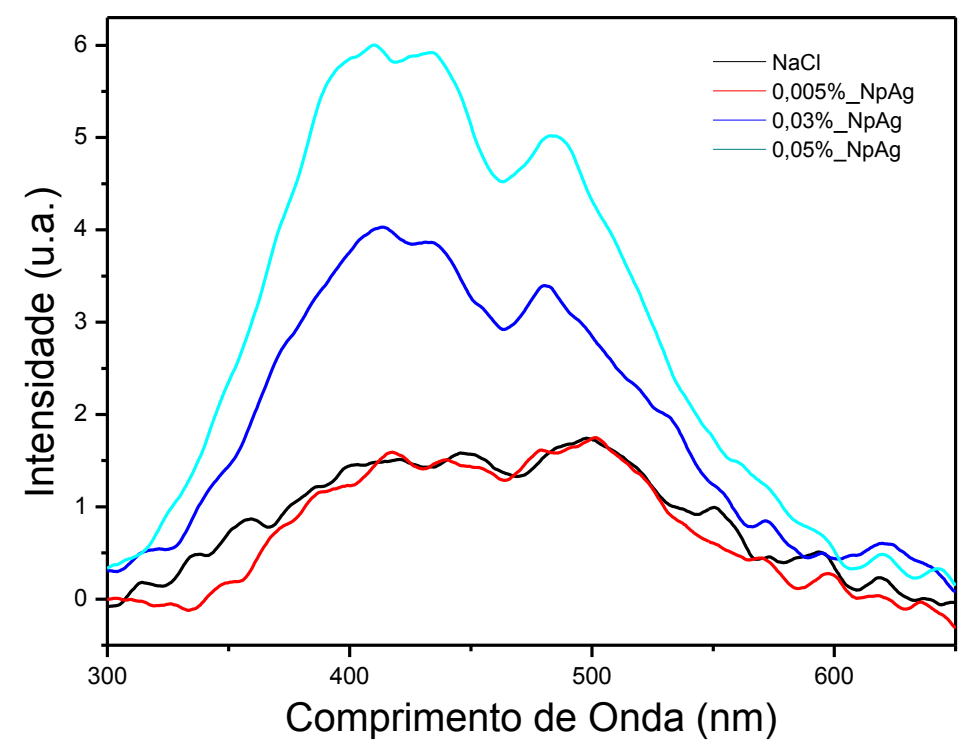

Figura 4.8: Espectros de radioluminescência para as amostras $0 \% \mathrm{NpAg}, 0,005 \% \mathrm{NpAg}, 0,03 \% \mathrm{NpAg}$ e $0,05 \% \mathrm{NpAg}$.

Para as amostras contendo nanopartículas de prata, é possível observar que todas as bandas apresentam maior intensidade luminescente para as amostras 0,03\%_NpAg e 0,05\%_NpAg. O aumento da radioluminescência entre 300-600 nm do $\mathrm{NaCl}$ pode indicar o aumento no número de centros luminescentes característicos do $\mathrm{NaCl}$ ocasionados pela criação de defeitos. No entanto, é válido ressaltar também que essa banda luminescente está dentro da banda de ressonância plasmônica das nanopartículas de prata e, portanto, esse aumento de luminescência pode ser resultado do acoplamento entre os centros luminescentes do $\mathrm{NaCl}$ com os plásmons na superfícies das nanopartículas de prata durante o processo de emissão luminescente. $\mathrm{O}$ aumento em luminescência da banda entre 300-600 nm é cerca de 4 vezes para a amostra $0,05 \% \mathrm{NpAg}$, quando comparada a amostra de $\mathrm{NaCl}$ puro.

\subsection{Espectros de Luminescência}

Os espectros de luminescência das amostras $0 \% \mathrm{NpAg}, 0,05 \% \mathrm{NpAg}$ e $0,05 \% \mathrm{MpAg}$ com excitação em $350 \mathrm{~nm}$ estão apresentados na Figura 4.9 (a). Nessa figura pode ser observada uma extensa banda de emissão na região de 400-600 nm. A intensidade 
luminescente dessa banda para a amostra $0,05 \% \mathrm{NpAg}$ é cerca de 7 vezes maior que a intensidade do $\mathrm{NaCl}$ puro. A luminescência do $\mathrm{NaCl}$ é descrita na literatura como oriunda da absorção de luz devido à transição $3 p^{6} \rightarrow 3 p^{5} 4 s^{1}$ do íon $\mathrm{Cl}^{-}$[59]. Uma vez que seu orbital $4 \mathrm{~s}$ mais externo se sobrepõe aos íons $\mathrm{Na}^{+}$, o estado excitado pode ser considerado como um buraco no íon $\mathrm{Cl}^{-}$e um elétron no íon $\mathrm{Na}^{+}$. Após esse processo de absorção, o átomo de cloro se desloca na rede em direção a um íon $\mathrm{Cl}^{-}$formando uma pseudomolécula de $\mathrm{Cl}_{2}{ }^{-}$, fícando um elétron aprisionado na vacância de cloro gerada pelo deslocamento. Esse elétron aprisionado na vacância de cloro é conhecido como centro $\mathrm{F}$, e a pseudomolécula $\mathrm{Cl}_{2}{ }^{-}$é nomeada de centro H. Assim, a emissão ocorre pela relaxação dos centros $\mathrm{F}$ e $\mathrm{H}$, retornando ao estado fundamental. Impurezas na estrutura do $\mathrm{NaCl}$ também podem originar emissões luminescentes nessa região do espectro tanto por atuarem como centros luminescentes quanto por recombinarem com centros $\mathrm{H}$ pré-existentes [56, 64]. Além disso, algumas impurezas podem também agir como doadoras de elétrons ao serem foto-excitadas com luz UV, liberando elétrons livres na banda de condução do $\mathrm{NaCl}$, que poderão se recombinar ou serem armadilhados em defeitos da rede ou impurezas [60, 65]. Esse último processo permite o uso do $\mathrm{NaCl}$ e do $\mathrm{KCl}$ como dosímetros de luz ultravioleta [60].

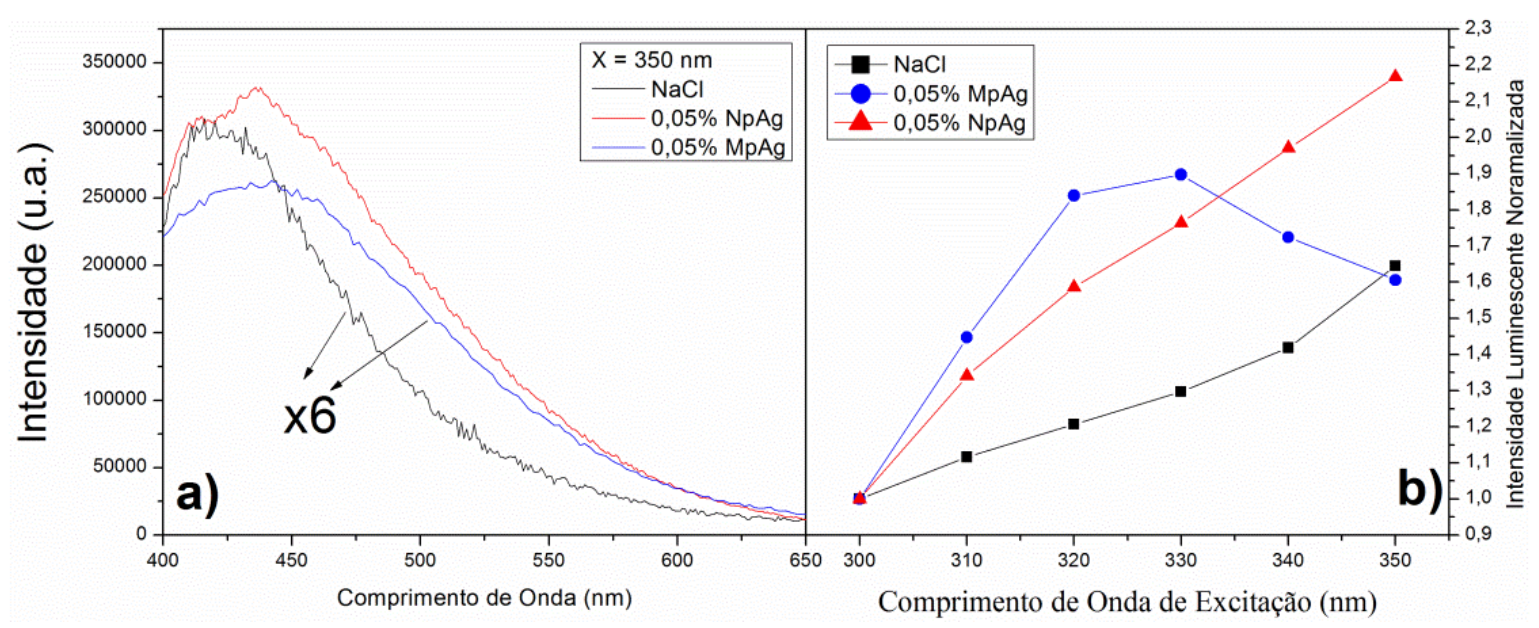

Figura 4.9: (a) Espectro de luminescência para amostras não irradiadas $(X=350 \mathrm{~nm})$. (b) Intensidade da banda em $425 \mathrm{~nm}$, excitada por comprimentos de onda entre 300-350 nm, e normalizada pela intensidade luminescente da mesma amostra quando excitada em $300 \mathrm{~nm}$.

A Figura 4.9 (b) mostra a intensidade luminescente (área do espectro) da banda entre 400-600 nm, para as amostras de $\mathrm{NaCl}$ puro, 0,05\% NpAg e 0,05\% MpAg, excitadas por diferentes comprimentos de onda entre 300-350 $\mathrm{nm}$. As áreas dos espectros de cada amostra foram normalizadas pela área do espectro obtido com excitação em $300 \mathrm{~nm}$. É possível verificar que à medida que o comprimento de onda de excitação aumenta, a emissão 
luminescente da banda entre 400-600 nm aumenta para as amostras de $\mathrm{NaCl}$ puro e $0,05 \% \mathrm{NpAg}$. No entanto, a emissão luminescente aumenta de forma mais significativa para a amostra contendo nanopartículas de prata. Esse resultado pode indicar um aumento na taxa de excitação dos centros luminescentes próximos às nanopartículas de prata, uma vez que a banda de ressonância plasmônica da prata tem seu máximo em $390 \mathrm{~nm}$. Logo, à medida que o comprimento de onda de excitação da amostra se aproxima do pico de ressonância plasmônica, o aumento dos campos locais originados pela ressonância plasmônica aumenta a taxa de desarmadilhamento de cargas presas nos centros $\mathrm{F}$, aumentando a emissão luminescente da amostra.

Esse comportamento, porém, não é observado para a amostra 0,05\% $\mathrm{MpAg}$. A intensidade luminescente aumenta na região entre 300 e $320 \mathrm{~nm}$, e diminui na região entre 330-350 nm. Aqui, é valido ressaltar que a região entre 300 e $320 \mathrm{~nm}$ consiste da região de menor absorbância, localizada entre a banda de ressonância plasmônica, e a região de transições interbandas $(\lambda<320 \mathrm{~nm})$. Em outras palavras, a maior emissão obtida para a amostra $0,05 \% \mathrm{MpAg}$ consiste da excitação na região onde a absorção da luz por parte das micropartículas é mínima, indicando que as micropartículas de prata absorvem (atenuam) a luz, impedindo a excitação da amostra. Uma hipótese para a redução da intensidade luminescente nos microcompósitos pode estar associada com a redução da razão área/volume das partículas de prata. A agregação das nanopartículas diminui a razão área/ volume e, consequentemente, reduz as regiões de aumento de campo elétrico local em torno das nanopartículas e que poderiam estar ocupadas pela matriz luminescente. Logo, enquanto partículas em escala nanométrica parecem aumentar a seção de choque de interação do centro luminescente com a luz, micropartículas atuam como centros de absorção de luz, reduzindo a probabilidade de interação da luz com o centro luminescente.

Para observar se as bandas de emissão fotoluminescente participam do processo de emissão OSL, as amostras de $\mathrm{NaCl}$ puro e $0,05 \% \mathrm{NpAg}$ foram irradiadas com uma dose de 450 Gy e os espectros de luminescência foram obtidos com excitação em $320 \mathrm{~nm}$ e emissão entre 370 e $550 \mathrm{~nm}$, com 10 medidas consecutivas (90 s cada medida) sem alterar o posicionamento da amostra no espectrofotômetro. A Figura 3.10 evidencia que os espectros das amostras irradiadas são semelhantes ao das amostras não irradiadas. É possível notar ainda que a intensidade das bandas diminui com o número de medidas. Os insets de cada figura correspondem à área total de cada espectro em função do número de medidas, e revelam que a intensidade luminescente da amostra decai de forma exponencial com o 
número de medidas ( $\propto$ tempo de exposição à luz) indicando a participação dessa banda no processo de emissão OSL.

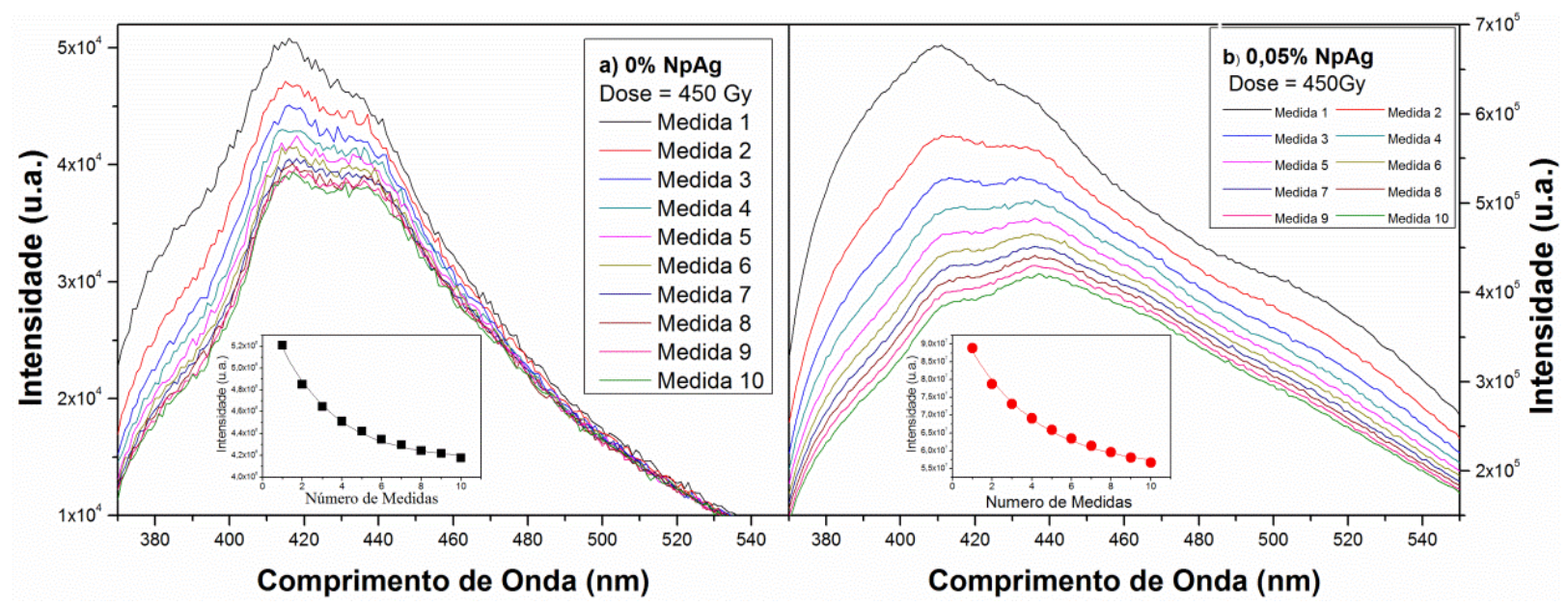

Figura 4.10: Espectros de luminescência do $\mathrm{NaCl}$ (a) e da amostra $0,05 \% \mathrm{NpAg}$ (b) irradiados com $450 \mathrm{~Gy}$, em 10 medidas consecutivas.

A extensa banda de emissão luminescente observadas nas Figuras 4.9 (a) e 4.10, é semelhante à banda de emissão de radioluminescência (Figura 4.8). Assim como no caso do espectro de emissão radioluminescente, essa larga banda de emissão pode ser deconvoluída em mais de um pico de emissão. O melhor ajuste dos espectros consiste na deconvolução da banda entre 370-600 nm em quatro picos de emissão centrados em torno de 380, 409, 418 e 495 nm, como mostrado na Figura 4.11.

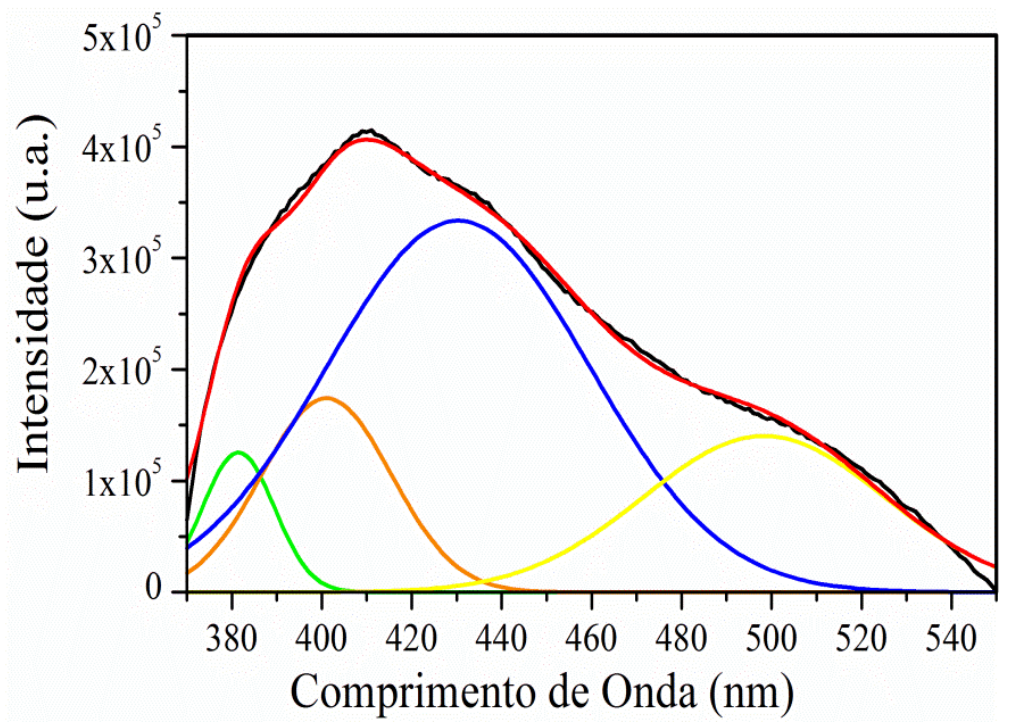

Figura 4.11: Deconvolução da banda de emissão luminescente da amostra $0,05 \% \mathrm{NpAg}$, irradiada com $450 \mathrm{~Gy}$, com excitação em $320 \mathrm{~nm}$. 
Construindo-se um gráfico da área de cada pico de emissão em função do número de medidas consecutivas, pode-se observar um decaimento exponencial para as bandas centradas em 380 e $410 \mathrm{~nm}$ enquanto as áreas das bandas em 418 e $495 \mathrm{~nm}$ permanecem praticamente constantes (Figura 4.12). Logo, pode-se concluir que somente as duas bandas de emissão de maior energia é que participam do processo de emissão OSL. As duas bandas de menor energia (418 e $595 \mathrm{~nm}$ ) estão provavelmente relacionadas apenas aos processos fotoluminescentes.

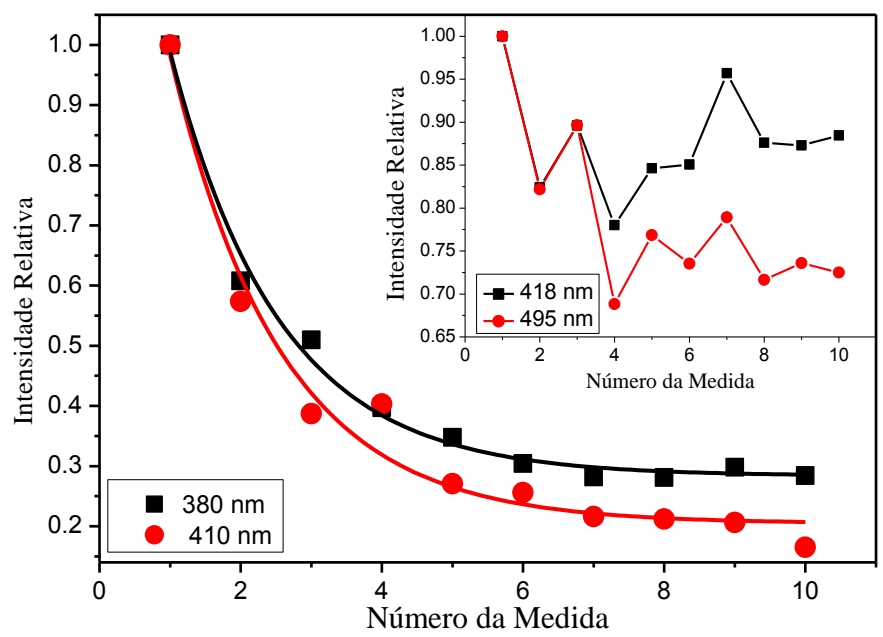

Figura 4.12: Decaimento da intensidade relativa da área das bandas de emissão luminescente da amostra $0,05 \% \mathrm{NpAg}$, irradiada com 450 Gy e com excitação em $320 \mathrm{~nm}$, em função do número de medidas.

\subsection{Conclusões}

Para os compósitos $\mathrm{NaCl} / \mathrm{Ag}$, quando utilizadas como dosímetros das radiações ionizantes, houve aumento da intensidade OSL para as amostras contendo nanopartículas de prata e redução da intensidade OSL para as amostras contendo micropartículas de prata, quando comparadas a amostra de $\mathrm{NaCl}$ puro. Espectros de fotoluminescência revelaram que à medida que o comprimento de onda de excitação da amostra se aproxima do pico de ressonância plasmônica, a emissão luminescente aumenta de forma mais significativa para a amostra contendo nanopartículas de prata, sugerindo que o aumento dos campos locais originados pela ressonância plasmônica aumenta a taxa de excitação dos centros luminescentes, aumentando a emissão luminescente da amostra. Portanto, essa é uma forte evidência da existência de acoplamento plasmônico no processo de estimulação OSL. Sob o 
ponto de vista da criação de defeitos, o aumento da intensidade OSL pode indicar tanto aumento no número de armadilhas quanto aumento do número de centros luminescentes. Porém, o aumento da intensidade RL indica aumento do número de centros luminescentes uma vez que o aumento do número de armadilhas teria como resultado a redução da quantidade de recombinações imediatas e consequentemente reduziria a intensidade RL. O aumento da intensidade RL e o fato de que o espectro radioluminescente do $\mathrm{NaCl}$ puro ser semelhante ao espectro da amostra contendo nanopartículas de prata sugerem que, além do aumento dos campos elétricos locais e o consequente aumento da taxa de excitação dos centros luminescentes, o aumento da intensidade luminescente (OSL, RL e PL) pode também ser consequência do acoplamento entre os centros luminescentes do $\mathrm{NaCl}$ e os plásmons na superfície das nanopartículas de prata durante o processo de emissão (transferência de energia). No caso das nanopartículas de prata, esse acoplamento é factível porque a emissão luminescente do $\mathrm{NaCl}$ dá origem a fótons com comprimentos de onda dentro da banda de ressonância plasmônica das NpAgs. Sendo assim, os nanocompósitos NaCl/Ag evidenciaram a existência de acoplamento plasmônico durante o processo de excitação do centros luminescente e da estimulação OSL, e sugeriram a existência de um acoplamento durante o processo de emissão. No entanto, não foi possível, com os instrumentos/equipamentos disponíveis, elaborar um experimento para comprovar o acoplamento plasmônico durante o processo emissivo. Além disso, não é possível desconsiderar a possibilidade de que o aumento de luminescência das amostras de $\mathrm{NaCl} / \mathrm{NpAg}$ pode também ser causado pela criação de defeitos na estrutura do $\mathrm{NaCl}$. Essas lacunas e questões abertas é que levaram a produção de diferentes materiais e/ou estruturas/geometrias, como será discutido nos capítulos posteriores. 


\section{Estudo e Caracterização dos Nanocompósitos $\mathrm{ZnO} / \mathrm{Ag}$ e $\mathrm{ZnO} / \mathrm{Au}$}

O capítulo anterior evidenciou a existência de acoplamento plasmônico durante o processo de excitação do centro luminescente ao mostrar que o aumento da luminescência é maior quando a excitação se aproxima do pico de ressonância plasmônica. Porém, o aumento da intensidade radioluminescente sugere, mas não comprova, a existência de acoplamento plasmônico também durante o processo emissivo. Com essa questão em mente é que inicia-se um novo capítulo dessa tese.

Para essa investigação, foi escolhido um sistema consistindo de compósitos de óxido de zinco $(\mathrm{ZnO})$ produzido e ancorado sobre nanopartículas esféricas de ouro e prata. O $\mathrm{ZnO}$ foi escolhido por ser um óxido que pode ser produzido em temperaturas relativamente baixas, além de apresentar OSL, TL e RL [66-68]. Além disso, a luminescência do seu gap coincide parcialmente com a banda de ressonância plasmônica das nanopartículas de prata e ouro, aumentando a probabilidade de ocorrer aumento de luminescência por interação plasmônica. Dessa forma, mesmo que necessárias altas doses de radiação para originar luminescência opticamente estimulada, esse sistema reúne propriedades importantes para responder a principal questão dessa tese. Portanto, foram produzidos e caracterizados os nanocompósitos $\mathrm{ZnO} / \mathrm{Ag}$ e $\mathrm{ZnO} / \mathrm{Au}$, detalhadamente descritos a seguir.

\subsection{Difração de Raios-X}

Para verificar a estrutura cristalina do $\mathrm{ZnO}$, foi realizada difração de raios-X das amostras produzidas. A Figura 5.1 mostra os difratogramas para os nanocompósitos $\mathrm{ZnO} / \mathrm{Ag}$ e $\mathrm{ZnO} / \mathrm{Au}$. Seis picos principais foram detectados em $31.7^{\circ}, 34.4^{\circ}, 36.2^{\circ}, 47.5^{\circ}, 56.5^{\circ}$, e $62.9^{\circ}$, e foram indexados como (100), (002), (101), (102), (110), e (103) referentes à estrutura hexagonal do óxido de zinco do tipo wurtzita [69].

Como pode ser observado na Figura 5.1, na ausência de nanopartículas em solução, o crescimento do oxido de zinco ocorre preferencialmente na direção do plano (002), sugerindo a formação de partículas ordenadas de $\mathrm{ZnO}$ em forma de bastões. No entanto, o mecanismo de crescimento do $\mathrm{ZnO}$ na presença de nanopartículas não ocorre da mesma forma. Para os nanocompósistos de $\mathrm{ZnO} / \mathrm{Ag}$, a adição de até $2 \mathrm{~mL}$ de nanopartículas de prata parece não alterar o crescimento do filme. Porém, para os volumes de 4 e $8 \mathrm{~mL}$, os difratogramas sugerem que o crescimento dos filmes de óxido de zinco não ocorreu com uma dada 
orientação preferencial. Comportamento similar pode ser observado para os compósitos de ouro. Porém, nesse caso, os difratogramas sugerem o crescimento de um filme totalmente randômico para volumes a partir de $1 \mathrm{~mL}$, e para a amostra contendo $8 \mathrm{ml}$ de nanopartículas de ouro, o plano (001) passa a ser a orientação preferencial de crescimento do filme.

Alguns autores demonstraram que nanopartículas de prata e ouro podem agir como sementes para a cristalização de óxido de zinco, e essa pode ser uma razão para a alteração do mecanismo de crescimento dos filmes [70-72]. No entanto, como o óxido de zinco é um cristal polar, o uso de surfactantes e solventes como EG e PVP também pode modificar a estrutura e a morfologia do $\mathrm{ZnO}$ [73]. No entanto, como os volumes de nanopartículas necessários para modificar o mecanismo de crescimento dos filmes são diferentes para a prata e para o ouro, as nanopartículas metálicas parecem desempenhar um papel mais importante no crescimento desses filmes.
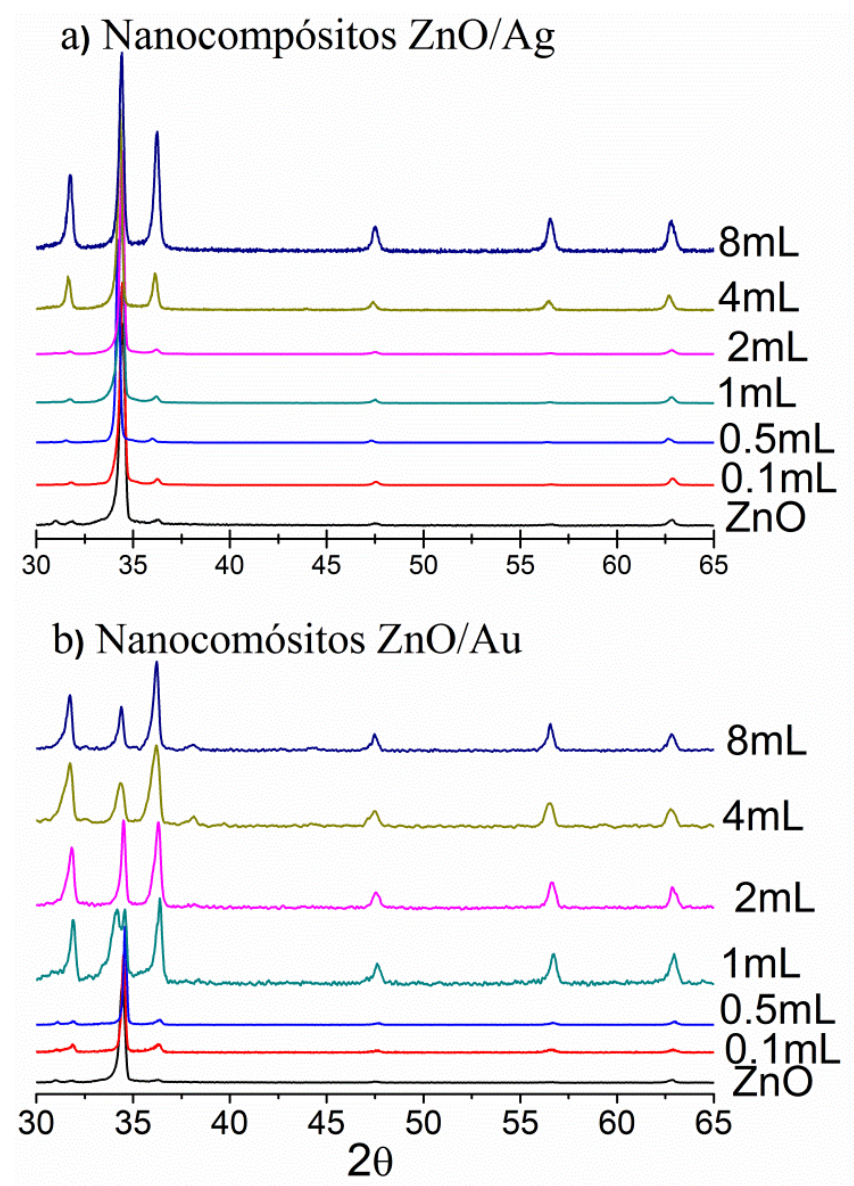

Figura 5.1: Difratogramas dos nanocompósitos $\mathrm{ZnO} / \mathrm{Ag}$ (a) e $\mathrm{ZnO} / \mathrm{Au}$ (b).

\subsection{Espectroscopia UV-Vis}


A Figura 5.2 mostra os espectros de refletância difusa dos nanocompósitos $\mathrm{ZnO} / \mathrm{Ag}$ e $\mathrm{ZnO} / \mathrm{Au}$, assim como das dispersões coloidais de prata e ouro. A banda plasmônica da prata e do ouro podem ser detectadas em 400 e $520 \mathrm{~nm}$, respectivamente. A absorção em torno de $360 \mathrm{~nm}$ é característica do óxido de zinco devido a transição de elétrons da banda de valência para a banda de condução. A banda plasmônica da prata pode ser detectada com pico em 450 $\mathrm{nm}$ somente para as amostras de $\mathrm{ZnO} / \mathrm{Ag}$ contendo 4 e $8 \mathrm{~mL}$ de nanopartículas de prata. A presença dessa banda sugere que as nanopartículas de prata são estáveis e bem dispersas na matriz de $\mathrm{ZnO}$. O deslocamento para maiores comprimentos de onda não é acompanhado do alargamento da banda, sugerindo que esse deslocamento é consequência do maior índice de refração do óxido de zinco, e não é devido a aglomeração das partículas de prata [26, 34]. A ausência da banda plasmônica da prata para as amostras 0.1mL_NpAg, 0.5mL_NpAg, $1 \mathrm{~mL} \_N p A g$, e 2 mL_NpAg pode estar relacionada a baixa concentração de nanopartículas de prata e também devido à alta absorbância do óxido de zinco na região do UV-Visível.

Para os nanocompósitos de $\mathrm{ZnO} / \mathrm{Au}$, a banda plasmônica em $550 \mathrm{~nm}$, característica de nanopartículas de ouro, pode ser detectada para amostras contendo volumes acima de $0.5 \mathrm{~mL}$. A presença das bandas de ressonância plasmônica do ouro e da prata nos filmes de $\mathrm{ZnO}$ sugere que as nanopartículas metálicas estão ligadas ao óxido de zinco. Caso contrário, a nanopartículas deveriam permanecer em solução.
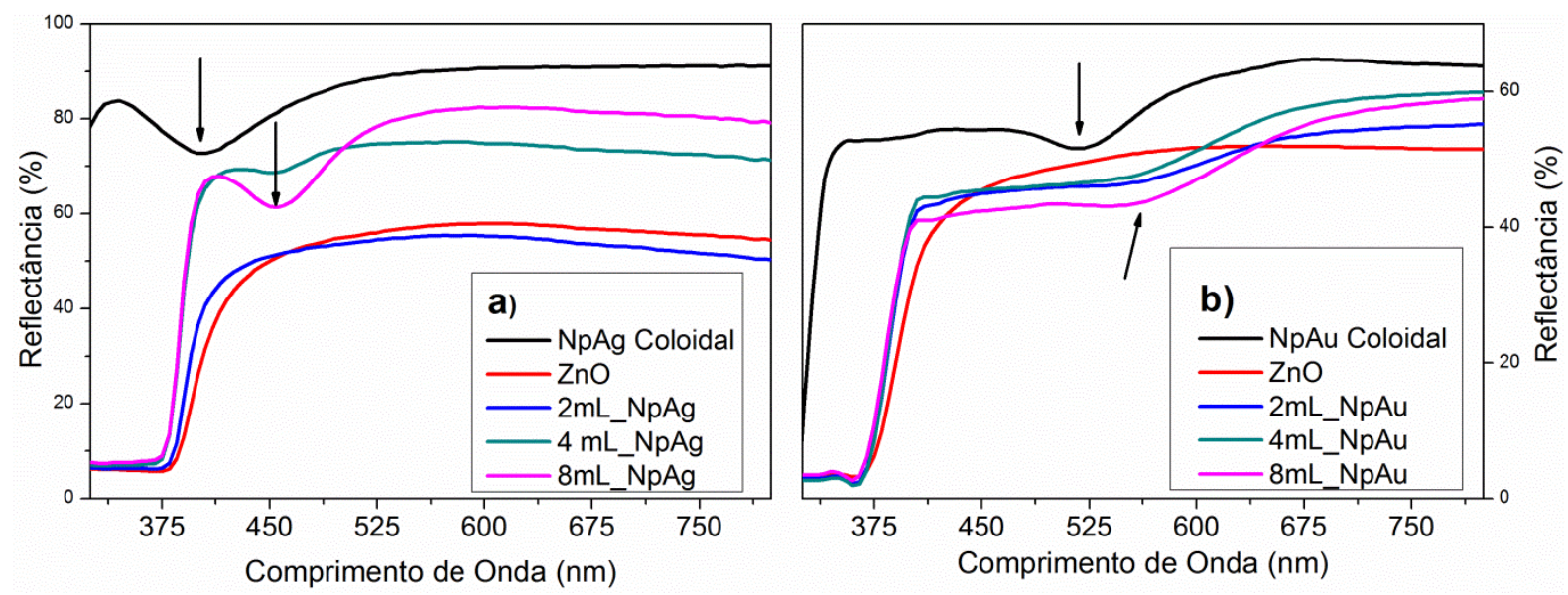

Figura 5.2: Reflectância UV-Vis das amostras $\mathrm{ZnO} / \mathrm{Ag}$ (a) e $\mathrm{ZnO} / \mathrm{Au}$ (b).

\subsection{Microscopia Eletrônica de Varredura}

Imagens de microscopia eletrônica de varredura revelaram a presença de bastões de $\mathrm{ZnO}$ alinhados perpendicularmente ao substrato para as amostras em que os difratogramas 
indicaram o crescimento de um filme com orientação preferencial (Figura 5.3 (a) e (b)). Para as amostras contendo mais que $4 \mathrm{~mL}$ de nanopartículas de prata e mais que $1 \mathrm{~mL}$ de nanopartículas de ouro, partículas em forma de estrela foram obtidas (Figura 5.3 (c) e (d)), confirmando a estrutura randômica do $\mathrm{ZnO}$, como indicado pelos difratogramas.
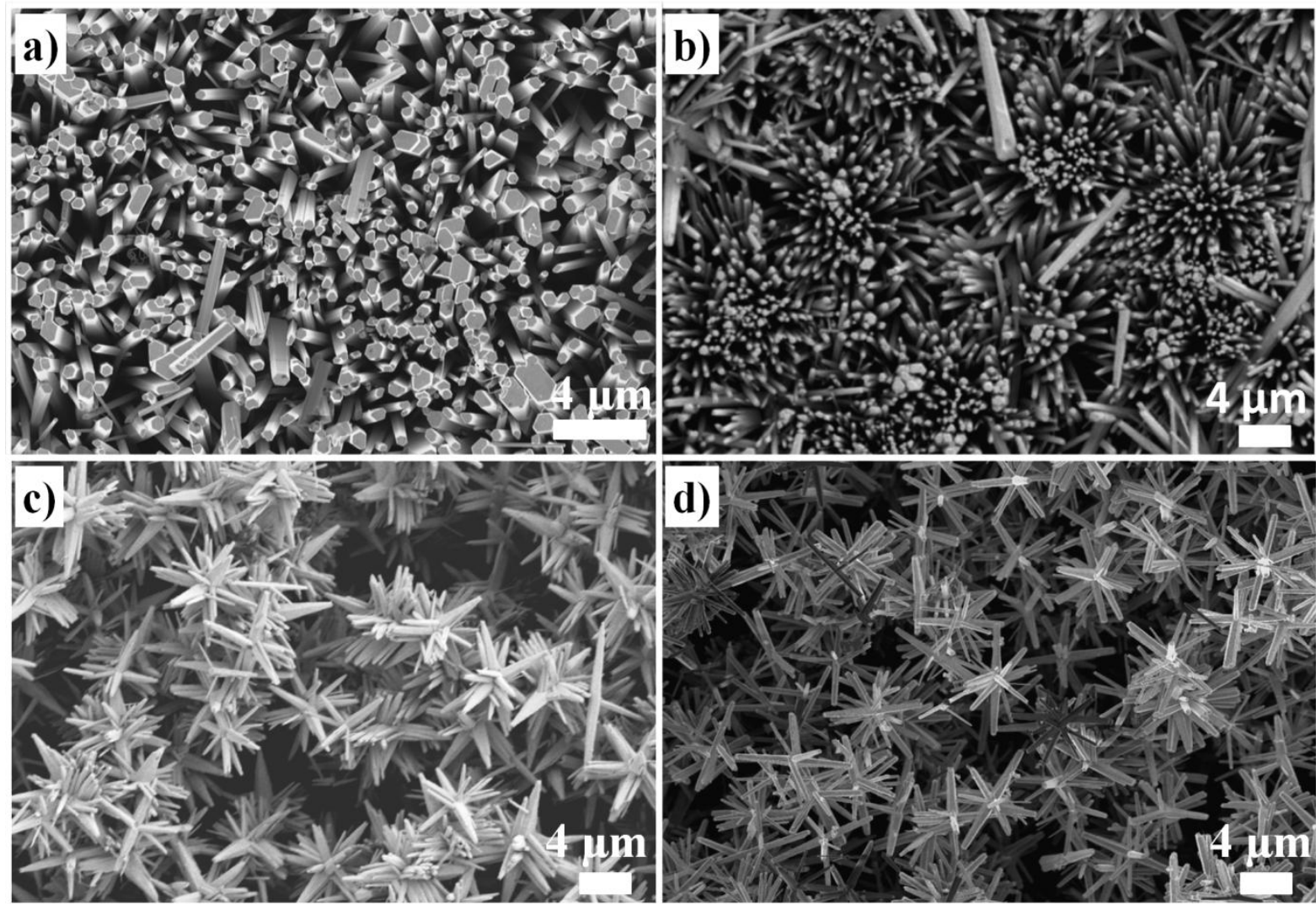

Figura 5.3: Imagens de microscopia eletrônica de varredura das amostras $\mathrm{ZnO}$ (a), 2mL_NpAg (b), 8mL_NpAg (c), e 8mL_NpAu (d).

Uma possível explicação para essa mudança na morfologia dos filmes consiste no fato de que as nanopartículas metálicas podem agir como sementes para a cristalização do óxido de zinco. Por meio de microscopia eletrônica de transmissão, foi demonstrado que o crescimento de bastões de $\mathrm{ZnO}$ crescem preferencialmente na direção (111) de nanopartículas de prata em solução aquosa [70]. Dessa forma, parece haver uma competição entre as sementes previamente implantadas nos substratos vítreos e as nanopartículas metálicas em solução, fazendo com que as partículas de óxido de zinco cristalizem-se sobre a superfície das nanopartículas metálicas em vez de crescer sobre as sementes do substrato. Nesse caso, as partículas em forma de estrela deveriam conter nanopartículas metálicas em seus centros (core). 
Para investigar essa hipótese, imagens de microscopia eletrônica de varredura foram obtidas utilizando-se um detector de retroespalhamento de elétrons. O contraste das imagens obtidas por esse detector ocorre com base no número atômico (densidade eletrônica) do material analisado. Logo, devido ao seu alto número atômico, nanopartículas de ouro devem aparecer como pontos de maior brilho, permitindo sua localização em meio à matriz de $\mathrm{ZnO}$. Assim, com o uso do detector de retroespalhamento e buscando-se por pequenas partículas presentes sobre as partículas maiores, pôde ser verificado o crescimento de pequenos "braços" sobre a superfície das nanopartículas de ouro (Figura 5.4 (a) e (b)), reforçando a hipótese de que as nanopartículas metálicas podem agir como sementes para a cristalização do óxido de zinco. Os insets em cada figura correspondem a suas respectivas imagens obtidas sem o detector de retroespalhamento de elétrons.

Em seguida, para confirmar que as partículas de $\mathrm{ZnO}$ em forma de estrela correspondem ao crescimento dos braços de óxido de zinco sobre as nanopartículas metálicas, foram obtidas imagens de partículas quebradas de $\mathrm{ZnO}$ e, com o auxílio do detector de elétrons retroespalhados, foi possível encontrar nanopartículas de ouro ocupando a posição central das partículas de $\mathrm{ZnO}$ em forma de estrela (Figura 5.4 (c) e (d)). A Figura 5.4 (d) corresponde à mesma figura presente na Figura 5.4 (c), porém obtida com o detector de retroespalhamento de elétrons. 


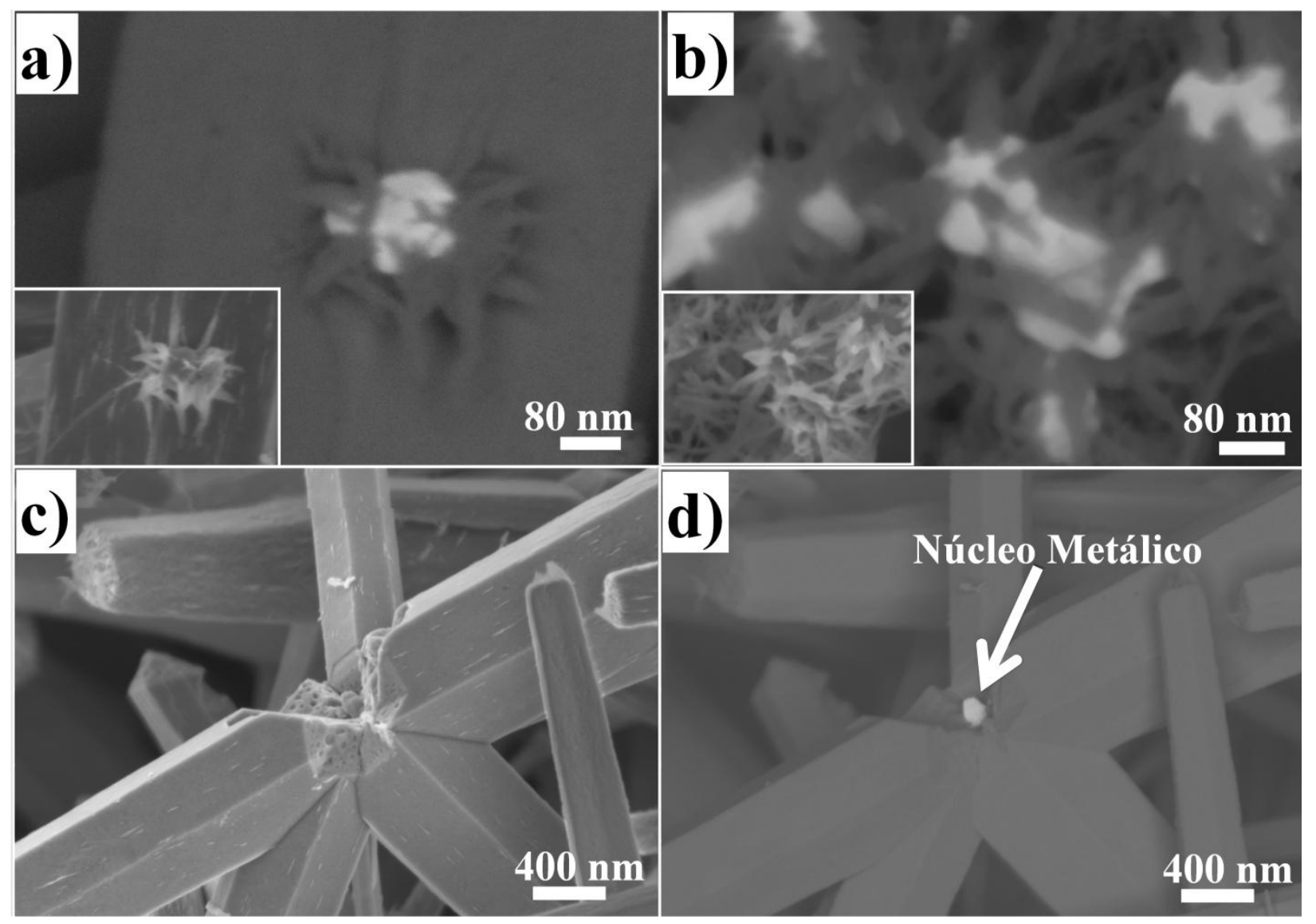

Figura 5.4: (a) e (b) Imagens de microscopia eletrônica de varredura, obtidas com e sem (insets) o auxílio de um detector de retroespalhamento de elétrons. (c) Imagem de uma partícula quebrada de $\mathrm{ZnO}$ obtida sem (c) e com o detector de elétrons retroespalhados (d).

Deve ainda ser mencionado que tanto o EG como o PVP, usados como solvente e estabilizante para as nanopartículas metálicas, também podem modificar o mecanismo de crescimento do $\mathrm{ZnO}$ [73-74]. Uma vez que o $\mathrm{ZnO}$ é um cristal polar, a velocidade de crescimento de cada uma de suas faces pode ser ajustada com o uso de surfactantes, dando origem a partículas com diferentes estruturas e morfologias [73]. Nesse sentido, a presença de EG e PVP pode influenciar de forma a diminuir/bloquear o crescimento do óxido de zinco sobre o substrato. Esse bloqueio forçaria o crescimento sobre centros de nucleação préexistentes em solução, como por exemplo, as nanopartículas de ouro e prata. 


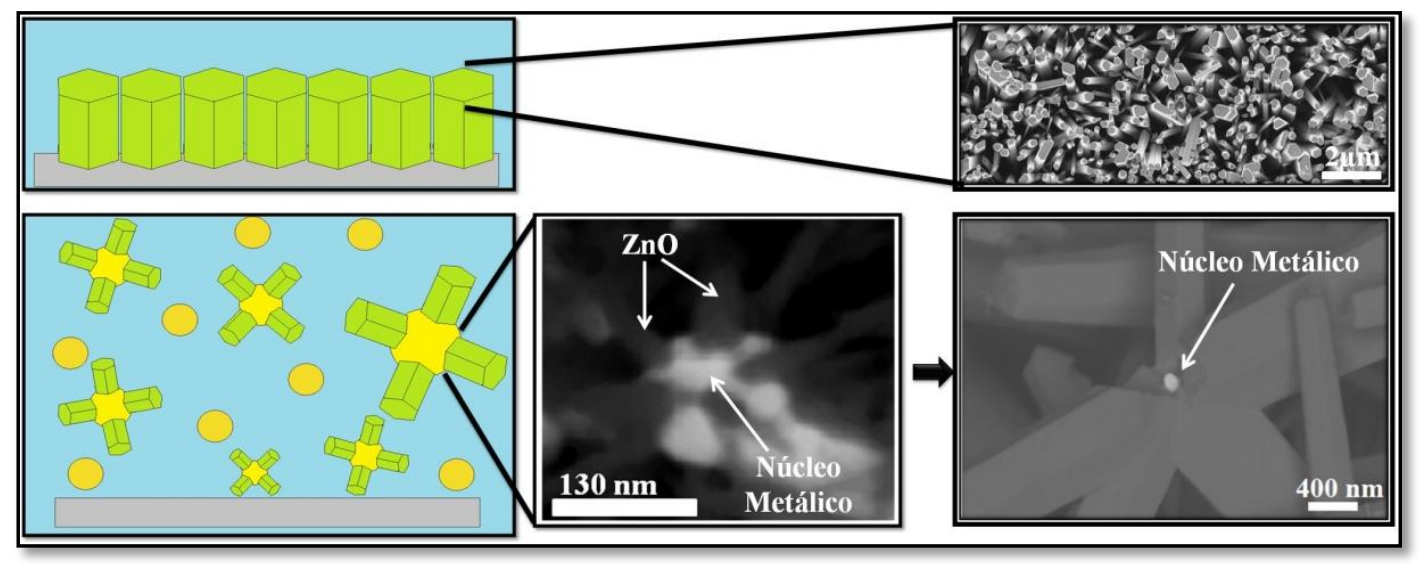

Figura 5.5: Ilustração do crescimento do $\mathrm{ZnO}$ na ausência (superior) e na presença (inferior) de nanopartículas metálicas.

Portanto, o crescimento de partículas de zinco com nanopartículas metálicas no centro ocorre devido a uma ação simultânea do EG, PVP e das nanopartículas metálicas, de forma que o EG e o PVP facilitam o crescimento do ZnO sobre a superfície das nanopartículas metálicas pré-existentes, bloqueando o crescimento do $\mathrm{ZnO}$ sobre o substrato.

\subsection{Espectros de Luminescência}

As Figura 5.6 (a) e (b) mostram o espectro de fotoluminescência das amostras excitadas com comprimento de onda de $325 \mathrm{~nm}$. O espectro é composto por três principais bandas na região entre $350-450 \mathrm{~nm}, 450-750 \mathrm{~nm}$ e $750-800 \mathrm{~nm}$. A emissão UV está relacionada à transição entre a banda de valência e condução do semicondutor. De acordo com a literatura, a banda na região visível (450-750 nm) é composta pela sobreposição de várias bandas relacionadas a defeitos na estrutura cristalina do oxido de zinco como, por exemplo, vacâncias de oxigênio e/ou oxigênios intersticiais [75-77], e são geralmente originadas pela recombinação de buracos na banda de valência com centros F ( elétron aprisionado em uma vacância de oxigênio) [77]. A atribuição da banda entre 750-800 nm é ainda controversa. Alguns autores atribuem essa emissão a defeitos na estrutura do $\mathrm{ZnO}$ enquanto outros autores a identificam como sendo uma emissão de segunda ordem da banda UV [75-76]. 

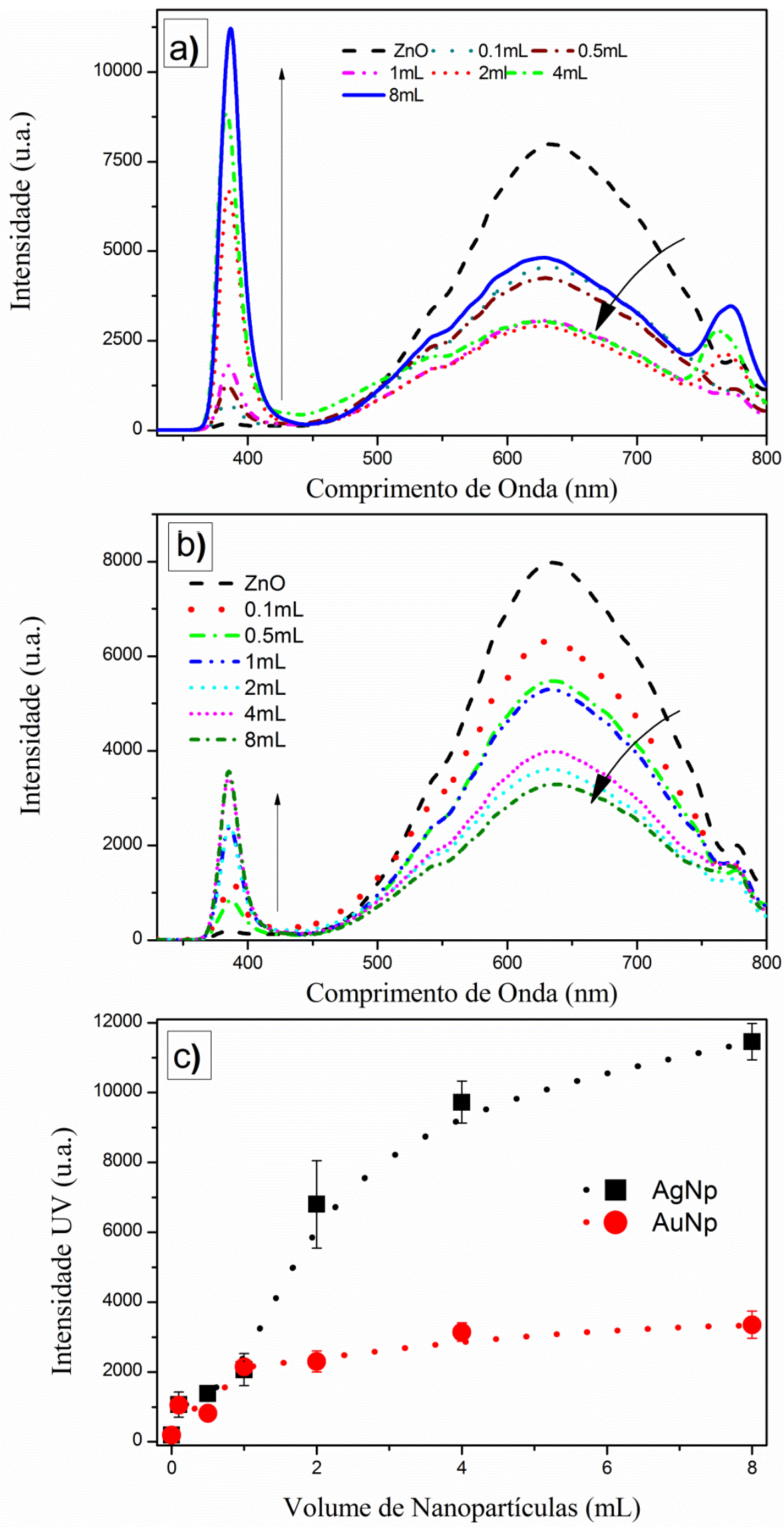

Figura 5.6: Espectro de fotoluminescência das amostras $\mathrm{ZnO} / \mathrm{Ag}$ (a) and $\mathrm{ZnO} / \mathrm{Au}$ (b) com excitação em $325 \mathrm{~nm}$. A intensidade da banda UV é proporcional à concentração de nanopartículas (c). 
A presença de nanopartículas metálicas aumenta a intensidade da banda UV e diminui a intensidade da banda na região visível. A Figura 5.6 (c) revela que o aumento da intensidade UV é proporcional à concentração de nanopartículas metálicas. $\mathrm{O}$ aumento da luminescência UV das amostras $\mathrm{ZnO} / \mathrm{Au}$ e $\mathrm{ZnO} / \mathrm{Ag}$ pode estar relacionado ao aumento do campo elétrico local próximo à superfície das nanopartículas. Uma vez que o comprimento de onda da luz é muito maior que o diâmetro das nanopartículas, a alta densidade de elétrons livres na superfície das partículas forma uma nuvem eletrônica que oscila em ressonância com o campo elétrico da luz incidente. Essa oscilação coletiva dos elétrons (ressonância plasmônica), aumenta o campo elétrico local em torno das nanopartículas metálicas.

A taxa de excitação de um centro luminescente depende do campo elétrico local da seguinte maneira [78]:

$$
\mathbf{R}_{\text {excit }} \alpha \mid \text { p. }\left.E\right|^{2}
$$

Equação 36

Onde p é o momento de dipolo e E é o campo elétrico total (campo da luz incidente + campo gerado pelos plásmons). Assim, o aumento do campo elétrico local é capaz de aumentar a excitação de elétrons para a banda de condução, aumentando a luminescência UV do óxido de zinco. Em outras palavras, o aumento da luminescência UV das amostras contendo nanopartículas metálicas seria causado pelo aumento da taxa de excitação devido à intensificação dos campos elétricos locais em torno das nanopartículas em ressonância plasmônica.

Para investigar essa hipótese, foram coletados espectros de fotoluminescência de um cristal único de óxido de zinco em função da intensidade de excitação (potência do laser). A intensidade (potência) do laser por unidade de área é proporcional ao quadrado da intensidade do campo elétrico da luz $\left(I=\frac{1}{2} c \varepsilon_{0} E^{2}\right)$ [79]. Portanto, ao aumentar a potência do laser, aumenta-se a intensidade do campo elétrico incidente no cristal. A Figura 5.7 (a) mostra o espectro (absoluto) do $\mathrm{ZnO}$ para cinco valores diferentes de potência, revelando uma relação linear da intensidade total com a potência do laser. Ao analisar a intensidade de cada espectro normalizada pela banda de defeitos, ou seja, pela intensidade em $540 \mathrm{~nm}$, observa-se que o aumento da potência do laser $\left(\propto \mathrm{E}^{2}\right)$ aumenta a intensidade relativa da banda UV. Esse resultado sugere que, sob a ação de campos elétricos de maior magnitude, a luminescência do 
óxido de zinco ocorre preferencialmente pela banda UV. Portanto, esse resultado sugere que o aumento da emissão UV para as amostras contendo nanopartículas metálicas pode ser consequência do aumento do campo elétrico local em torno das partículas.

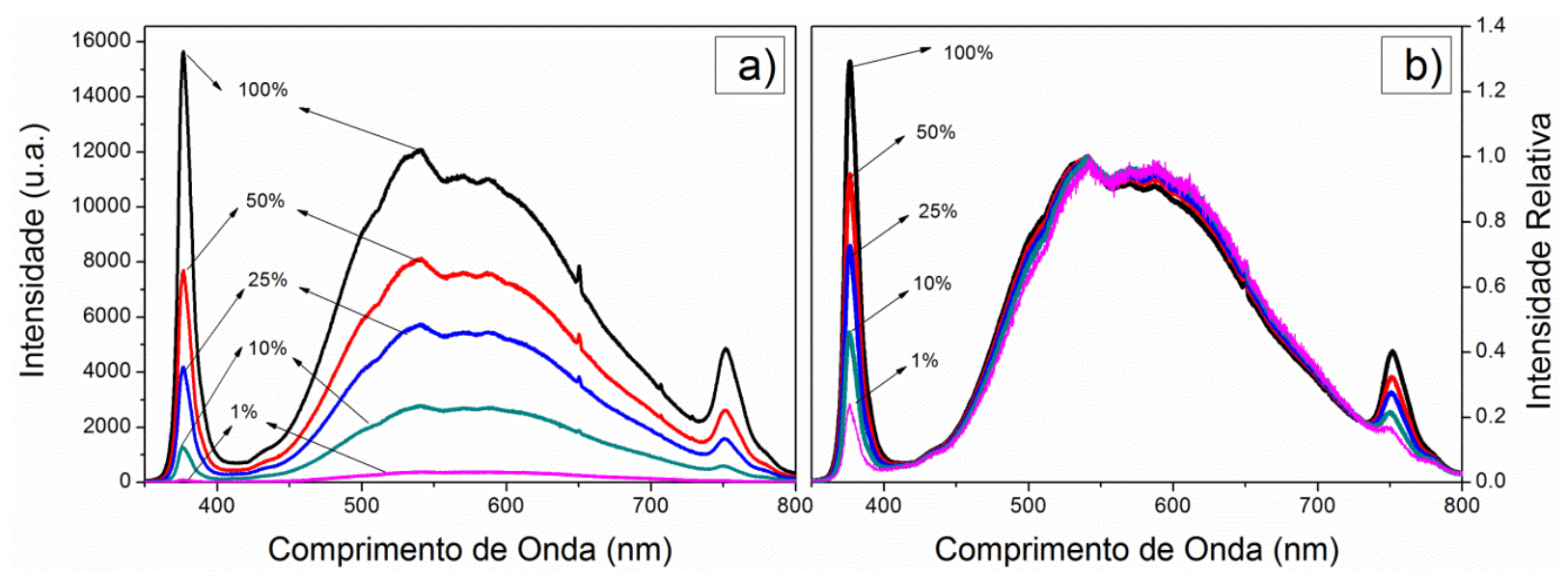

Figura 5.7: (a) Espectros de fotoluminescência para um cristal único de $\mathrm{ZnO}$ para diferentes valores de potência do laser; (b) $\mathrm{O}$ mesmo gráfico normalizado pela intensidade em $540 \mathrm{~nm}$ (banda de defeitos).

A Figura 5.8 mostra os espectros de fotoluminescência para um cristal único de $\mathrm{ZnO}$ para diferentes valores de potência do laser, normalizados pela intensidade em $540 \mathrm{~nm}$ (banda de defeitos) e também os espectros de fotoluminescência para os nanocompósitos $\mathrm{ZnO} / \mathrm{Ag}$ com diferentes concentrações de NpAgs. É possível verificar que tanto o aumento da potência do laser quanto o aumento da concentração de nanopartículas de prata, causam um deslocamento do espectro para menores comprimentos de onda, sugerindo mais uma vez que os efeitos causados pelo aumento da concentração de nanopartículas de prata nas propriedades luminescentes do $\mathrm{ZnO}$ são consequência do aumento dos campos elétricos locais em torno das nanopartículas metálicas.

Deslocamentos dos espectros de fotoluminescência em função do aumento da potência de excitação têm sido reportados na literatura. $O$ deslocamento do espectro de fotoluminescência do $\mathrm{ZnO}$ para maiores comprimentos de onda em função do aumento da potência de excitação foi relatado com sendo decorrente do aumento local de temperatura em função da maior potência do laser de excitação [80]. Porém, esse não é o caso observado aqui, visto que o espectro se desloca para menores comprimentos de onda. De acordo com a literatura, o deslocamento do espectro de fotoluminescência para menores comprimentos de onda ocorre porque, devido ao aumento da potência de excitação, mais cargas conseguem preencher os níveis de defeitos de maior energia [81]. 

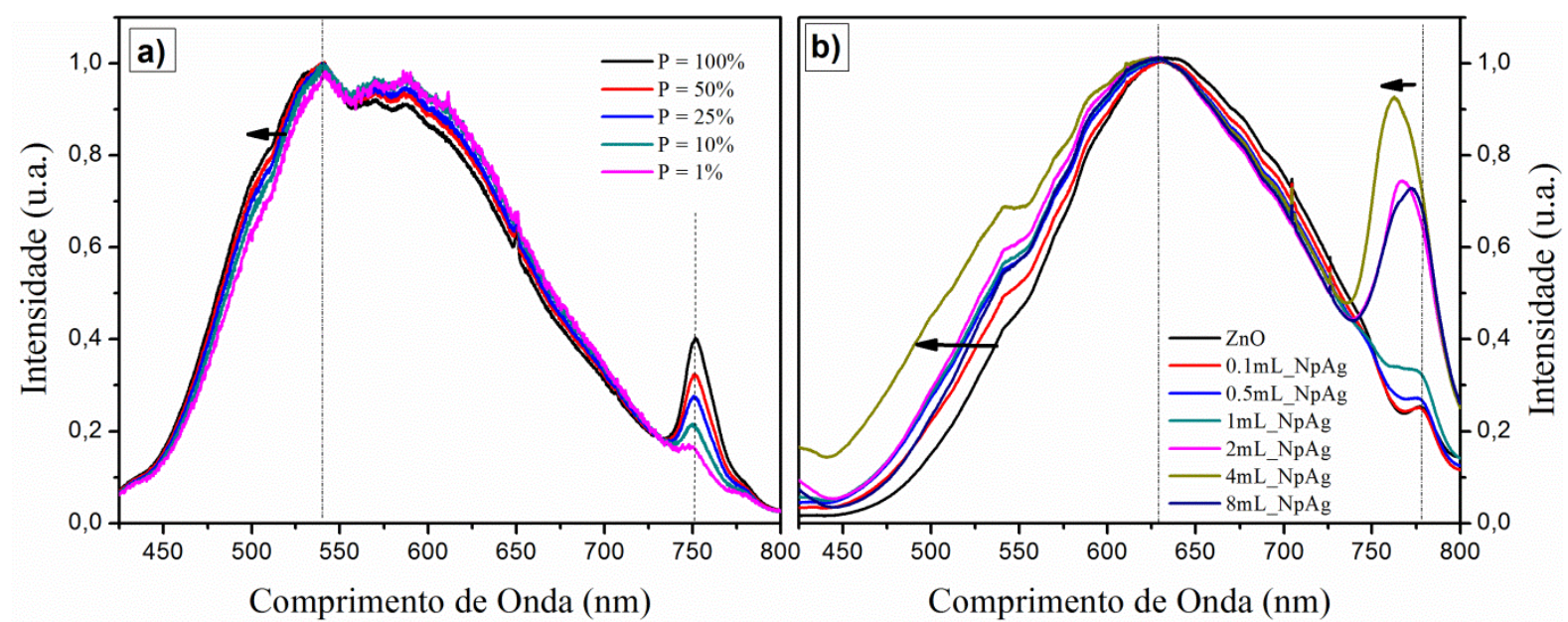

Figura 5.8:(a) Espectros de fotoluminescência para um cristal único de $\mathrm{ZnO}$ para diferentes valores de potência do laser, normalizados pela intensidade em $540 \mathrm{~nm}$ (banda de defeitos). (b) Espectros de fotoluminescência para os nanocompósitos $\mathrm{ZnO} / \mathrm{Ag}$ com diferentes concentrações de NpAg. É possível verificar que tanto o aumento da potência do laser quanto o aumento da concentração de nanopartículas de prata, causam um deslocamento do espectro para menores comprimentos.

Logo, tanto o aumento da potência de excitação do laser, quanto o aumento da concentração de nanopartículas de prata, aumenta a densidade de campos elétricos no óxido de zinco, aumentando a intensidade UV, a intensidade relativa UV/defeito, e deslocando o espectro de fotoluminescência para menores comprimento de onda.

Uma vez que os nanocompósitos $\mathrm{ZnO} / \mathrm{Ag}$ apresentaram maior intensidade luminescente que os nanocompósitos $\mathrm{ZnO} / \mathrm{Au}$, os estudos e caracterizações descritos à seguir serão concentrados nas amostras contendo nanopartículas de prata.

\subsection{Luminescência Resolvida no Tempo}

A Figura 5.9 mostra o decaimento da luminescência no comprimento de onda de 385 $\mathrm{nm}$, das amostras de $\mathrm{ZnO}, 2 \mathrm{~mL} \_N p A g$ e 8mL_NpAg, com excitação em $308 \mathrm{~nm}$. Verifica-se um decaimento mais rápido para as amostras contendo nanopartículas de prata, comparado à amostra de $\mathrm{ZnO}$ puro. Essas curvas foram melhor ajustadas por um decaimento biexponencial, e os valores dos tempos de vida encontrados estão na Tabela 5.1. De acordo com a literatura, a componente rápida do tempo de vida $\left(\tau_{1}\right)$ é atribuída à recombinações não radiativas e armadilhamento de cargas, e a componente lenta $\left(\tau_{2}\right)$ corresponde à recombinação radiativa de éxcitons livres do $\mathrm{ZnO}$ [82-84]. 


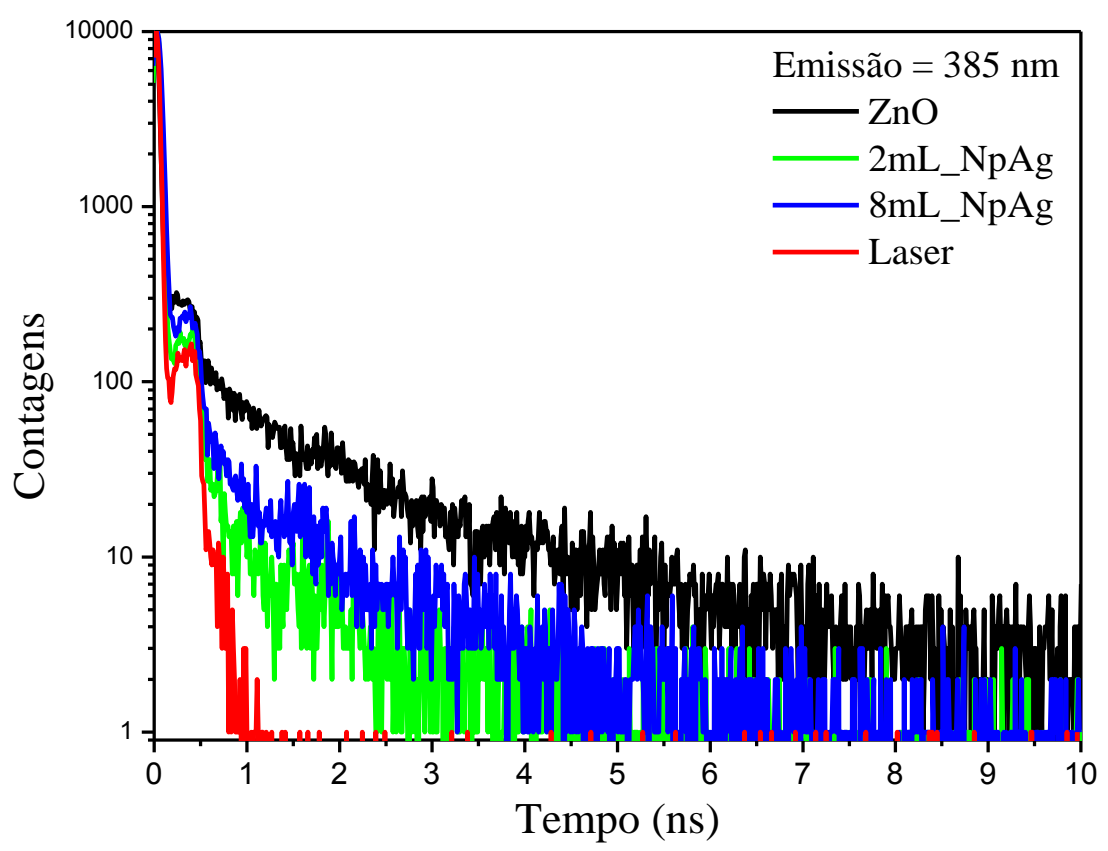

Figura 5.9: Decaimento da luminescência no comprimento de onda de $385 \mathrm{~nm}$, das amostras de $\mathrm{ZnO}, 2 \mathrm{~mL} \_N p A g$ e 8mL_NpAg, com excitação em $308 \mathrm{~nm}$.

A Tabela 5.1 mostra os valores dos tempos de vida obtidos pelo ajuste das curvas de decaimento da luminescência. O tempo de vida mais curto é da ordem de picosegundos, enquanto o tempo de vida mais longo é da ordem de nanosegundos, o que está de acordo com os valores encontrados na literatura [82]. Nota-se um aumento do tempo de vida mais curto $\left(\tau_{1}\right)$, e que está relacionado às transições não radiativas, e uma redução do tempo de vida mais longo $\left(\tau_{2}\right)$, associado a transições radiativas.

A redução do tempo de vida das transições radiativas é uma característica da emissão acoplada aos plásmons. Nesse caso, o aumento da luminescência ocorre por meio de uma transferência de energia do centro luminescente (éxcitons do $\mathrm{ZnO}$ ) para os plásmons que, por sua vez, irradiam a energia recebida em campo distante [38]. Dessa forma, como o tempo de vida das oscilações plasmônicas é da ordem de femtosegundos [36-37] e, de maneira geral, o tempo de vida dos centros luminescentes varia entre pico e milisegundos, o aumento da luminescência é acompanhado da redução do tempo de vida da emissão luminescente. Devido ao fato de que os fótons emitidos carregam características tanto do centro luminescente quanto dos plásmons, fica difícil identificar qual espécie está emitindo. Por isso, na literatura, denomina-se como plasmóforo [37] esse sistema de luminescência acoplado entre o centro luminescente (luminóforo) e os plásmons, apresentando propriedades tanto do luminóforo quanto do metal [37]. 
Tabela 5.1: Tempos de vida obtidos pelo ajuste das curvas de decaimento da luminescência presentes na Figura 5.9 .

\begin{tabular}{ccc}
\hline Amostra & $\tau_{1}$ (ps) & $\tau_{\mathbf{2}}$ (ns) \\
\hline ZnO & 12 & 1.57 \\
2mL_NpAg & 15 & 1.017 \\
8mL_NpAg & 19 & 1.045 \\
\hline
\end{tabular}

De acordo com a literatura, o aumento da luminescência originado pelo aumento dos campos elétricos em torno das nanopartículas metálicas ocorre para distâncias muito curtas entre a nanopartícula e o luminóforo (em geral d $\leq 10 \mathrm{~nm}$ ) [85]. Já os processos de transferência de energia do centro luminescente para os plásmons podem ocorrer para distâncias de até $400 \mathrm{~nm}$ [36]. Logo, em teoria, o aumento da luminescência por interação plasmônica pode ocorrer para um raio de até $400 \mathrm{~nm}$ na região central das partículas de $\mathrm{ZnO}$ em torno das nanopartículas metálicas.

\subsection{Radioluminescência}

Os resultados apresentados até aqui sugerem que o aumento de luminescência pode estar relacionado tanto ao aumento do campo elétrico próximo às nanopartículas metálicas em ressonância plasmônica, durante o processo de excitação, quanto ao processo de transferência de energia do centro luminescente para os plásmons de superfície, durante o processo de emissão. Nesse sentido, uma vez que a radioluminescência informa a respeito do espectro de emissão luminescente das amostras por meio da excitação com raios-x, ela pode ajudar a distinguir qual dos dois processos (excitação e/ou emissão) é responsável pelo aumento da intensidade da banda UV e pela redução da intensidade da banda de defeitos do ZnO. Isso porque, na radioluminescência, a excitação da amostra não ocorre com comprimentos de onda que se sobreponham à banda de ressonância plasmônica das nanopartículas.

A Figura 5.10 mostra os espectros de radioluminescência das amostras de ZnO e 8mL_NpAg. Os espectros de emissão radioluminescente das duas amostras são bastante similares a seus respectivos espectros de fotoluminescência, indicando que os mesmos centros luminescentes participam dos dois processos de radio e fotoluminescência. É possível 
observar um aumento da intensidade da banda UV para a amostra contendo nanopartículas de prata, comparada a amostra de $\mathrm{ZnO}$ puro. Porém, o aumento da intensidade UV nos espectros de radioluminescência não é tão expressivo quanto nos espectros de fotoluminescência. Logo, uma vez que as amostras são excitadas com raios-x e portanto não há oscilação plasmônica durante o processo de excitação, esse resultado reforça a hipótese de que o aumento da banda UV é, pelo menos parcialmente, originado pela transferência de energia entre o centro luminescente e os plásmons, como sugerido pelas curvas de decaimento da luminescência.

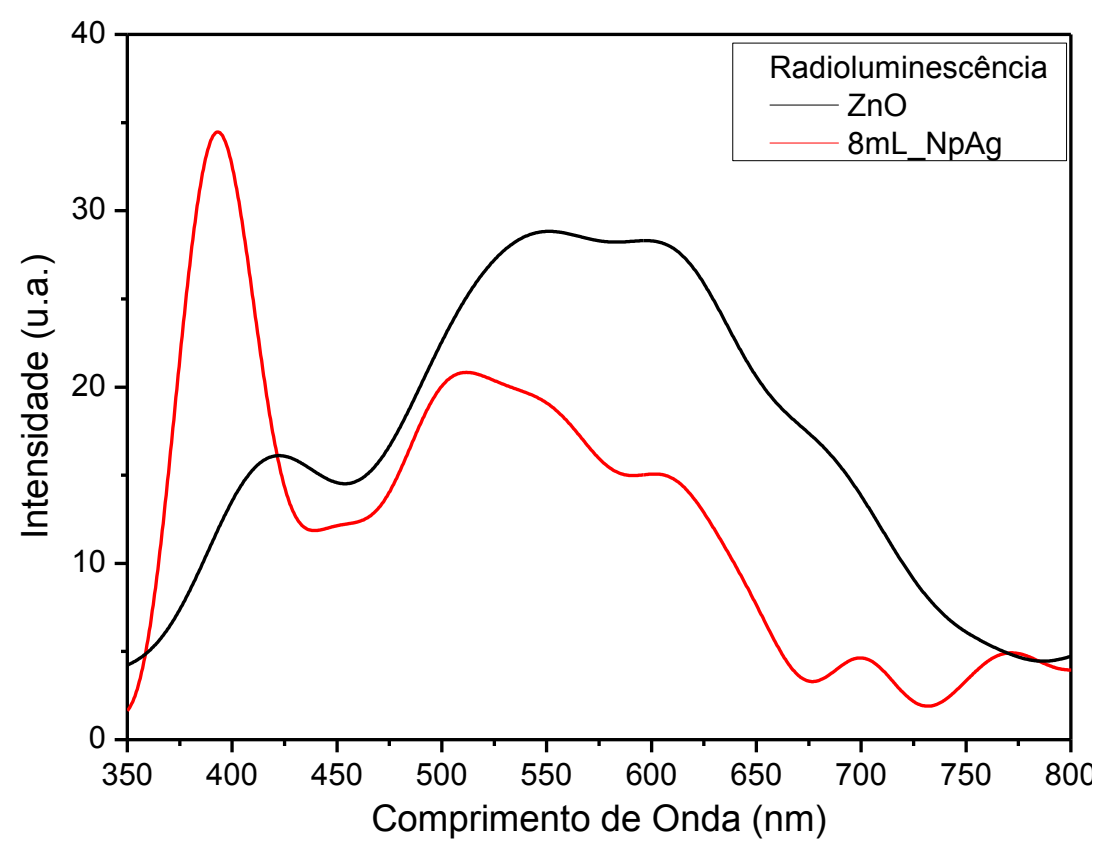

Figura 5.10: Espectro de emissão radioluminescente das amostras de $\mathrm{ZnO}$ e $8 \mathrm{~mL} \_\mathrm{NpAg}$.

É possível notar também que há uma redução da banda de defeitos da amostra 8mL_NpAg em relação a amostra de $\mathrm{ZnO}$ nos espectros de radioluminescência, assim como observado nos espectros de fotoluminescência (Figura 5.6). Logo, a redução da intensidade da banda de defeitos nos espectros de fotoluminescência pode estar associada à absorção (atenuação), causada pela banda de ressonância plasmônica, dos fótons emitidos pelos defeitos do $\mathrm{ZnO}$.

\subsection{Luminescência Opticamente Estimulada}

As amostras foram testadas como dosímetros das radiações por meio da luminescência opticamente estimulada. Inicialmente, as amostras de $\mathrm{ZnO}$ puro e com as diferentes 
concentrações de nanopartículas de prata foram irradiadas com um feixe de raios-X de 48 kVp e dose de 500 Gy. Em seguida, as curvas OSL foram obtidas com a intuito de investigar a influência da concentração de nanopartículas de prata na intensidade da luminescência opticamente estimulada. A Figura 5.11 mostra a curva OSL para as amostras ZnO, 2mL_NpAg e 8mL_NpAg. É possível observar que o decaimento OSL possui duas componentes de decaimento, sendo uma primeira componente muito rápida, decaindo em cerca de $1 \mathrm{~s}$, e uma segunda componente mais longa, caracterizada pela longa cauda que se estende até o final da medida. Esse resultado pode indicar a contribuição de armadilhas com diferentes seções de choque de fotoionização [86-87], visto que armadilhas com pequena seção de choque de fotoionização demoram mais para serem esvaziadas.

Em geral, a longa cauda da curva OSL está relacionada à presença de armadilhas rasas e pouco estáveis, decaindo com o próprio estímulo térmico em temperatura ambiente [4] e é comumente denominada de fosforescência em livros e artigos de dosimetria $[4,15]$, embora essa terminologia não seja adequada. Isso porque o termo fosforescência refere-se a uma transição onde o elétron no orbital do estado excitado possui a mesma orientação de spin do elétron ocupando o orbital do estado fundamental. Como essa transição é proibida, a taxa de emissão é lenta, e por isso os tempos de emissão da fosforescência são geralmente longos [42]. Devido a esse maior tempo de emissão, é que a longa cauda da curva OSL é denominada fosforescência, embora não se trate necessariamente de uma transição envolvendo mudança de spin eletrônico.

A Figura 5.11 revela um aumento da intensidade OSL à medida que aumenta a concentração de nanopartículas de prata. O inset na Figura 5.11 mostra a intensidade OSL (integral) em função do volume de nanopartículas de prata utilizado. Os comportamentos das curvas da intensidade OSL e da fotoluminescência (Figura 5.6 e Figura 5.11, respectivamente) em função do volume de nanopartículas de prata, são similares, tendendo a um patamar de saturação para volumes de nanopartículas de prata acima de $2 \mathrm{~mL}$. Esse resultado sugere que o aumento da intensidade OSL pode estar relacionado à maior intensidade de luminescência da banda UV do óxido de zinco contendo nanopartículas de prata. Um aumento em torno de 2.5 vezes foi obtido para a amostra $8 \mathrm{~mL} \_\mathrm{NpAg}$. 


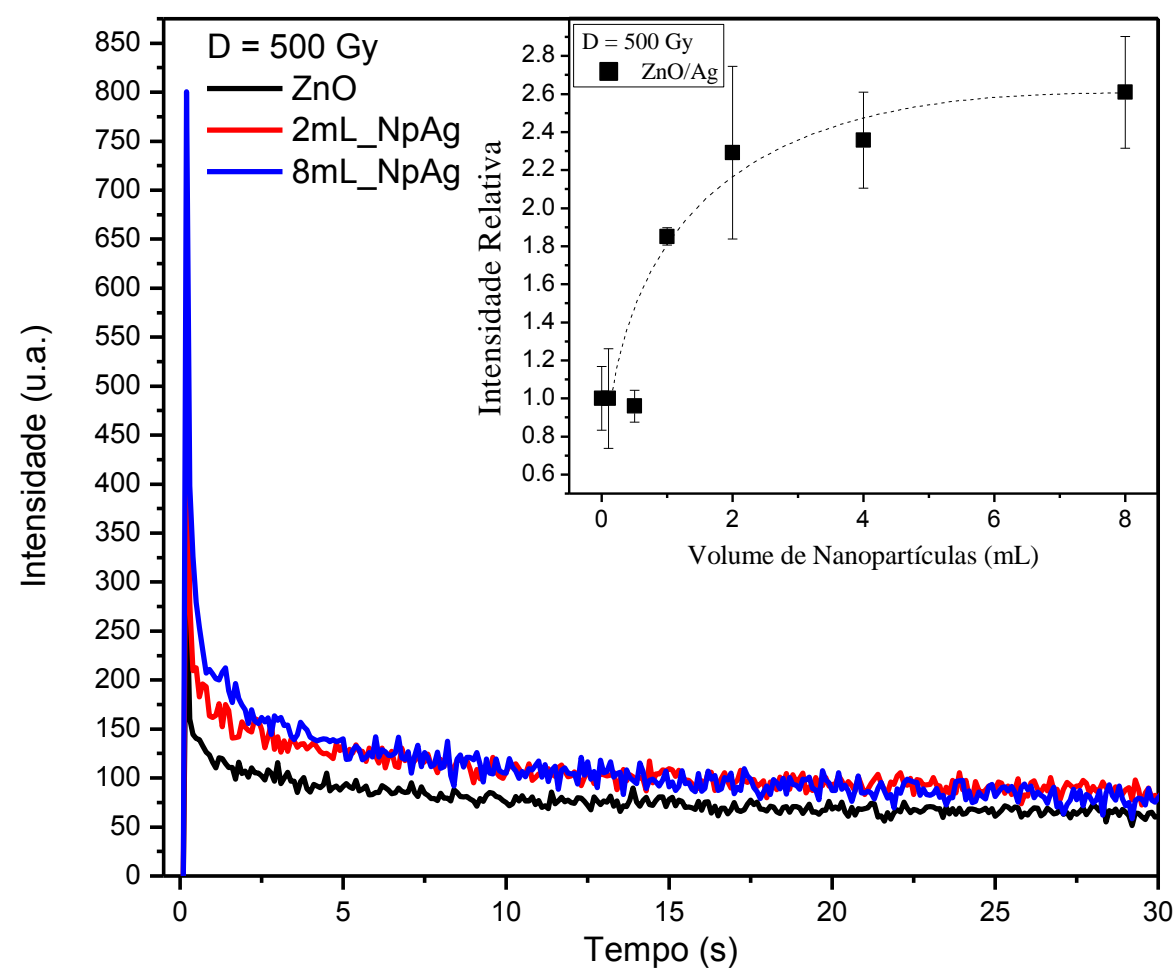

Figura 5.11: Curva OSL das amostras de $\mathrm{ZnO}$ puro, $2 \mathrm{~mL} \_N p A g$ e $8 \mathrm{~mL} \_N p A g$ irradiadas com 500 Gy. O inset revela o comportamento da intensidade OSL (integral) em função do volume de nanopartículas de prata presente em cada amostra.

A luminescência opticamente estimulada envolve a emissão de luz por elétrons que permanecem armadilhados em defeitos do $\mathrm{ZnO}$ após a exposição aos raios-X. No caso do $\mathrm{ZnO}$, a emissão desses defeitos ocorre na região entre 450-800 nm, como indicado pelos espectros de fotoluminescência. No entanto, a emissão OSL é detectada somente para comprimentos de onda menores que $390 \mathrm{~nm}$, sugerindo que apenas a emissão UV do ZnO contribui para a curva OSL. Logo, o aumento da intensidade OSL observado pode ser resultado da maior excitação de elétrons armadilhados em defeitos, devido ao aumento do campo elétrico local em torno das nanopartículas metálicas em ressonância plasmônica, fazendo com que eles retornem para a banda de condução e recombinem, dando origem à emissão UV.

Com o intuito de diminuir a influência da componente mais lenta da curva OSL dos nanocompósitos de $\mathrm{ZnO} / \mathrm{Ag}$, as curvas OSL foram tratadas de forma a eliminar a longa cauda do sinal OSL. As curvas obtidas estão na Figura 5.12. O inset na Figura 5.12 revela a intensidade da curva OSL em função do volume de nanopartículas de prata presente em cada amostra, revelando o aumento da intensidade OSL com o aumento do volume de nanopartículas de prata, mesmo após a eliminação da componente lenta das curvas. O 
aumento da intensidade OSL para a amostra 8mL_NpAg foi de 2.1 vezes, valor muito próximo e dentro da incerteza do valor obtido quando considerado toda a curva OSL.

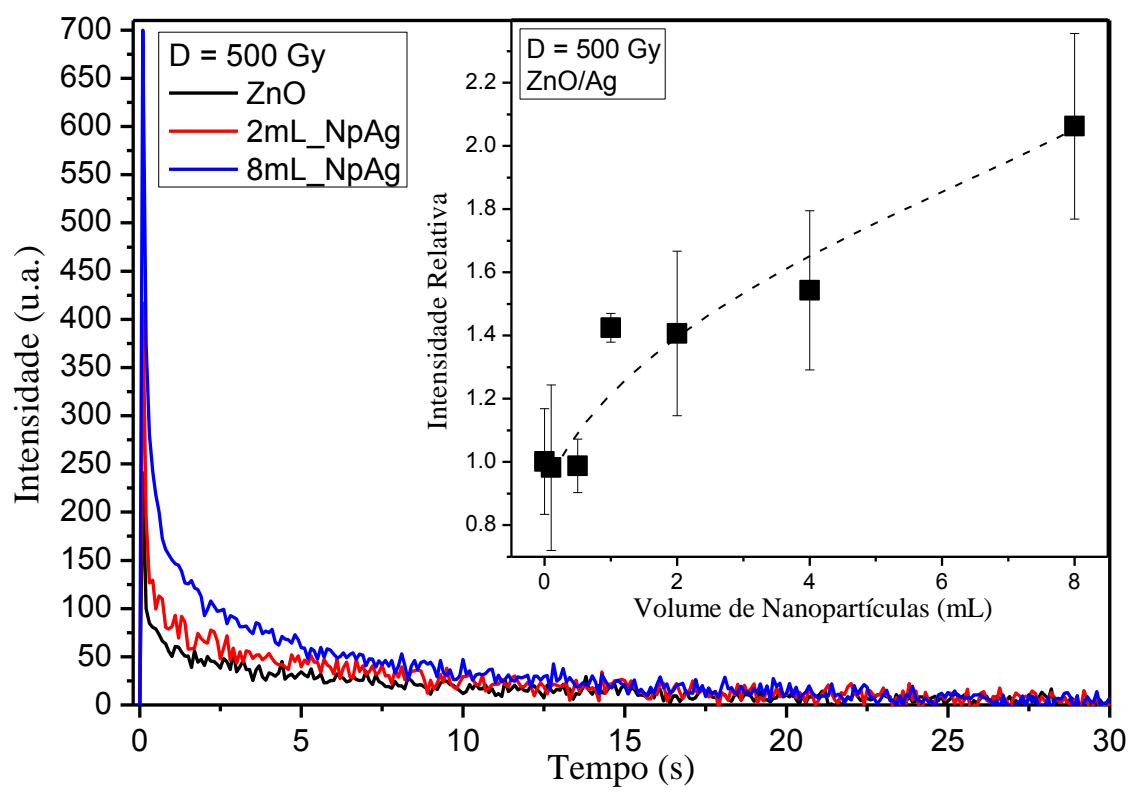

Figura 5.12: Sinal OSL das amostras $\mathrm{ZnO}, 2 \mathrm{~mL} \_N p A g$ e $8 \mathrm{~mL} \_N p A g$, irradiados com $500 \mathrm{~Gy}$. O inset mostra a integral da curva OSL em função do volume de nanopartículas de prata.

\subsubsection{Variação na Forma da Curva OSL}

A Figura 5.13 mostra as curvas OSL normalizadas, para as amostras de $\mathrm{ZnO}$, $1 \mathrm{~mL} \_N p A g, 2 \mathrm{~mL} \_N p A g$ e $8 \mathrm{~mL} \_N p A g$, revelando uma tendência de decaimento mais rápido da curva OSL à medida que aumenta a concentração de nanopartículas de prata no $\mathrm{ZnO}$. O inset na Figura 5.13 corresponde a uma ampliação de uma região da Figura 5.13, para uma melhor visualização do decaimento OSL mais rápido. A Figura 5.14 mostra as curvas OSL das amostras de $\mathrm{ZnO}$ puro e 8mL_NpAg irradiadas com $1000 \mathrm{~Gy}$, onde o decaimento mais rápido para a amostra contendo nanopartículas de prata é ainda mais evidente. 


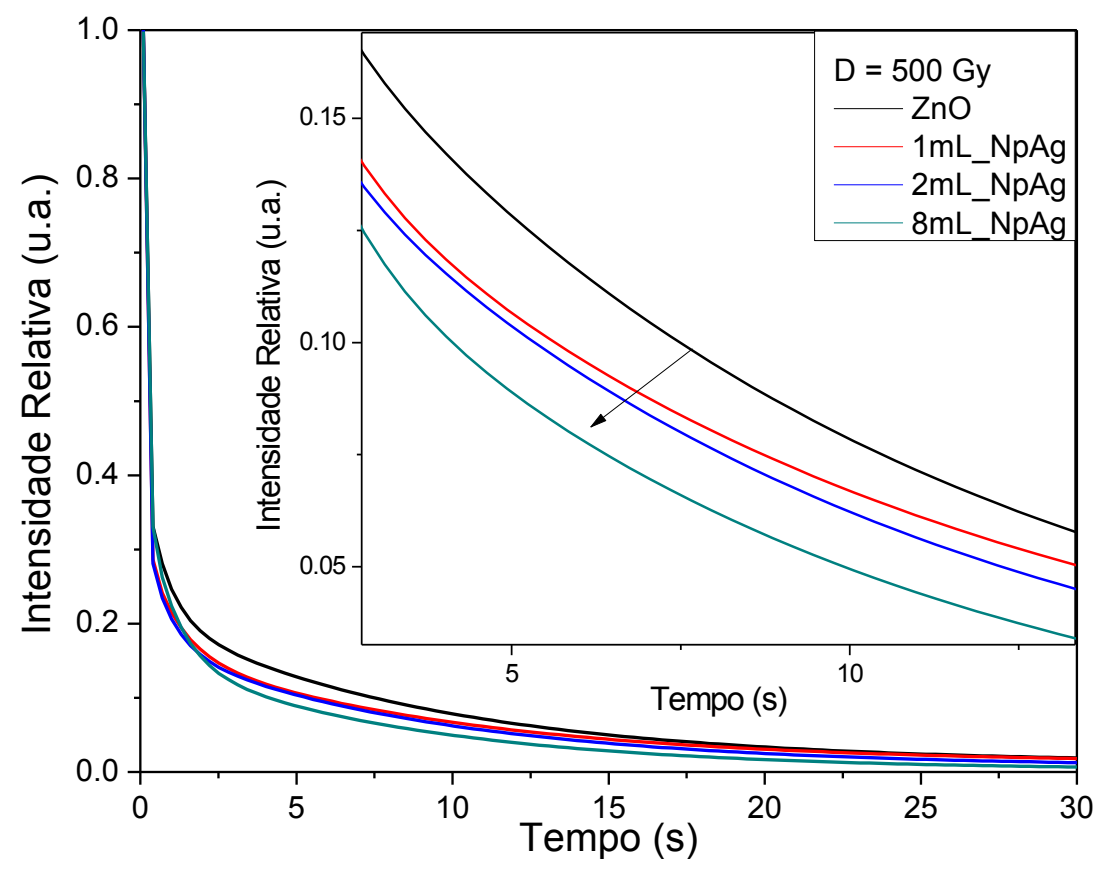

Figura 5.13: Curvas OSL das amostras de $\mathrm{ZnO}$ puro, $1 \mathrm{~mL} \_\mathrm{NpAg}, 2 \mathrm{~mL} \_\mathrm{NpAg}$ e $8 \mathrm{~mL} \_\mathrm{NpAg}$, irradiadas com 500 Gy e normalizadas pela intensidade OSL inicial. É possível verificar um decaimento mais rápido da curva OSL à medida que aumenta a concentração de nanopartículas de prata.

De acordo com a literatura, o aumento da intensidade da luz de estimulação OSL $\left(\propto E^{2}\right)$ de uma dada amostra aumenta a intensidade OSL inicial e torna o decaimento da curva OSL mais rápido, de forma que o valor da integral da curva OSL ( $\propto$ dose) é mantido constante [4]. As duas primeiras características são as mesma observadas para as amostras de $\mathrm{ZnO}$ contendo nanopartículas de prata: $\mathrm{O}$ aumento da concentração de nanopartículas de prata aumenta a intensidade OSL inicial, e torna o decaimento da curva OSL mais rápido. Como a intensidade da luz de excitação é a mesma para todas as amostras, esse resultado está em concordância com os resultados observados nos espectros de fotoluminescência, sugerindo que o aumento da concentração de nanopartículas de prata causa um aumento da intensidade do campo elétrico em torno das nanopartículas. Assim, devido ao aumento dos campos elétricos locais em torno das nanopartículas em ressonância plasmônica, os elétrons são desarmadilhados de forma mais eficiente, aumentando a intensidade OSL inicial e tornando mais rápido o decaimento da curva OSL. 


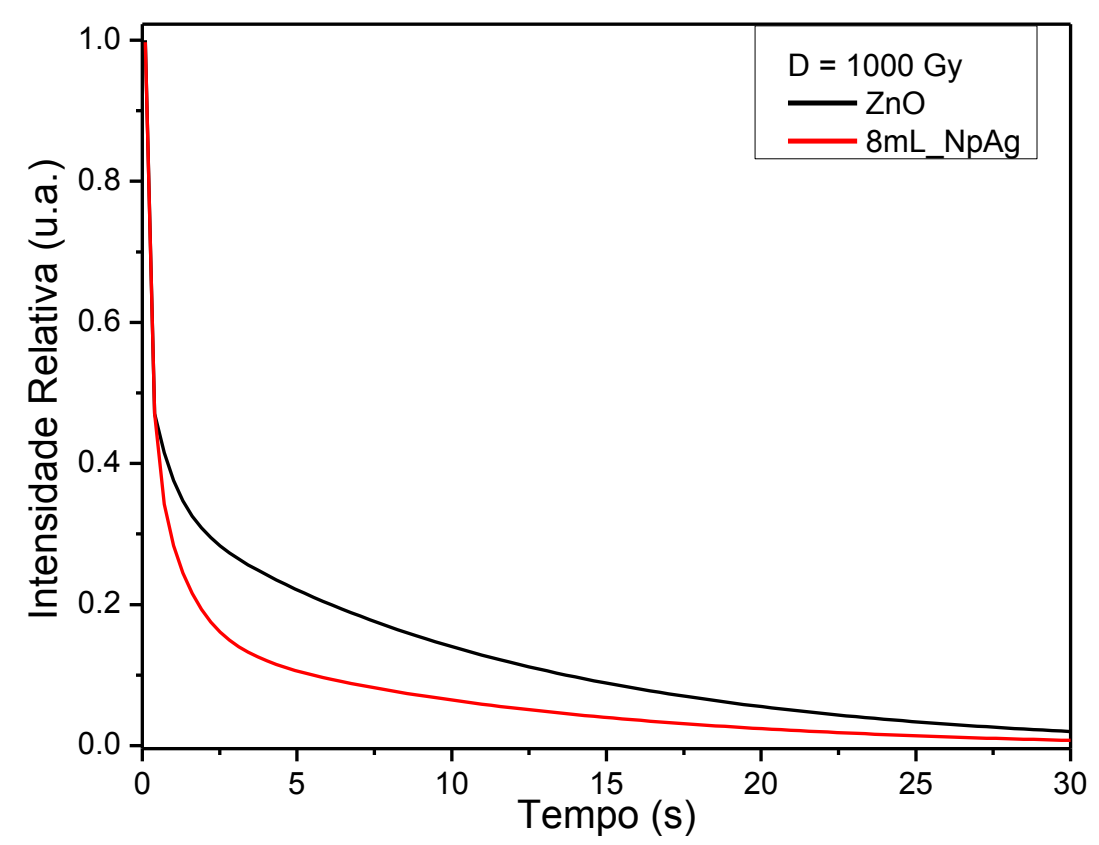

Figura 5.14: Curvas OSL das amostras de $\mathrm{ZnO}$ puro e $8 \mathrm{~mL} \_N p A g$, irradiadas com $1000 \mathrm{~Gy}$, normalizadas pela intensidade OSL inicial. O decaimento mais rápido para a amostra contendo nanopartículas de prata é ainda mais evidente.

Além disso, a maior eficiência de luminescência da banda UV, devido ao possível mecanismo de transferência de energia do centro luminescente para os plásmons, pode colaborar para o aumento da intensidade OSL, diminuindo a probabilidade de que os elétrons já excitados para a banda de condução decaiam de forma não radiativa e/ou sejam rearmadilhados na banda proibida. Esse pode ser o motivo pelo qual houve aumento do valor da integral da curva OSL com o aumento da concentração de nanopartículas de prata. Portanto, o aumento do campo elétrico local causado pelas nanopartículas em ressonância plasmônica é responsável pelo aumento da intensidade OSL inicial e pelo decaimento mais rápido da curva OSL, enquanto que a transferência de energia do centro luminescente para os plasmons é responsável pelo aumento do valor da integral da curva OSL.

A Figura 5.15 mostra as curvas OSL da amostra 8mL_NpAg irradiadas com diferentes doses, evidenciando que, como esperado, há um aumento da intensidade OSL em função da dose devido ao maior número de cargas armadilhadas. $\mathrm{O}$ aumento da dose de radiação causa tanto aumento da intensidade inicial quanto da integral da curva OSL. 


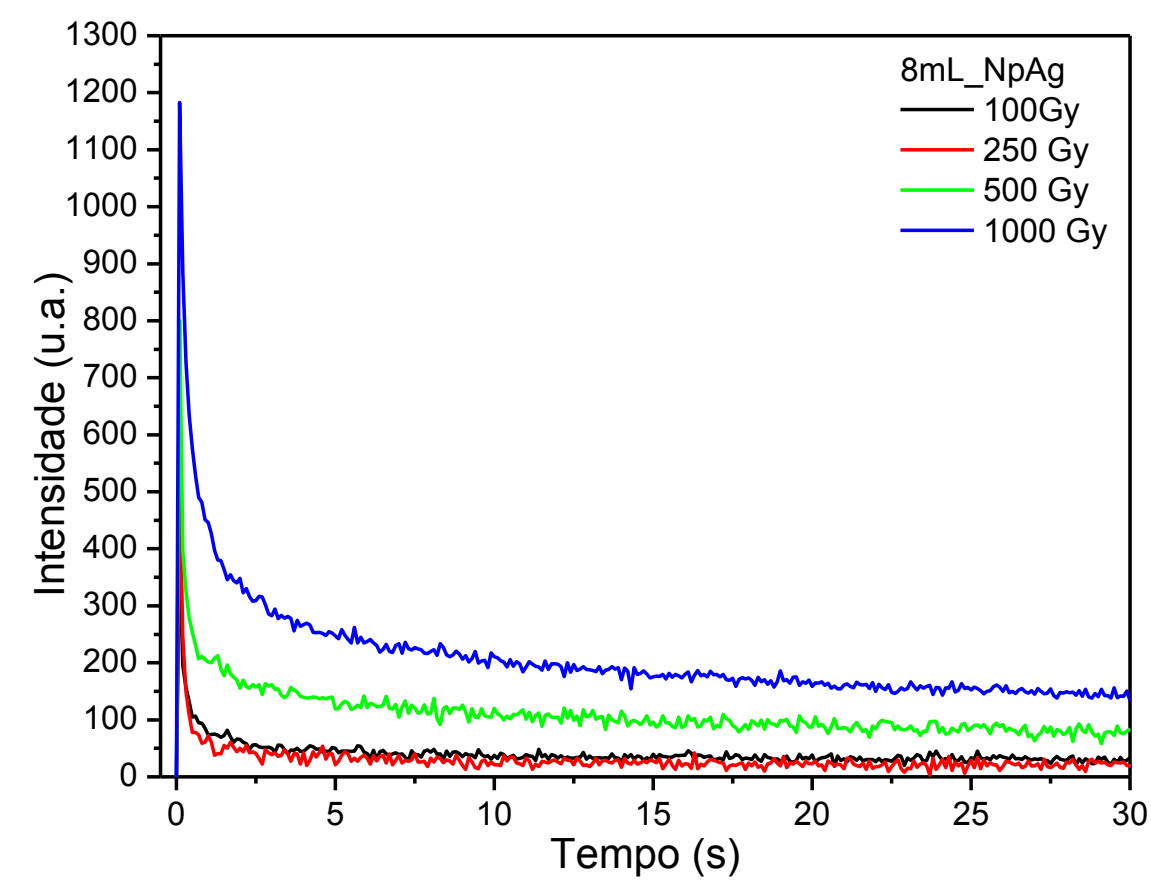

Figura 5.15: Curvas OSL da amostra $8 \mathrm{~mL} \_N p A g$ irradiada com diferentes doses.

A Figura 5.16 (a) mostra as curvas OSL, normalizadas pela intensidade OSL inicial, para a amostra 8mL_NpAg irradiada com 100, 250, 500 e 1000 Gy, revelando um decaimento mais lento à medida que aumenta a dose depositada. Distorções na forma da curva OSL são também observadas para $\mathrm{o} \mathrm{Al}_{2} \mathrm{O}_{3}: \mathrm{C}$ para doses acima de $10 \mathrm{~Gy}$, devido à maior contribuição de armadilhas com maior seção de choque de fotoionização, aumentando a taxa de decaimento da curva OSL [86]. Nesse sentido, a razão para o decaimento mais lento das curvas OSL do $\mathrm{ZnO}$ irradiado com doses mais altas de radiação seria a maior contribuição de armadilhas com menor seção de choque de fotoionização, aumentando a intensidade da cauda da curva OSL. Assim, com o intuito de diminuir a influência da componente mais lenta da curva OSL dos nanocompósitos de $\mathrm{ZnO} / \mathrm{Ag}$, foi subtraído o valor da intensidade da cauda da curva OSL, ou seja, o valor da intensidade OSL para o tempo de estimulação de 30s (Figura 5.16 (b)). É possível observar que mesmo após a eliminação da componente de fundo, as curvas OSL tendem a apresentar um decaimento mais lento para maiores doses de radiação.

Aqui é importante ressaltar que o aumento da concentração de nanopartículas de prata causa um decaimento mais rápido da curva OSL (maior taxa de decaimento) enquanto o aumento da dose depositada na amostra torna o decaimento mais lento (menor taxa de decaimento). Assim, pode-se inferir que o aumento da intensidade OSL observado em função do aumento da concentração de nanopartículas de prata não é causado pelo aumento do coeficiente mássico de absorção da radiação, devido ao maior número atômico da prata. Além 
disso, o valor estimado para o aumento de dose devido a inserção de átomos de prata no óxido de zinco, calculado pela regra das misturas de Bragg, seria de apenas $0.6 \%$ para a amostra contendo $8 \mathrm{~mL}$ de nanopartículas de prata e considerando a energia efetiva do feixe de raios$\mathrm{X}$ como sendo $10 \mathrm{keV}$.
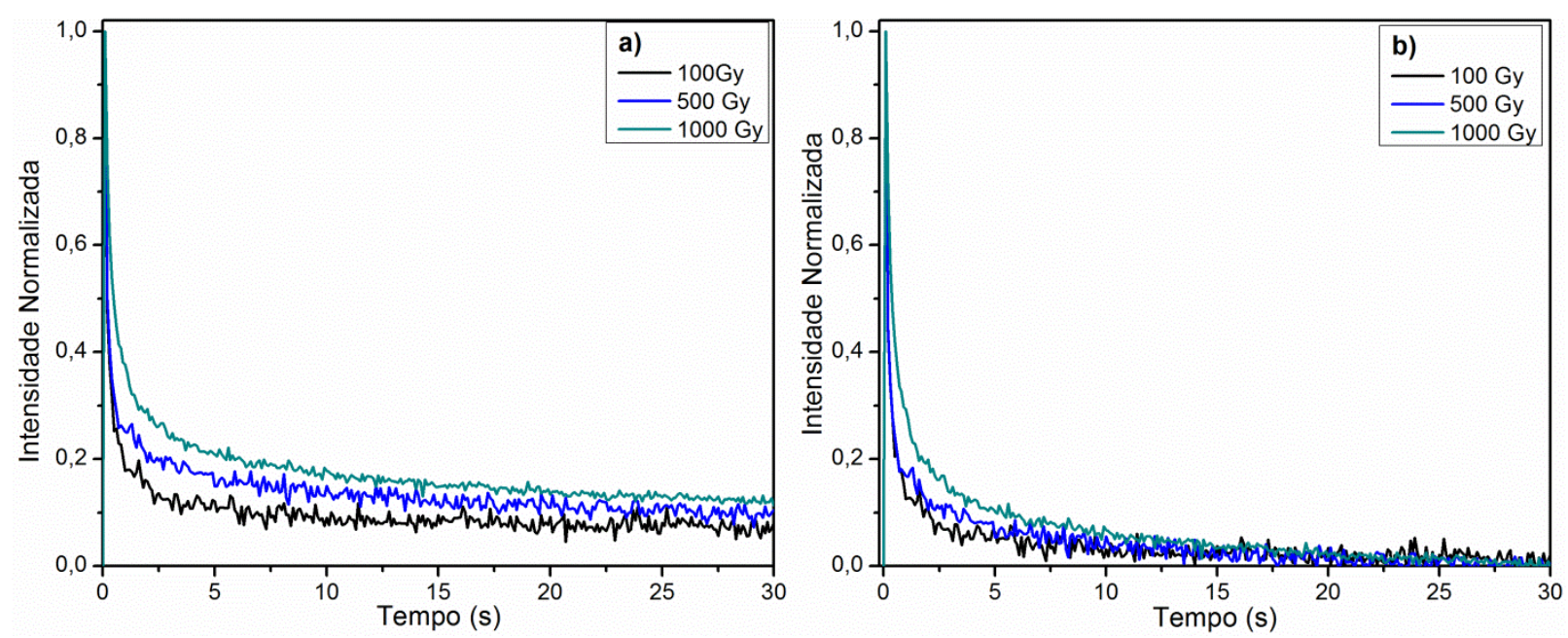

Figura 5.16: Curvas OSL da amostra $8 \mathrm{~mL} \_\mathrm{NpAg}$, normalizadas pela intensidade inicial, e irradiadas com doses de 100, 500 e 1000 Gy (a). As curvas no item (b) correspondem as mesmas curvas do item (a) porém com a subtração do sinal de fundo.

A Figura 5.17 mostra a curva dose resposta das amostras de $\mathrm{ZnO}$ e 8mL_NpAg irradiadas com doses de 100 a 1000 Gy. É possível observar que a curva dose resposta do $\mathrm{ZnO}$ não é linear, e este resultado está de acordo com o reportado na literatura $[67,88]$. Assim como o $\mathrm{ZnO}$ puro, a amostra 8mL_NpAg também apresenta um comportamento não linear para a curva dose-reposta. Assim, pode-se concluir que as nanopartículas de prata agem como amplificadores da intensidade da emissão luminescente, porém não alteram as características luminescentes típicas do material emissor. Essa é uma propriedade característica da luminescência acoplada aos plásmons [36, 38]. 


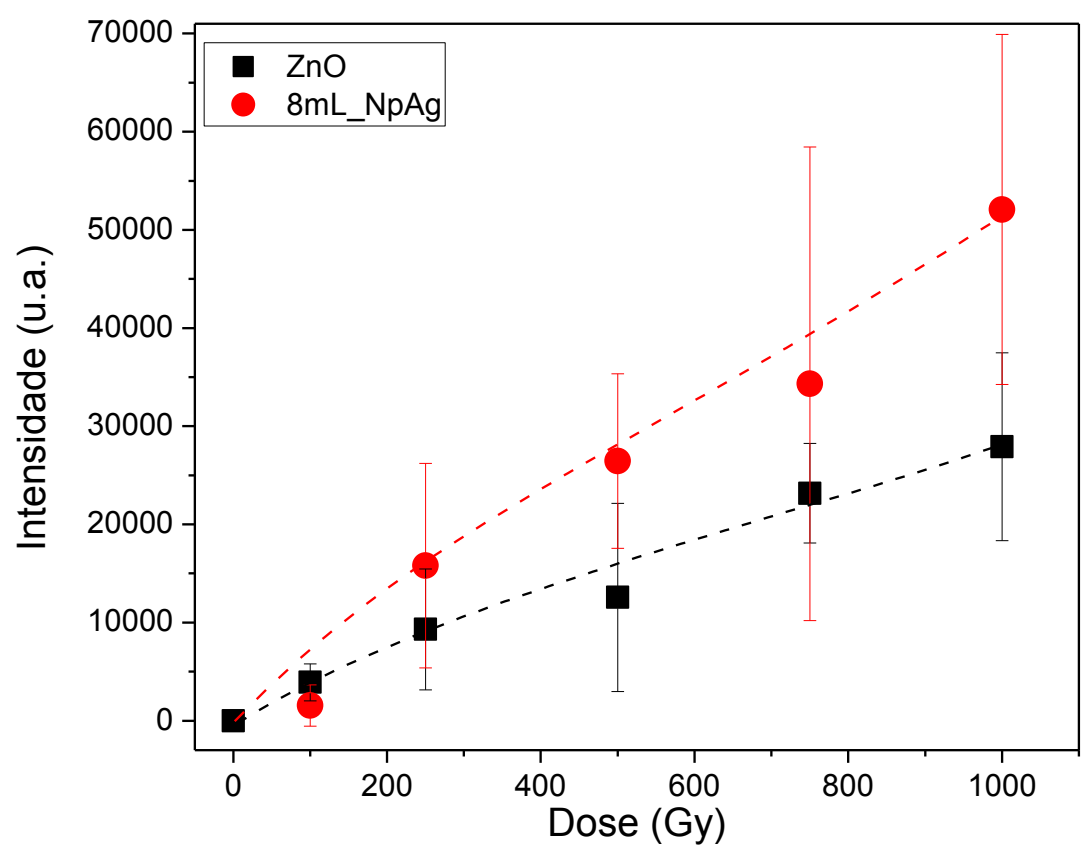

Figura 5.17: Curva dose-resposta para as amostras de $\mathrm{ZnO}$ puro e 8mL_NpAg

\subsubsection{Influência do Substrato}

Uma vez que os filmes de $\mathrm{ZnO}$ foram produzidos em substratos de vidro e por terem sido utilizadas altas doses de radiação, é pertinente verificar se a luminescência opticamente estimulada observada não é produzida pelo substrato vítreo. Para isso, alguns filmes da amostra 8mL_NpAg foram removidos e o substrato de vidro foi lavado. Em seguida, essas amostras de vidro foram irradiadas com doses de 100 a $1000 \mathrm{~Gy}$, e as curvas OSL foram coletadas. A Figura 5.18 mostra a curva OSL obtida para o substrato de vidro irradiado com uma dose de $500 \mathrm{~Gy}$, junto com a curva OSL da amostra 8mL_NpAg, para fins comparativos. É possível observar que a curva OSL do vidro possui um decaimento muito mais longo do que a curva OSL da amostra 8mL_NpAg. A intensidade inicial do vidro é cerca de metade da intensidade inicial da amostra $8 \mathrm{~mL} \_\mathrm{NpAg}$, porém, a intensidade do vidro torna-se mais intensa para tempos maiores de estimulação, devido ao longo tempo de decaimento, o que dá origem a uma longa cauda na curva OSL. Assim, dada a grande diferença dos tempos de decaimento da curva OSL, fica evidente que o sinal observado para as amostras de ZnO não é originado pelo substrato vítreo. 


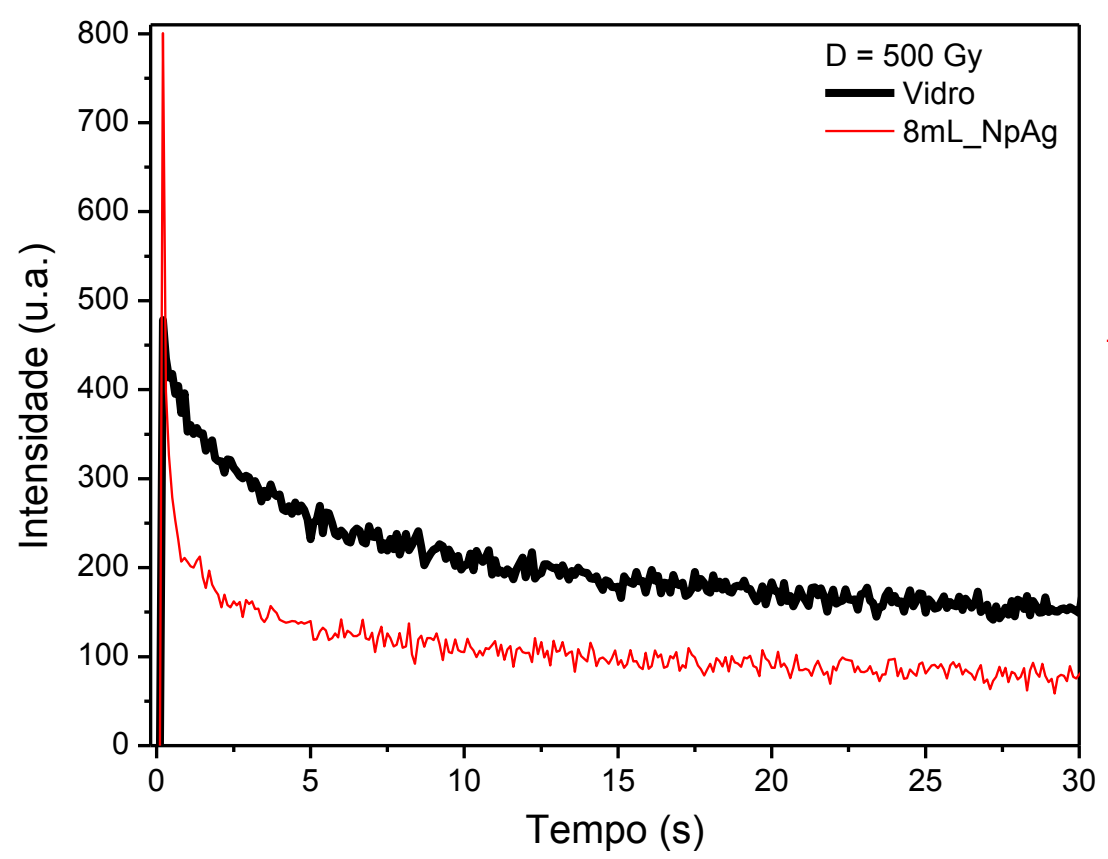

Figura 5.18: Curvas OSL para a amostra $8 \mathrm{~mL} \_N p A g$ e para o substrato de vidro utilizado para depositar as amostras de $\mathrm{ZnO} / \mathrm{Ag}$.

Além disso, como mostrado na Figura 5.19, a curva dose resposta do vidro apresenta comportamento linear, diferentemente do comportamento não linear apresentado pela curva dose resposta das amostras de $\mathrm{ZnO}$ e $8 \mathrm{~mL} \_\mathrm{NpAg}$. Logo, esse resultado sugere que a presença dos filmes de $\mathrm{ZnO}$ sobre o substrato vítreo, impede que o substrato de vidro seja estimulado pela luz durante a leitura OSL e, portanto, as curvas OSL obtidas para as amostras em que os filmes foram depositados sobre o vidro correspondem à emissão OSL do óxido de zinco, e não do substrato de vidro. 


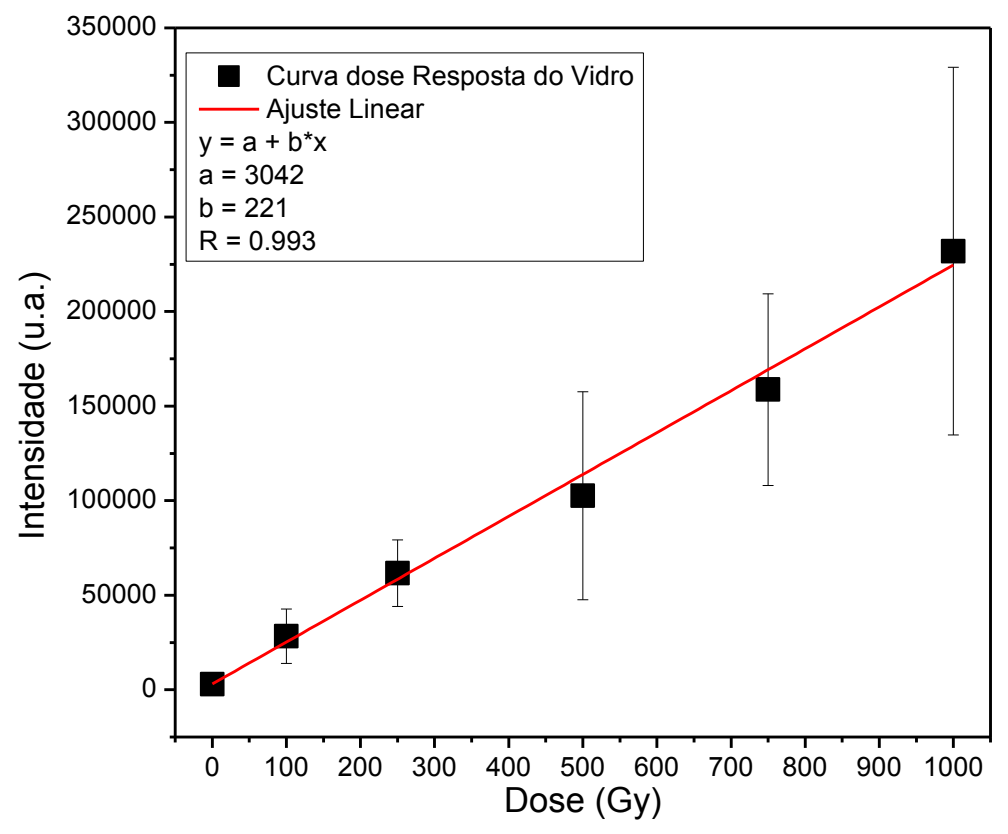

Figura 5.19: Curva dose-resposta para o substrato de vidro.

\subsection{Conclusões}

Nesse capítulo, foram produzidas partículas de óxido de zinco ancoradas em nanopartículas metálicas. A nucleação e o crescimento do óxido de zinco sobre a superfície de nanopartículas de ouro e prata pré-existentes em solução puderam ser verificados e confirmados pelas imagens de microscopia eletrônica de varredura utilizando um detector de retroespalhamento de elétrons, bem como pela presença da banda de ressonância plasmônica nos espectros de refletância. Os nanocompósitos $\mathrm{ZnO} / \mathrm{Ag}$ e $\mathrm{ZnO} / \mathrm{Au}$ apresentaram aumento da emissão UV do $\mathrm{ZnO}$ proporcionalmente à concentração de nanopartículas metálicas. As variações no espectro de fotoluminescência do $\mathrm{ZnO}$ produzidas pelo aumento da concentração de nanopartículas de prata foram similares às variações produzidas pelo aumento da potência do laser de excitação das amostras, sugerindo que essas alterações resultam do aumento do campo elétrico local nos cristais de $\mathrm{ZnO}$. Houve redução do tempo de vida da banda UV do $\mathrm{ZnO}$ para as amostras contendo nanopartículas de prata. Além disso, houve aumento da intensidade (intensidade inicial e integral da curva) e redução do tempo de decaimento das curvas OSL em função do aumento da concentração de nanopartículas de prata. Assim, o aumento das intensidades de fotoluminescência e de luminescência opticamente estimulada, aliado à redução do tempo de vida da banda UV, sugerem a ocorrência do mecanismo de luminescência acoplada aos plásmons durante o processo de emissão (transferência de energia dos éxcitons do $\mathrm{ZnO}$ para os plásmons das NpAgs). A redução do tempo de decaimento das 
curvas OSL sugere que o desarmadilhamento de elétrons ocorre de forma mais rápida na presença das nanopartículas de prata, indicando que o aumento dos campos elétricos locais próximo à superfície das nanopartículas de prata em condições de ressonância plasmônica, também contribui para a intensificação processo de emissão OSL. Uma vez que o tempo de vida da emissão luminescente é muito curto em comparação ao tempo da estimulação OSL, a forma da curva OSL será mais influenciada pelas variações nas taxas de desarmadilhamento (probabilidade de estimulação) do que pela mudança dos tempos de vida.

Portanto, os resultados apresentados nesse capítulo mostram que a presença de nanopartículas metálicas pode aumentar a eficiência de conversão de elétrons armadilhados em luminescência opticamente estimulada, tanto pelo aumento da taxa de excitação (desarmadilhamento de elétrons) quanto pelo acoplamento plasmônico no processo de emissão. Embora tenha sido demonstrado que as propriedades plasmônicas podem ser utilizadas para aumentar a intensidade OSL, objetivo principal dessa tese, o uso desses nanocompósitos não permite um fino controle da variação das distâncias entre o material luminescente e as nanoestruturas metálicas. Por esse motivo, foram realizadas mais investigações utilizando filmes finos nanoestruturados, como será descrito nos capítulos seguintes. 


\section{Estudo e Caracterização dos Filmes de Nanopartículas de Prata}

O capítulo anterior mostrou que as propriedades plasmônicas de nanopartículas metálicas aumentam a intensidade da luminescência opticamente estimulada tanto pelo aumento da taxa de desarmadilhamento de elétrons quanto pelo acoplamento plasmônico durante o processo de emissão. Porém, não foi possível determinar se possíveis defeitos introduzidos pela inserção de nanopartículas na estrutura do material luminescente, ou ainda por diferenças estruturais e morfológicas, contribuem para as diferentes propriedades de luminescência das amostras. Além disso, o uso de nanocompósitos impossibilita a variação de parâmetros bastante utilizados no estudo de interações entre centros luminescentes e plásmons. Dessa forma, serão utilizados, nesse capítulo, filmes automontados de nanopartículas de prata com diferentes espessuras e depositados sobre diferentes substratos. Serão utilizados também filmes poliméricos com espessuras variadas, como espaçamento entre os filmes nanoestruturados e o material luminescente; e entre o substrato e o filme. $\mathrm{O}$ material com propriedades de luminescência opticamente estimulada escolhido foi o $\mathrm{NaCl}$ devido à facilidade de deposição sobre os diversos filmes produzidos. Sabendo que as interações entre centros luminescentes e plásmons variam de acordo com a distância entre as partes, cabe aqui a seguinte questão: a intensidade OSL apresenta alguma dependência com a distância entre o material luminescente e a nanoestrutura plasmônica?

\subsection{Espectroscopia UV-Vis e FTIR}

A Figura 6.1 mostra os espectros UV-Vis dos filmes de nanopartículas de prata. A banda de ressonância plasmônica das nanopartículas de prata pode ser detectada em $420 \mathrm{~nm}$. O aumento do número de bicamadas aumenta o coeficiente de extinção da banda plasmônica, indicando o crescimento do filme. É possível observar ainda um deslocamento da banda plasmônica para maiores comprimentos de onda à medida que o número de camadas dos filmes é aumentado. A largura à meia altura das bandas de ressonância plasmônica também aumenta à medida que o número de bicamadas aumenta, e os valores encontrados para os filmes com 3, 5 e 10 bicamadas foi de 120, 135 e $160 \mathrm{~nm}$, respectivamente. 

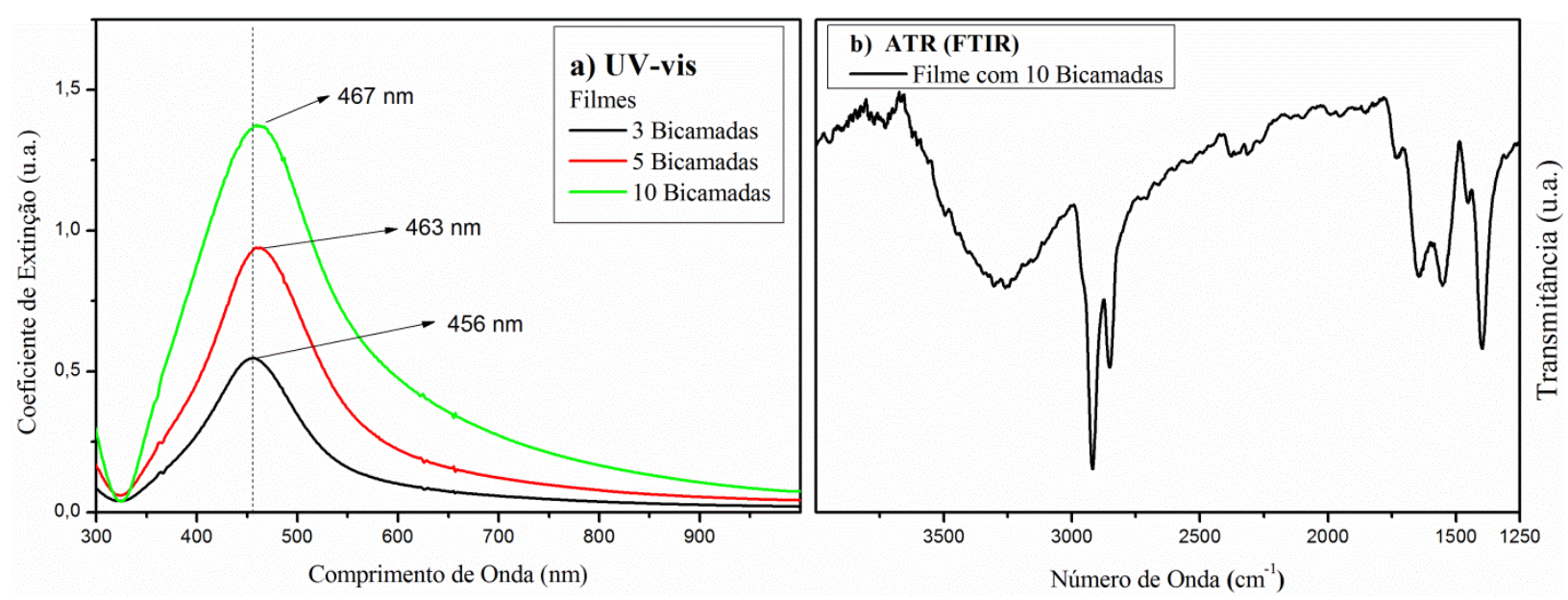

Figura 6.1: (a) Espectro UV-Vis dos filmes de nanopartículas de prata. (b) Espectro de Infravermelho do filme com 10 bicamadas.

Simulações computacionais têm mostrado que, para um sistema consistindo de nanopartículas de prata alinhadas, igualmente espaçadas, depositadas sobre substrato vítreo, e com luz de incidência polarizada longitudinalmente ao substrato, o deslocamento da banda de ressonância plasmônica ocorre em função do espaçamento entre as partículas devido ao acoplamento entre as mesmas [89]. Para luz polarizada logitudinalmente às partículas, a banda plasmônica desloca-se para maiores comprimentos de onda à medida que a distância entre as nanopartículas diminui enquanto que, para luz polarizada transversalmente ao alinhamento das partículas, a banda plasmônica desloca-se para menores comprimentos de onda [89-91]. Esses deslocamentos ocorrem porque, para a polarização longitudinal (transversal), a atração (repulsão) entre as cargas na superfície das nanopartículas vizinhas, diminui (aumenta) a energia necessária para induzir a oscilacão plasmônica coletiva das nanopartículas [89-91]. Os deslocamentos para menores comprimentos de onda originados pela polarização transversal são moderados enquanto os deslocamentos para maiores comprimentos de onda causados pela polarização longitudinal são mais notórios [89, 92]. Para dispersões coloidais de nanopartículas de prata, o deslocamento do pico de ressonância plasmônica para maiores comprimentos de onda está associado ao crescimento e/ou agregação das nanopartículas [27, 93]. Logo, o deslocamento da banda plasmônica de $456 \mathrm{~nm}$ para 467 $\mathrm{nm}$ do filme com 3 bicamadas para o filme com 10 bicamadas pode estar associado a uma menor distância entre as partículas devido ao crescimento do filme.

Enquanto a espectroscopia UV-Vis traz informações a respeito das nanopartículas de prata, a espectroscopia de infravermelho por transformada de Fourier (FTIR) pode complementar com informações estruturais, pois permite inferir a respeito das vibrações de 
grupos presentes nas moléculas de quitosana dos filmes. A Figura 6.1 (b) mostra o espectro FTIR obtido para o filme com 10 bicamadas. $\mathrm{O}$ espectro do filme se assemelha ao espectro característico da quitosana pura [94-96]. A banda entre 3000-3600 $\mathrm{cm}^{-1}$ corresponde a sobreposição do estiramento dos grupos O-H e N-H da quitosana [94-96]. As bandas em 2916 e $2854 \mathrm{~cm}^{-1}$ estão associadas ao estiramentto simétrico e asimétrico do grupo $\mathrm{CH}_{2}$ e as bandas em 1650 e $1550 \mathrm{~cm}^{-1}$ estão relacionadas a torção do grupo N-H [94-96]. O papel do grupo amina na redução e estabilização de nanopartículas de prata é bem conhecido na literatura, assim como a utilização de moléculas de quitosana na síntese de NpAgs [96-98]. Assim, além da ligação eletrostática existente devido à alternância entre cargas positivas e negativas do sistema Qt/NpAg, deve-se ressaltar a afinidade química da quitosana com a prata, devido à presença do grupo NH. Logo, por meio das espectroscopias UV-Vis e FTIR, é possível confirmar a adsorção da quitosana ao substrato e às nanopartículas, levando ao crescimento de um filme automontado.

\subsection{Microscopia de Força Atômica}

\subsubsection{Filmes de Nanopartículas de Prata Depositados em Substratos Vítreos}

A Figura 6.2 mostra as imagens de microscopia de Força Atômica (AFM) da superfície dos filmes com 3, 5 e 10 bicamadas. É possível observar que a superfície do filme com 3 bicamadas é irregular, apresentando regiões mais altas constituídas por aglomerados de nanopartículas de prata, formando ilhas na superfície do filme, e regiões mais baixas (vales). O filme com 5 bicamadas apresenta um superfície mais regular, ainda com a presença de ilhas, porém os interstícios entre cada ilha são menores comparados aos do filme com três bicamadas. Já a superfície do filme com 10 bicamadas é totalmente preenchida com nanopartículas de prata, tornando menos notável a presença de ilhas. Essa mudança na superfície do filme em função do número de bicamadas pode indicar a dinâmica de crescimento do filme. Para a primeira bicamada, por exemplo, as nanopartículas aderem somente nas regiões recobertas por quitosana dando origem a uma superficie irregular com ilhas de nanopartículas de prata. À medida que uma nova camada de quitosana é depositada, as moléculas se acumulam nos interstícios/vales existentes entre as ilhas de nanopartículas da primeira bicamada. Consequentemente, as nanopartículas de prata terão maior probabilidade de se ligar nessas regiões intersticiais onde há maior concentração de moléculas com carga 
positiva e grupos amina. Assim, os interstícios serão preenchidos à medida que mais camadas são depositadas, e as ilhas vão se tornando menos proeminentes devido a elevação/crescimento do plano mais profundo/base do filme. Resultado semelhante foi encontrado na literatura, no qual o crescimento de cristais de carbonato de cálcio sobre a superfície de filmes orgânicos, ocorre nas regiões de vale, tornando a superfície menos rugosa [99].

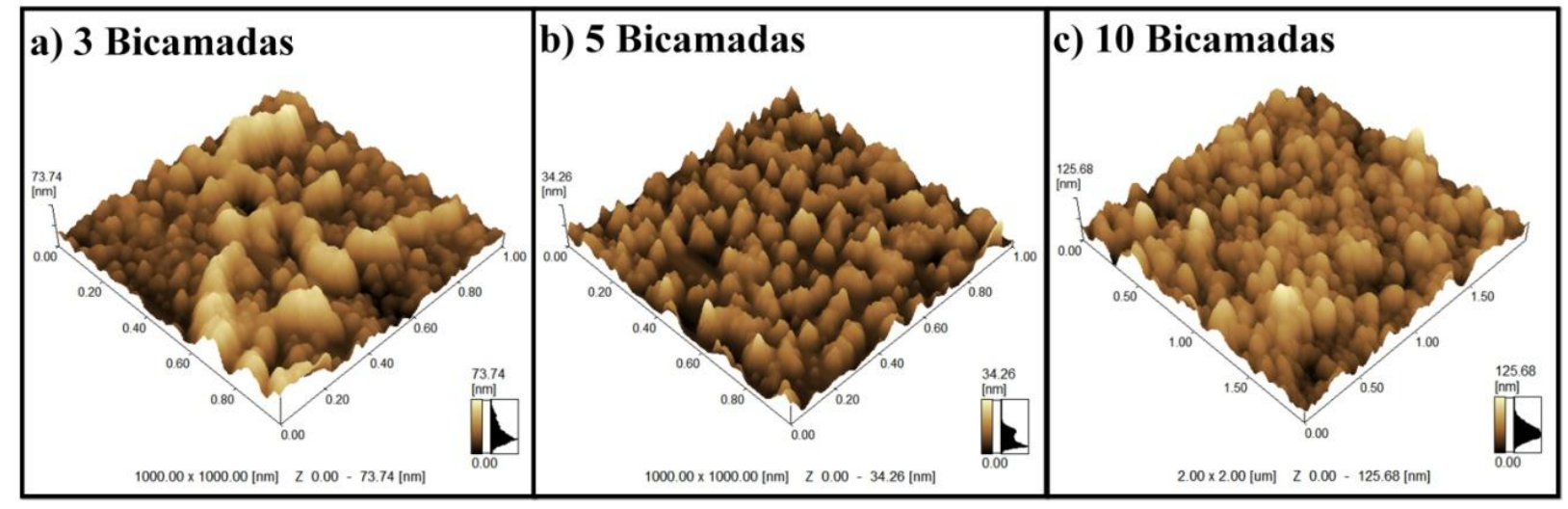

Figura 6.2: Imagens de Microscopia de Força Atômica da superfície dos filmes de nanopartículas de prata depositados sobre substratos vítreos.

A Figura 6.3 mostra uma imagem referente à superfície do filme com 5 bicamadas onde é possível verificar a presença das ilhas constituídas por pequenas nanopartículas de prata (regiões mais claras). As regiões mais escuras correspondem ao plano mais profundo do filme. É possível observar nas bordas das ilhas, uma região amarela pálida localizada entre as ilhas e as partes negras referentes ao plano mais profundo da imagem. Como não há nanopartículas aderidas, essa região amarela provavelmente corresponde ao recobrimento final de quitosana utilizado com o intuito de proteger a superfície do filme contra oxidação. Assim, essa imagem parece confirmar a hipótese levantada anteriormente de haver primeiro uma tendência de crescimento lateral do filme, no sentido de preencher as suas regiões mais profundas, reduzindo os espaços intersticiais, causando interconexão das ilhas de nanopartículas de prata e tornando a superfície do filme mais homogênea. 


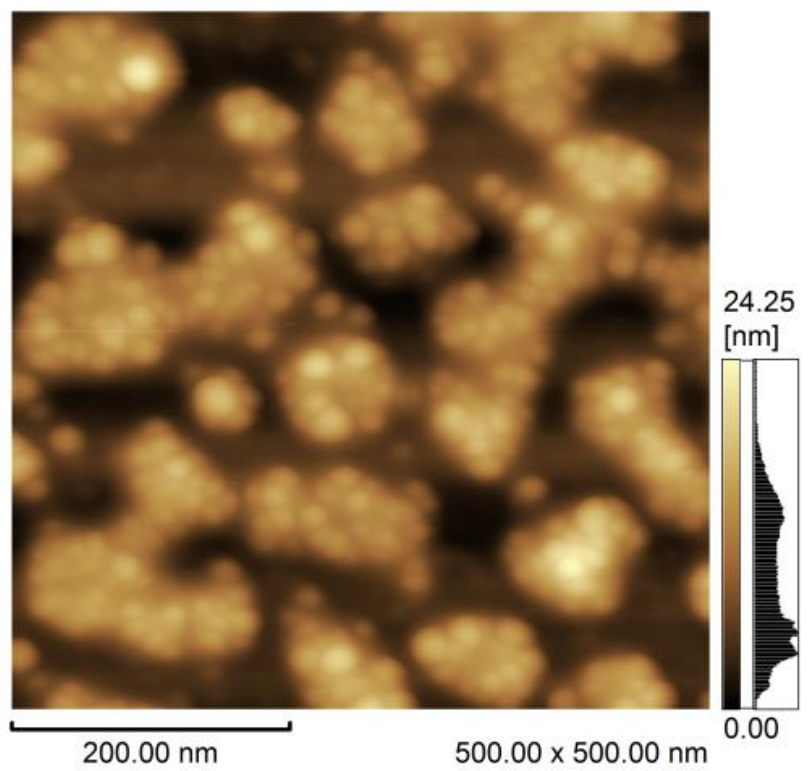

Figura 6.3: Imagens de Microscopia de Força Atômica da superfície do filme com 3 bicamadas de nanopartículas de prata depositado sobre substrato vítreo.

\subsubsection{Filmes de Nanopartículas de Prata Depositados em Substratos de Alumínio}

A Figura 6.4 mostra imagens de microscopia de força atômica dos filmes contendo 10 bicamadas de nanopartículas de prata depositados sobre os substratos de alumínio. Devido a processos oxidativos nas condições ambientes, a superfície do substrato de alumínio metálico torna-se recoberta por uma camada nanométrica de óxido de alumínio. O ponto isoelétrico do óxido de alumínio ocorre para um valor de $\mathrm{pH}$ em torno de 9 e o potencial zeta para valores de $\mathrm{pH}$ menores que 9 é positivo [64]. Portanto, é provável que a primeira camada de quitosana (carga positiva) não seja tão bem depositada como no caso da superfície de vidro, cujo potencial é negativo no $\mathrm{pH}$ de deposição $(\mathrm{pH}=4,5)$. Nesse caso, é provável que o crescimento dos filmes se inicie com a primeira camada de moléculas de quitosana com carga neutra, ou ainda a partir da primeira camada de nanopartículas de prata. No entanto, assim como nos filmes depositados sobre o vidro, pode-se observar que a superfície do substrato de alumínio está totalmente preenchida com nanopartículas de prata. 


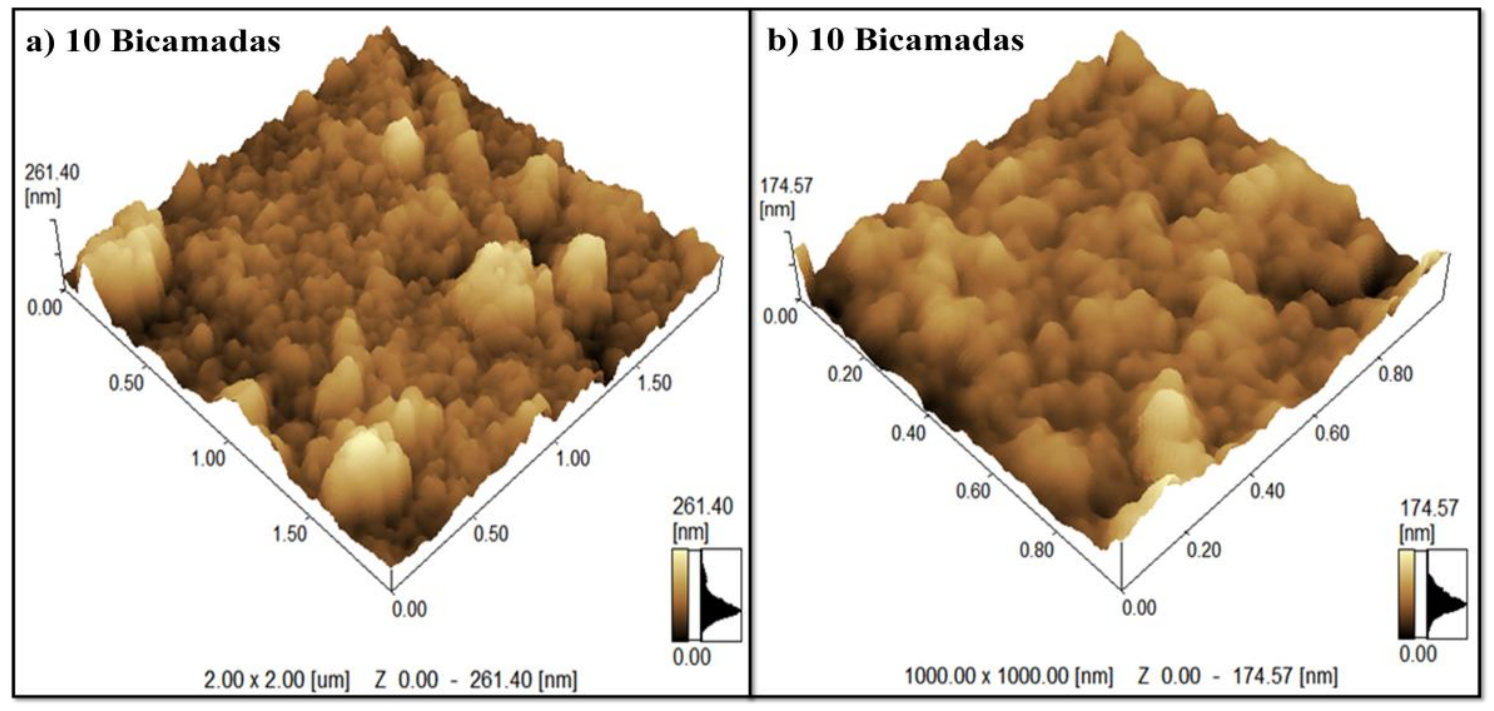

Figura 6.4: Imagens de microscopia de força atômica dos filmes com 10 bicamadas de nanopartículas de prata depositados sobre substrato de alumínio.

\subsubsection{Filmes de Quitosana/Poli(ácido acrílico)}

Filmes de Qt/PAA foram utilizados para inserir um espaçamento entre os filmes nanoestruturados e o substrato, ou entre os filmes nanoestruturados e o material luminescente. Assim, é interessante verificar a espessura de cada bicamada de Qt/PAA, de forma a se determinar o espaçamento inserido por cada bicamada depositada. Para isso, bicamadas de Qt/PAA foram depositadas em substratos de sílica e, posteriormente, foram realizados riscos sobre o filme com o uso de um bisturi. Dessa maneira, ao determinar a profundidade dos vales produzidos pelos riscos sobre o filme depositado, pode-se determinar a espessura do filme, e o espaçamento introduzido por cada bicamada. Substratos de sílica foram utilizados por apresentarem superfície plana de forma a não interferir na espessura medida.

A Figura 6.5 mostra a imagem de um filme com 1 bicamada Qt/PAA, onde fica evidente a presença do risco produzido pelo bisturi. O valor médio obtido para espessura do filme com base nas 4 medidas presentes na Figura 6.5 foi de $15 \pm 2 \mathrm{~nm}$. Esse valor experimental é muito próximo ao valor teórico obtido pela equação de Debye [100], que aponta para um valor de $18 \mathrm{~nm}$ para a espessura desse filme [100]. Dessa forma, para todos os filmes e configurações de Qt/PAA, será considerado um valor de $15 \mathrm{~nm}$ para a espessura de cada bicamada. 


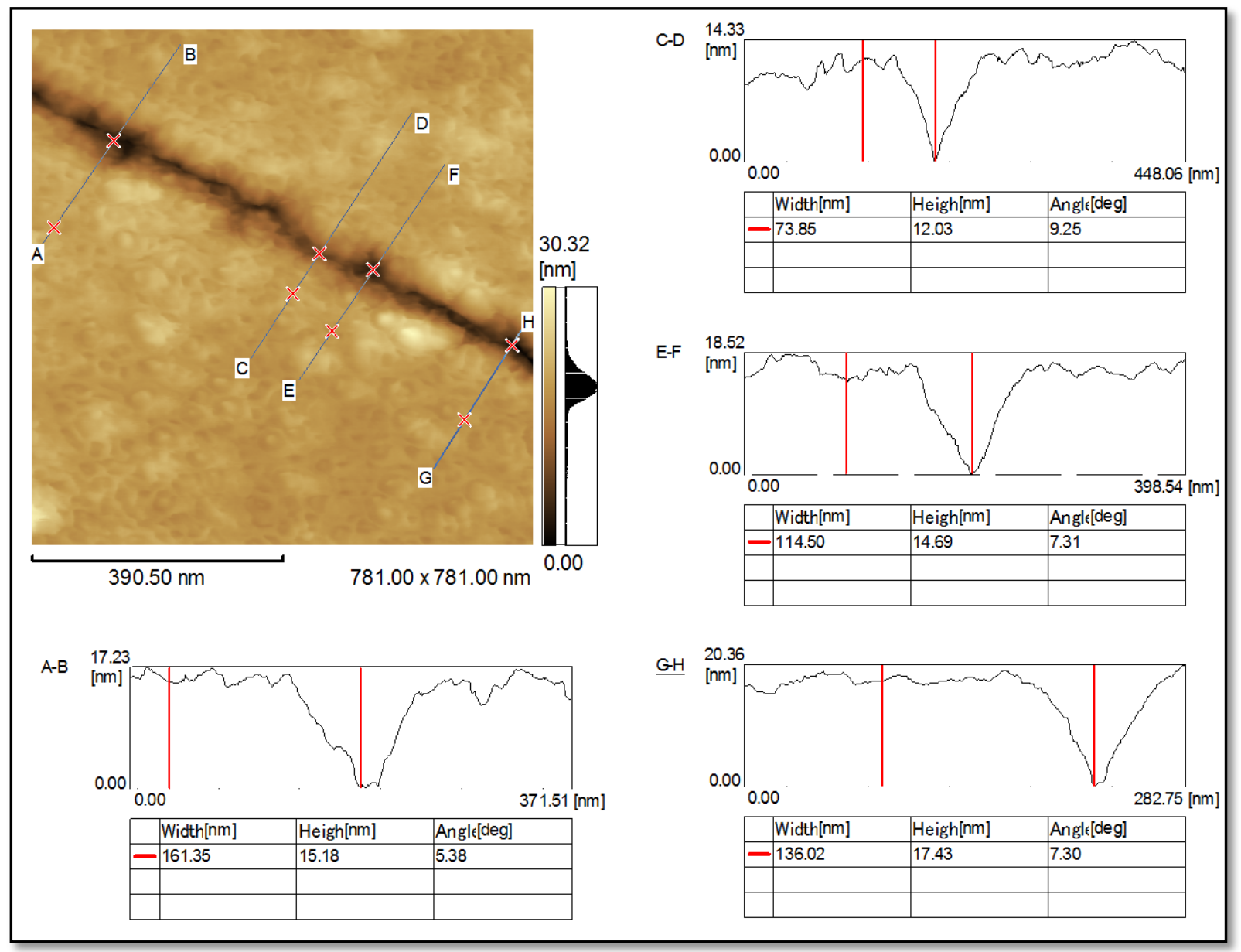

Figura 6.5: Imagem de microscopia de força atômica do filme com 1 bicamada de quitosana/poli(ácido acrílico) depositado sobre substrato de sílica. As imagens laterais correspondem aos perfis referentes aos respectivos traços presentes na imagem de microscopia. A espessura encontrada em cada traço está representada sob o título height presente nas respectivas tabelas.

\subsection{Luminescência Opticamente Estimulada}

A Figura 6.6 (a) mostra as curvas OSL para a amostra de $\mathrm{NaCl}$ depositado sobre o vidro e para o $\mathrm{NaCl}$ depositado sobre o filme com 10 bicamadas, irradiadas com $10 \mathrm{~Gy}$, evidenciando o aumento de luminescência da amostra quando depositada sobre o filme de prata. Cabe ressaltar aqui que os substratos vítreos não apresentaram sinal OSL para as doses utilizadas nestes experimentos. Uma vez que o $\mathrm{NaCl}$ está depositado sobre o filme de prata, a hipótese de que o aumento de luminescência tenha sido causado pela criação de defeitos na estrutura cristalina do $\mathrm{NaCl}$ torna-se menos relevante, uma vez que processo de automontagem pelo qual o filme foi produzido e os vários procedimentos de lavagem do filme antes de sua utilização, garantem a não liberação das nanopartículas para a solução de $\mathrm{NaCl}$ gotejada sobre o filme. Dessa forma, a única possibilidade de criação de defeitos seria na 
interface $\mathrm{NpAg} / \mathrm{Qt} / \mathrm{NaCl}$. Em contrapartida, são encontrados na literatura muitos trabalhos relatando o aumento de luminescência de centros luminescentes depositados sobre filmes nanoestruturados de prata. $\mathrm{O}$ aumento ocorre devido à oscilação dos elétrons livres das nanopartículas com o campo eletromagnético da luz em condições de ressonância, aumentando o campo elétrico próximo ao filme/partícula.

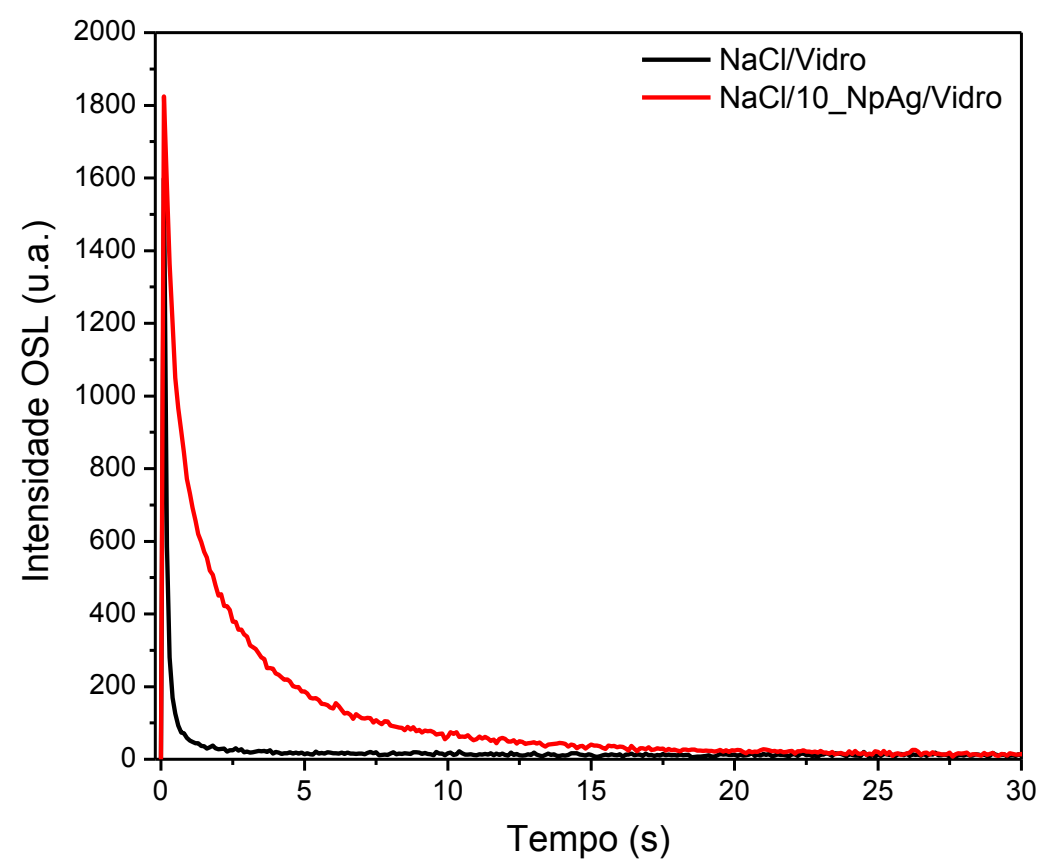

Figura 6.6: Curvas OSL para o $\mathrm{NaCl}$ depositado sobre o vidro e sobre o filme com 10 bicamadas $\mathrm{Qt} / \mathrm{NpAg}$, irradiados com $10 \mathrm{~Gy}$.

A Figura 6.7 mostra as curvas de decaimento OSL para o $\mathrm{NaCl}$ depositado sobre o vidro (a) e sobre o filme 10_NpAg (b) com seus respectivos ajustes exponenciais. A curva OSL foi melhor ajustada por um decaimento exponencial de terceira ordem, revelando assim a participação de pelo menos três armadilhas de elétrons no processo de emissão OSL. Para o $\mathrm{NaCl}$ depositado sobre o filme de NpAgs, houve aumento dos três tempos de decaimentos, quando comparados aos tempos de decaimento do $\mathrm{NaCl}$ depositado sobre vidro. 


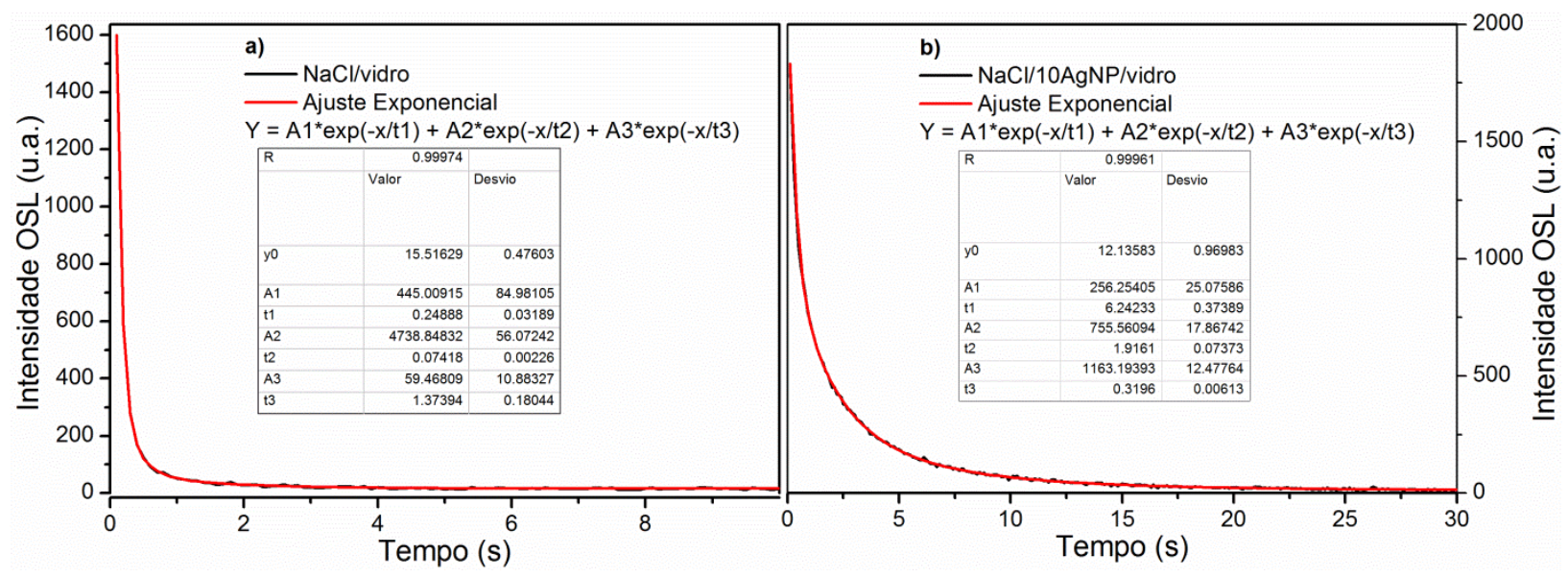

Figura 6.7: Ajuste exponencial das curvas de decaimento OSL.

\subsubsection{Influência do Número de Bicamadas de Qt/NpAg}

A Figura 6.8 (a) mostra a resposta OSL das amostras irradiadas com $10 \mathrm{~Gy}$, em função do número de bicamadas de Qt/NpAg dos filmes. É possível observar que o aumento do número de bicamadas proporciona o aumento da intensidade OSL. No entanto, o ganho observado para os filmes com 3 e 5 bicamadas é proporcionalmente menor do que para o filme com 10 bicamadas. Por exemplo, o aumento médio da intensidade OSL para o filme com 3 e 5 bicamadas ficou em torno de 3 e 5 vezes, respectivamente. Assim, se o aumento da intensidade OSL seguisse a mesma proporção de crescimento em função do número de bicamadas, seria obtido, para esse filme, um aumento médio de 10 vezes. Porém o aumento médio para o filme com 10 bicamadas foi 6.5 de vezes. Esse resultado sugere que o aumento de luminescência tem maior influência das nanopartículas localizadas na superfície do filme, dependendo de forma menos acentuada das nanopartículas do bulk. Uma explicação seria o fato de que o aumento de luminescência pode estar associado ao aumento do campo elétrico local experimentado pelo centro luminescente quando localizado próximo à nanopartícula metálica. Logo, embora a banda de absorção plasmônica aumente em intensidade com o aumento do número de bicamadas, o $\mathrm{NaCl}$ depositado sobre o filme sofrerá a ação dos campos elétricos principalmente das nanopartículas superficiais, uma vez que as nanopartículas localizadas no "bulk" do filme estão envoltas de nanopartículas de prata e não dos centros luminescentes do $\mathrm{NaCl}$. 

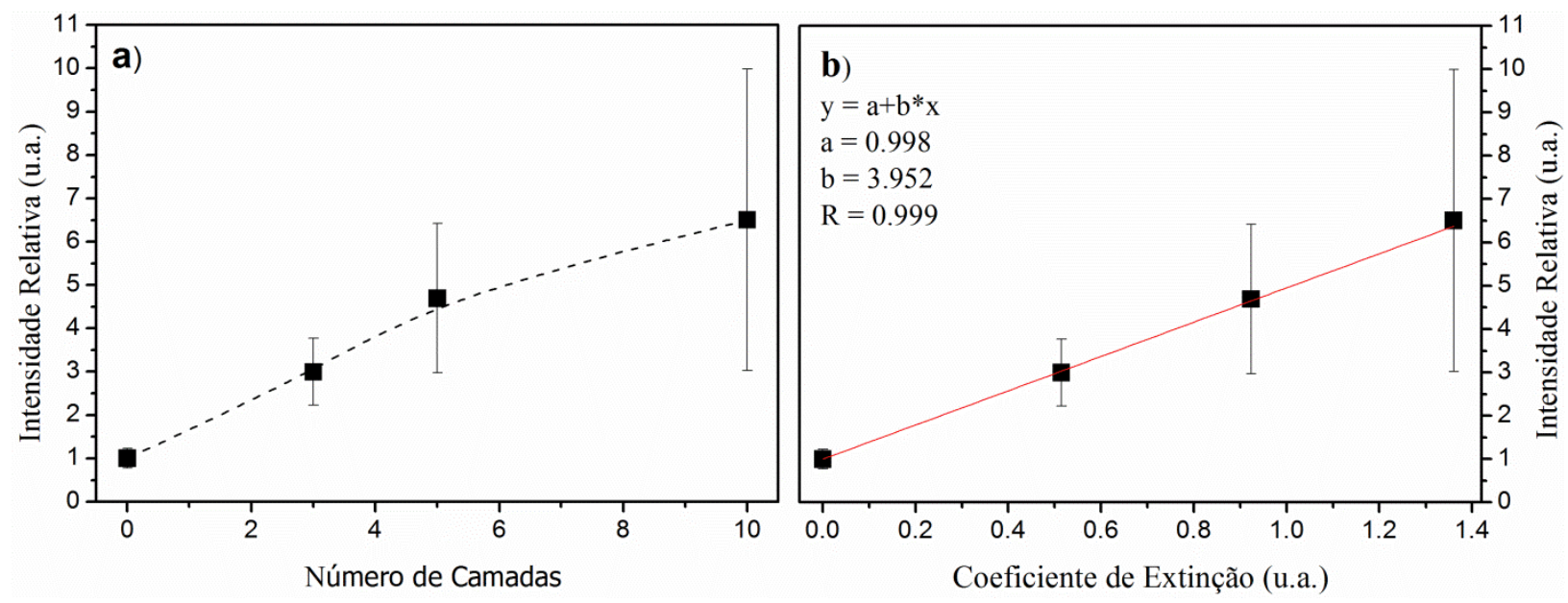

Figura 6.8: (a) Intensidade OSL em função do número de bicamadas do filme de nanopartículas de prata. (b) Intensidade OSL em função da absorbância em $470 \mathrm{~nm}$ dos filmes de nanopartículas de prata.

Além de investigar o comportamento da intensidade OSL em função do número de bicamadas do filme, é importante verificar a influência da intensidade da banda de ressonância plasmônica (absorbância/coeficiente de extinção) na intensidade OSL. A Figura 6.8 (b) sugere um comportamento linear da intensidade OSL em função do coeficiente de extinção em $470 \mathrm{~nm}$ dos filmes de nanopartículas de prata. O termo coeficiente de extinção foi utilizado em vez de absorbância visto que não foram feitas correções para perdas por reflexão. O comprimento de onda de $470 \mathrm{~nm}$ foi escolhido por corresponder ao comprimento de onda de máxima intensidade do espectro de emissão do LED azul utilizado para estimulação OSL.

Esse resultado é semelhante ao obtido por Vicki et.al [101]. Nesse trabalho, os autores reportam que a intensidade do espalhamento Raman de moléculas de tetrafenilporfirina depositadas sobre filmes de nanopartículas de prata apresentou comportamento linear em função do coeficiente de extinção dos filmes, de forma que quanto maior a intensidade da banda de ressonância plasmônica, maior o aumento da intensidade do espalhamento Raman. Essa relação linear entre o aumento da intensidade OSL e o coeficiente de extinção dos filmes é consistente com a hipótese de que o aumento da intensidade OSL ocorre devido ao aumento do campo elétrico local próximo às nanopartículas de prata em ressonância plasmônica [101]. Nesse sentido, quanto maior a intensidade da banda de ressonância plasmônica, maior o aumento do campo elétrico em torno das nanopartículas e consequentemente, maior o aumento da intensidade OSL.

A Figura 6.9 mostra os valores da intensidade OSL inicial em função do número de bicamadas Qt/NpAgs (a) e em função do coeficiente de extinção dos respectivos filmes (b). É 
possível observar que o ganho na intensidade OSL inicial é muito pequeno ou até mesmo irrelevante se comparado ao aumento da integral da curva. Além disso, o comportamento linear da intensidade em função do coeficiente de extinção não é observado para o caso da intensidade OSL inicial.

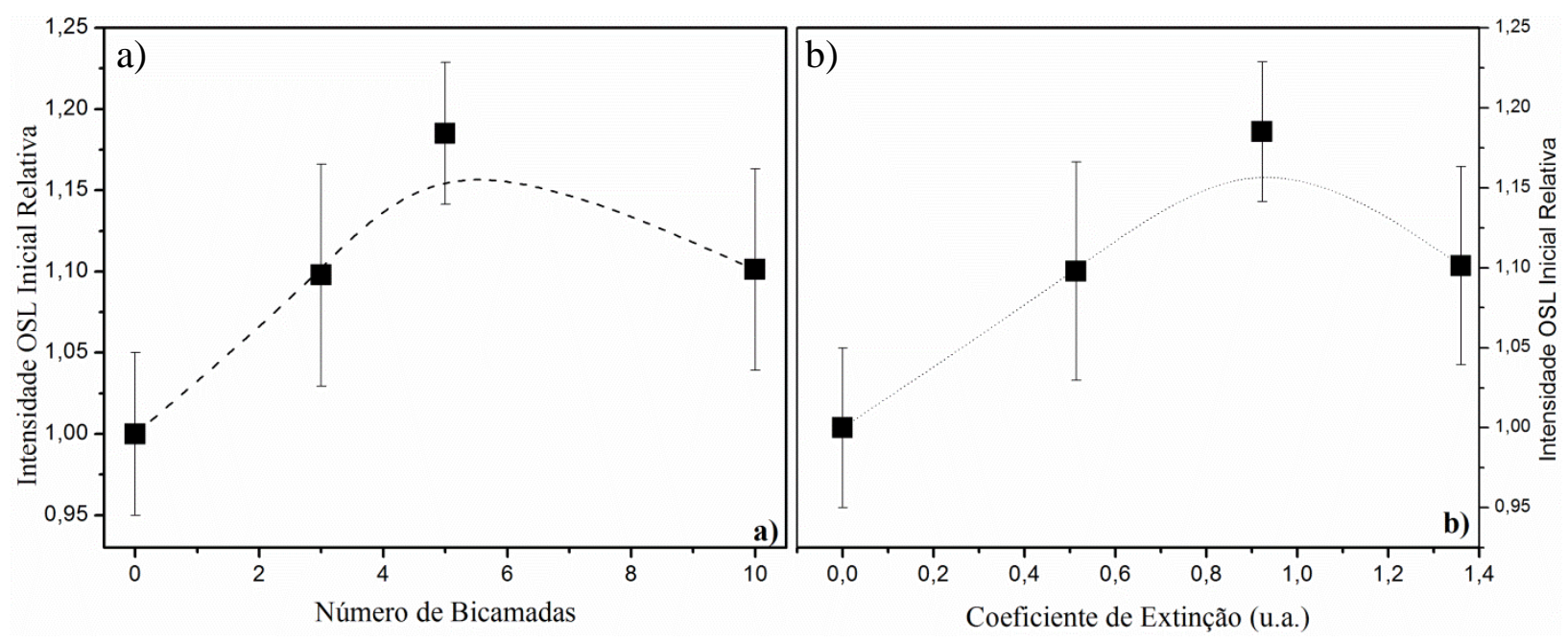

Figura 6.9: (a) Intensidade OSL inicial em função do número de bicamadas do filme de nanopartículas de prata. (b) Intensidade OSL inicial em função da absorbância em $470 \mathrm{~nm}$ dos filmes de nanopartículas de prata.

O fato de que a curva OSL do $\mathrm{NaCl}$ pode ser ajustada por uma exponencial de terceira ordem indica que sua luminescência opticamente estimulada origina-se de várias armadilhas com diferentes seções de choque de fotoionização e/ou tempos de decaimento. Assim, é provável que o acoplamento plasmônico seja maior para as armadilhas com tempos de decaimento mais longos, não contribuindo para o aumento da intensidade OSL inicial. Aqui cabe ressaltar que, em geral, armadilhas com pequena seção de choque de fotoionização apresentam tempos de decaimentos mais longos [86-87]. Portanto, afirmar que o acoplamento é maior com armadilhas com tempos de decaimentos mais longos implica em afirmar que o acoplamento é maior com armadilhas com menores seções de choque de fotoionização.

\subsubsection{Influência do Substrato}

Uma vez que a interação entre os plásmons e centros luminescentes depende das propriedades dielétricas do meio em torno das nanopartículas, o substrato onde o filme é depositado pode desempenhar importante papel no aumento de luminescência causado pelo 
filme. Assim, foram produzidos filmes com 3, 5 e 10 bicamadas sobre um substrato de alumínio, com as mesmas dimensões e sob as mesmas condições. A Figura 6.10 mostra que o aumento médio da intensidade OSL obtido para o filme com 10 bicamadas de nanopartículas de prata depositado sobre o substrato de alumínio foi de apenas 1,6 vezes, muito menor que o valor médio obtido para o mesmo filme depositado sobre o vidro.

Embora o aumento da intensidade OSL dos filmes depositados sobre o alumínio sejam consideravelmente menores que o aumento da intensidade OSL dos filmes depositados sobre o vidro, o inset da Figura 6.10 revela que o comportamento da curva de intensidade OSL em função do número de bicamadas de $\mathrm{Qt} / \mathrm{NpAg}$ depositadas sobre os substratos de alumínio é similar ao comportamento observado para os filmes depositados sobre o vidro. Assim, esse resultado é mais uma evidência de que os aumentos de luminescência observados para o $\mathrm{NaCl}$ depositado sobre os filmes de prata não é causado pela criação de defeitos na interface filme/Qt/ $\mathrm{NaCl}$ uma vez que, independentemente do substrato utilizado, a interface entre o luminóforo e o filme é a mesma.

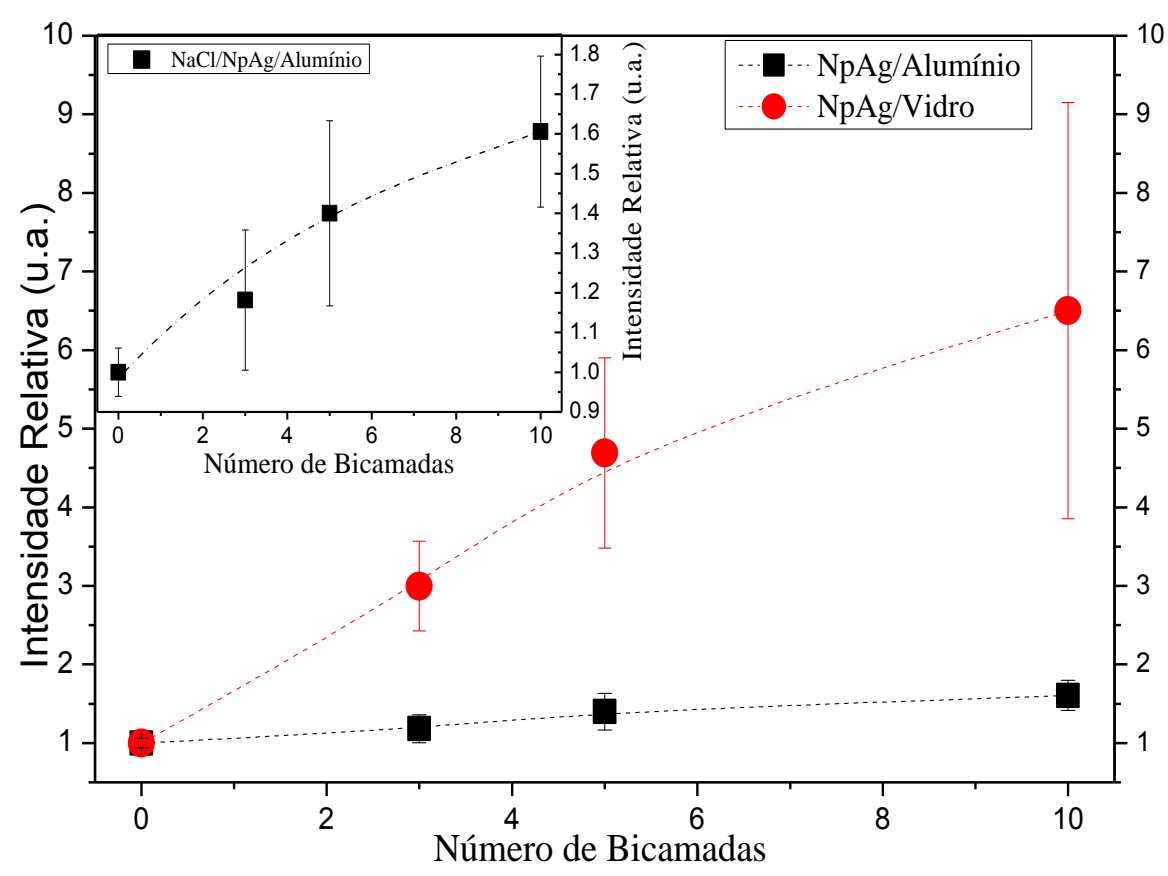

Figura 6.10: Intensidade OSL em função do número de bicamadas dos filmes de nanopartículas de prata depositados sobre substratos de vidro e alumínio.

De fato, os substratos mais utilizados para deposição de filmes nanoestruturados com propriedades plasmônicas são substratos dielétricos de quartzo e vidro, porém substratos de plástico e papel têm sido também reportados [102-103]. Deposição de filmes metálicos nanoestruturados em substratos metálicos são utilizados somente em condições específicas 
onde consegue-se o acoplamento das ondas plásmons-poláritons da superfície metálica (ondas spp) com os plásmons localizados da nanopartícula metálica [104]. No entanto, essas ondas spp são obtidas somente em condições específicas de incidência de luz com polarização transversal à superfície metálica e com ângulo de incidência maior que o ângulo de reflexão total [34]. Uma vez que essas condições não foram atendidas durante a leitura OSL, não deve haver ondas spp na superfície do substrato de alumínio e, portanto, não há acoplamento com os plásmons das nanopartículas de prata.

De maneira geral, o substrato metálico pode causar deslocamentos da banda plasmônica e até mesmo o seu desaparecimento, dependendo da polarização da luz e da distância da nanopartícula ao substrato, entre outros fatores [29, 105-107]. Essas alterações da banda plasmônica podem ser compreendidas por meio do método das imagens de um sistema consistindo de um dipolo oscilando sobre uma superfície condutora/metálica. Para um dipolo oscilando longitudinalmente (paralelo) à superfície metálica, o dipolo-imagem produzido no substrato metálico terá momento em sentido oposto ao momento de dipolo da nanopartícula metálica, aumentando a energia necessária para produzir ressonância e reduzindo a eficiência de espalhamento da luz, podendo causar drástica redução e até mesmo o desaparecimento da banda plasmônica [90, 104, 106] (Figura 6.11 (a)). Já para um dipolo oscilando verticalmente à superfície condutora, o dipolo-imagem produzido oscilará no mesmo sentido do dipolo da nanopartícula, diminuindo a energia de ressonância e causando deslocamento da banda plasmônica para maiores comprimentos de onda [90, 104, 106] (Figura 6.11 (b)). Por exemplo, o deslocamento reportado na literatura foi da ordem de $200 \mathrm{~nm}$ para uma nanopartícula de prata depositada sobre um substrato de ouro [106]. Além disso, a parte imaginária da função dielétrica da prata aumenta de 0,2 para 0,5 para comprimentos de onda de $450 \mathrm{~nm}$ e $616 \mathrm{~nm}$, respectivamente [108]. Logo, o deslocamento da banda plasmônica para maiores comprimentos de onda causa, para a prata, amortecimento da oscilação plasmônica, diminuindo o espalhamento da luz [109]. 


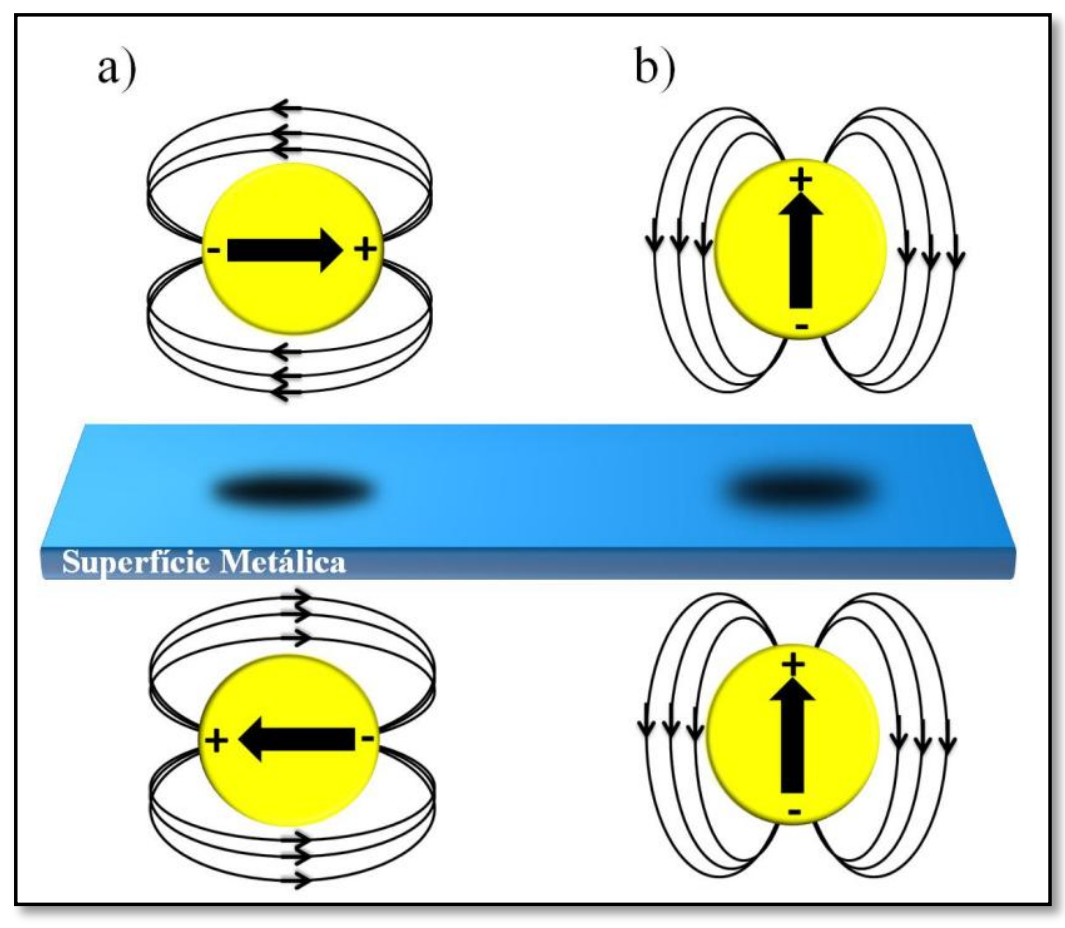

Figura 6.11: Representação da interação entre uma nanopartícula metálica e uma superfície condutora. (a) $\mathrm{O}$ dipolo paralelo à superfície condutora é cancelado pela imagem induzida. (b) $\mathrm{O}$ dipolo perpendicular à superfície acopla-se com a imagem induzida, causando deslocamento da banda de ressonância plasmônica para maiores comprimentos de onda ${ }^{[104]}$.

No caso dos experimentos reportados nesse trabalho, as nanopartículas foram depositadas diretamente sobre o substrato de alumínio (a não ser pelas camadas de quitosana) e, portanto, deve haver forte interação entre os dipolos das nanopartículas com seus respectivos dipolos-imagem. Logo, independente da direção de oscilação do dipolo real, tanto a redução da eficiência de espalhamento quanto o deslocamento da banda plasmônica serão desfavoráveis ao aumento da intensidade OSL do $\mathrm{NaCl}$. Assim, para o caso do $\mathrm{NaCl}$ depositado sobre o filme $\mathrm{NpAg}$ /vidro, todos os dipolos oscilantes contribuirão para o aumento da intensidade do campo elétrico na superfície do filme. Já para o sistema onde o $\mathrm{NaCl}$ foi depositado sobre o filme $\mathrm{NpAg/alumínio,} \mathrm{as} \mathrm{nanopartículas} \mathrm{polarizadas} \mathrm{longitudinalmente} \mathrm{ao}$ substrato de alumínio terão a intensidade da banda plasmônica reduzida, enquanto que as nanopartículas polarizadas verticalmente em relação ao substrato terão a banda plasmônica deslocadas para maiores comprimentos de onda. Esse deslocamento diminuirá a sobreposição com a banda de estimulação OSL (470 nm) além de diminuir a intensidade de luz espalhada. Essa parece ser a razão pela qual o filme depositado sobre o vidro apresentou melhor desempenho para aumento da intensidade OSL do que o filme depositado sobre alumínio. 


\subsubsection{Influência da Distância entre o Substrato Metálico e o Filme de NpAgs}

As interações entre as nanopartículas e suas respectivas imagens podem ser reduzidas aumentando-se o espaçamento dielétrico entre a nanopartícula e o substrato condutor [104, 106]. Com o propósito de variar esse espaçamento, foram depositados filmes com até 6 bicamadas de Qt/PAA sobre o substrato de alumínio. Em seguida, filmes de Qt/NpAg foram depositados sobre os substratos de alumínio contendo diferentes números de bicamadas de Qt/PAA em suas superfícies, conforme apresentado na ilustração abaixo (Figura 6.12).

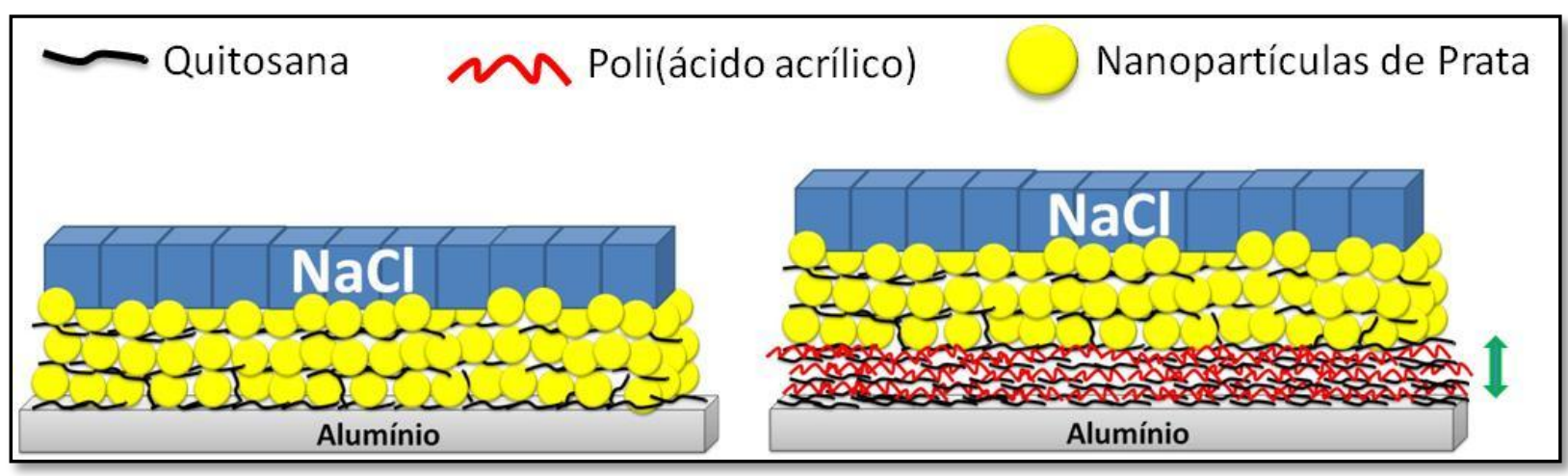

Figura 6.12: Representação da deposição de bicamadas de Qt/PAA entre o substrato de alumínio e o filme de nanopartículas de prata.

A Figura 6.13 revela um aumento da intensidade OSL à medida que aumenta o número de bicamadas de Qt/PAA (espaçamento) entre o substrato de alumínio e o filme contendo 3 bicamadas de Qt/NpAg. Esse resultado reforça a hipótese de que o menor aumento da intensidade OSL obtido para os filmes depositados sobre o substrato de alumínio é causado pela interação entre os dipolos induzidos nas nanopartículas metálicas com seus respectivos dipolos-imagem no substrato metálico. Assim, quanto maior o número de bicamadas de Qt/PAA entre o substrato de alumínio e o filme de nanopartículas de prata, menor será a interação entre os dipolos oscilantes das nanopartículas e seus respectivos dipolos-imagem. Consequentemente, maior será o aumento da intensidade OSL. Além disso, esse resultado também reforça a hipótese de que o aumento da intensidade OSL é de natureza eletromagnética, causado pelo aumento do campo elétrico local nas proximidades das nanopartículas metálicas, e não é causado pela criação de defeitos na interface $\mathrm{NaCl} / \mathrm{Qt} / \mathrm{NpAg}$. 


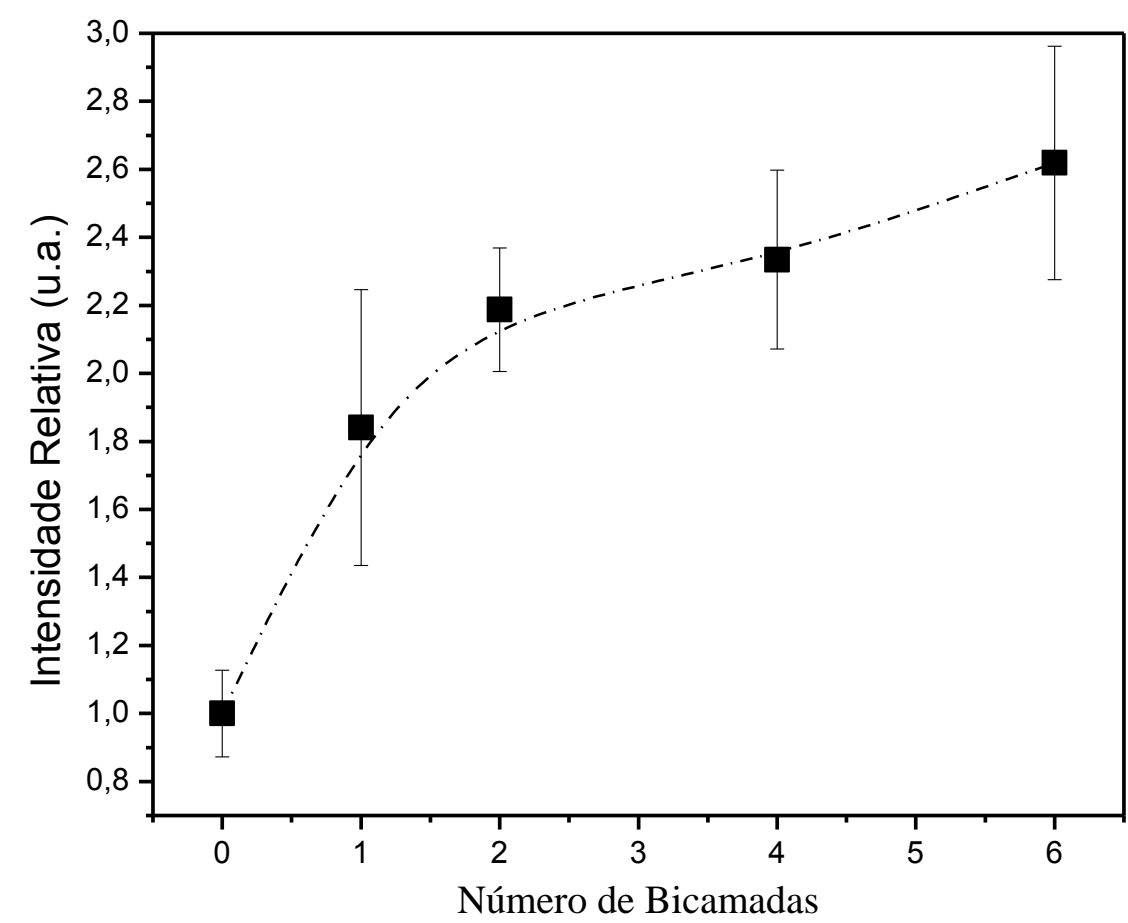

Figura 6.13: Intensidade OSL em função do número de bicamadas de Qt/PAA entre o substrato de alumínio e os filmes de nanopartículas de prata (3_NpAg).

\subsubsection{Influência do Espaçamento entre o Filme de NpAgs e o NaCl}

Além do aumento de luminescência causado pelo aumento do campo elétrico local próximo às nanopartículas metálicas em ressonância plasmônica, é também possível que o aumento da intensidade OSL seja originado pela transferência de energia do centro luminescente para os plásmons. É possível verificar qual tipo de interação plasmônica é responsável pelo aumento de luminescência, investigando-se a influência da distância entre o centro luminescente e o filme de nanopartículas de prata $[36,38,110]$. Caso o aumento de luminescência seja causado exclusivamente pelo aumento do campo elétrico local, o centro luminescente deve estar localizado bem próximo das nanopartículas metálicas. Nesse caso, a intensidade luminescente deve diminuir à medida que se aumenta a distância entre o centro luminescente e o filme de nanopartículas de prata $[36,38,110]$.

De acordo com a literatura, a transferência de energia do centro luminescente para os plásmons pode ocorrer para distâncias de até $400 \mathrm{~nm}$, tendo maior probabilidade de ocorrer para distâncias maiores que $10 \mathrm{~nm}[36,38,110]$. Para distâncias menores que $10 \mathrm{~nm}$, pode ocorrer uma transferência de cargas do centro luminescente para o filme metálico, com um consequente desvanecimento da luminescência [36, 38, 110]. Dessa forma, a intensidade 
luminescente pode ser otimizada com a presença de uma fina camada $(<10 \mathrm{~nm})$ isolante entre o material luminescente e o filme de nanopartículas metálicas, evitando a transferência de cargas do luminóforo para o filme metálico e a redução da intensidade luminescente [36, 38, 110]

Nesse contexto, para investigar a influência da distância entre os centros de emissão do $\mathrm{NaCl}$ e o filme de nanopartículas de prata na intensidade OSL, foram produzidos filmes com 0,5, 1, 2, 4 e 6 bicamadas de Qt/PAA, sobre filmes contendo três bicamadas de Qt/NpAg, conforme ilustração apresentada na Figura 6.14. Nesse caso, o cloreto de sódio foi depositado sobre os filmes de Qt/PAA. Assim, é possível variar a distância entre os centros luminescentes do cloreto de sódio e o filme de nanopartículas de prata, aumentando-se o número de bicamadas de Qt/PAA.

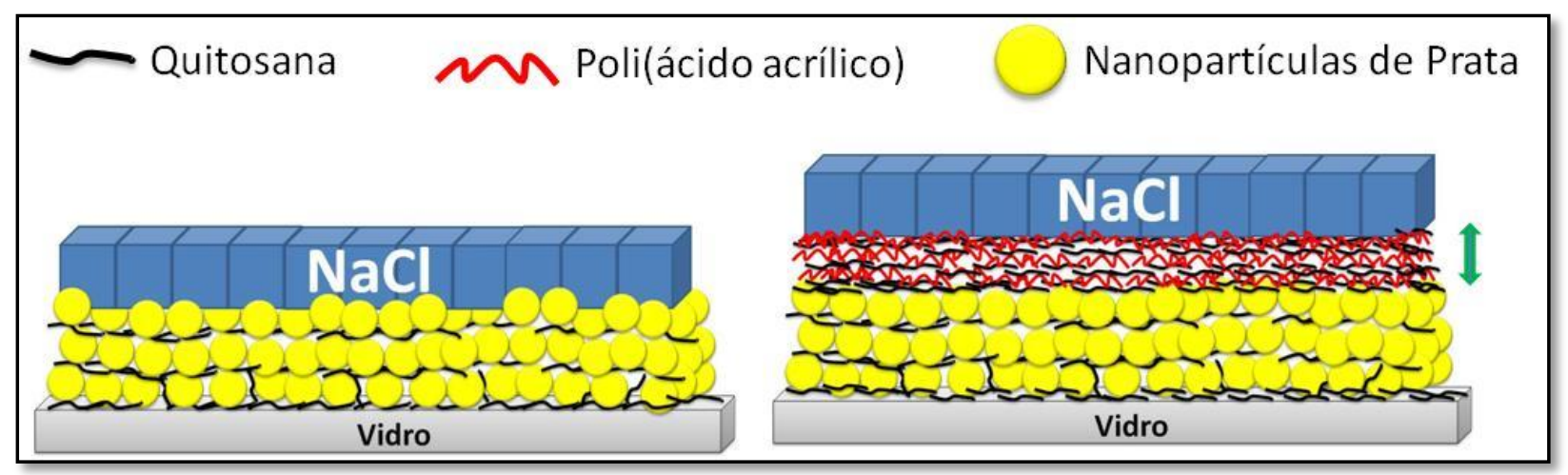

Figura 6.14: Representação da deposição de bicamadas de Qt/PAA entre o filme de nanopartículas de prata e o cloreto de sódio.

Para obter um valor médio da variação da intensidade OSL em função do número de bicamadas Qt/PAA sobre o filme de nanopartículas de prata, a produção dos filmes com 3 bicamadas de Qt/NpAg contendo os 6 diferentes números de bicamadas de Qt/PAA foram repetidas cinco vezes. Da mesma forma, as irradiações e leituras da intensidade OSL também foram repetidas cinco vezes sendo que, para cada valor do número de bicamadas, foram irradiadas e realizadas as leituras OSL de pelo menos seis filmes diferentes. Dessa forma, o desvio experimental apresentado na Figura 6.15 representa o desvio obtido desde os procedimentos de produção dos filmes, até as irradiações e leituras dos dosímetros. 


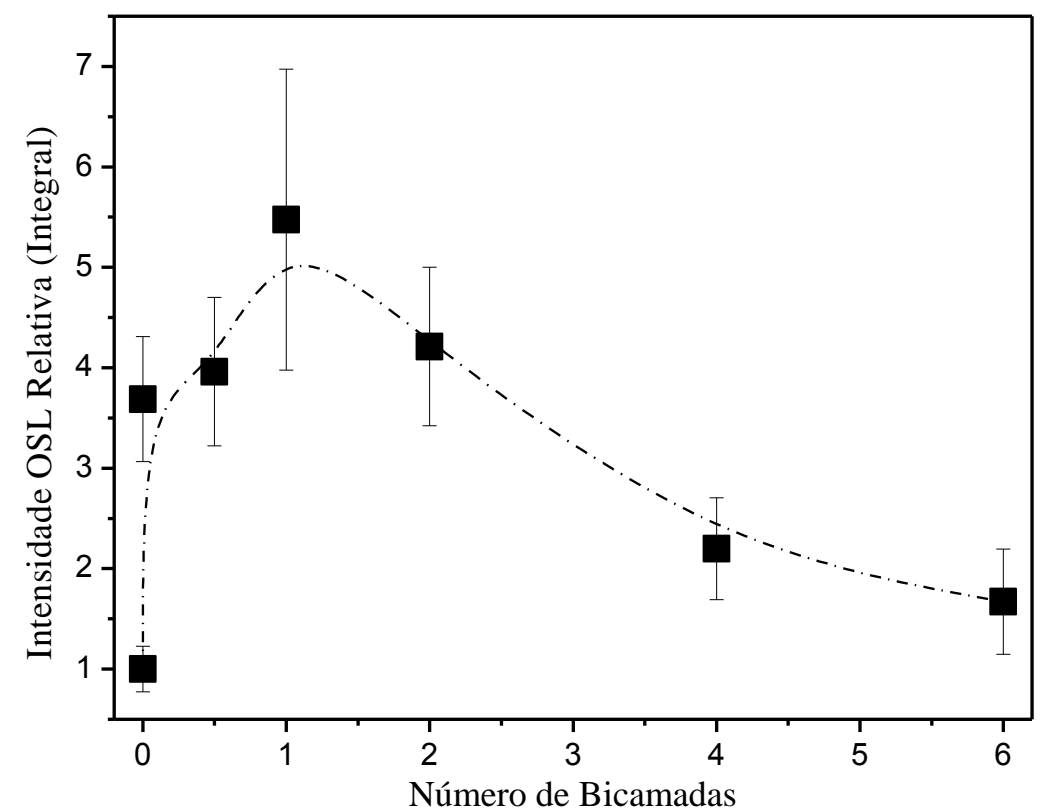

Figura 6.15: Intensidade OSL (integral) em função do número de bicamadas de Qt/PAA (espaçamento) entre o $\mathrm{NaCl}$ e o filme de nanopartículas de prata (3_NpAg). A espessura estimada de cada bicamada de Qt/PAA é de $15 \mathrm{~nm}$.

A Figura 6.15, que corresponde ao valor médio referente as cinco medidas da intensidade OSL, revela um ligeiro aumento da intensidade OSL à medida que as duas primeiras bicamadas de Qt/PAA são adicionadas sobre o filme de nanopartículas de prata, sendo que a maior intensidade OSL foi obtida para os filmes contendo uma bicamada de Qt/PAA $(\approx 15 \mathrm{~nm})$. O filme contendo duas bicamadas de Qt/PAA ainda apresentou intensidade OSL maior que o filme sem nenhuma deposição de Qt/PAA, porém a intensidade OSL obtida foi menor do que intensidade obtida para o filme com uma bicamada de Qt/PAA. Para filmes contendo mais que duas bicamadas de Qt/PAA, é possível observar um decaimento da intensidade OSL. Dessa forma, esse resultado sugere que há uma distância "ideal" entre o material dosimétrico (centros luminescentes) e os filmes de nanopartículas de prata, para aumentar/otimizar a intensidade OSL.

Além disso, o fato de que a maior intensidade OSL foi obtida para filmes com uma e duas bicamadas de Qt/PAA entre o material dosimétrico e o filmes de nanopartículas de prata (e não para as amostras em que o luminóforo foi depositado diretamente sobre o filme de nanopartículas de prata), indica que o aumento da intensidade OSL pode também ser originado pela transferência de energia do centro luminescente para os plásmons, e não unicamente devido ao aumento do campo elétrico local em torno das nanopartículas de prata. Reforça ainda essa hipótese o fato de que a intensidade OSL do $\mathrm{NaCl}$ depositado sobre o filme com seis bicamadas de Qt/PAA, o que correspondem a uma distância em torno de 90 
nm do filme de NpAgs, é cerca de duas vezes maior do que a intensidade do $\mathrm{NaCl}$ depositado sobre o vidro. Como discutido anteriormente, o aumento do campo elétrico local causa aumento das taxas de excitação e da intensidade da emissão luminescente para luminóforos com distâncias de até $10 \mathrm{~nm}$ da nanoestrutura metálica.

Portanto, a Figura 6.15 sugere que elétrons presos em uma dada armadilha são liberados para a banda de condução durante a estimulação OSL, até serem capturados por centros de recombinação. Os centros de recombinação no estado excitado relaxam por meio de uma transferência de energia para os plásmons na superfície das nanopartículas metálicas, produzindo aumento da intensidade OSL. A Figura 6.16 ilustra esse processo.

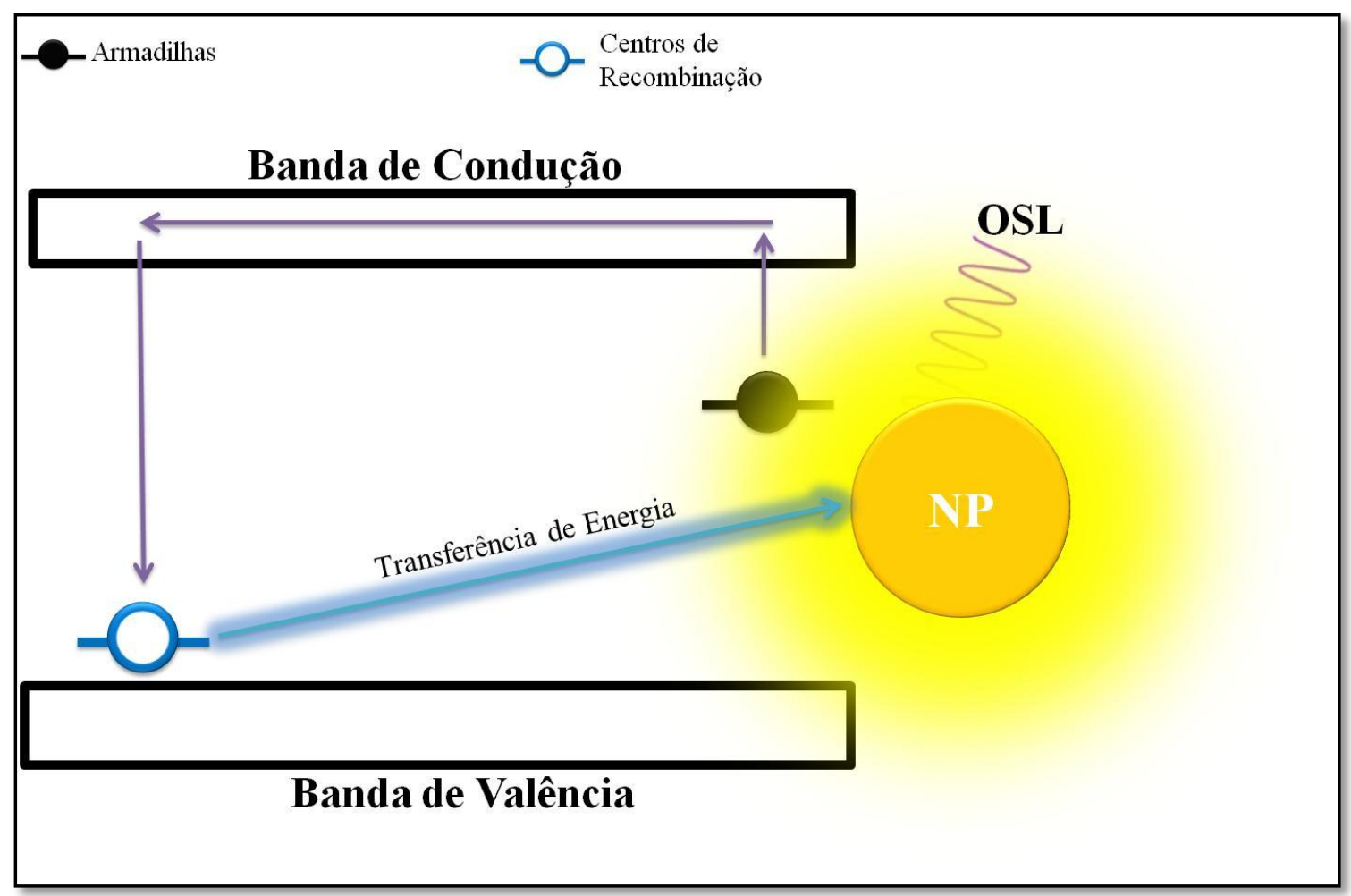

Figura 6.16: Ilustração das transições eletrônicas e da transferência de energia envolvidas no processo de luminescência opticamente estimulada em condições de ressonância plasmônica.

\subsubsection{Variação na Forma da Curva OSL}

De acordo com as equações que descrevem a curva OSL (Equações 13 e 14), caso o aumento da intensidade OSL fosse causado exclusivamente pelo aumento dos campos elétricos locais e a consequente maior taxa de excitação dos centros luminescentes, esse 
processo seria semelhante ao observado para uma amostra submetida à crescentes potências de estimulação OSL e, portanto, seria esperado que a curva OSL apresentasse uma intensidade inicial maior e decaimento mais rápido. Isso porque, considerando-se que o número de elétrons armadilhados é proporcional a dose de radiação recebida pela amostra, e que todas as amostras receberam exatamente a mesma dose de radiação, então, uma maior taxa de excitação dos elétrons armadilhados teria como consequência um esvaziamento mais rápido das armadilhas eletrônicas e, portanto, deveria produzir um decaimento mais rápido da curva OSL.

A Figura 6.17 mostra as curvas OSL normalizadas pela intensidade inicial, obtidas para amostras de $\mathrm{NaCl}$ em pó, irradiadas com a mesma dose, e com leituras OSL realizadas com potências do LED de 3, 5, 9, 12 e 15\%. Essas medidas foram realizadas na Oklahoma State Univesity, com um equipamento Riso. Como esperado teoricamente, o aumento da potência de estimulação causa o aumento da intensidade OSL inicial, mas o decaimento da curva se torna mais rápido.

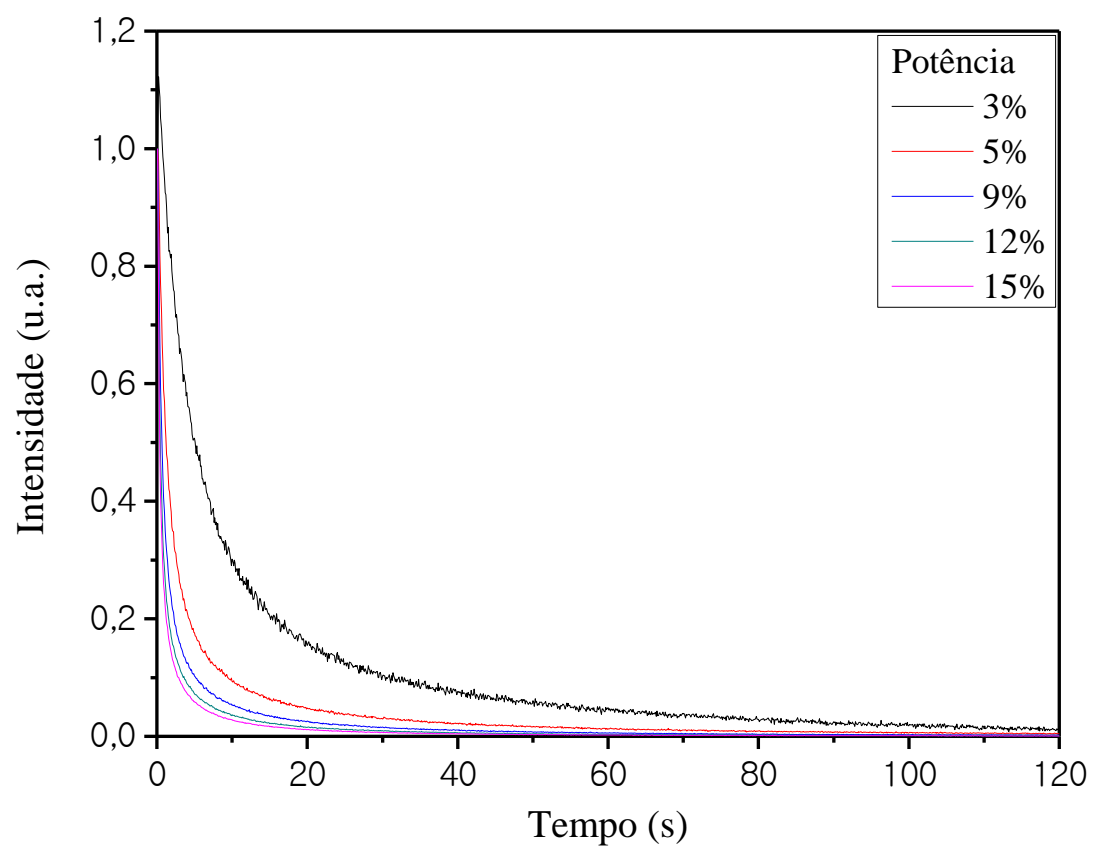

Figura 6.17: Curvas OSL normalizadas pela intensidade inicial, de amostras em pó de cloreto de sódio irradiadas com a mesma dose e obtidas com diferentes potências de estimulação OSL.

A Figura 6.18 mostra as curvas OSL normalizadas para o $\mathrm{NaCl}$ depositado sobre o vidro e sobre os filmes com 3, 5 e 10 bicamadas de Qt/NpAg. É possível observar que à medida que aumenta o número de bicamadas de nanopartículas de prata (aumenta a intensidade da banda de ressonância plasmônica), o decaimento da curva OSL torna-se mais 
lento. Assim, esse resultado não exclui a hipótese de que o aumento da intensidade OSL seja causado pelo aumento dos campos elétricos locais em torno das nanopartículas metálicas em ressonância plasmônica, mas evidencia, mais uma vez, que esse pode não ser o único processo físico que determina o aumento OSL. O decaimento da curva OSL mais lento pode ser indício de que há mudanças nas taxas de decaimentos radiativos e/ou não radiativos do cloreto de sódio quando próximo das nanopartículas metálicas, de forma a aumentar a taxa de decaimento radiativo e/ou diminuir a taxa de decaimento não radiativo. Assim, quando desarmadilhados, mais elétrons decaem por processos radiativos, ao invés de processos não radiativos, aumentando a luminescência opticamente estimulada.

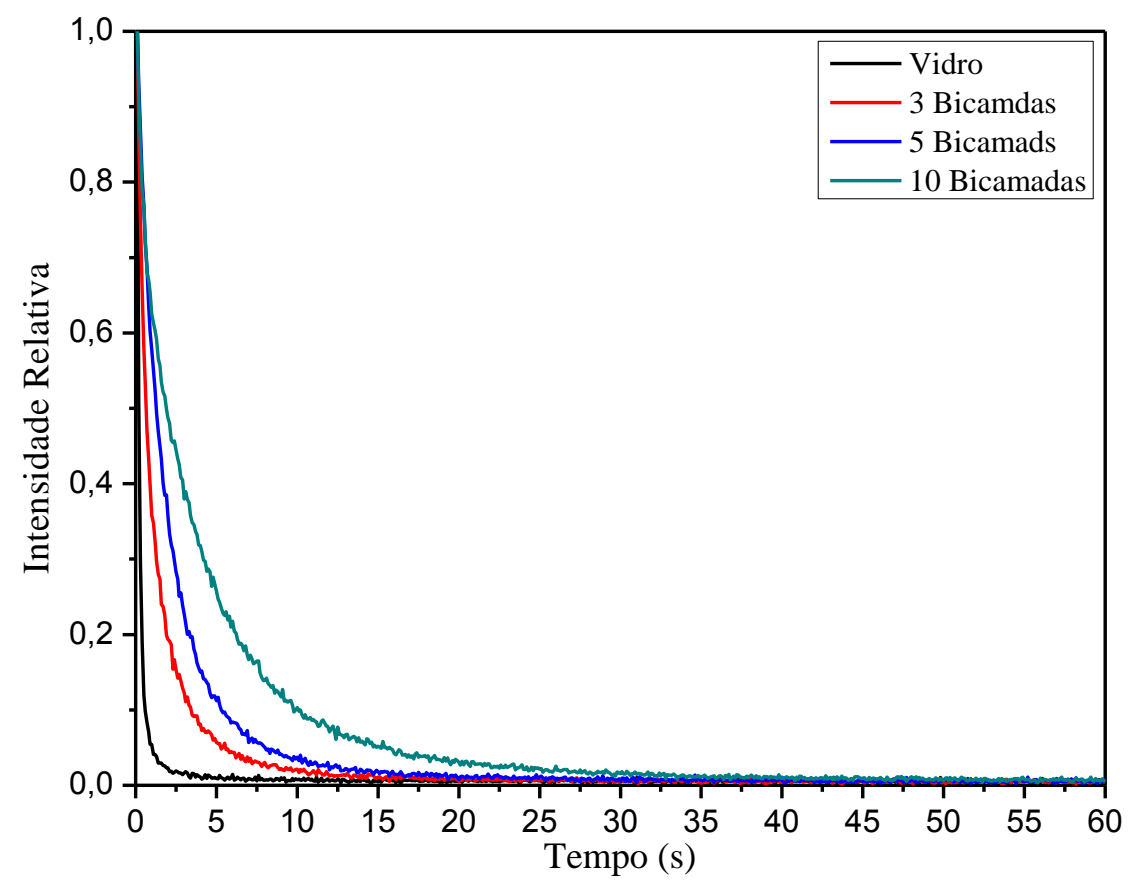

Figura 6.18: Curvas OSL do $\mathrm{NaCl}$ depositados sobre filmes com 3, 5 e 10 bicamadas de $\mathrm{Qt} / \mathrm{NpAg}$, normalizadas pela intensidade inicial das respectivas curvas.

A Figura 6.19 mostra as curvas OSL normalizadas para o $\mathrm{NaCl}$ depositado sobre os filmes com 1, 2, 4 e 6 bicamadas de Qt/PAA. Fica evidente que à medida que se aumenta 0 número de bicamadas de Qt/PAA, o decaimento da curva OSL torna-se mais rápido. Isso significa que o decaimento da curva OSL é mais lento somente quando o $\mathrm{NaCl}$ está próximo aos filmes de NpAgs. 


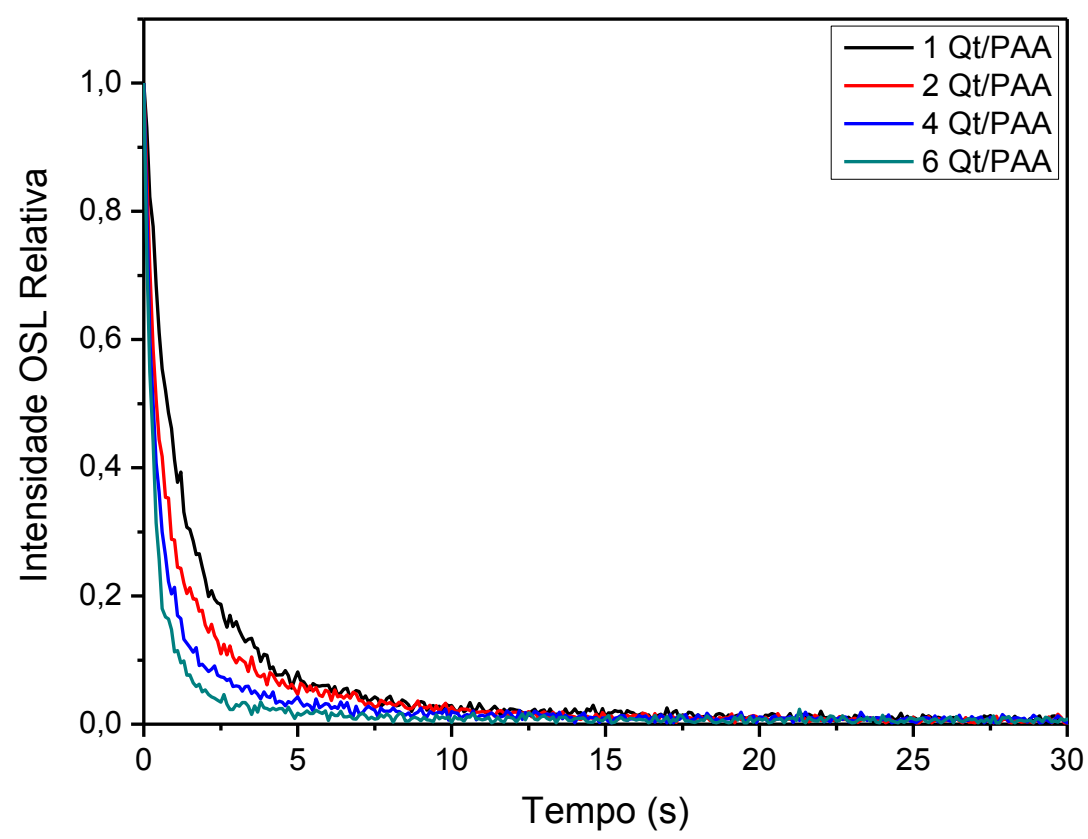

Figura 6.19: Curvas OSL normalizadas para o $\mathrm{NaCl}$ depositado sobre os filmes com 1, 2, 4 e 6 bicamadas de Qt/PAA, sobre filmes com 3 bicamadas de Qt/NpAg.

Recentemente, alguns autores reportaram a existência de um fenômeno de recuperação do sinal OSL do cloreto de sódio [111], e esse fenômeno físico pode ajudar na melhor compreensão da interação entre o $\mathrm{NaCl}$ e o filme de nanopartículas de prata, como será explicado a seguir. Os autores observaram que havia um ganho na intensidade OSL ao realizar uma segunda leitura OSL (modo contínuo) alguns minutos após a primeira leitura, de forma que a intensidade OSL inicial da segunda leitura era maior que a intensidade OSL final da primeira leitura. O modelo físico apresentado pelos autores propõe a existência de armadilhas insensíveis (ou muito pouco sensíveis) à estimulação óptica, permitindo que elétrons permaneçam presos na banda proibida do $\mathrm{NaCl}$, mesmo após uma leitura OSL completa [111]. Em outras palavras, existem armadilhas com pequenas seções de choque de fotoionização que mantêm elétrons aprisionados mesmo após o estímulo óptico. Assim, com o esvaziamento das armadilhas opticamente estimuláveis (armadilhas com grandes seções de choque de fotoionização), alguns elétrons presos nas armadilhas opticamente não estimuláveis são transferidos para armadilhas opticamente estimuláveis (Figura 6.20), e uma pequena recuperação do sinal OSL pode então ser observada na segunda leitura. 


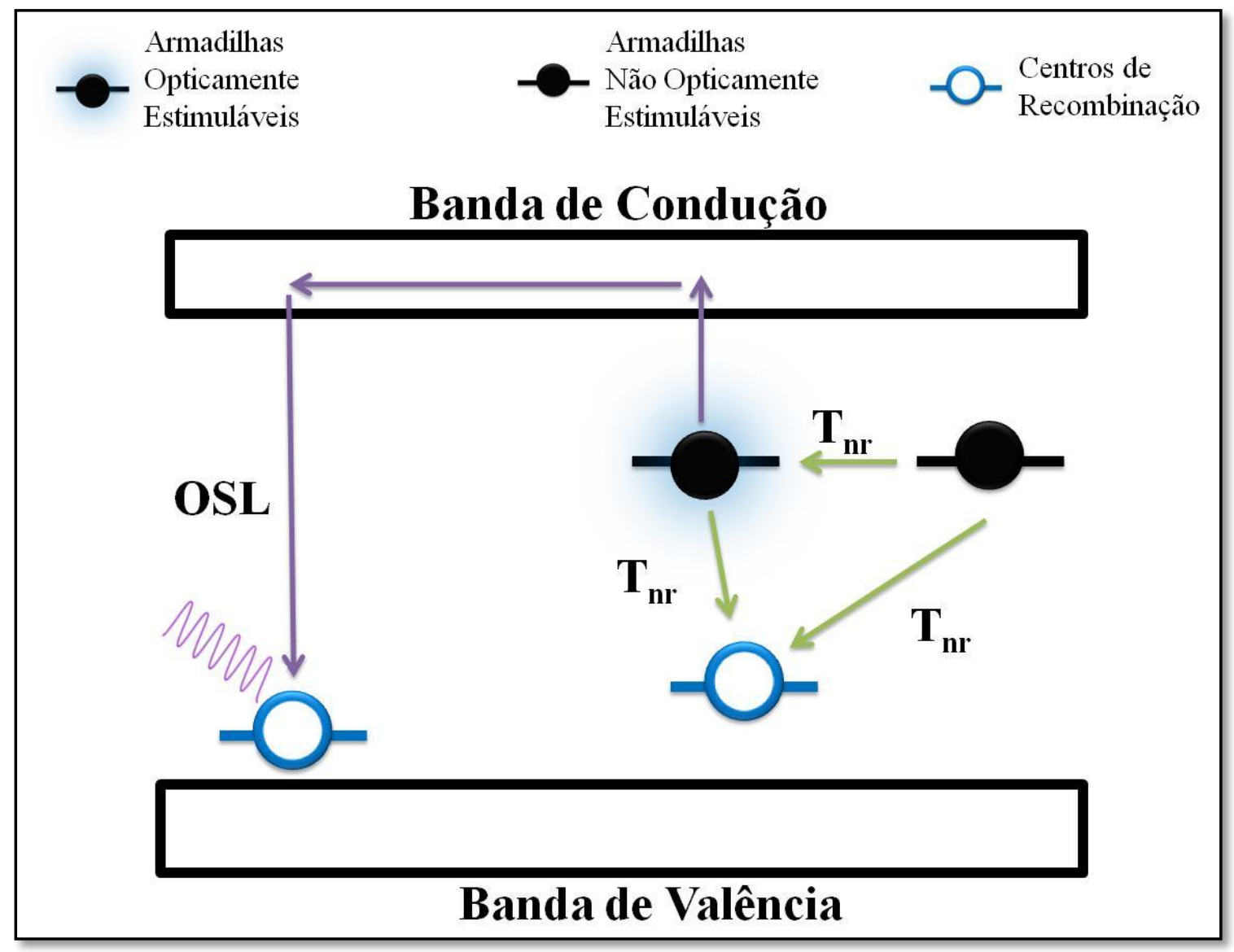

Figura 6.20: Ilustração das transições eletrônicas radiativas (OSL) e não radiativas $\left(\mathrm{T}_{\mathrm{nr}}\right)$, envolvidos nos processos de emissão e recuperação do sinal OSL do cloreto de sódio ${ }^{[111]}$.

Essa recuperação da intensidade OSL pôde também ser observada nas amostras de $\mathrm{NaCl}$ depositado sobre vidro. A Figura 6.21 mostra a primeira leitura OSL de uma amostra de $\mathrm{NaCl}$ depositada sobre vidro e irradiada com $10 \mathrm{~Gy}$, com tempo de leitura de 30 segundos. É evidente que o sinal OSL é totalmente nulo para tempos de leitura maiores que $15 \mathrm{~s}$. No entanto, houve uma recuperação do sinal OSL, sendo a intensidade OSL inicial para a segunda leitura (realizada dez minutos mais tarde) cerca de $10 \%$ da intensidade OSL inicial da primeira leitura. Essa recuperação é atribuída ao processo de transferência de elétrons de armadilhas não opticamente estimuláveis para armadilhas opticamente estimuláveis, como discutido no parágrafo anterior, e mais detalhadamente descrita na referência [111]. 


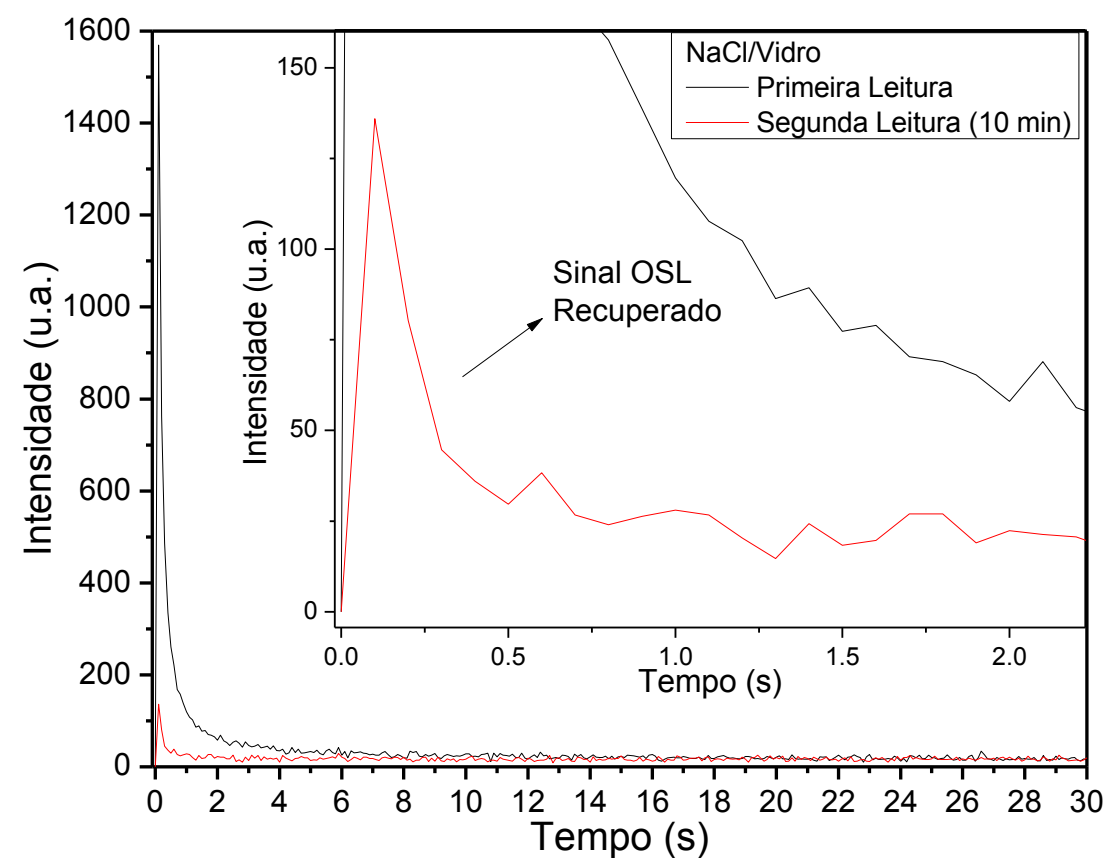

Figura 6.21: Primeira e segunda leitura do sinal OSL para o $\mathrm{NaCl}$ depositado sobre vidro. A segunda leitura, realizada 10 minutos após a primeira leitura, evidencia a recuperação do sinal OSL.

A Figura 6.22 mostra a primeira leitura OSL de uma amostra de $\mathrm{NaCl}$ depositada sobre o filme 10_NpAg/vidro e irradiada com $10 \mathrm{~Gy}$, com tempo de leitura de 30 segundos. Devido à maior intensidade e ao maior tempo de decaimento da curva OSL do $\mathrm{NaCl}$ depositado sobre o filme de nanopartículas de prata, o sinal OSL torna-se nulo apenas para tempos de estimulação em torno de 30 s. Porém, não há recuperação do sinal OSL para a segunda leitura OSL realizada dez minutos mais tarde, e a leitura apresentou apenas o ruído de fundo (inset da Figura 6.22). 


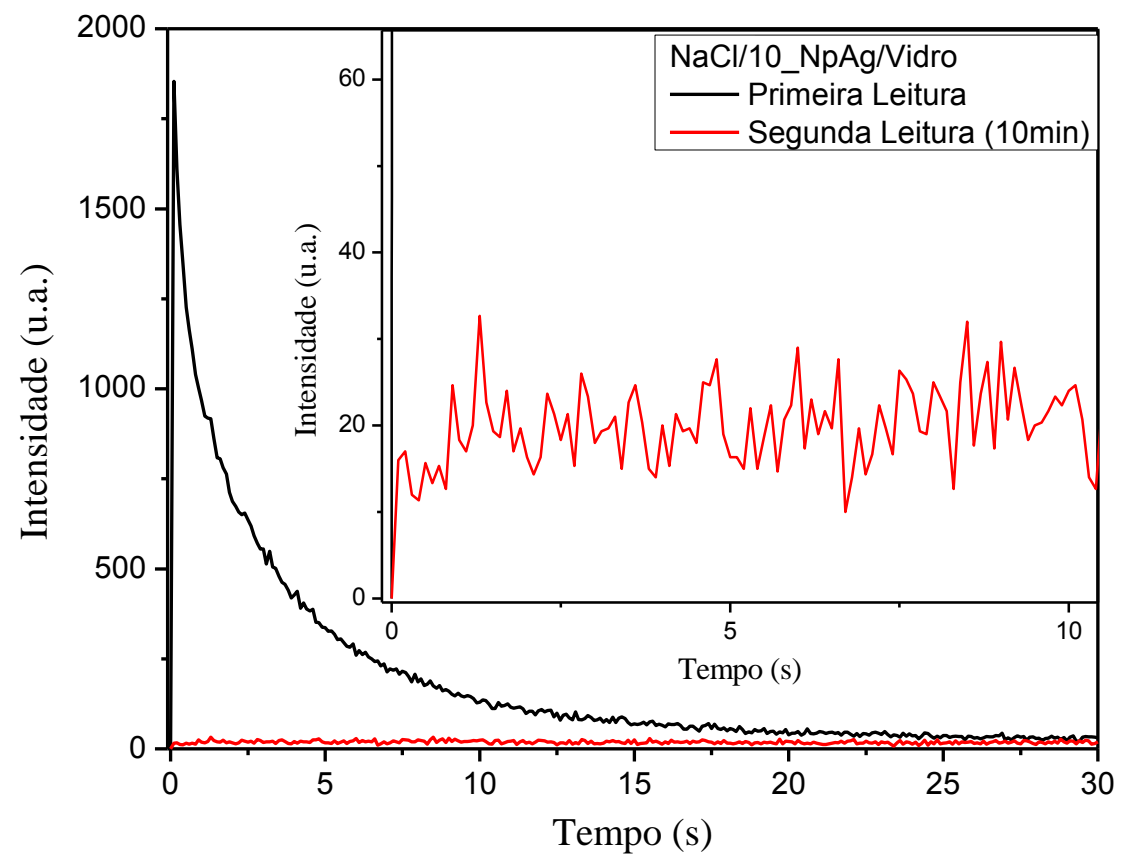

Figura 6.22: Primeira e segunda leitura do sinal OSL para o $\mathrm{NaCl}$ depositado sobre o filme 10_NpAg/vidro. Não há recuperação do sinal OSL na segunda leitura, evidenciando o total esvaziamento de armadilhas eletrônicas durante a primeira leitura.

A não recuperação do sinal OSL para a segunda leitura do dosímetro e o grande aumento da intensidade OSL observada na primeira leitura do $\mathrm{NaCl}$ depositado sobre o filme de nanopartículas de prata, sugerem que todos os elétrons são liberados das armadilhas do cloreto de sódio durante a primeira leitura, recombinando-se, preferencialmente, por meio de transições radiativas. São liberados até mesmo os elétrons presos em armadilhas com pequenas seções de choque de fotoionização, provavelmente devido a uma rápida transferência de elétrons para armadilhas opticamente estimuláveis ainda durante a leitura OSL. Em outras palavras, em condições de ressonância plasmônica, há uma população maior de armadilhas que participam do processo OSL.

Para o $\mathrm{NaCl}$ depositado sobre o vidro, o sinal OSL decai rapidamente devido ao rápido esvaziamento das armadilhas com grandes seções de choque de fotoionização. Os elétrons presos em armadilhas com pequenas seções de choque de fotoionização não são liberados com a estimulação OSL, sendo que parte se transfere para armadilhas com maior seção de choque de fotoionização causando a regeneração parcial do sinal OSL, e parte acaba se recombinado por meio de transições não radiativas. Para o $\mathrm{NaCl}$ depositado sobre o filme de NpAgs, os elétrons presos em armadilhas com pequena seção de choque de fotoionização são transferidos para as armadilhas com maior seção de choque de fotoionização, possivelmente devido ao aumento dos campos elétricos locais (Figura 6.23). Essa 
transferência de elétrons faz com que as armadilhas opticamente ativas continuem sendo preenchidas enquanto houver elétrons aprisionados em armadilhas não opticamente ativas. Portanto, as armadilhas opticamente ativas acabam demorando mais tempo para serem esvaziadas, aumentando o tempo de decaimento da curva OSL.

Uma vez que, devido ao aumento dos campos elétricos em torno das nanopartículas metálicas, elétrons oriundos de armadilhas não opticamente ativas são transferidos para armadilhas opticamente ativas, mais elétrons acabam contribuindo para o sinal OSL, ocasionando também o aumento da intensidade OSL. Como mostrado na Figura 6.19, à medida que o espaçamento entre o $\mathrm{NaCl}$ e o filme de $\mathrm{NpAgs} \mathrm{aumenta,} \mathrm{o} \mathrm{decaimento} \mathrm{da} \mathrm{curva}$ OSL volta a ser mais rápido. Esse resultado sugere que o processo de transferência de elétrons para as armadilhas opticamente estimuláveis depende do aumento dos campos elétricos locais, visto que ocorre somente para regiões próximas ao filme de nanopartículas de prata.

Logo, o aumento da intensidade OSL ocorre por dois processos. Para amostras em que o $\mathrm{NaCl}$ está depositado próximo ao filme de nanopartículas, o aumento da intensidade OSL é causado tanto pela transferência de elétrons originalmente presos em armadilhas com pequenas seção de choque de fotoionização para armadilhas com maiores seção de choque de fotoionização, quanto pela transferência de energia dos centros de recombinação para os plásmons. À medida que o $\mathrm{NaCl}$ é distanciado do filme de nanopartículas de prata, a transferência de elétrons entre armadilhas é cessada, e o aumento da intensidade OSL ocorre devido a transferência de energia dos centros de recombinação/ luminescentes, para os plásmons.

Dado que a seção de choque de uma nanopartícula metálica em condições de ressonância plasmônica pode ser da ordem de $10^{5}$ vezes maior que a de um luminóforo [3638], outra possibilidade para a total liberação de elétrons durante a primeira leitura seria o aumento da seção de choque de fotoionização das armadilhas não opticamente estimuláveis (armadilhas com pequenas seção de choque), causado pelo acoplamento plasmônico com as nanopartículas de prata em condições de ressonância plasmônica. Esse aumento da seção de choque faria com que essas armadilhas fossem diretamente estimuladas e esvaziadas durante a leitura OSL, não havendo transferência de elétrons entre armadilhas. 


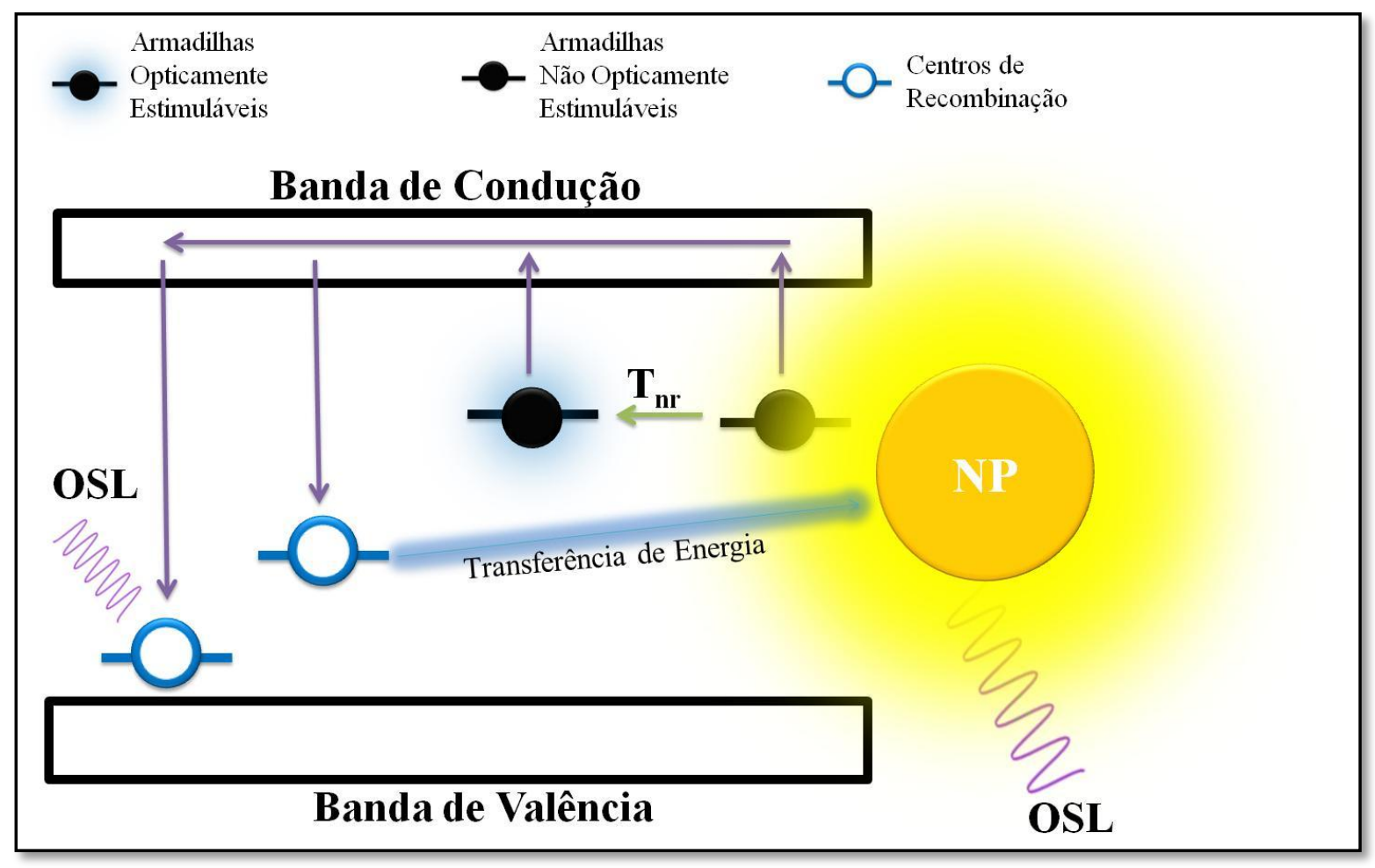

Figura 6.23: Ilustração das transições eletrônicas radiativas (OSL), não radiativas ( $\mathrm{T}_{\mathrm{nr}}$ ), e do processo de transferência de energia, envolvidos nos processos de emissão do sinal OSL do cloreto de sódio em condições de ressonância plasmônica.

Nesse sentido, o aumento da intensidade OSL bem como o decaimento mais longo da curva, são consequências da redução da taxa de decaimento não radiativo de elétrons presos em armadilhas opticamente não estimuláveis, seja pela transferência de elétrons para armadilhas opticamente estimuláveis durante a leitura OSL, ou pelo aumento da seção de choque de fotoionização de armadilhas não opticamente estimuláveis. Além disso, o fato de que há aumento da intensidade OSL mesmo para o $\mathrm{NaCl}$ depositado a uma distância de cerca de $90 \mathrm{~nm}$ do filme de nanopartículas de prata, evidencia que a transferência de energia dos centros luminescentes/ recombinação para os plásmons também contribui para o aumento da intensidade OSL.

A Figura 6.24 mostra a curva dose resposta para o $\mathrm{NaCl}$ depositado sobre o vidro e sobre o filme 3_NpAg. É possível observar que, embora a intensidade e a forma da curva OSL sejam alteradas pela presença do filme nanoestruturado, não é alterada a linearidade característica da curva dose-reposta do $\mathrm{NaCl}$, no intervalo de dose estudado. 


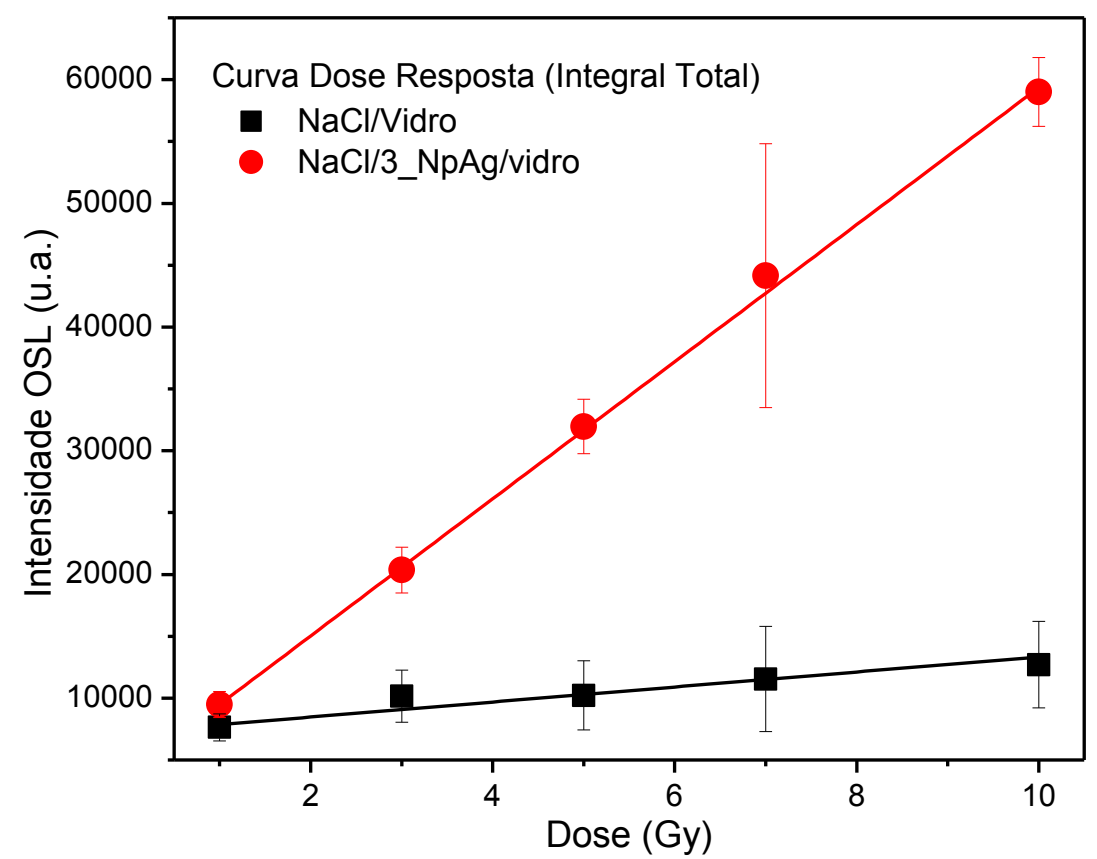

Figura 6.24: Curva dose-resposta para o $\mathrm{NaCl}$ depositado sobre o vidro e sobre o filme 3_NpAg.

\subsection{Conclusões}

$\mathrm{O}$ aumento da intensidade OSL do $\mathrm{NaCl}$ depositado sobre os filmes nanoestruturados de prata indica que o aumento de luminescência não é causado pela criação de defeitos na estrutura cristalina do $\mathrm{NaCl}$, reforçando a hipótese de que o aumento de luminescência seja causado pelas propriedades plasmônicas do filme. A intensidade OSL (integral) aumenta linearmente em função do coeficiente de extinção dos filmes. Houve grande aumento da intensidade OSL para filmes depositados sobre vidro e aumentos bem menos significativos para os filmes depositados sobre alumínio. O sinal OSL aumenta com o distanciamento do filme de NpAgs em relação ao substrato de alumínio, sugerindo que a interação entre as nanopartículas de prata e suas imagens projetadas no substrato metálico diminuem a intensidade dos campos elétricos em torno das nanopartículas em ressonância plasmônica.

Com relação ao espaçamento entre o $\mathrm{NaCl}$ e o filme de $\mathrm{NpAg}$ /vidro, a maior intensidade OSL foi obtida para uma distância de cerca de $15 \mathrm{~nm}$ (1 bicamada Qt/PAA), sugerindo que o aumento dos campos elétricos locais não é o único responsável pelo aumento da intensidade OSL. Além disso, o fato de que há aumento da intensidade OSL mesmo quando o $\mathrm{NaCl}$ está depositado a uma distância de $90 \mathrm{~nm}$, evidencia que há uma transferência de energia do centro de recombinação para os plásmons, que por sua vez irradia em campo distante. A maior intensidade OSL, o maior tempo de decaimento da curva OSL e a não 
regeneração do sinal OSL do $\mathrm{NaCl}$ depositado sobre o filme de NpAgs, sugerem que, quando o $\mathrm{NaCl}$ está próximo ao filme de nanopartículas, há uma transferência de elétrons de armadilhas não opticamente estimuláveis para armadilhas opticamente estimuláveis, aumentando a população de elétrons que decai radiativamente e que contribui para o sinal OSL.

Vale ressaltar ainda que, enquanto o decaimento mais rápido da curva OSL das amostras de $\mathrm{ZnO}$ contendo nanopartículas de prata indicou aumento da taxa de desarmadilhamento de elétrons, o decaimento mais lento do $\mathrm{NaCl}$ quando depositado sobre filmes de nanopartículas de ouro e prata indica o aumento do número de armadilhas e de elétrons que participam do processo de emissão OSL. Dessa forma, a redução da taxa de decaimento não radiativo ocorre devido a contribuição de armadilhas que, na ausência de nanoestruturas metálicas, não participam do processo OSL por causa da pequena seção de choque de fotoionização.

Para distâncias maiores $(90 \mathrm{~nm})$, a redução do tempo de decaimento da curva OSL e o fato de que ainda há aumento da intensidade OSL, sugere que há uma transferência de energia dos centros de recombinação para os plásmons, e não há transferência de elétrons entre as armadilhas. Portanto, há acoplamento plasmônico tanto no processo de estimulação quanto no processo de emissão OSL. A contribuição de cada um desses processos para o sinal OSL depende da distância entre as armadilhas, os centros luminescentes/recombinação e o filme nanoestruturado. 


\section{Estudo e Caracterização dos Filmes de Nanopartículas de Ouro}

Os capítulos anteriores responderam à quase todas as questões que haviam no início do desenvolvimento desse projeto. Dentre as respostas obtidas destacam-se as evidências de que a intensificação dos campos elétricos locais aumenta a taxa de desarmadilhamento de elétrons durante a estimulação OSL; que o acoplamento plasmônico também pode modificar as taxas de decaimentos radiativos e não radiativos, produzindo aumento da intensidade OSL; e que as interações entre as armadilhas/centros luminescentes e os plámons variam de acordo com a distância entre as partes. Resta ainda verificar se as variações na posição da banda plasmônica também influenciam a luminescência opticamente estimulada. Neste último capítulo serão investigadas as propriedades plasmônicas de filmes de ouro para o aumento da intensidade OSL, uma vez que sua banda de ressonância plasmônica é deslocada em cerca de 120 nm com relação à banda de ressonância plasmônica da prata.

Os filmes de ouro foram depositados por sputtering devido à algumas vantagens como maior controle da espessura e da quantidade de material depositado nos filmes. Além disso, íons de ouro não são tão bons ativadores de luminescência, como é o caso de íons de prata. Assim, a possibilidade de que o aumento de luminescência seja causado pela ativação do cloreto de sódio devido à difusão de íons metálicos provenientes do filme torna-se irrelevante. Como a banda plasmônica do ouro é deslocada em cerca de $120 \mathrm{~nm}$ com relação à banda de ressonância plasmônica da prata, a interação $\mathrm{NaCl} / \mathrm{NpAu}$ deve ser diferente da interação $\mathrm{NaCl} / \mathrm{NpAg}$. Será também investigada a influência do número atômico do substrato na luminescência opticamente estimulada: é possível que o aumento da intensidade OSL seja consequência do maior número atômico dos filmes metálicos em relação ao vidro?

\subsection{Espectroscopia UV-Vis}

A Figura 7.1 mostra o espectro de absorção UV-Vis do filme de nanopartículas de ouro obtidos com tempo de deposição de $50 \mathrm{~s}$. É possível observar a presença de um pico bem definido em $585 \mathrm{~nm}$, referente à banda de ressonância plasmônica de nanopartículas de ouro. Para maiores tempos de deposição de ouro, a banda de ressonância plasmônica torna-se mais intensa, porém, mais larga, estendendo-se por toda a região visível. Esse alargamento da banda de ressonância plasmônica pode indicar aglomeração e/ou crescimento das 
nanopartículas de ouro no filme, ou ainda, pode ser causada pela maior proximidade das nanopartículas de ouro devido ao aumento da massa de ouro depositada.
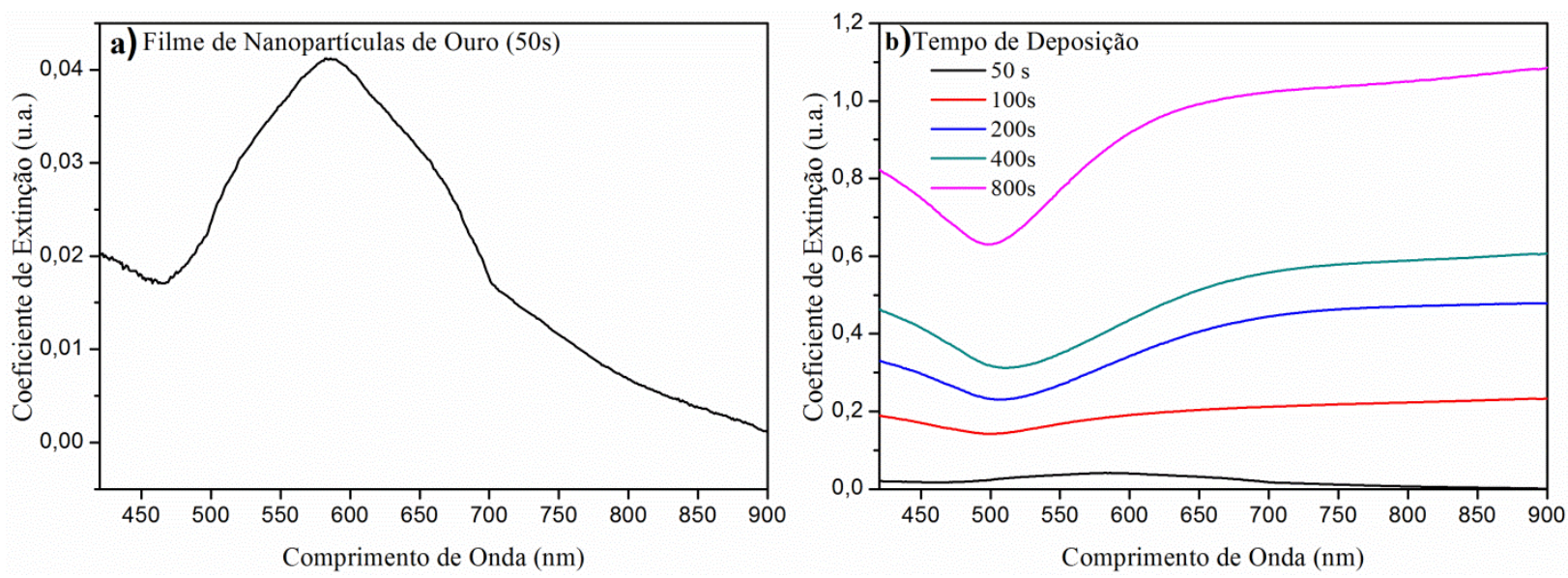

Figura 7.1: (a) Banda de ressonância plasmônica do filme de ouro com $50 \mathrm{~s}$ de deposição e para os demais tempos de deposição (b).

A Figura 7.2 evidencia ainda um deslocamento da banda de ressonâcia plasmônica para maiores comprimentos de onda. Como discutido anteriormente, o deslocamento da banda de ressonância plasmônica para maiores comprimentos de onda pode ocorrer devido à redução do espaçamento e ao maior acoplamento entre as nanopartículas [89]. Para luz polarizada logitudinalmente às partículas, a banda plasmônica desloca-se para maiores comprimentos de onda à medida que a distância entre as nanopartículas diminui porque a atração entre as cargas na superfícies de nanopartículas vizinhas diminui a energia necessária para induzir a oscilacão plasmônica coletiva das nanopartículas [89-91]. Efeito contrário ocorre para o caso da polarização transversal. No entanto, os deslocamentos para menores comprimentos de onda originados pela polarização transversal são moderados quando comparados aos deslocamentos para maiores comprimentos de onda causados pela polarização longitudinal $[89,92]$. 


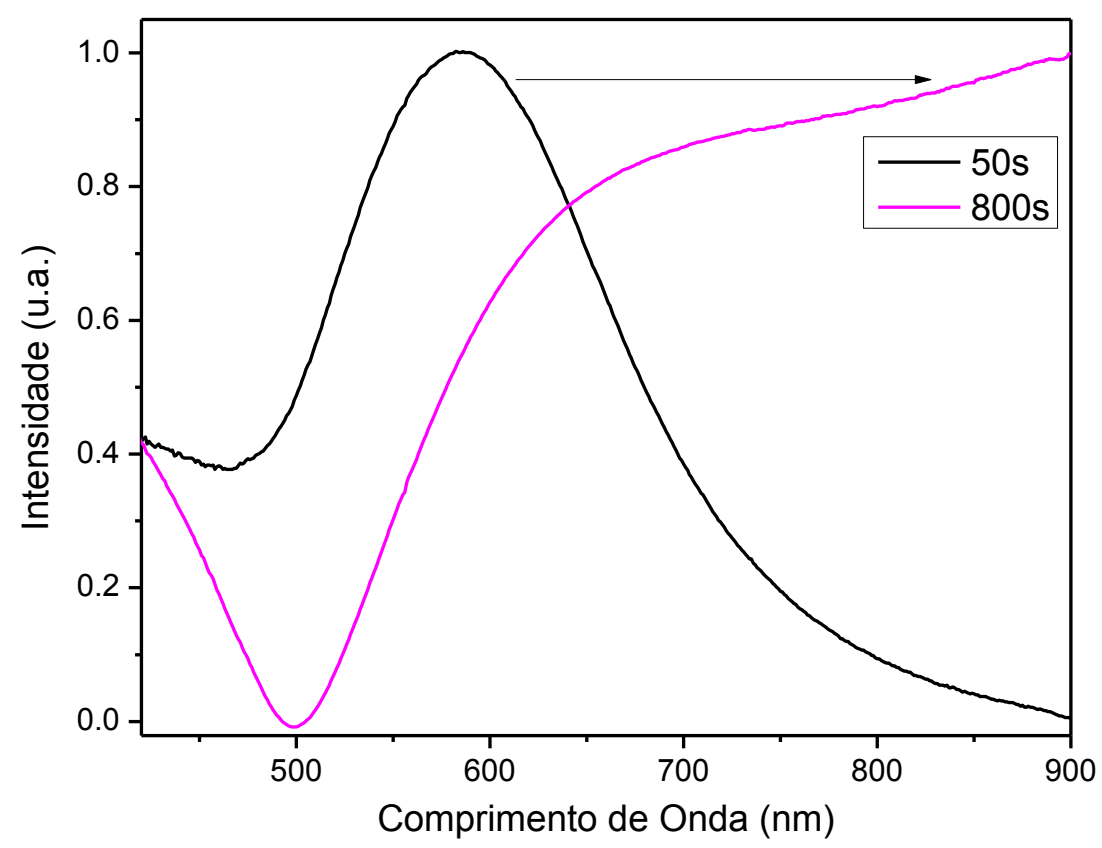

Figura 7.2: Banda de ressonância plasmônica do filme de ouro com 50 s e 800 s de deposição.

Além disso, o deslocamento do pico de ressonância plasmônica para maiores comprimentos de onda pode também estar associado ao crescimento e/ou agregação das nanopartículas de ouro devido ao aumento da massa de ouro nos filmes [27, 93]. Logo, o deslocamento e alargamento da banda plasmônica causado pelo aumento do tempo de deposição de ouro pode estar associado a menor distância e/ou agregação/crescimento das partículas do filme.

\subsubsection{Influência do Tempo de Deposição no Coeficiente de Extinção dos Filmes de Ouro}

A Figura 7.3 revela o comportamento do coeficiente de extinção dos filmes em função do tempo de deposição de ouro. Esse comportamento não linear revela uma "desaceleração" do coeficiente de extinção à medida que aumenta o tempo de deposição de ouro. Uma possível causa para essa observação pode estar relacionada às mudança estruturais do filme, como evidenciado pelos espectros UV-Vis. À medida que aumenta-se a massa de ouro presente no filme, diminui-se as distâncias entre as nanopartículas. Dessa forma, é possível que a grande proximidade entre elas faça com que as nanopartículas de ouro localizadas abaixo da superfície coaslesçam. A maior proximidade entre as partículas e/ou a presença de 
partículas maiores devido a coalescência, faz com que os elétrons livres em partículas metálicas experimentem um atraso de fase [112-113], dando origem a modos de ressonâncias de mais altas ordens, tendo como consequência o alargamento da banda de ressonância plasmônica e a redução do valor de seu coeficiente de extinção, proporcionalmente à massa de ouro.

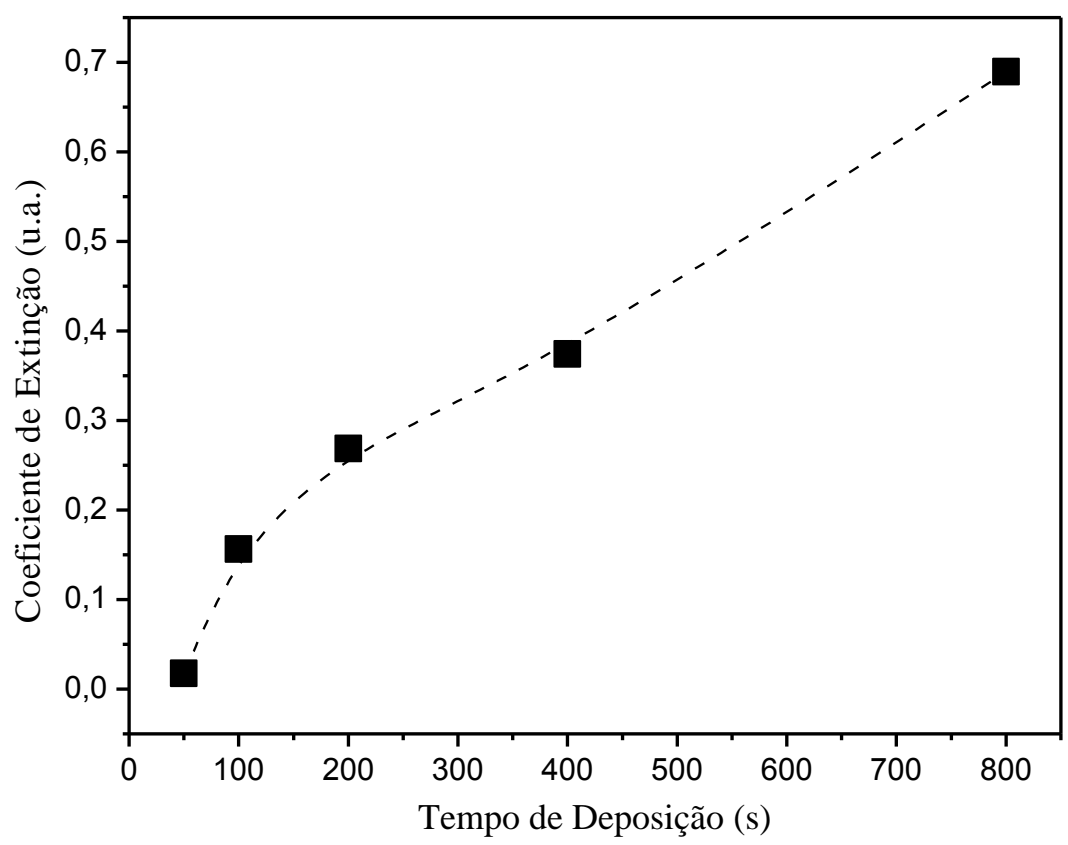

Figura 7.3: Coeficiente de extinção em $470 \mathrm{~nm}$ em função do tempo de deposição dos filmes de ouro.

\subsection{Microscopia de Força Atômica}

A Figura 7.4 mostra as imagens de microscopia de força atômica dos filmes de ouro com 800 s de deposição em substrato de vidro (a) e alumínio (b). Nos dois caso é possível observar que o filme é composto por nanopartículas de ouro com tamanhos entre 20 e $40 \mathrm{~nm}$ de diâmetro. Assim, devido ao pequeno tamanho das nanopartículas de ouro presentes na superfície do filme, o alargamento da banda de ressonância plasmônica, como apontado pela espectroscopia UV-Vis, parece ser consequência da maior proximidade e da alta densidade de nanopartículas. Além disso, não há nenhum agente dispersante no filme, como por exemplo a quitosana no caso dos filmes de nanopartículas de prata. 


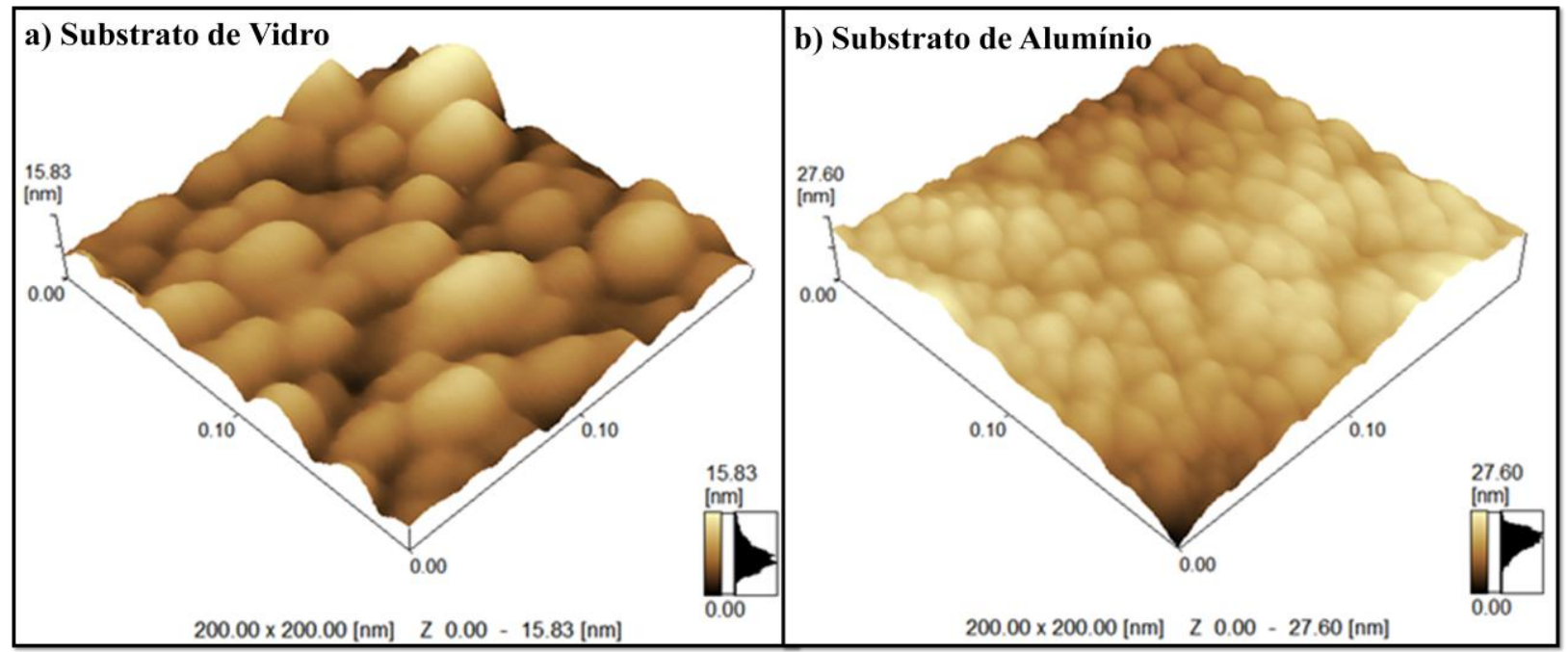

Figura 7.4: Imagens de Microscopia de Força Atômica dos filmes de ouro com $800 \mathrm{~s}$ de deposição sobre substratos de vidro (a) e alumínio (b).

É notável ainda, comparando as Figura 7.4 (a) e (b), que as nanopartículas de ouro presentes no filme depositado sobre o substrato de alumínio parecem ser menores que as nanopartículas de ouro presentes no filme sobre o vidro. A Figura 7.5 e a Figura 7.6 mostram os valores obtidos para os diâmetros das nanopartículas de ouro quando depositados em substrato de vidro e alumínio, respectivamente. 


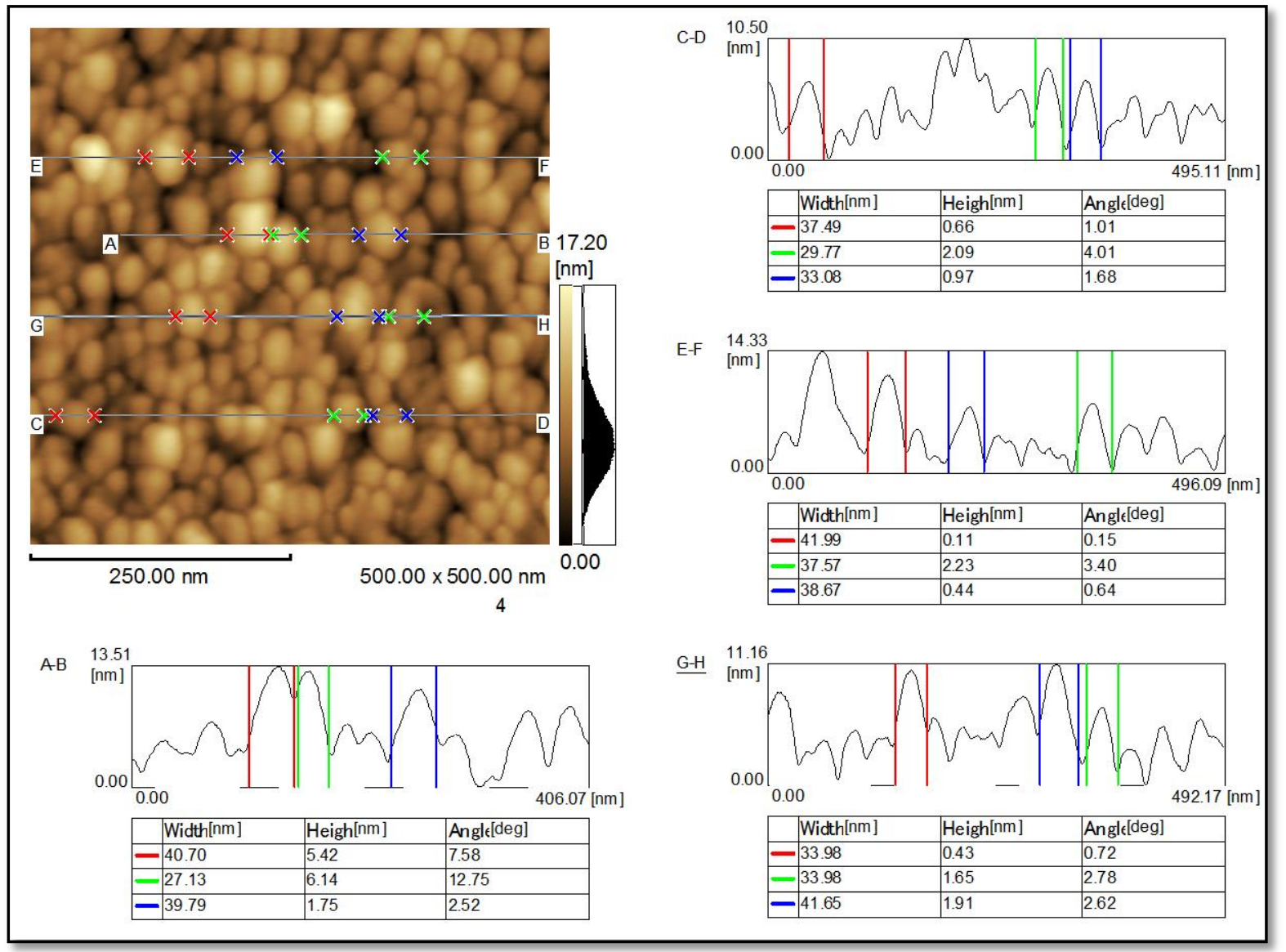

Figura 7.5: Imagens de Microscopia de Força Atômica do filmes de ouro com $800 \mathrm{~s}$ de deposição sobre substratos de vidro, evidenciando os diâmetros das nanopartículas presentes no filme.

Os valores médios para os diâmetros dessas nanopartículas de ouro foram de $23 \pm 4 \mathrm{~nm}$ e $34 \pm 7 \mathrm{~nm}$, para os filmes depositados sobre o substrato de alumínio e vidro, respectivamente. Portanto, as nanopartículas de ouro presentes nos filmes depositados sobre o substrato de vidro apresentam um diâmetro maior comparado às nanopartículas presentes no filme depositado sobre o substrato de alumínio, embora as diferenças de tamanho observadas estejam no limite das incertezas. 


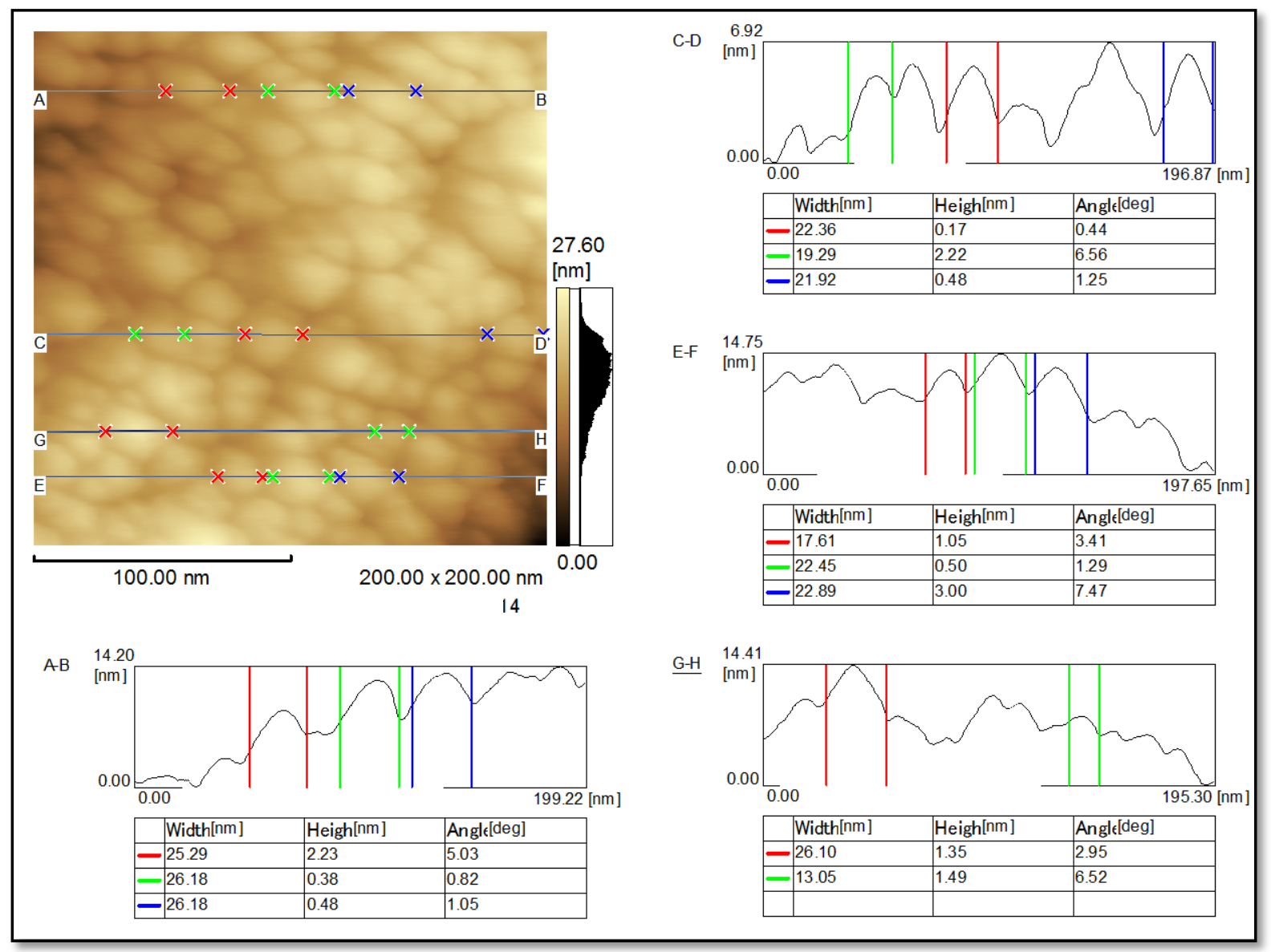

Figura 7.6: Imagens de Microscopia de Força Atômica dos filmes de ouro com $800 \mathrm{~s}$ de deposição sobre substratos de alumínio, evidenciando os diâmetros das nanopartículas presentes no filme.

A técnica de sputtering baseia-se no bombardeamento de uma superfície metálica por partículas energéticas. Os átomos do material alvo são então ejetados e podem ser depositados em um dado substrato, formando um filme. Uma vez que os átomos ejetados apresentam uma energia cinética relativamente alta quando comparadas a outras formas de deposição de filmes (como a evaporação térmica, por exemplo) os átomos depositados tem grande probabilidade de serem embebidos na superfície do material que compõe o substrato, formando uma alta densidade de centros de nucleação. Subsequente deposição causa o crescimento dos centros de nucleação até que um filme contínuo seja formado [114]. Assim, o substrato pode influenciar na morfologia e na estrutura cristalina do filme de ouro. Alguns autores mostraram que filmes de ouro e prata produzidos por sputtering, tendem a cristalizar-se preferencialmente na direção (111), em substratos que não influenciem no crescimento do filme. Já para substratos cristalinos como os de silício, sua estrutura cristalina cúbica interfere na tendência natural de crescimento dos filmes de ouro, inibindo o crescimento em (111) [114]. Assim, a influência do substrato pode ser o motivo pelo qual as nanopartículas de ouro 
presentes no filme depositado sobre o substrato vítreo é, em média, $10 \mathrm{~nm}$ maior do que as nanopartículas de ouro no filme depositado sobre o substrato de alumínio.

\subsection{Luminescência Opticamente Estimulada}

A Figura 7.7 mostra as curvas OSL do $\mathrm{NaCl}$ depositado sobre o vidro e sobre o filme de ouro com 800 s de deposição em substrato vítreo. É possível observar um aumento significativo da intensidade OSL para a amostra de $\mathrm{NaCl}$ depositada sobre o filme de ouro com 800 s de deposição. Diferentemente dos íons de prata, íons de ouro não são reconhecidos como bons ativadores de luminescência. Assim, a hipótese de que o aumento de luminescência seja causado pela criação de defeitos na estrutura cristalina do $\mathrm{NaCl}$ torna-se menos relevante. Dessa forma, as hipóteses mais fortes para explicar o aumento da intensidade OSL poderiam ser o aumento de deposição de dose por elétrons retroespalhados, uma vez que o ouro possui um alto número atômico e as amostras são irradiadas com raios- $\mathrm{x}$ de baixa energia; ou ainda o aumento de luminescência por interações plasmônicas.

Cabe ressaltar aqui que os substratos vítreos não apresentaram sinal OSL para as doses utilizadas nestes experimentos. Além disso, deve ser ressaltado também que a dose máxima utilizada para as amostras de $\mathrm{NaCl}$ depositadas sobre os filmes ouro/vidro foi de 5 Gy porque, devido ao grande aumento da intensidade OSL inicial obtido e a uma limitação do sistema de leitura OSL utilizado, a intensidade OSL inicial atingiu a intensidade máxima de contagens do leitor para a dose de 5 Gy. 


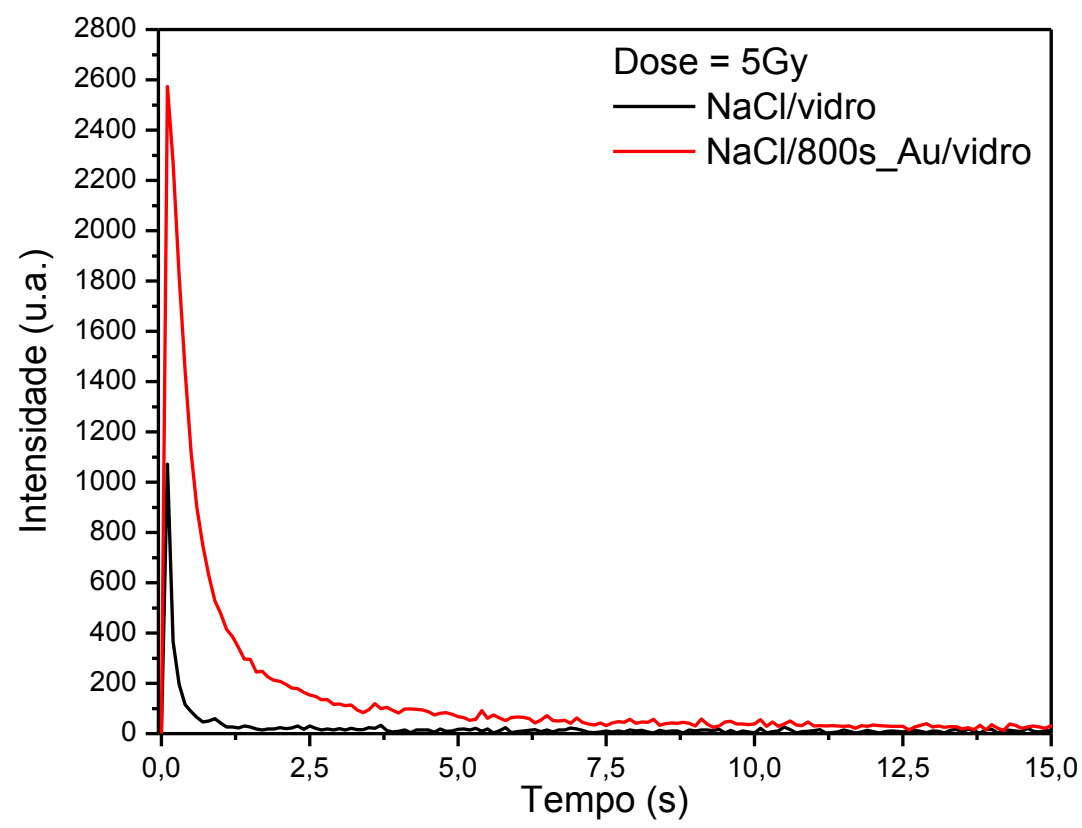

Figura 7.7: Curva OSL para o $\mathrm{NaCl}$ depositado sobre o vidro e sobre o filme de ouro depositado com 800 s em substrato vítreo.

\subsubsection{Influência do Tempo de Deposição dos Filmes de Ouro}

A Figura 7.8 (a) mostra a resposta OSL das amostras irradiadas com 5 Gy, em função do tempo de deposição de ouro. O aumento do tempo de deposição de ouro proporciona o aumento da intensidade OSL. O crescimento é linear até um tempo de $200 \mathrm{~s}$ de deposição, e parece tender um patamar de saturação para tempos a partir de $400 \mathrm{~s}$.

Além de investigar o comportamento da intensidade OSL em função do tempo de deposição de ouro, é também importante verificar o comportamento da intensidade OSL em função do valor do coeficiente de extinção da banda de ressonância plasmônica para o comprimento de onda de $470 \mathrm{~nm}$, que corresponde ao comprimento de onda do máximo do espectro de emissão do LED azul utilizado. Mais uma vez, o termo coeficiente de extinção foi utilizado em vez de absorbância visto que não foram feitas correções para perdas por reflexão. A Figura 7.8 (b) revela um comportamento linear da intensidade OSL em função do coeficiente de extinção em $470 \mathrm{~nm}$ dos filmes ouro. Esse comportamento linear também foi observado para a intensidade SERS (do inglês Surface Enhanced Raman Scattering) de moléculas de tetrafenilporfirina depositadas sobre filmes de nanopartículas de prata, em função do coeficiente de extinção dos respectivos filmes. Essa relação linear entre o aumento da intensidade OSL e o coeficiente de extinção dos filmes de nanopartículas de ouro é consistente com a hipótese de que o aumento da intensidade OSL ocorre devido as interações plasmônicas dos centros de luminescência do $\mathrm{NaCl}$ com as nanoestruturas metálicas [101]. 

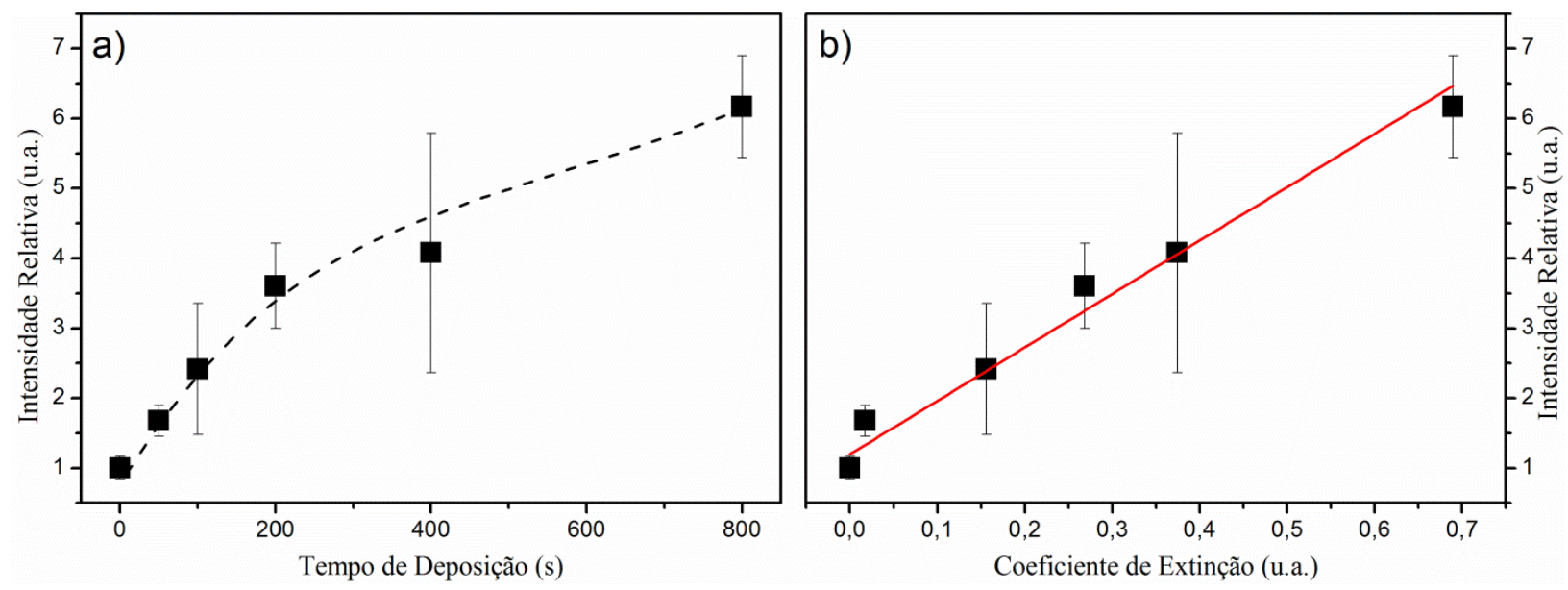

Figura 7.8: Intensidade OSL relativa (integral) em função do tempo de deposição (a) e do coeficiente de extinção em $470 \mathrm{~nm}$ (b) dos filmes de ouro.

Uma vez que o tempo de deposição de ouro é linearmente proporcional à massa de ouro depositada, é curioso o fato de que a intensidade OSL apresente comportamentos diferentes em função do tempo de deposição (massa de douro) e do coeficiente de extinção do filme. Resultado semelhante foi observado para o caso dos filmes de nanopartículas de prata depositados por layer-by-layer do capítulo anterior. Porém, naquele caso, o método de deposição dos filmes não permitia afirmar que a massa depositada de nanopartículas de prata era a mesma para cada camada depositada.

A Figura 7.9 mostra o coeficiente de extinção e a intensidade OSL em função do tempo de deposição dos filmes de ouro, revelando um comportamento similar entre as duas curvas. Juntas, a Figura 7.8 e a Figura 7.9 revelam que o aumento da intensidade OSL não está exatamente associado a massa de ouro depositada em cada filme, mas sim às suas propriedades ópticas. Como discutido anteriormente, filmes finos de ouro apresentam propriedades ópticas dependentes de sua estrutura [115-116]. Assim, embora a massa de ouro aumente linearmente com o tempo de deposição, o coeficiente de extinção em $470 \mathrm{~nm}$ varia em função da massa de ouro e da estrutura do filme, como por exemplo, tamanho, distância e estado de agregação das nanopartículas depositadas. Assim, a Figura 7.9 deixa claro que o aumento da intensidade OSL está relacionado a variação do coeficiente de extinção dos filmes de nanopartículas de ouro. 


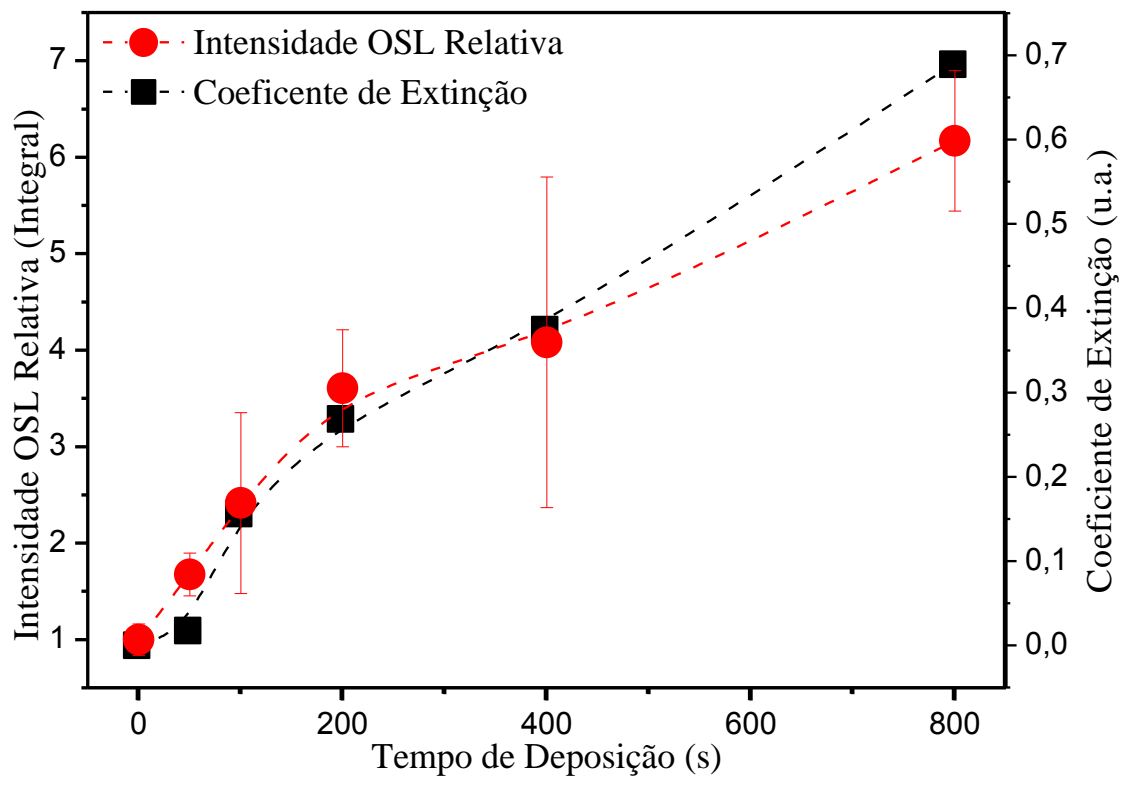

Figura 7.9: Curvas de intensidade OSL relativa e coeficiente de extinção em função do tempo de deposição dos filmes de ouro.

Além de investigar o comportamento da intensidade OSL em termos da integral total da curva de decaimento, é também interessante estudar o valor da intensidade inicial OSL em função do coeficiente de extinção dos filmes de ouro. Para assegurar a não saturação da intensidade OSL inicial devido à limitação do sistema de leitura OSL, foi utilizado para esse experimento a dose de $1 \mathrm{~Gy}$.

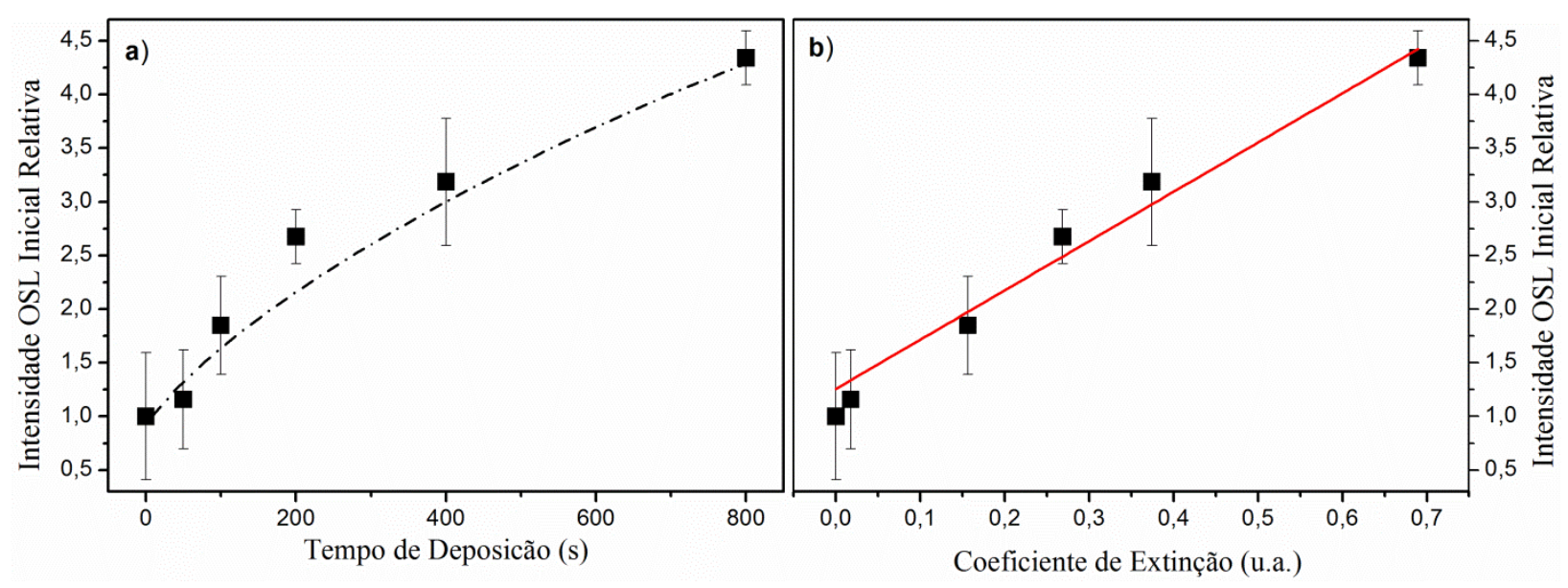

Figura 7.10: Intensidade OSL inicial em função do tempo de deposição (a) e do coeficiente de extinção (b) dos filmes de ouro.

A Figura 7.10 (a) revela que a intensidade OSL inicial aumenta de forma não linear em função do tempo de deposição (espessura) de ouro. No entanto, a intensidade inicial da curva OSL segue um comportamento linear em função do coeficiente de extinção dos filmes, 
assim como a integral total da curva OSL. Esse resultado é diferente do resultado observado para os filmes de nanopartículas de prata, que apresentaram o aumento da intensidade OSL inicial praticamente irrelevante. Essa diferença observada entre os filmes de ouro e prata sugere que o acoplamento plasmônico ocorre com diferentes armadilhas/centros luminescentes em cada sistema $\mathrm{NaCl} / \mathrm{NpAg}$ e $\mathrm{NaCl} / \mathrm{NpAu}$. Para fins comparativos, a Figura 7.11 mostra as curvas OSL para o $\mathrm{NaCl}$ depositado sobre o vidro e sobre os filmes 800s_Au e 3_NpAg.

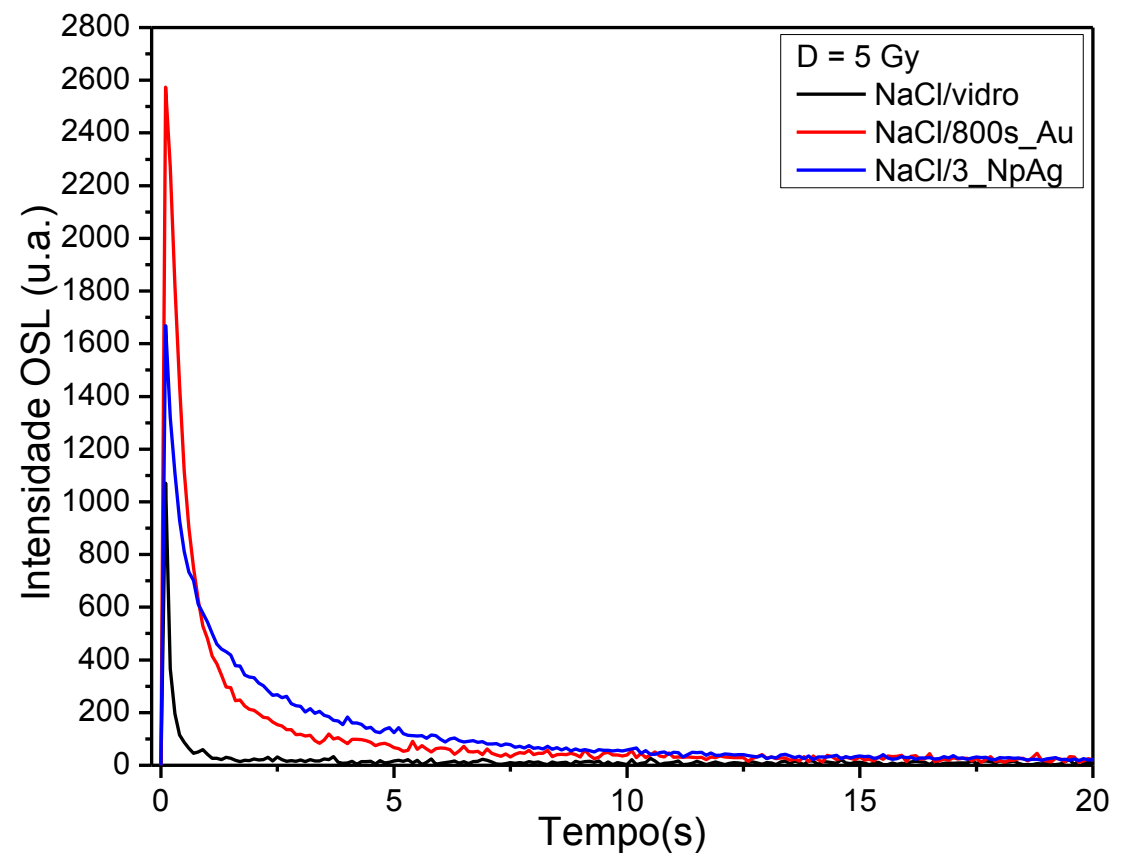

Figura 7.11: Curvas OSL para o $\mathrm{NaCl}$ depositado sobre o vidro e sobre os filmes 800s_Au e 3_NpAg.

A Figura 7.11 evidencia que o aumento da intensidade OSL decorre principalmente do aumento da intensidade inicial para os filmes de ouro. Para os filmes de prata, o aumento da integral da curva foi o maior responsável pelo aumento da intensidade OSL. Essa observação sugere que no caso dos filmes de nanopartículas de prata, o acoplamento é maior para as armadilhas com maiores tempos de decaimento (menor seção de choque de fotoionização) e, portanto, com contribuição pouco relevante para a intensidade OSL inicial. Para os filmes de ouro, há maior acoplamento com as armadilhas com tempos de decaimentos mais curtos (maior seção de choque de fotoionização), e que contribuem mais efetivamente para intensidade OSL inicial. O acoplamento é menor com as armadilhas com tempos mais longos de decaimento, contribuindo menos significativamente para a integral da curva. Isso pode estar relacionado com as diferentes posições das bandas de ressonância plasmônica do ouro e 
da prata, o que fará com que o acoplamento plasmônico ocorra com populações de armadilhas/centros luminescentes com diferentes energias.

\subsubsection{Variação na Forma da Curva OSL e a Regeneração da Luminescência Opticamente Estimulada}

A Figura 7.12 mostra as curvas OSL, normalizadas pela intensidade inicial, do $\mathrm{NaCl}$ depositado sobre o vidro e sobre os filmes de ouro com diferentes tempos de deposição. Mesmo com grande aumento da intensidade OSL inicial, ainda ocorre um decaimento mais lento da curva OSL em função do tempo de deposição de ouro.

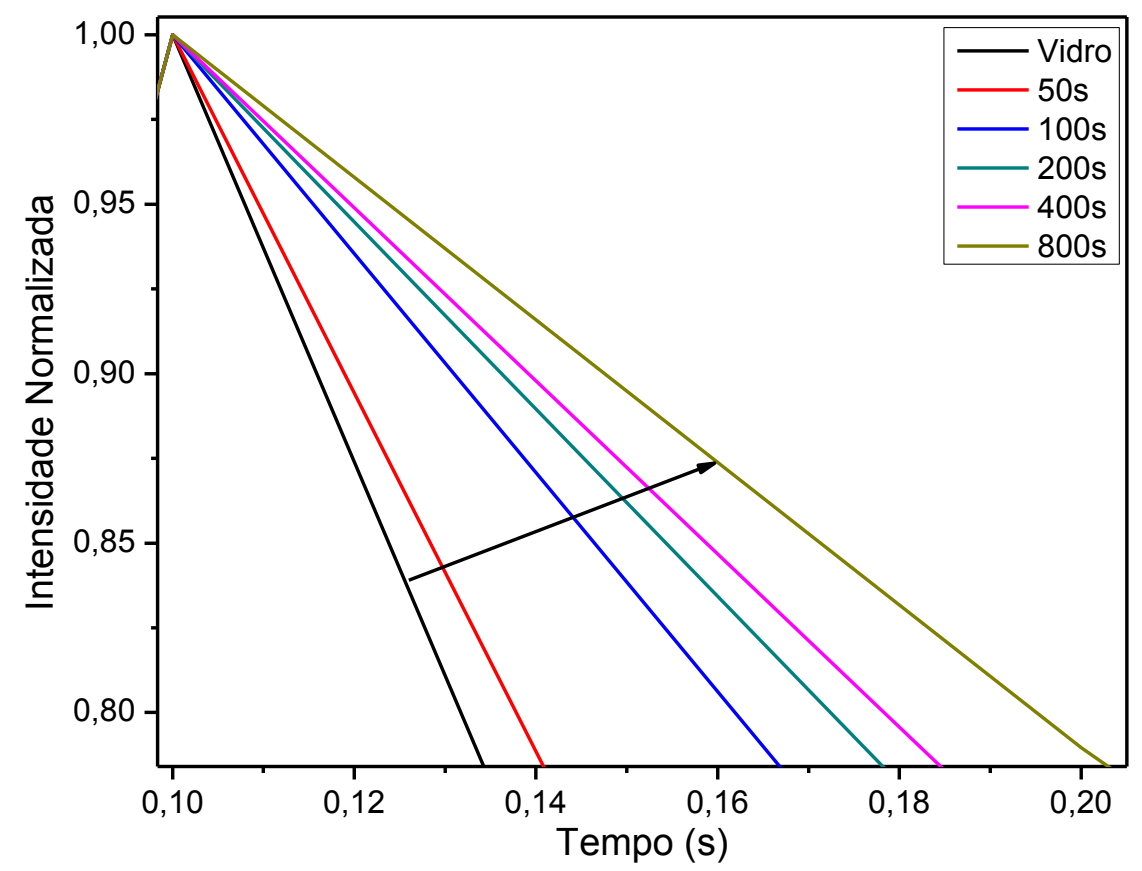

Figura 7.12: Curvas OSL normalizadas pela intensidade inicial, para o $\mathrm{NaCl}$ depositado sobre filmes de ouro com diferentes tempos de deposição.

Assim como no caso do $\mathrm{NaCl}$ depositado sobre os filmes de nanopartículas de prata, não houve regeneração do sinal OSL para a segunda leitura, realizada após 10 minutos, para o $\mathrm{NaCl}$ depositado sobre o filme 800s_Au (Figura 7.13). Esse resultado sugere uma maior eficiência no processo de esvaziamento de armadilhas durante a primeira leitura OSL, assim como no caso dos filmes de NpAgs. Portanto, a não regeneração do sinal OSL e o decaimento mais lento da curva corroboram a hipótese de que o aumento da intensidade OSL é causado pela transferência de elétrons de armadilhas com pequena seção de choque de fotoionização 
para armadilhas com maior seção de choque de fotoionização, como discutido no capítulo anterior.

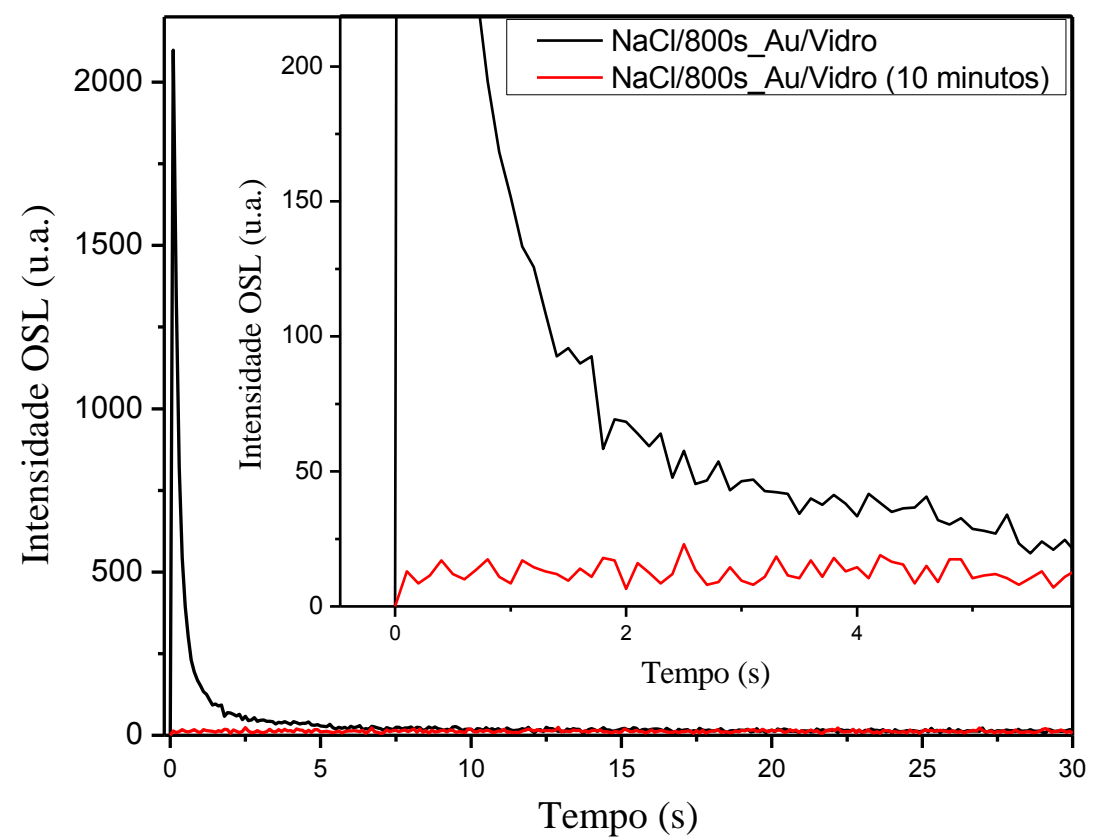

Figura 7.13: Primeira e segunda leitura do sinal OSL para o $\mathrm{NaCl}$ depositado sobre o filme de ouro com 800 s de deposição. Não há recuperação do sinal OSL na segunda leitura, evidenciando o total esvaziamento de armadilhas eletrônicas durante a primeira leitura.

\subsubsection{Influência do Número Atômico do Substrato}

Do ponto de vista da interação das radiações ionizantes com o dosímetro, uma possível explicação para o aumento da intensidade e da variação da forma das curvas OSL do cloreto de sódio poderia ser o aumento da dose depositada, ou diferenças no espectro de energia de fótons e partículas incidindo no dosímetro, devido aos elétrons e fótons retroespalhados pelo filme de ouro. Assim, é possível que a dose recebida pelo $\mathrm{NaCl}$ sobre o filme de ouro seja maior que do $\mathrm{NaCl}$ depositado sobre o vidro, devido a maior incidência de elétrons e fótons retroespalhados, como consequência do alto número atômico do metal $(Z=79)$ e à baixa energia do feixe de raios-x utilizado. Para inferir se o aumento de retroespalhamento e da dose pode estar relacionado ao aumento da intensidade OSL, a solução de cloreto de sódio foi também gotejada sobre substratos de chumbo $(Z=82)$ com $2 \mathrm{~mm}$ de espessura. Em seguida, foram obtidas as curvas dose resposta do $\mathrm{NaCl}$ depositado sobre vidro, sobre o filme de ouro (800s) e sobre os substratos de chumbo. Comparado com a intensidade do $\mathrm{NaCl}$ depositado sobre vidro, a Figura 7.14 revela aumento da intensidade OSL sobre o filme de ouro e uma 
redução da intensidade OSL sobre o substrato de chumbo, comparado à intensidade OSL do $\mathrm{NaCl}$ depositado sobre o vidro.

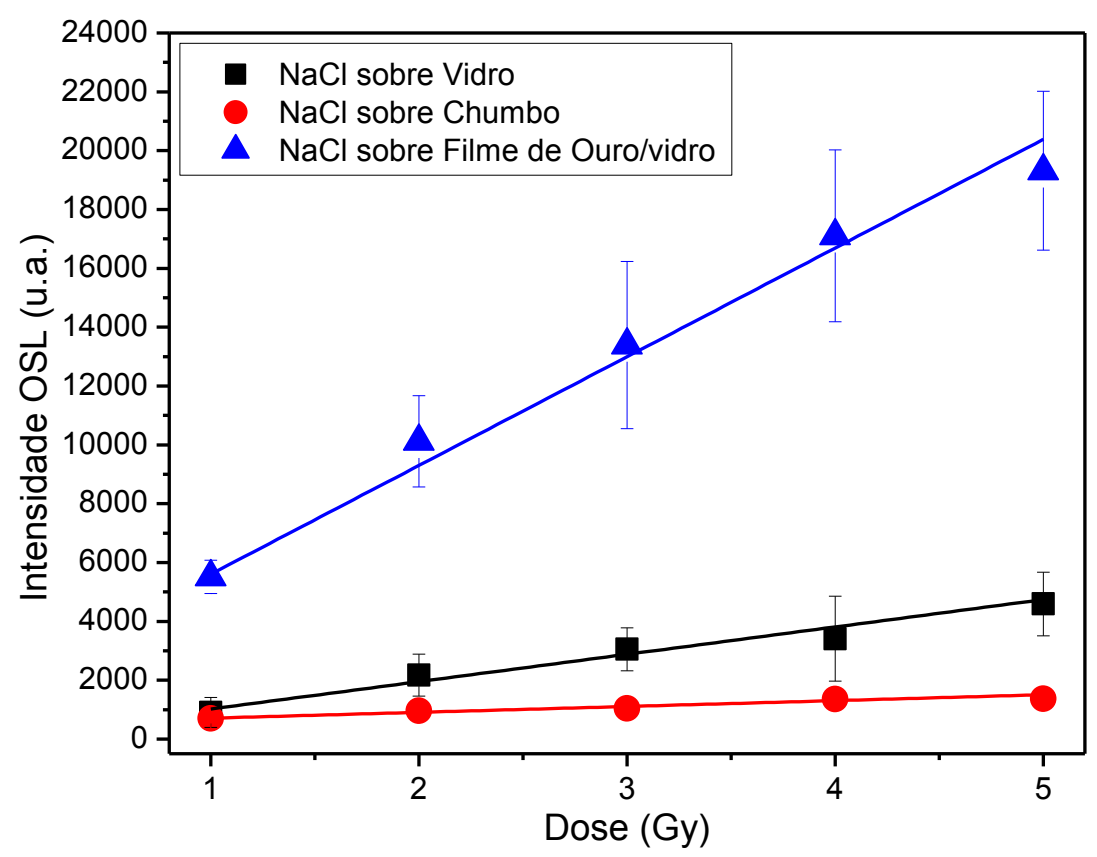

Figura 7.14: Curva dose-resposta do $\mathrm{NaCl}$ depositado sobre o filme de ouro (800s), sobre o vidro e sobre o chumbo.

Uma vez que o número atômico do chumbo é ligeiramente maior que o número atômico do ouro, era esperado que, caso o aumento da intensidade fosse consequência da maior dose depositada devido ao retroespalhamento de fótons e elétrons, o aumento da intensidade OSL também deveria ser observado para as amostras de $\mathrm{NaCl}$ depositado sobre os substratos de chumbo. No entanto, a redução da intensidade do $\mathrm{NaCl}$ depositado sobre o chumbo reforça a hipótese de que as variações das intensidades OSL são oriundas das interações entre os centros luminescentes do $\mathrm{NaCl}$ e os substratos metálicos, e não são causadas pelo aumento do número atômico do substrato.

Processos luminescentes são notoriamente modificados quando próximos à superfícies metálicas devido à combinação de diversas interações. Para distâncias muito curtas entre um centro luminescente e uma superfície metálica, em geral, processos não radiativos dominam a taxa de decaimento, podendo causar redução da intensidade luminescente. Esses processos são determinados por mecanismos de perda intrínsecos ao metal em questão, como absorção interbandas, perdas por espalhamento de elétrons e excitação de pares elétron-buraco [117]. O 
que define qual desses mecanismos é o mais relevante para um dado sistema, são as propriedades do metal no comprimento de onda de emissão do luminóforo.

No caso de metais com propriedades plasmônicas, o aumento da luminescência pode ocorrer tanto pelo aumento de campos elétricos locais que resultam em aumento da taxa de excitação do luminóforo, quanto pelo aumento da taxa de decaimento radiativo e/ou redução das taxas de decaimentos não-radiativos (transferência de energia). Assim, o aumento da luminescência para o $\mathrm{NaCl}$ sobre o filme de ouro pode ser atribuído à intensa banda de ressonância plasmônica e ao fato de o filme de ouro apresentar espessuras e partículas em escala nanométrica. Já para o $\mathrm{NaCl}$ depositado sobre o substrato de chumbo, contribuem para a redução de luminescência a fraca, ou até mesmo ausente, intensidade de ressonância plasmônica do chumbo, geralmente observada em comprimentos de onda menores que 250 nm [118] e, portanto, fora das regiões de estimulação e leitura da luminescência opticamente estimulada. Além disso, o substrato de chumbo não apresenta espessura em nano escala.

\subsubsection{Influência do Substrato}

Filmes de ouro foram também depositados sobre substratos de alumínio, com as mesmas dimensões e sob as mesmas condições que os filmes depositados sobre o vidro. A Figura 7.15 revela a redução da intensidade OSL à medida que aumenta o tempo de deposição dos filmes de ouro em substratos de alumínio. Para tempos de deposição maiores que $100 \mathrm{~s}$, foi observado o total desvanecimento da intensidade OSL. Esse resultado é mais uma evidência de que os aumentos de luminescência observados para o $\mathrm{NaCl}$ depositado sobre os filmes de ouro não são causados pela criação de defeitos no $\mathrm{NaCl}$ porque a interface entre o luminóforo e o filme é a mesma para os dois substratos em questão. 


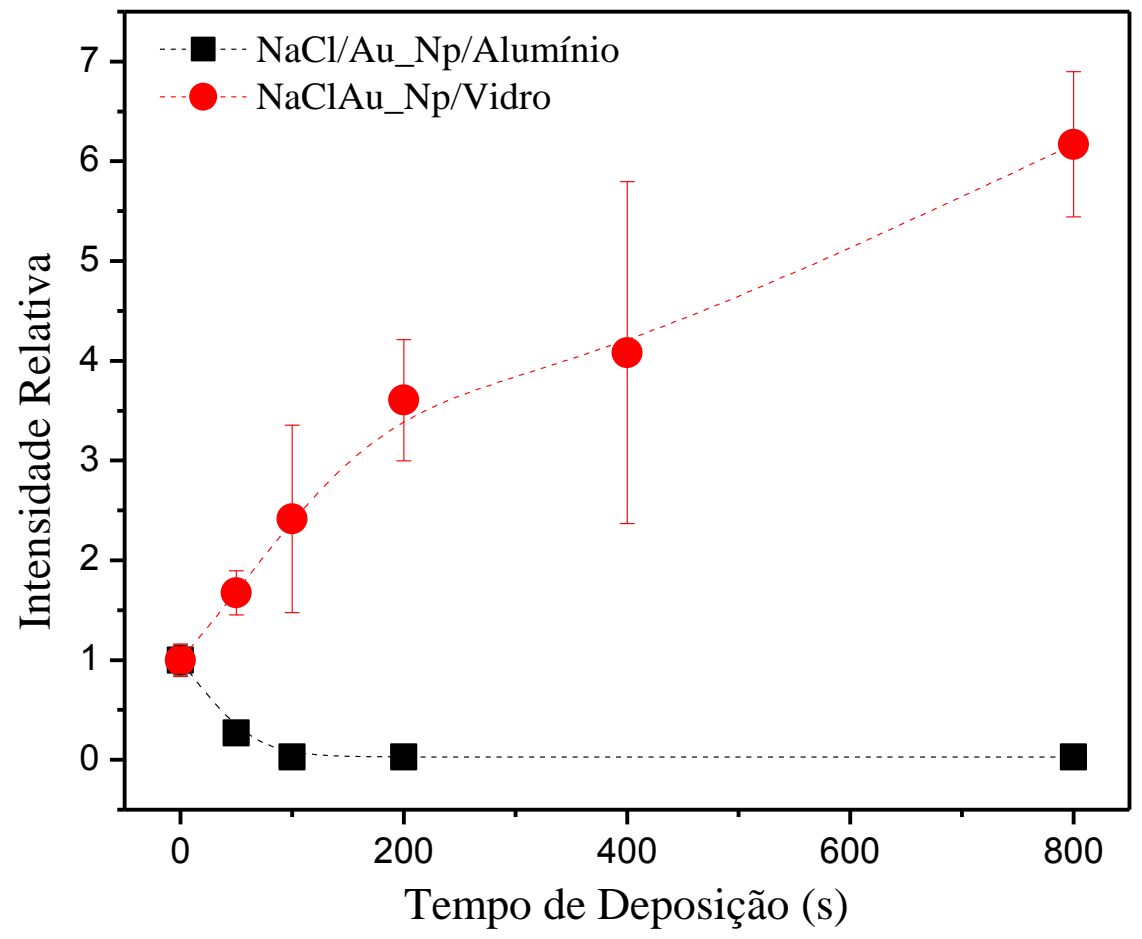

Figura 7.15: Intensidade OSL em função do tempo de deposição de ouro em substrato de vidro e alumínio.

Como discutido anteriormente, as propriedades ópticas do substrato exercem grande influência nas propriedades luminescentes da amostra. Para o caso do filme de nanopartículas de prata depositado sobre o substrato de alumínio, foi observada uma redução do ganho em intensidade OSL quando comparado aos filmes de NpAgs depositados em substratos de vidro. Porém, em nenhuma das condições testadas foi observado o total desvanecimento da luminescência opticamente estimulada, como no caso dos filmes de ouro depositados diretamente sobre o substrato de alumínio. Uma possível razão para o não desvanecimento da intensidade OSL para os filmes de NpAgs em substratos de alumínio pode ser o fato de que a camada de quitosana sob a camada de NpAgs evita o contato direto das nanopartículas de prata com o substrato de alumínio. Além disso, como observado nas imagens de microscopia de força atômica, as nanopartículas de ouro parecem estar imersas ou parcialmente inseridas no substrato de alumínio, aumentando assim o contato com o substrato metálico.

Substratos metálicos causam deslocamentos da banda de ressonância plasmônica e podem até mesmo ocasionar o seu desaparecimento, dependendo da polarização da luz e da distância da nanopartícula ao substrato, entre alguns outros fatores [29, 105-107]. O desaparecimento/deslocamento da banda de ressonância plasmônica faz com que não haja aumento de campos elétricos locais próximo às nanopartículas metálicas, podendo diminuir o ganho em intensidade luminescente. No entanto, o total desvanecimento da intensidade OSL 
do $\mathrm{NaCl}$ depositado sobre os filmes Au/Alumínio sugere, mais uma vez, que essa interação entre as armadilhas/ centros luminescentes, o filme nanoestruturado e o substratos, alteram as taxas de decaimento radiativo e não radiativo do $\mathrm{NaCl}$. Nesse caso, para os filmes depositados em substratos de alumínio, é provável que os elétrons armadilhados decaiam por meio de transições não radiativas, de forma que nenhum sinal OSL seja detectado.

\subsubsection{Influência do Espaçamento entre o Substrato e o Filme de Ouro}

As interações entre as nanopartículas e o substrato metálico podem ser reduzidas aumentando-se o espaçamento dielétrico entre as partes [104, 106]. Com esse propósito, foram depositados filmes com até 12 bicamadas de Qt/PAA sobre o substrato de alumínio. Em seguida foram depositados filmes de ouro (800s) sobre os substratos de alumínio com os diferentes números de bicamadas de Qt/PAA, e o cloreto de sódio foi depositado sobre o filme de nanopartículas de ouro, conforme a ilustração presente na Figura 7.16.

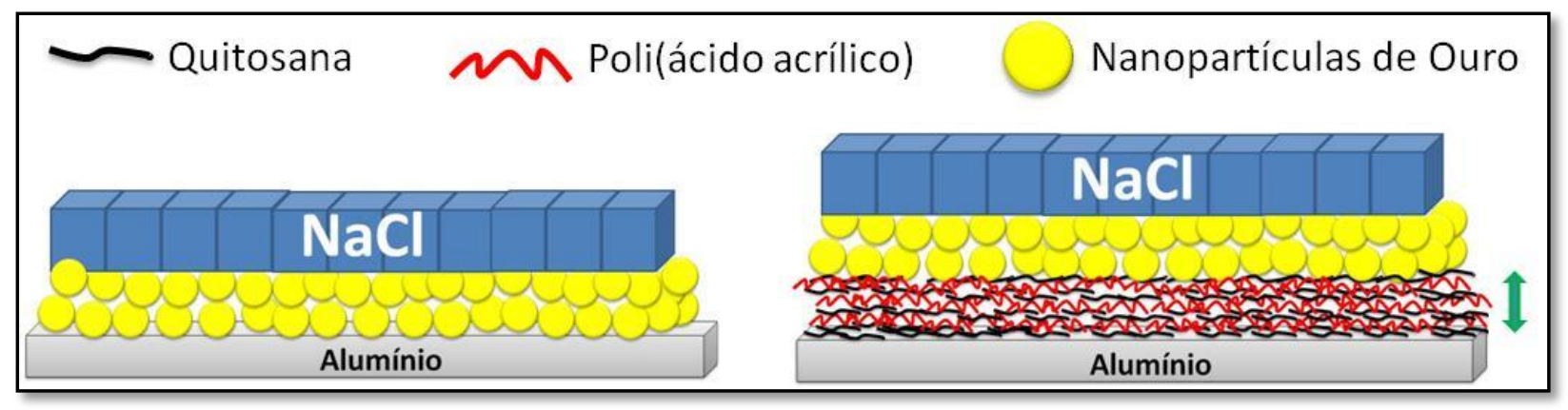

Figura 7.16: Representação da deposição de bicamadas de Qt/PAA entre o substrato de alumínio e o filme de nanopartículas de ouro.

A Figura 7.17 revela um aumento da intensidade OSL à medida que aumenta o número de bicamadas de Qt/PAA (espaçamento) entre o substrato de alumínio e o filme contendo ouro. É válido observar que a dose necessária para a obtenção de um sinal OSL mensurável foi de 100 Gy. Essa dose é vinte vezes maior que a dose utilizada para irradiação dos filmes de ouro depositados sobre o vidro. 


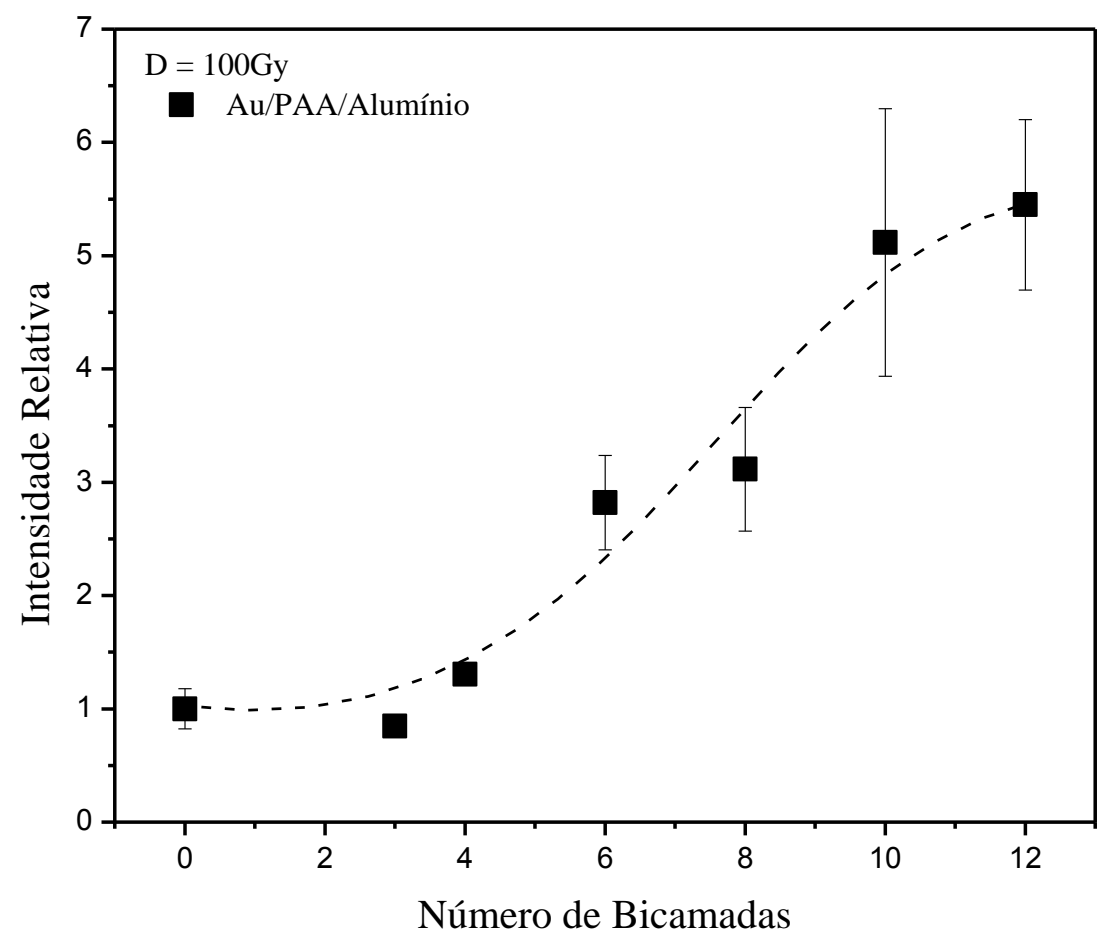

Figura 7.17: Intensidade OSL normalizada pela intensidade do $\mathrm{NaCl}$ depositado sobre o filme 800s_Au/Alumínio, em função do número de bicamadas Qt/PAA depositado entre o substrato de alumínio e o filme de ouro. A espessura de cada bicamada é de $15 \pm 2 \mathrm{~nm}$.

A Figura 7.18 evidencia que mesmo utilizando um valor de dose vinte vezes maior que o utilizado para as amostras de $\mathrm{NaCl}$ depositados sobre o vidro, a intensidade OSL do $\mathrm{NaCl}$ depositado sobre os filmes 800s_Au/12_PAA/Alumínio é ainda cerca de duas vezes menor que a intensidade OSL do $\mathrm{NaCl}$ depositado sobre o filme 800s_Au/vidro e irradiado com 5 Gy. Esse resultado revela que a redução da intensidade OSL obtido para os filmes de ouro depositados sobre o substrato de alumínio é causada, pelo menos parcialmente, pela interação entre as nanopartículas de ouro e suas respectivas imagens no substrato metálico. Dessa forma, quanto maior o número de bicamadas de Qt/PAA entre o substrato de alumínio e o filme de nanopartículas de ouro, menor será a interação entre os dipolos oscilantes das nanopartículas e seus respectivos dipolos-imagem. 


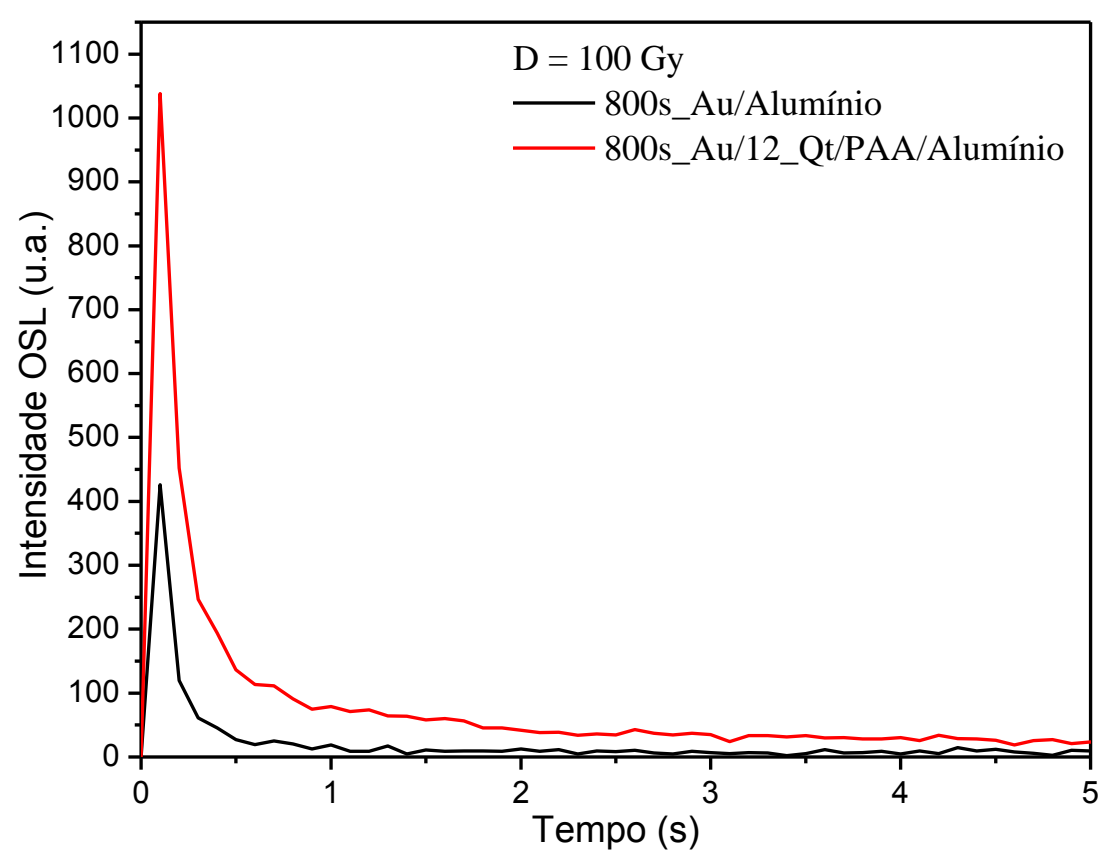

Figura 7.18: Curva OSL da amostra sobre o filme de ouro depositado diretamente sobre o substrato de alumínio com e sem o filme com 12 bicamadas de Qt/PAA.

Como discutido anteriormente, para o caso do $\mathrm{NaCl}$ depositado sobre os filmes Au/vidro, o aumento da intensidade OSL é devido a redução da transições não radiativas de elétrons armadilhados. Nesse sentido, o fato de que a intensidade OSL para o $\mathrm{NaCl}$ depositado sobre o filme de ouro com um espaçamento de 12 bicamadas de Qt/PAA entre o filme e o substrato ( $180 \mathrm{~nm}$ ) é ainda muito menor do que a intensidade do $\mathrm{NaCl}$ depositado diretamente sobre o alumínio, evidencia que a interação entre o filme nanoestruturado e o substrato é muito forte e relevante para a emissão luminescente. A baixa intensidade OSL mesmo com o grande distanciamento filme-substrato $(\sim 180 \mathrm{~nm})$ reforça a hipótese de que o desvanecimento da intensidade OSL ocorre por uma transferência de energia dos centros de recombinação para os plásmons que, por sua vez, decaem por meio de processos não radiativos.

\subsection{Conclusões}

Os estudos apresentados nesse capítulo revelaram que o aumento de intensidade OSL não está diretamente associado à massa de nanopartículas depositada em cada filme, mas sim às propriedades ópticas dos filmes. A intensidade OSL (inicial e integral) aumenta de forma linear em função do aumento do coeficiente de extinção no comprimento de onda da 
estimulação OSL (470 nm). Esse resultado é diferente do resultado observado para os filmes de nanopartículas de prata, em que não houve aumento significativo da intensidade OSL inicial. Nesse sentido, as nanopartículas de ouro acoplam-se mais efetivamente com as armadilhas com tempos de decaimentos mais curtos (que contribuem mais para intensidade OSL inicial), e menos com as armadilhas com tempos longos de decaimento, contribuindo menos significativamente para a integral da curva. Para os filmes de nanopartículas de prata, há maior acoplamento com as armadilhas com longos tempos de decaimento e, portanto, a contribuição para a intensidade OSL inicial é pouco relevante. Essas diferenças observadas decorrem das diferentes posições das bandas de ressonância plasmônica do ouro e da prata, o que faz com que o acoplamento plasmônico ocorra com populações de armadilhas/centros luminescentes com energias diferentes. As variações das intensidades OSL não são causadas pelo aumento do número atômico do substrato. O total desvanecimento da intensidade OSL para os filmes de ouro depositados sobre substratos de alumínio e a gradativa recuperação do sinal OSL com o aumento da distância entre o filme nanoestruturado e o substrato metálico reforçam a hipótese de que o aumento/redução da intensidade OSL é causado por interações eletromagnéticas entre o $\mathrm{NaCl}$, o filme nanoestruturado e o substrato. Essas interações são responsáveis por aumentar/diminuir as transições não radiativas durante a leitura OSL. 


\section{Conclusões e Considerações Finais}

Retomando a questão inicial que guiou todo o desenvolvimento dessa tese, pode-se concluir que, sim, as propriedades plasmônicas de nanoestruturas metálicas podem ser utilizadas para aumentar a intensidade da luminescência opticamente estimulada. Essa resposta ficou evidente quando houve aumento da intensidade OSL para compósitos de $\mathrm{NaCl} / \mathrm{Ag}$ contendo nanopartículas de prata, e redução da intensidade para compósitos contendo micropartículas. Foi possível verificar a correlação entre os processos de fotoluminescência e luminescência opticamente estimulada. Além disso, houve aumento da intensidade fotoluminescente para excitação com comprimentos de onda se aproximando da máxima intensidade da banda de ressonância plasmônica, sugerindo que o aumento dos campos elétricos locais em condições de ressonância plasmônica aumentam a taxa de excitação/desarmadilhamento dos centros $\mathrm{F}$ do $\mathrm{NaCl}$. $\mathrm{O}$ aumento da intensidade de radioluminescência sugeriu ainda que o acoplamento com os plásmons pode também ocorrer durante o processo da emissão luminescente.

O mecanismo de luminescência acoplada aos plásmons pôde ser verificado devido à redução do tempo de vida da emissão luminescente. O decaimento mais rápido do sinal OSL revelou o aumento da taxa de desarmadilhamento de elétrons em condições de ressonância plasmônica. Os processos de transferência de energia e cargas foram minuciosamente investigados, revelando que os processos de estimulação e emissão OSL dependem fortemente das interações entre as armadilhas/ centros de recombinação, os plásmons e o substrato.

Portanto, dentre as respostas obtidas destacam-se as evidências de que a intensificação dos campos elétricos locais aumenta a taxa de desarmadilhamento de elétrons durante a estimulação OSL e que o acoplamento plasmônico também pode modificar as taxas de decaimentos radiativos e não radiativos, produzindo aumento da intensidade OSL. Além disso, as interações entre as armadilhas/centros luminescentes e os plásmons variam de acordo com a distância entre as partes, com meio/substrato em que se encontram, com o coeficiente de extinção e com a posição da banda de ressonância plasmônica.

Assim, a presente tese revela não só a potencial aplicação das propriedades plasmônicas de nanoestruturas metálicas para a dosimetria e detecção das radiações ionizantes, como 
também pode ser de grande valia para áreas como a datação arqueológica por luminescência opticamente estimulada e termoluminesência. 


\section{Referências}

[1] S. McKeever, "Optically stimulated luminescence: A brief overview," Radiation Measurements, vol. 46, pp. 1336-1341, 2011.

[2] J. F. Fowler, "Solid state dosimetry," Physics in Medicine and Biology, vol. 8, p. 1, 1963.

[3] D. J. Huntley, et al., "Optical dating of sediments," 1985.

[4] E. G. Yukihara and S. W. S. McKeever, "Optically stimulated luminescence (OSL) dosimetry in medicine," Physics in Medicine and Biology, vol. 53, pp. R351-R379, 2008.

[5] Y. A. Krutyakov, et al., "Synthesis and properties of silver nanoparticles: advances and prospects," Russian Chemical Reviews, vol. 77, pp. 233-257, 2008.

[6] R. W. Wood, "On a remarkable case of uneven distribution of light in a diffraction grating spectrum," 1902.

[7] J. M. Garnett, "Colours in metal glasses, in metallic films, and in metallic solutions. II," Philosophical Transactions of the Royal Society of London. Series A, Containing Papers of a Mathematical or Physical Character, pp. 237-288, 1906.

[8] M. L. Brongersma and P. G. Kik, Surface Plasmon Nanophotonics: Springer, 2007.

[9] D. Pines, "COLLECTIVE ENERGY LOSSES IN SOLIDS," Reviews of Modern Physics, vol. 28, pp. 184-198, 19561956.

[10] M. Garcia, "Surface plasmons in metallic nanoparticles: fundamentals and applications," Journal of Physics D: Applied Physics, vol. 44, p. 283001, 2011.

[11] Y. Zhang, et al., "Metal-enhanced phosphorescence (MEP)," Chemical Physics Letters, vol. 427, pp. 432-437, Aug 312006.

[12] M. H. Chowdhury, et al., "Metal-enhanced chemiluminescence," Journal of fluorescence, vol. 16, pp. 295-299, 2006.

[13] S. M. Lee, et al., "Localized surface plasmon enhanced cathodoluminescence from Eu 3+doped phosphor near the nanoscaled silver particles," Optics Express, vol. 19, pp. 1320913217, 2011.

[14] Lars Botter-Jensen, et al., Optically Stimulated Luminescence Dosimetry: Elsevier, 2003.

[15] Eduardo G. Yukihara and S. W. S. McKeever, Optically Stimulated Luminescence: Fundamentals and Applications, 1st ed.: John Wiley \& Sons Ltd, 2011.

[16] M. Kerikmae, et al., "OSL and TSL interrelations in SrSO4:Eu," Radiation Measurements, vol. 45, pp. 559-561, 2010.

[17] H. Nanto, et al., "OPTICALLY STIMULATED LUMINESCENCE IN KCL-EU SINGLE-CRYSTALS," Radiation Protection Dosimetry, vol. 47, pp. 281-284, 1993.

[18] S. P. Puppalwar, et al., "Cu+ emission in Li2BPO5 material for thermoluminescence dosimetry," Radiation Effects and Defects in Solids, vol. 167, pp. 333-341, 20122012.

[19] M. G. Rodriguez, et al., "Thermoluminescence, optically stimulated luminescence and radioluminescence properties of Al2O3:C,Mg," Radiation Measurements, vol. 46, pp. 14691473, Dec 2011.

[20] P. Seth, et al., "Role of Mg in the thermoluminescence of LiF crystals grown by edge defined film fed growth (EFG) technique," Nuclear Instruments \& Methods in Physics Research Section B-Beam Interactions with Materials and Atoms, vol. 278, pp. 46-49, May 12012.

[21] Y. Wang, et al., "Influence of Li dopants on thermoluminescence spectra of CaSO4 doped with Dy or Tm," Journal of Luminescence, vol. 131, pp. 1864-1868, Sep 2011.

[22] S. J. McMahon, et al., "Radiotherapy in the presence of contrast agents: a general figure of merit and its application to gold nanoparticles," Physics in Medicine and Biology, vol. 53, pp. 5635-5651, Oct 212008.

[23] D. B. Chithrani, et al., "Gold Nanoparticles as Radiation Sensitizers in Cancer Therapy," Radiation Research, vol. 173, pp. 719-728, Jun 2010. 
[24] J. F. Hainfeld, et al., "Gold nanoparticles: a new X-ray contrast agent," British Journal of Radiology, vol. 79, pp. 248-253, 2006.

[25] S. J. McMahon, et al., "Biological consequences of nanoscale energy deposition near irradiated heavy atom nanoparticles," Scientific Reports, vol. 1, Jun 202011.

[26] É. Guidelli, et al., "Silver nanoparticles delivery system based on natural rubber latex membranes," Journal of Nanoparticle Research, vol. 15, pp. 1-9, 2013/03/10 2013.

[27] E. J. Guidelli, et al., "Synthesis and characterization of silver/alanine nanocomposites for radiation detection in medical applications: the influence of particle size on the detection properties," Nanoscale, vol. 4, pp. 2884-2893, 20122012.

[28] O. Stranik, et al., "Plasmonic enhancement of fluorescence for sensor applications," Sensors and Actuators B-Chemical, vol. 107, pp. 148-153, 2005.

[29] P. K. Jain, et al., "Noble Metals on the Nanoscale: Optical and Photothermal Properties and Some Applications in Imaging, Sensing, Biology, and Medicine," Accounts of Chemical Research, vol. 41, pp. 1578-1586, Dec 2008.

[30] E. J. Guidelli, et al., "Synthesis and Characterization of Gold/Alanine Nanocomposites with Potential Properties for Medical Application as Radiation Sensors," Acs Applied Materials \& Interfaces, vol. 4, pp. 5844-5851, Nov 2012.

[31] E. J. Guidelli, et al., "Synthesis of silver nanoparticles using DL-alanine for ESR dosimetry applications," Radiation Physics and Chemistry, vol. 81, pp. 301-307, Mar 2012.

[32] S. Kapoor, "Preparation, characterization, and surface modification of silver particles," Langmuir, vol. 14, pp. 1021-1025, Mar 31998.

[33] N. G. Khlebtsov, "Optics and biophotonics of nanoparticles with a plasmon resonance," Quantum Electronics, vol. 38, pp. 504-529, 2008.

[34] S. A. Maier, Plasmonics: Fundamentals and Applications: Springer, 2010.

[35] H. Kuwata, et al., "Resonant light scattering from metal nanoparticles: Practical analysis beyond Rayleigh approximation," Applied Physics Letters, vol. 83, pp. 4625-4627, 2003.

[36] J. R. Lakowicz, "Radiative decay engineering 5: metal-enhanced fluorescence and plasmon emission," Analytical Biochemistry, vol. 337, pp. 171-194, 2005.

[37] J. R. Lakowicz, et al., "Plasmon-controlled fluorescence: a new paradigm in fluorescence spectroscopy," Analyst, vol. 133, pp. 1308-1346, 2008.

[38] J. R. Lakowicz, "Plasmonics in biology and plasmon-controlled fluorescence," Plasmonics, vol. 1, pp. 5-33, 2006.

[39] J. R. Lakowicz, et al., "Radiative decay engineering 2. Effects of silver island films on fluorescence intensity, lifetimes, and resonance energy transfer," Analytical Biochemistry, vol. 301, pp. 261-277, Feb 152002.

[40] G. Cnossen, et al., "Fluorescence properties of submonolayers of rhodamine $6 \mathrm{G}$ in front of a mirror," The Journal of chemical physics, vol. 98, pp. 5276-5280, 1993.

[41] A. Campion, et al., "Electronic energy transfer to metal surfaces: a test of classical image dipole theory at short distances," Chemical Physics Letters, vol. 73, pp. 447-450, 1980.

[42] J. R. Lakowicz, Principles of Fluorescence Spectroscopy: Springer, 2007.

[43] I. Gryczynski, et al., "Radiative decay engineering 4. Experimental studies of surface plasmoncoupled directional emission," Analytical Biochemistry, vol. 324, pp. 170-182, 2004.

[44] S. D. Solomon, et al., "Synthesis and study of silver nanoparticles," Journal of Chemical Education, vol. 84, pp. 322-325, Feb 2007.

[45] M. Yang, et al., "Well-aligned $\mathrm{ZnO}$ rod arrays grown on glass substrate from aqueous solution," Applied Surface Science, vol. 254, pp. 2917-2921, Mar 152008.

[46] G. Decher, et al., "BUILDUP OF ULTRATHIN MULTILAYER FILMS BY A SELF-ASSEMBLY PROCESS .3. CONSECUTIVELY ALTERNATING ADSORPTION OF ANIONIC AND CATIONIC POLYELECTROLYTES ON CHARGED SURFACES," Thin Solid Films, vol. 210, pp. 831-835, Apr 30 1992. 
[47] O. A. Yeshchenko, et al., "Surface plasmon as a probe for melting of silver nanoparticles," Nanotechnology, vol. 21, Jan 292010.

[48] T. Kurobori, et al., "The role of silver in the radiophotoluminescent properties in silveractivated phosphate glass and sodium chloride crystal," Optical Materials, vol. 32, pp. 12311236, Jul 2010.

[49] R. M. Bailey, et al., "OSL properties of $\mathrm{NaCl}$ relative to dating and dosimetry," Radiation Measurements, vol. 32, pp. 717-723, Oct-Dec 2000.

[50] D. Ekendahl and L. Judas, "NaCl as a retrospective and accident dosemeter," Radiation Protection Dosimetry, vol. 145, pp. 36-44, Apr 2011.

[51] H. M. Sun, et al., "Star-PDMAEMA--CD-Stabilized Colloidal Gold Nanoparticles: Synthesis, Characterization and $\mathrm{pH}-$ Controlled Assembly," Journal of Macromolecular Science Part aPure and Applied Chemistry, vol. 48, pp. 291-298, 2011.

[52] H. Parab, et al., "An anisotropic snowflake-like structural assembly of polymer-capped gold nanoparticles," Journal of Nanoparticle Research, vol. 13, pp. 2173-2180, 2011.

[53] I. Medina-Ramirez, et al., "Green synthesis and characterization of polymer-stabilized silver nanoparticles," Colloids and Surfaces B-Biointerfaces, vol. 73, pp. 185-191, 2009.

[54] R. Joshi and J. K. Wessly, "Luminescence of undoped sodium chloride," Acta Crystallographica Section A: Crystal Physics, Diffraction, Theoretical and General Crystallography, vol. 33, pp. 344-345, 1977.

[55] C. Song, et al., "Electrolytic coloration of hydroxyl-doped sodium chloride crystals," Journal of Luminescence, vol. 113, pp. 169-173, 2005.

[56] M. Kondo and S. Adachi, "Optical Properties of $\mathrm{NaCl}$ : Sn2+ Phosphor Synthesized from Aqueous $\mathrm{NaCl} / \mathrm{SnCl} 2 / \mathrm{HCl}$ Solution," ECS Journal of Solid State Science and Technology, vol. 2, pp. R9-R15, 2013.

[57] O. A. Yeshchenko, et al., "Surface plasmon enhanced photoluminescence from fullerene C-60 film on Au nanoparticles array: Resonant dependence on excitation frequency," Journal of Applied Physics, vol. 111, Jun 152012.

[58] D. Mariani and J. A. Rivas, "Thermoluminescence in $\mathrm{KI}, \mathrm{KBr}, \mathrm{NaCl}$ and $\mathrm{NaF}$ crystals irradiated at room temperature," Journal of Physics C: Solid State Physics, vol. 11, p. 3499, 1978.

[59] G. Blasse and B. C. Grabmaier, Luminescent materials: Springer-Verlag, 1994.

[60] I. A. de Carcer, et al., "Europium-doped alkali halides as a selective ultraviolet dosimeter material in the actinic region," Applied Physics Letters, vol. 58, pp. 1825-1826, 1991.

[61] H. Nanto, et al., "Photostimulated luminescence in alkali halides induced by excitation with ionizing radiation," Nuclear Instruments and Methods in Physics Research Section B: Beam Interactions with Materials and Atoms, vol. 91, pp. 205-209, 1994.

[62] S. M. Lee and K. C. Choi, "Enhanced emission from BaMgAl10017:Eu2+ by localized surface plasmon resonance of silver particles," Optics Express, vol. 18, pp. 12144-12152, 2010.

[63] Y. Rodriguez-Lazcano, et al., "Luminescence emission of natural $\mathrm{NaCl}$," Radiation Physics and Chemistry, vol. 81, pp. 126-130, Feb 2012.

[64] L. Delgado and J. A. Rivas, "On the charge compensation and thermoluminescence in $\mathrm{NaCl}$ : Mn irradiated at room temperature," Journal of Physics C: Solid State Physics, vol. 15, p. 1591, 1982.

[65] S. Barghare, et al., "Intrinsic thermoluminescence of nacl: Tl in uv dosimetry," Radiation Effects, vol. 66, pp. 217-222, 1982.

[66] E. I. Gorokhova, et al., "Structural, optical, and scintillation characteristics of $\mathrm{ZnO}$ ceramics," Journal of Optical Technology, vol. 78, pp. 753-760, Nov 2011.

[67] C. Cruz-Vazquez, et al., "Thermally and optically stimulated luminescence of new ZnO nanophosphors exposed to beta particle irradiation," Radiation Effects and Defects in Solids, vol. 162, pp. 737-743, Oct-Dec 2007.

[68] E. I. Gorokhova, et al., "Optical, luminescence, and scintillation properties of $\mathrm{ZnO}$ and $\mathrm{ZnO}: \mathrm{Ga}$ ceramics," Journal of Optical Technology, vol. 75, pp. 741-746, Nov 2008. 
[69] S. J. Chen, et al., "Structural and optical properties of uniform ZnO nanosheets," Advanced Materials, vol. 17, pp. 586-+, Mar 82005.

[70] F.-R. Fan, et al., "Facet-Selective Epitaxial Growth of Heterogeneous Nanostructures of Semiconductor and Metal: ZnO Nanorods on Ag Nanocrystals," Journal of the American Chemical Society, vol. 131, pp. 12036-+, Sep 22009.

[71] X. Yin, et al., "Ag nanoparticle/ZnO nanorods nanocomposites derived by a seed-mediated method and their photocatalytic properties," Journal of Alloys and Compounds, vol. 524, pp. 13-21, May 252012.

[72] M. M. Brewster, et al., "Role of Au in the Growth and Nanoscale Optical Properties of ZnO Nanowires," Journal of Physical Chemistry Letters, vol. 2, pp. 586-591, Mar 172011.

[73] J. Zhang, et al., "Polyvinylpyrrolidone-directed crystallization of ZnO with tunable morphology and bandgap," Advanced Functional Materials, vol. 17, pp. 3897-3905, Dec 17 2007.

[74] S. Ashoka, et al., "Ethylene glycol assisted hydrothermal synthesis of flower like ZnO architectures," Materials Letters, vol. 63, pp. 873-876, Apr 302009.

[75] R. B. M. Cross, et al., "A low temperature combination method for the production of $\mathrm{ZnO}$ nanowires," Nanotechnology, vol. 16, pp. 2188-2192, Oct 2005.

[76] T. Mahalingam, et al., "Low temperature wet chemical synthesis of good optical quality vertically aligned crystalline ZnO nanorods," Nanotechnology, vol. 18, Jan 242007.

[77] K. Mahmood, et al., "Enhanced photoluminescence, Raman spectra and field-emission behavior of indium-doped $\mathrm{ZnO}$ nanostructures," Journal of Materials Chemistry C, vol. 1, pp. 3138-3149, 20132013.

[78] S. Chandra, et al., "Enhanced quantum dot emission for luminescent solar concentrators using plasmonic interaction," Solar Energy Materials and Solar Cells, vol. 98, pp. 385-390, Mar 2012.

[79] D. J. Griffiths, Introduction to electrodynamics: Prentice Hall, 1999.

[80] X. Ye, et al., "Dependence of photoluminescence properties on excitation power in $\mathrm{ZnO}$ and ZnCdO microrods," Crystal Research and Technology, vol. 46, pp. 1303-1308, 2011.

[81] C. Yang, et al., "Enhanced ultraviolet emission and optical properties in polyvinyl pyrrolidone surface modified ZnO quantum dots," Journal of Applied Physics, vol. 90, pp. 4489-4493, 2001.

[82] Ü. Özgür, et al., "A comprehensive review of ZnO materials and devices," Journal of Applied Physics, vol. 98, p. 041301, 2005.

[83] Y. Zhong, et al., "Exceptionally long exciton photoluminescence lifetime in ZnO tetrapods," The Journal of Physical Chemistry C, vol. 112, pp. 16286-16295, 2008.

[84] S.-K. Lee, et al., "Long lifetime of free excitons in $\mathrm{ZnO}$ tetrapod structures," Applied Physics Letters, vol. 96, p. 083104, 2010.

[85] M. Eichelbaum and K. Rademann, "Plasmonic Enhancement or Energy Transfer? On the Luminescence of Gold-, Silver-, and Lanthanide-Doped Silicate Glasses and Its Potential for Light-Emitting Devices," Advanced Functional Materials, vol. 19, pp. 2045-2052, 2009.

[86] E. Yukihara, et al., "Effect of high-dose irradiation on the optically stimulated luminescence of Al< sub> 2</sub> O< sub> 3</sub>: C," Radiation Measurements, vol. 38, pp. 317-330, 2004.

[87] J. Mittani, et al., "Optically stimulated luminescence and thermoluminescence of terbiumactivated silicates and aluminates," Radiation Measurements, vol. 43, pp. 323-326, 2008.

[88] V. Cruz, et al., "Optically stimulated luminescence of $\mathrm{ZnO}$ obtained by thermal treatment of ZnS chemically synthesized," 2005.

[89] L. A. Sweatlock, et al., "Highly confined electromagnetic fields in arrays of strongly coupled Ag nanoparticles," Physical Review B, vol. 71, Jun 2005.

[90] C. Noguez, "Surface plasmons on metal nanoparticles: The influence of shpae and physical environment," Journal of Physical Chemistry C, vol. 111, pp. 3806-3819, Mar 152007. 
[91] L. L. Zhao, et al., "The extinction spectra of silver nanoparticle arrays: Influence of array structure on plasmon resonance wavelength and width," Journal of Physical Chemistry $B$, vol. 107, pp. 7343-7350, Jul 312003.

[92] W. Rechberger, et al., "Optical properties of two interacting gold nanoparticles," Optics Communications, vol. 220, pp. 137-141, May 12003.

[93] S. Link, et al., "Simulation of the optical absorption spectra of gold nanorods as a function of their aspect ratio and the effect of the medium dielectric constant (vol 103B, pg 3073, 1999)," Journal of Physical Chemistry B, vol. 109, pp. 10531-10532, 2005.

[94] M. Bin Ahmad, et al., "Synthesis of Silver Nanoparticles in Chitosan, Gelatin and Chitosan/Gelatin Bionanocomposites by a Chemical Reducing Agent and Their Characterization," Molecules, vol. 16, pp. 7237-7248, Sep 2011.

[95] W. Ding, et al., "Synthesis and characterization of a novel derivative of chitosan," Polymer, vol. 44, pp. 547-556, Feb 2003.

[96] D. Wei, et al., "The synthesis of chitosan-based silver nanoparticles and their antibacterial activity," Carbohydrate Research, vol. 344, pp. 2375-2382, Nov 232009.

[97] E. J. Guidelli, et al., "Green synthesis of colloidal silver nanoparticles using natural rubber latex extracted from Hevea brasiliensis," Spectrochimica Acta Part a-Molecular and Biomolecular Spectroscopy, vol. 82, pp. 140-145, Nov 2011.

[98] A. Frattini, et al., "Effect of amine groups in the synthesis of Ag nanoparticles using aminosilanes," Materials Chemistry and Physics, vol. 94, pp. 148-152, 2005.

[99] A. P. Ramos, et al., "Influence of the type of phospholipid head and of the conformation of the polyelectrolyte on the growth of calcium carbonate thin films on LB/LbL matrices," Colloids and Surfaces B-Biointerfaces, vol. 95, pp. 178-185, Jun 152012.

[100] M. E. D. Z. Ana Paula Ramos, "Modificação de Superfícies Metálicas por meio da deposição de filmes finos orgânicos LB/LbL e filmes híbridos contendo CaCO3," Doutorado, Departamento de Química, FFCLRP, Universidade de São Paulo, Ribeirão Preto, 2009.

[101] V. L. Schlegel and T. M. Cotton, "SILVER-ISLAND FILMS AS SUBSTRATES FOR ENHANCED RAMAN-SCATTERING - EFFECT OF DEPOSITION RATE ON INTENSITY," Analytical Chemistry, vol. 63, pp. 241-247, Feb 11991.

[102] K. Aslan, et al., "Metal-enhanced fluorescence from plastic substrates," Journal of Fluorescence, vol. 15, pp. 99-104, Mar 2005.

[103] Y. Zhang, et al., "Metal-enhanced fluorescence from paper substrates: Modified spectral properties of dyes for potential high-throughput surface analysis and assays and as an anticounterfeiting technology," Dyes and Pigments, vol. 77, pp. 545-549, 20082008.

[104] J. J. Mock, et al., "Distance-dependent plasmon resonant coupling between a gold nanoparticle and gold film," Nano Letters, vol. 8, pp. 2245-2252, Aug 2008.

[105] W. R. Holland and D. G. Hall, "FREQUENCY-SHIFTS OF AN ELECTRIC-DIPOLE RESONANCE NEAR A CONDUCTING SURFACE," Physical Review Letters, vol. 52, pp. 1041-1044, 19841984.

[106] M. Hu, et al., "Single Particle Spectroscopy Study of Metal-Film-Induced Tuning of Silver Nanoparticle Plasmon Resonances," Journal of Physical Chemistry C, vol. 114, pp. 7509-7514, Apr 292010.

[107] A. Leitner, et al., "OPTICAL-PROPERTIES OF A METAL ISLAND FILM CLOSE TO A SMOOTH METAL-SURFACE," Applied Optics, vol. 32, pp. 102-110, Jan 11993.

[108] P. B. Johnson and R. W. Christy, "OPTICAL CONSTANTS OF NOBLE METALS," Physical Review B, vol. 6, pp. 4370-4379, 19721972.

[109] C. Lumdee, et al., "Post-fabrication Voltage Controlled Resonance Tuning of Nanoscale Plasmonic Antennas," Acs Nano, vol. 6, pp. 6301-6307, Jul 2012.

[110] L.-W. Jang, et al., "Investigation of Optical and Structural Stability of Localized Surface Plasmon Mediated Light-Emitting Diodes by $\mathrm{Ag}$ and $\mathrm{Ag} / \mathrm{SiO} 2$ Nanoparticles," Advanced Functional Materials, vol. 22, pp. 2728-2734, Jul 102012. 
[111] A. Mandowski and M. Biernacka, "Anomalous regeneration of OSL in sodium chlorideExperiment and modeling," Radiation Measurements, vol. 71, pp. 265-269, 2014.

[112] V. Amendola, et al., "A Study of the Surface Plasmon Resonance of Silver Nanoparticles by the Discrete Dipole Approximation Method: Effect of Shape, Size, Structure, and Assembly," Plasmonics, vol. 5, pp. 85-97, Mar 2010.

[113] A. S. Kumbhar, et al., "Multipole plasmon resonances of submicron silver particles," Journal of the American Chemical Society, vol. 127, pp. 12444-12445, Sep 142005.

[114] Y. Golan, et al., "Vacuum-deposited gold films: I. Factors affecting the film morphology," Surface Science, vol. 264, pp. 312-326, 1992.

[115] J. Siegel, et al., "Properties of gold nanostructures sputtered on glass," Nanoscale Res. Lett, vol. 6, p. 96, 2011.

[116] I. Doron-Mor, et al., "Ultrathin gold island films on silanized glass. Morphology and optical properties," Chemistry of Materials, vol. 16, pp. 3476-3483, 2004.

[117] G. W. Ford and W. Weber, "Electromagnetic interactions of molecules with metal surfaces," Physics Reports, vol. 113, pp. 195-287, 1984.

[118] L. Ramírez-Rodríuez, et al., "Plasmon resonance and Raman modes in Pb nanoparticles obtained in extract of Opuntia ficus-indica plant," NANO. 